Aus der Abteilung Präventive Zahnmedizin, Parodontologie und Kariologie

(komm. Direktor: Prof. Dr. med. dent. M. Hülsmann )

im Zentrum Zahn-, Mund- und Kieferheilkunde

der Medizinischen Fakultät der Universität Göttingen

\title{
Wirkung von antiseptischen Mundspüllösungen auf die menschlichen Zellen der Mundschleimhaut
}

Eine in-vitro-Studie

\author{
INAUGURAL-DISSERTATION
}

zur Erlangung des Doktorgrades

für Zahnheilkunde

der Medizinischen Fakultät

der Georg-August-Universität zu Göttingen

vorgelegt von

Vitalij Zyba

aus

Charkow/Ukraine

Göttingen 2010 
Dekan: Prof. Dr. med. C. Frömmel

I. Berichterstatter: Prof. Dr. med. dent. R. Mausberg

II. Berichterstatter/in: Prof. Dr. med. Dr. med. dent. Kramer

III. Berichterstatter/in: Prof. Dr. med. Dr. rer. nat. Crozier

Tag der mündlichen Prüfung: 13.07.2011 


\section{Inhaltsverzeichnis}

1. Einleitung

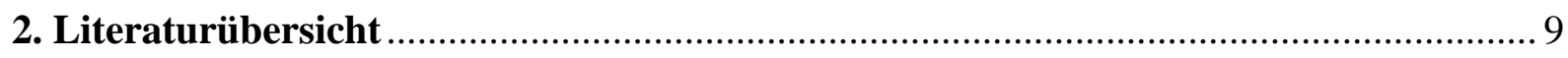

2.1 Anatomie und Physiologie des Parodonts ............................................................... 9

2.2 Erkrankungen der Mundhöhle und oraler Biofilm .................................................... 14

2.2.1. Klassifikation parodontaler Erkrankungen............................................................... 14

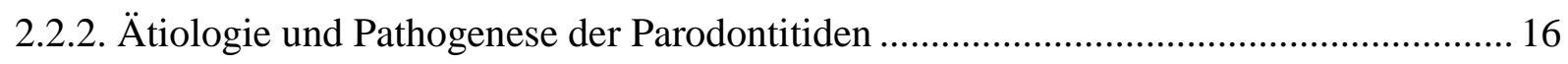

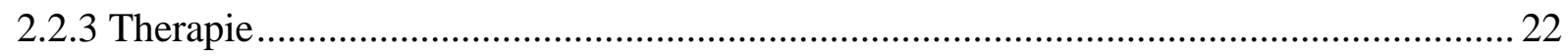

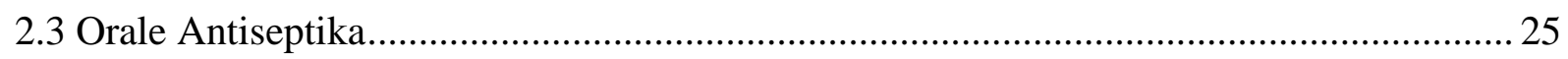

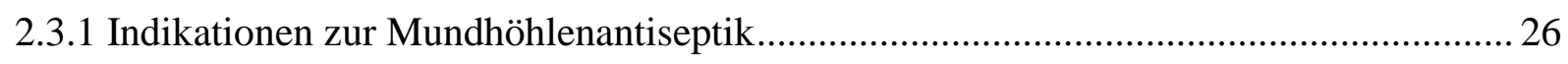

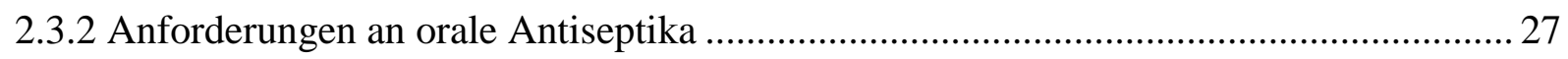

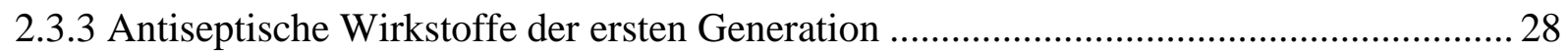

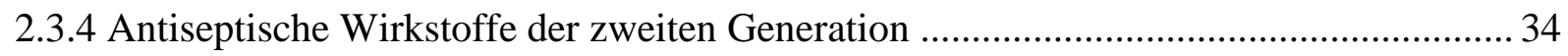

2.3.5 Antiseptische Wirkstoffe der dritten Generation .................................................... 40

2.4 Untersuchungsmethoden zur Beschreibung zellulärer Ereignisse ................................ 44

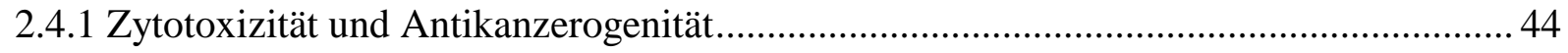

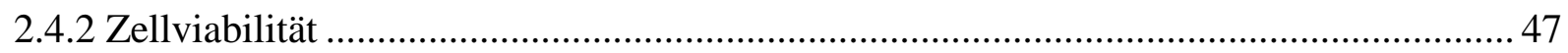

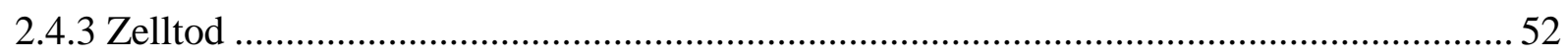

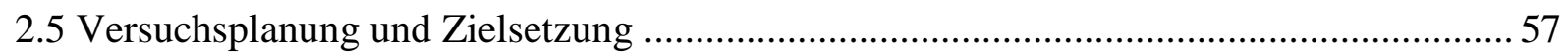

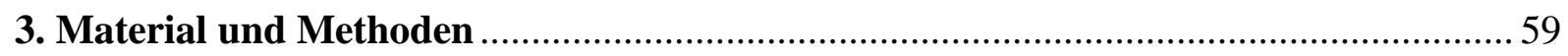

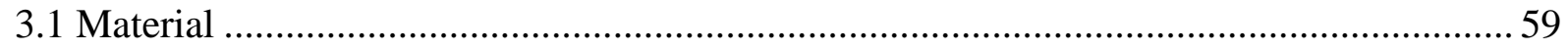

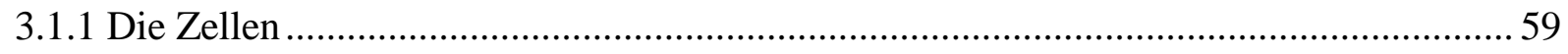

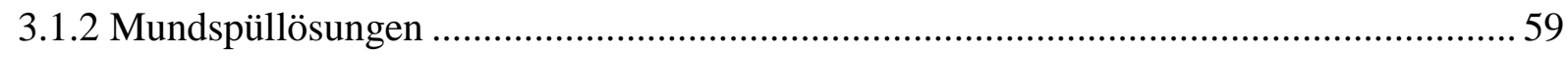

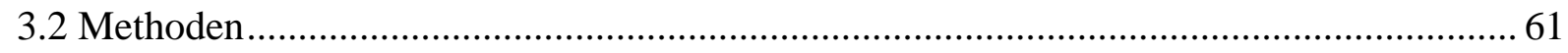

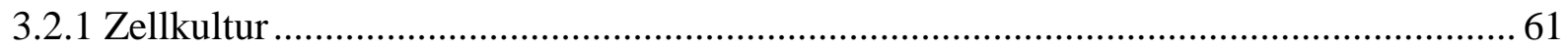




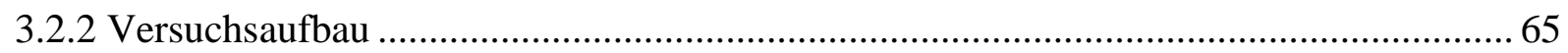

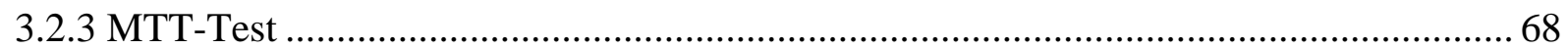

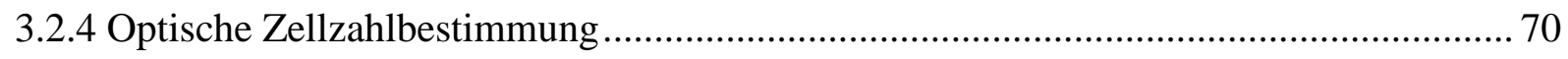

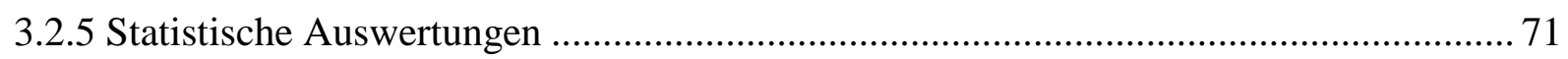

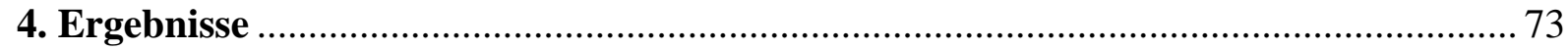

4.1 Versuche mit primären humanen Gingiva-Fibroblasten (HGFIB) ................................ 73

4.1.1 Bestimmung der Toxizität von oralen Antiseptika mittels MTT-Tests ........................ 73

4.1.1.1 Ergebnisse der einzelnen Antiseptika nach Einwirkzeiten ........................................ 73

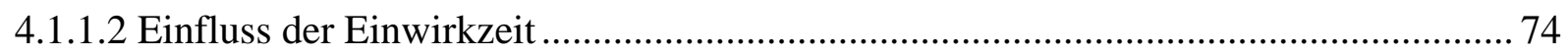

4.1.1.3 Vergleich der Mundspüllösungen untereinander .................................................. 78

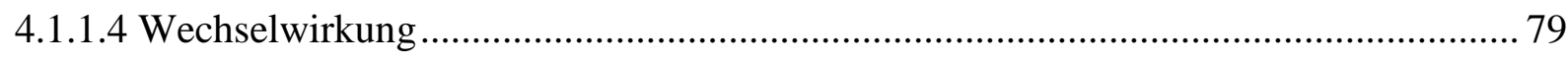

4.1.2 Optische Zellzählung mittels Cellometer ${ }^{\mathrm{TM}}$ Auto T4 ................................................ 79

4.1.2.1 Ergebnisse der einzelnen Antiseptika nach Einwirkzeiten ........................................ 79

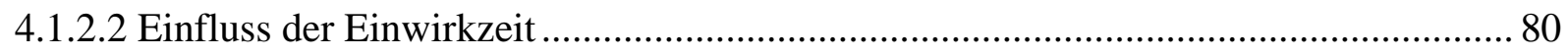

4.1.2.3 Vergleich der Mundspüllösungen untereinander ...................................................... 84

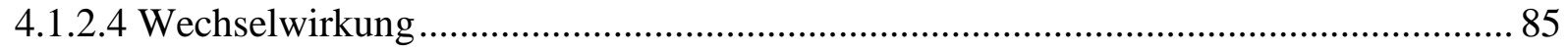

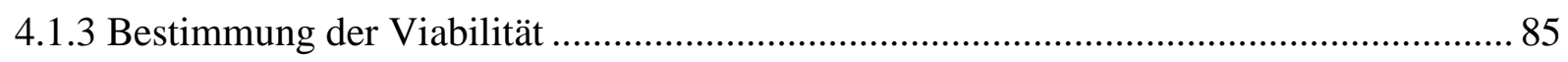

4.1.3.1 Ergebnisse der einzelnen Antiseptika nach Einwirkzeiten ...................................... 86

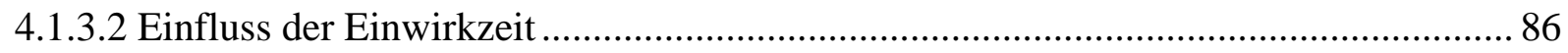

4.1.3.3 Vergleich der Mundspüllösungen untereinander ....................................................... 90

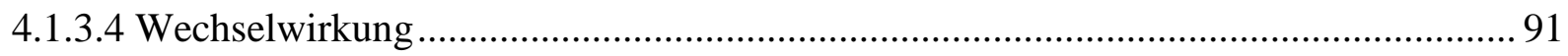

4.1.4 Durchmesser der HGFIB nach Antiseptikabehandlung ............................................ 91

4.1.4.1 Ergebnisse der einzelnen Antiseptika nach Einwirkzeiten ....................................... 92

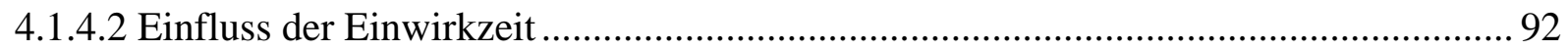

4.1.4.3 Vergleich der Mundspüllösungen untereinander .................................................... 96

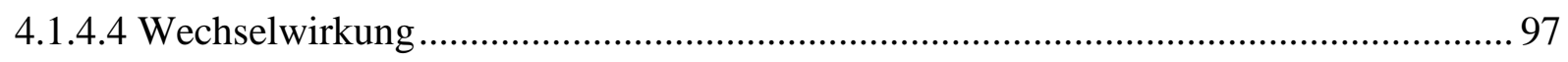

4.1.5 Vergleich des MTT-Tests und der optischen Zellcharakterisierung mittels Cellometer ${ }^{\mathrm{TM}}$

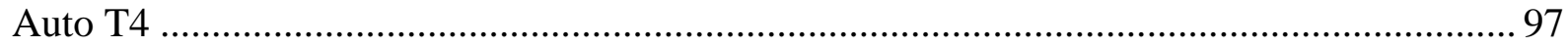


4.2.1 Bestimmung der Toxizität von oralen Antiseptika mittels MTT-Test ..........................99

4.2.1.1 Ergebnisse der einzelnen Antiseptika nach Einwirkzeiten ...................................... 99

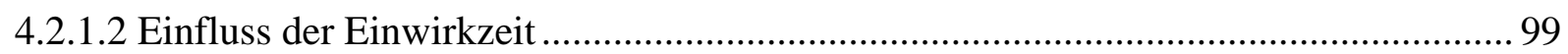

4.2.1.3 Vergleich der Mundspüllösungen untereinander .................................................... 103

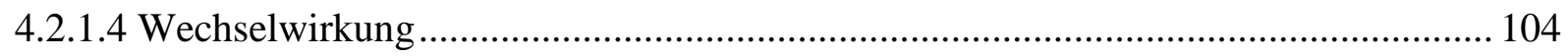

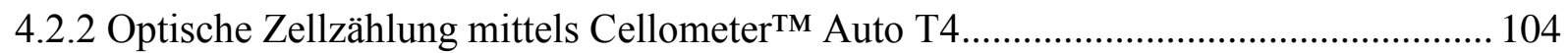

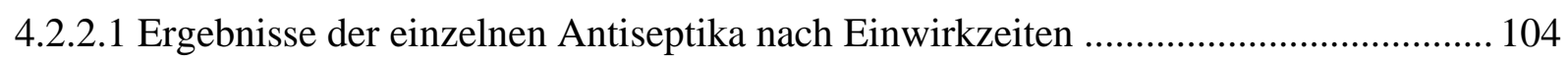

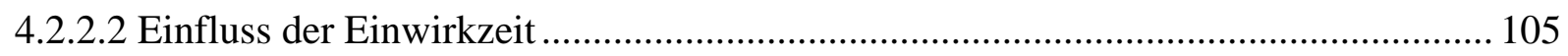

4.2.2.3 Vergleich der Mundspüllösungen untereinander .................................................... 109

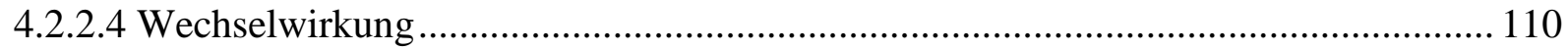

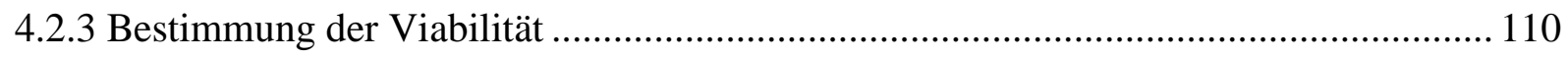

4.2.3.1 Ergebnisse der einzelnen Antiseptika nach Einwirkzeiten ..................................... 111

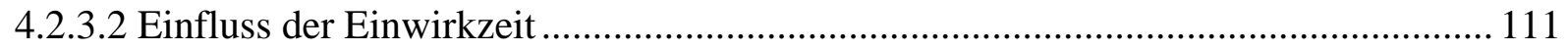

4.2.3.3 Vergleich der Mundspüllösungen untereinander ................................................... 115

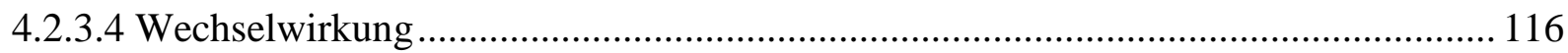

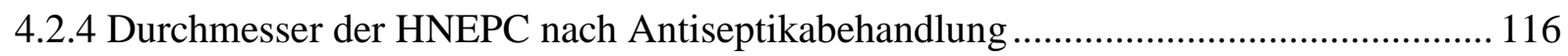

4.2.4.1 Ergebnisse der einzelnen Antiseptika nach Einwirkzeiten ..................................... 117

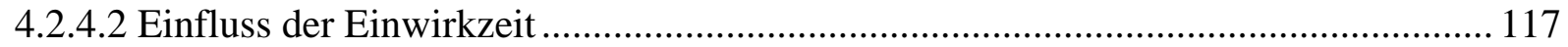

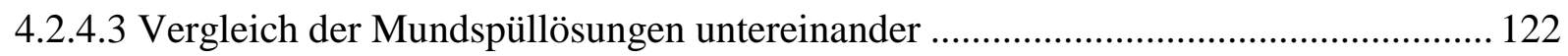

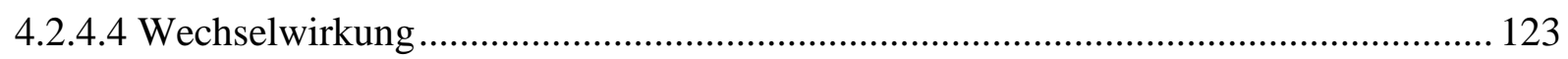

4.2.5 Vergleich von MTT-Test und optischer Zellcharakterisierung mittels Cellometer ${ }^{\mathrm{TM}}$ Auto T4

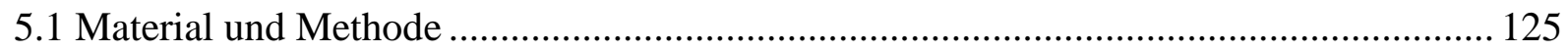

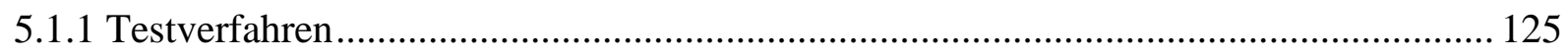

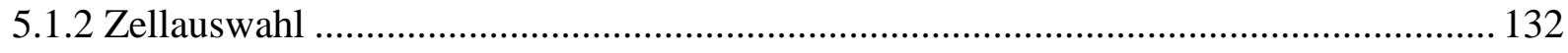




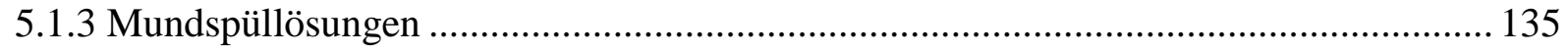

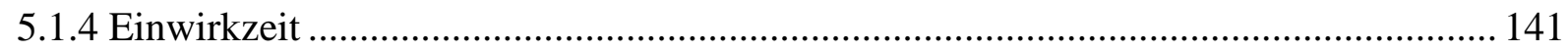

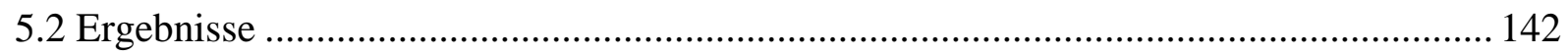

5.2.1 Bestimmung der Toxizität von oralen Antiseptika mittels MTT-Test.......................... 142

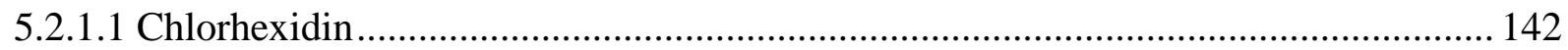

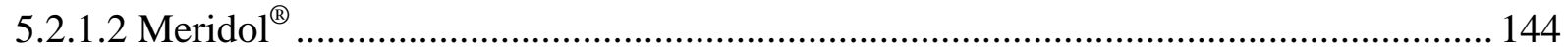

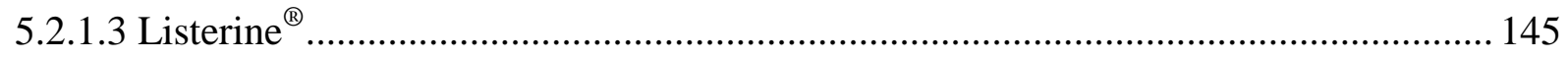

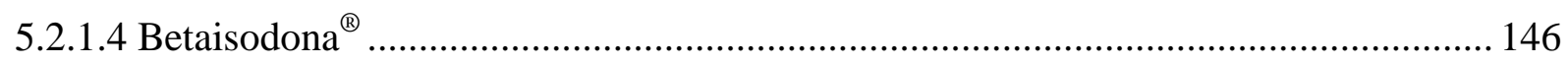

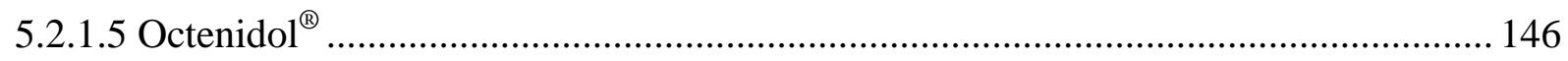

5.2.2 Bestimmung der Toxizität von oralen Antiseptika mittels Cellometer ${ }^{\mathrm{TM}}$ Auto T4 ...... 147

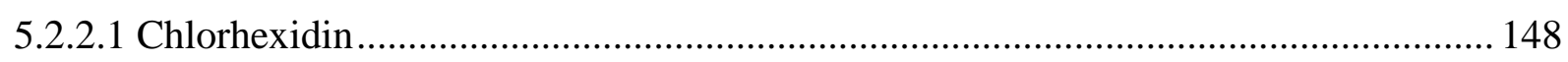

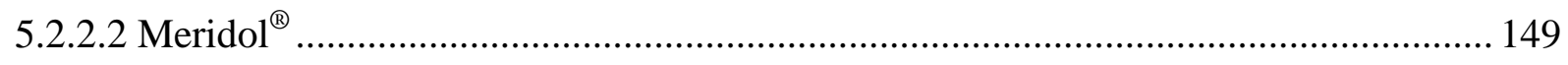

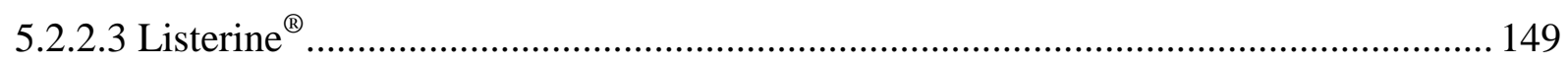

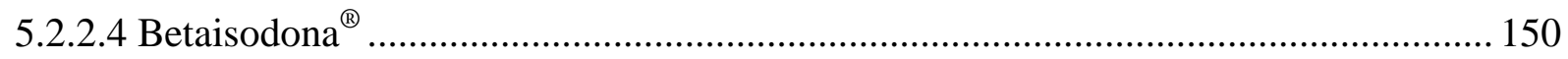

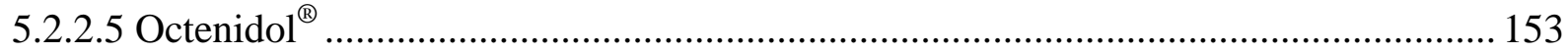

5.2.3 Vergleich der einzelnen Mundspüllösungen untereinander ...................................... 153

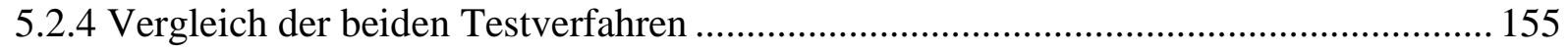

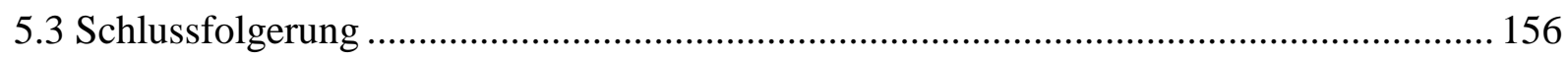

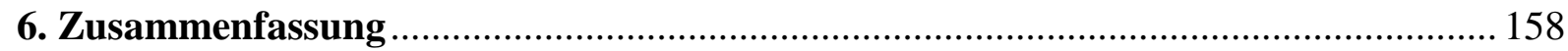

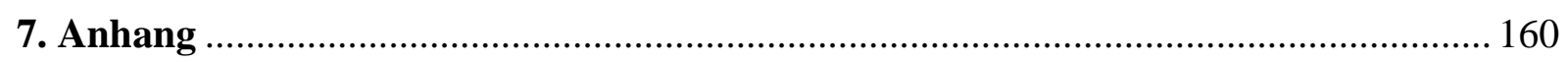

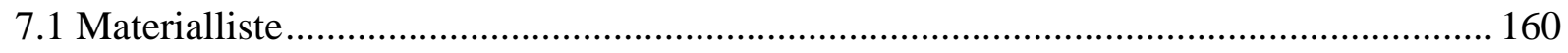

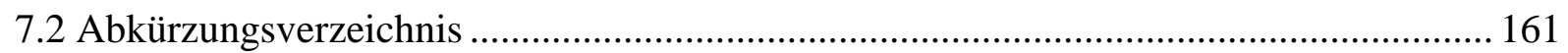

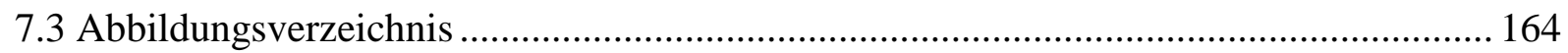

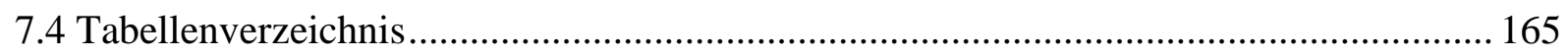

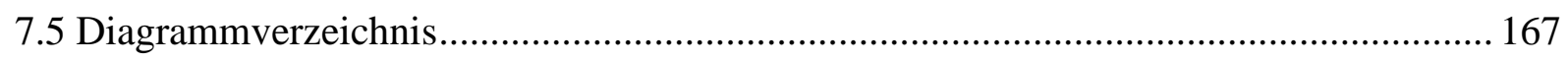

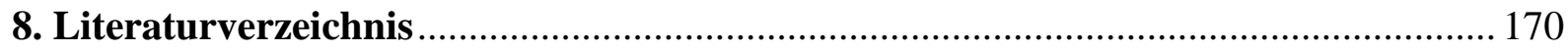




\section{Einleitung}

In den letzten Jahren sind zahlreiche Verfahren und neue Methoden auf dem Gebiet der Prävention von Parodontalerkrankungen eingeführt worden. Dabei wurden weniger die einzelnen erkrankten parodontalen Strukturen betrachtet, vielmehr ging es um Parodontitis, Gingivitis bzw. Plaqueentstehung als allgemeine Krankheiten des Zahnhalteapparates. Was mit den einzelnen Zellen der Mundschleimhaut bzw. des Parodontalapparates sowohl bei diesen pathologischen Prozessen als auch infolge der antibakteriellen Therapie passiert, ist heutzutage noch nicht vollständig geklärt. Deswegen ist es sehr wichtig, nicht nur die neuesten Methoden für die Behandlung von Parodontalerkrankungen zu testen, sondern auch Grundlagenforschung auf diesem Gebiet zu betreiben. In den letzten 40 Jahren herrschte die allgemeine Meinung, dass Plaque für die Entstehung und das Fortschreiten der Erkrankungen des Zahnhalteapparates verantwortlich sei. Die mechanischen Reinigungsverfahren mit Zahnbürste und Zahnseide sowie das Fluoridieren der Zahnhartsubstanz haben sich bei richtiger Handhabung als effektiv im Bereich der Bildungsvermeidung und Reduktion der Plaque erwiesen. Dabei wird die Entstehung von Erkrankungen des Zahnhalteapparates und der Zahnhartsubstanz verhindert. Der Prävention entzündlicher Parodontalerkrankungen kommt eine entscheidende Bedeutung zu und sie betrifft vor allem die Reduktion schädlicher Zahnbeläge. Derzeit werden antimikrobielle Mundspüllösungen als Bestandteile von Kariesund Parodontitispräventionsprogrammen zusätzlich zur mechanischen Zahnreinigung mit großen Erwartungen betrachtet, da die präventive Wirkung der Fluoride scheinbar ihr Optimum erreicht hat (CATE und MARSH 1994). Unter den chemischen Präventionsmaßnahmen mit antibakteriell wirksamen Substanzen, deren antiseptische Wirkung sowohl in zahlreichen Studien als auch evidenzbasiert bewiesen werden konnte, erwiesen sich Chlorhexidin 0,2\% ${ }^{\circledR}$, Meridol ${ }^{\circledR}$, Listerine ${ }^{\circledR}$, PVP-Iod $^{\circledR}$ und Octenidin $^{\circledR}$ als die klinisch relevanten Mundspüllösungen. Leider sind ihre zellschädigenden Eigenschaften nicht nur auf die Bakterien des Mundmilieus beschränkt, sondern sie betreffen auch die körpereigenen Zellen. Die momentane Situation ist dadurch gekennzeichnet, dass auf der einen Seite ein hoher Bedarf an Mitteln zur Parodontitisprophylaxe besteht und dass auf der anderen Seite die handelsüblichen Mittel nicht in jeder Hinsicht optimal sind. Das ideale Mittel zur Gingivitis- und Parodontitisprophylaxe sollte die pathogenen Keime reduzieren und dabei die physiologische Bakterienflora nicht beeinträchtigen, es sollte keine Nebenwirkungen besitzen, einfach zu benutzen und kostengünstig sein. 
Mit der vorliegenden Arbeit soll die Wirkung ausgewählter antibakterieller Substanzen $\left(\right.$ Chlorhexidin 0,2 \% ${ }^{\circledR}$, Meridol ${ }^{\circledR}$, Listerine ${ }^{\circledR}$, PVP-Iod $^{\circledR}$ und Octenidin $^{\circledR}$ ) auf die Proliferation von primären humanen Zellen der Mundschleimhaut und des Zahnhalteapparates (primäre Gingiva-Fibroblasten und nasale Epithelzellen) sowohl experimentell anhand eines Zytotoxizitättests, der auf der photometrischen Messung basiert (MTT-Test), als auch mittels eines optischen Verfahrens der Zellzählung und Vitalitätsbestimmung (Cellometer ${ }^{\mathrm{TM}}$ Auto T4) dokumentiert und vergleichend bewertet werden. 


\section{Literaturübersicht}

Die Parodontitis kann heute als Volkskrankheit bezeichnet werden. Sie hat die Karies als Hauptursache des Zahnverlustes abgelöst. Über 80 \% der über 30-Jährigen und auch immer mehr jüngere Patienten sind betroffen.

Die Zahnlosigkeit als finale Folge der Parodontitis ist heute nicht mehr nur ein medizinisches, sondern auch ein gesellschaftliches Problem mit funktionellen, psychosozialen und nicht zu vernachlässigenden wirtschaftlichen Konsequenzen. Besonders die möglichen Folgen entzündlicher Parodontalerkrankungen für den Gesamtorganismus rücken immer mehr in den Mittelpunkt des öffentlichen Interesses. So wird aktuell unter anderem das Auftreten ischämischer Herzerkrankungen mit Parodontitiden in Verbindung gebracht. Auch ein erhöhtes Risiko von Frühgeburten wurde in diesem Zusammenhang diskutiert.

Der mikrobiologische Hintergrund entzündlicher Parodontalerkrankungen ist mittlerweile im Bewusstsein der Fachwelt verankert. Eine ausgereifte Plaque enthält bis zu 300 Millionen Mikroorganismen pro mg Nassgewicht. In der physiologischen Flora der Gingiva lassen sich mindestens 200 verschiedene Arten differenzieren. Für die Auslösung der meisten destruktiven Parodontalerkrankungen werden demgegenüber etwa sechs bis zwölf Mikroorganismenarten verantwortlich gemacht.

\subsection{Anatomie und Physiologie des Parodonts}

Das Parodontium (griech. par- $=$ um, odont- $=$ Zahn) ist eine komplexe Einheit, die aus dem Wurzelzement des Zahnes, dem Alveolarknochen, den Kollagenfasern, den „Sharpey’schen“ Fasern und dem Weichgewebe der Gingiva und der Alveolarmukosa besteht (SCHROEDER 1982).

Der Alveolarknochen des Ober- und Unterkiefers bildet zusammen mit der natürlichen Bezahnung eine physiologische und funktionelle Einheit. Der Kieferknochen unterliegt - wie das gesamte Skelett - während des ganzen Lebens einem steten Umbau. Die Ursachen dafür liegen in der funktionellen Anpassung an die Druck- und Belastungsverhältnisse beim Kauen, Schlucken, Sprechen sowie in den irreversiblen entzündungsbedingten Destruktionsvorgängen.

Der Alveolarknochen besteht aus der periostbedeckten Knochenkortikalis lingual/palatinal, dem Spongiosaanteil des trabekulären Knochens, den Laminae cribriformes, die das Zahnfach 
auskleiden und eine Fortsetzung der kortikalen Platte bedeuten. Strukturell lassen sich die Knochenzellen (Osteoblasten, Osteoklasten und Osteozyten) innerhalb einer mineralisierten Matrix finden. Osteoblasten sind als knochenbildende Zellen mesenchymalen Ursprungs. Sie liegen fast immer in einer Schicht epithelähnlich eng beieinander und haben über kurze, zarte Fortsätze untereinander Kontakt. Das Zytoplasma der relativ kleinen Osteoblasten besitzt einen ausgeprägten Golgi-Apparat, ist reich an Mitochondrien und an granulärem endoplasmatischen Retikulum und folglich basophil. Die Osteoblasten produzieren die aus Grundsubstanz und Kollagenfasern (Typ I) bestehende Interzellularsubstanz des Knochengewebes. Durch die während der Knochenentwicklung und des Knochenwachstums anhaltende Matrixproduktion entfernen sich die zunächst eng benachbarten Osteoblasten immer mehr voneinander. Dadurch verschlechtern sich zunehmend die Bedingungen für Stoffwechsel und Matrixproduktion, die schließlich nahezu vollständig eingestellt wird. Die nun fast inaktiven, „eingemauerten“ Osteoblasten wandeln sich unter weitgehendem Verlust ihrer „blastentypischen“ Ausrüstung in Osteozyten um. Die Osteozyten bilden Osteone, in denen die Haver'schen Kanäle verlaufen, die für die Kommunikation zwischen den einzelnen Zellen sorgen. Die Laminae cribriformes sind an zahlreichen Stellen unterbrochen, die Foramina ermöglichen das Einstrahlen der desmodontalen Fasern in den Knochen bis in die Markräume hinein. Dieser Abschnitt des Alveolarknochens wird als der „Bündelknochen“ bezeichnet (SCHROEDER 1982).

Das Skelett unterliegt nach dem Wachstumsabschluss einer permanenten Erneuerung, dem „Remodeling“ (HOCK et al. 2001). Durch eine wechselseitig wirkende Aktivierung von Osteoklasten und Osteoblasten wird eine kontinuierliche Erneuerung des mineralisierten Knochenanteils erreicht (FROST 1994). Die Bilanz dieser Osteoklasten- und Osteoblastenaktivität bleibt ausgeglichen, solange der Knochen beispielsweise durch den Muskelzug physiologisch belastet wird. Bleibt eine Belastung aus oder wird der Knochen unphysiologisch belastet, wie zum Beispiel bei der Zerstörung des Parodontalapparates im Verlauf der fortgeschrittenen Parodontitis, folgt eine Bilanzverschiebung zugunsten der Osteoklastentätigkeit, und die knochenresorptiven Prozesse dominieren. Infolgedessen nimmt das Knochenvolumen kontinuierlich ab. Diesem Grundsatz folgen sowohl der enchondral gebildete Knochen als auch der auf eine mesenchymale embryonalgeschichtliche Entwicklung zurückgehende Knochen.

Die Gingiva bildet den Weichgewebsabschluss an der Durchtrittstelle der Zähne in die Mundhöhle. Sie ist aus dem gingivalen Epithel, dem Verbindungsepithel (Saumepithel), dem subepithelialen Bindegewebe, den darin enthaltenen Blut- und Lymphgefäßen und den 
Nervenfasern zusammengesetzt. Die Gingiva umgibt den sichtbaren Zahn und ist mit dem Zahnschmelz bzw. -wurzelzement durch den Epithelansatz verbunden. Diese Verbindung bedeutet eine wirkungsvolle Abschottung des Körpers gegen Mikroorganismen. Die Gingiva zwischen den Zähnen wird Interdental- oder Zahnfleischpapille genannt. Die direkt am Zahn anliegende Gingiva ist verschieblich. Sie bedeckt wurzelwärts den Alveolarfortsatz und haftet diesem unverschieblich an (attached gingiva), da die Subcutis an dieser Stelle fehlt. Die Gingiva kann nicht nachgebildet werden.

Das Zahnfleisch besteht histologisch aus einem mehrschichtigen Plattenepithel, das nur wenige Hornschichten aufweist. Epithelzellen bedecken alle inneren und äußeren Körperoberflächen. Die Zellen liegen dicht beieinander, sind reich an Zellkontakten und enthalten keine Blutgefäße. Eine weitere allen Epithelzellen gemeinsame Eigenschaft ist ihre Polarität. Sie haben eine äußere, apikale Seite, die dem Äußeren (z. B. bei der Haut) oder dem Lumen (z. B. bei der Mundhöhle, beim Darm oder bei Drüsen) zugewandt ist, sowie eine basale Seite, die über eine Basallamina mit dem darunterliegenden Gewebe verbunden ist. Die Polarität von Epithelzellen ist durch strukturelle und funktionelle Unterschiede zwischen apikaler und basaler Membran der Epithelzellen geprägt.

Das Saumepithel, bestehend lediglich aus dem Stratum basale und dem Stratum suprabasale, haftet über die Hemidesmosome am Zahn und über die Desmosome am Bindegewebe und dichtet den Zahnsulkus am Zahnhartgewebe ab. Ein wichtiger Bestandteil des Bindegewebes sind die Bindegewebsvorläuferzellen, die sogenannten Fibroblasten. Zwischen dem Rand des Alveolarknochens und dem anhaftenden Epithel inserieren die dento-alveolären und die dento-gingivalen Kollagenfasern aus dem Weichgewebe im azellulär-fibrillären Wurzelzement. Der Gefäßplexus des Bindegewebes sorgt für die Zirkulation und die Ernährung. Die zu den Venolen parallel verlaufenden Lymphbahnen führen zu den Lymphknoten (EGELBERG 1967). Das desmodontale Gewebe ist sehr stark vaskularisiert. Die Arteriolen und Venolen bilden ein korbartiges Geflecht um die Zahnwurzeln und verlaufen etwa in der Mitte des Parodontalspaltes. Die Hauptgefäße verlaufen palisadenartig in apiko-koronaler Richtung. Die venösen Abflüsse folgen dem Arterienverlauf (LINDHE und KARRING 1998).

Die Fibroblasten spielen eine wichtige Rolle bei der Synthese der Interzellularsubstanz, der extrazellulären Matrix. $\mathrm{Zu}$ den Produkten von Fibroblasten gehört hauptsächlich das Kollagen, das zusammen mit den ebenfalls gebildeten Proteoglykanen (saure Mukopolysaccharide) für eine erhöhte Festigkeit der extrazellulären Matrix sorgt. Weiterhin synthetisieren die Fibroblasten die Kollagenase, die für einen physiologischen Kollagenabbau 
zuständig ist. Eine Schädigung des Gewebes stimuliert die Proliferation von Fibroblasten und verstärkt die Abgabe von Zytokinen, die wiederum positiv auf die Reparatur der Verletzung bzw. die Ausheilung der Entzündung des Parodontalapparates einwirken. Fibroblasten sind bewegliche, aber ortsständige Bindegewebszellen mesenchymaler Herkunft, die nach der Reifung zu Fibrozyten bewegungsunfähig werden.

Die allgemeine Meinung, wonach antibakterielle Mundspüllösungen bei täglicher Anwendung das Fortschreiten von Parodontalerkrankungen verhindern und folglich die Regeneration der Mundschleimhaut, des Zahnhalteapparates und des Knochens positiv beeinflussen, erklärt das Interesse der vorliegenden Arbeit, die Wirkung oraler Antiseptika auf die einzelnen Zelltypen grundlegend zu untersuchen.

Eine regelmäßige Reinigung des Sulkus von bakteriellen Belägen und Speiseresten ist notwendig, um einer Gingivitis vorzubeugen, die sich schnell und unbemerkt zu einer Parodontitis entwickeln kann. Beim Zähneputzen selbst kommt es häufig zu einer vorübergehenden Bakteriämie, ganz gleich, welche Methode der Zahnreinigung verwendet wird. Die kapilläre Endstrombahn bildet im Bereich des Saumepithels den subepithelialen Gefäßplexus, der überwiegend aus anastomosierenden postkapillären Venolen mit einem Durchmesser von 7 bis $40 \mu \mathrm{m}$ besteht. Bereits bei einer geringfügigen mechanischen Reizung oder bei einer von kleinsten Mengen Antigens ausgelösten entzündlichen Reaktion erhöht sich die Permeabilität der zahlreichen Venolen des Plexus nachweislich. Das Austreten eines Exsudats wurde beobachtet, und im Tierexperiment ist ein Zusammenhang mit dem Blutkreislauf nachgewiesen worden (BRILL und KRASSE 1958 und 1959, EGELBERG 1963). Die Faktoren für die Entstehung eines Gradienten, die Entstehungsmechanismen und die Funktionen des Exsudats (im Folgenden Sulkusfluid [SF] genannt), sind in einer Reihe klinischer und experimenteller Studien bereits erforscht worden (EGELBERG 1963, 1966 a, b, c, d, e und 1967, BRILL und BJÖRN 1959, BRILL 1959, BOWLES und MÜHLEMANN 1971). Die Analyse der einzelnen Bestandteile des SF ergibt eine weitgehende Übereinstimmung mit den Komponenten des Blutserums (CIMASONI 1983, CURTIS et al., 1988 und 1990, EGELBERG 1963, GOODSON 2000, BANG und CIMASONI 1971). Der Anstieg der SF-Menge und die steigenden Konzentrationen der enthaltenen Entzündungsmediatoren (z. B. Interleukine [IL], des Tissue Necrosis Factor- $\alpha$ [TNF- $\alpha]$ ) können von Beginn an an einer Exposition des Sulkus den Bakterien der oralen Flora gegenüber kontinuierlich verfolgt werden (BIJL et al. 1986, CHAPPLE et al. 1995, EGELBERG 1964, GRIFFITHS et al. 1992, GRIFFITHS 2003). 
Die Steigerung der Gefäßwand- und der Gewebepermeabilität ist nur eine von vielen Etappen in einer ganzen Reihe von Immunreaktionen, die auf die Präsenz von Mikroorganismen im Sulkus folgen. Eine anhaltende Plaqueakkumulation und eine fortbestehende Entzündung lösen eine gingivale Reaktion aus, die von einer Steigerung der Sulkusfluidmenge begleitet wird (HANCOCK et al. 1979). Die Akkumulation der oralen Mikroorganismen, ihre Zusammensetzung und die Wirkung ihrer Präsenz auf den Entzündungszustand der Gingiva sind von SILNESS und LÖE (1964) klinisch untersucht worden. Sie konnten aufzeigen, wie das Bakterienspektrum innerhalb der Plaque eine Transformation von den überwiegend aeroben, grampositiven zur Dominanz von gramnegativen, anaeroben Spezies im Laufe des ungestörten Wachstums erfährt. Eine gingivale Entzündung wird als Gingivitis bezeichnet; sie ist durch die klassischen Symptome einer Entzündung charakterisiert: rubor, color, dolor, tumor und functio laesa.

Etwa 500 verschiedene bakterielle Spezies besiedeln die menschliche Mundhöhle (PASTER et al. 2001). Eine Vielzahl dieser Spezies lässt sich konstant in der dentalen Plaque nachweisen (DARVEAU et al. 1997). Diese Plaque wird heute als ein mikrobieller „Biofilm“ verstanden (MARSH und BRADSHAW 1995). Biofilme werden als „,in eine Matrix eingebettete bakterielle Population, die aneinander und/oder an Oberflächen/Grenzflächen angeheftet ist“", definiert (COSTERTON et al. 1994, S. 2139). Die oralen Mikroorganismen, die zunächst an den Zahnoberflächen adhärent werden, bilden unter Produktion einer extrazellulären Matrix eine dreidimensionale Struktur aus, die ausmineralisieren kann und als Biofilm bezeichnet wird (BERNIMOULIN 2003, WECKE et al. 2000). Die mikrobielle Besiedlung eines durchbrechenden oder frisch gereinigten Zahnes erfolgt rasch. Auf der Zahnoberfläche bildet sich innerhalb weniger Minuten eine Pellikel aus Proteinen und Glykoproteinen, die aus dem Speichel und dem Sulkusfluid stammen und sich an die Hydroxylapatitkristalle des Zahnschmelzes binden (MARSH und BRADSHAW 1995, LISTGARTEN 1994). Sowohl über spezifische Oberflächenstrukturen wie Adhäsine (Zuckermoleküle, Lectine) als auch über unspezifische Mechanismen wie die ionische Bindung der Teichonsäure der bakteriellen Zellmembran heften sich gramnegative aerobe Kokken an die Pellikel. Diese frühe Besiedlung erfolgt hauptsächlich durch Streptococcus-sp. und Aktinomyces-sp., später auch durch gramnegative kapnophile Capnocytophaga-sp. und gramnegative Anaerobier wie Fusobacterium nucleatum (F.n.) (MARSH und BRADSHAW 1995, LISTGARTEN 1994), wobei F.n. bei der weiteren Entwicklung des komplexen Biofilms eine Mediatorrolle zu spielen scheint (WEISS et al. 2000). Räumlich breitet sich die supragingivale Plaque innerhalb etwa einer Woche lateral aus, bis die verfügbare 
Zahnoberfläche bedeckt ist (WECKE et al. 2000). Während der Reifung der Plaque steigt neben der gesamten Keimzahl der Anteil gramnegativer Bakterien von etwa $15 \%$ der Gesamtflora an gesunden Stellen (TANNER et al. 1996) auf ca. $50 \%$ bei etablierter Gingivitis an (TANNER et al. 1996, THEILADE et al. 1966). In den mittlerweile klassischen Studien zu kurzzeitig bestehender, experimentell ausgelöster Gingivitis konnte gezeigt werden, dass die Symptome der gingivalen Entzündung wie Blutung, Rötung und Schwellung vollständig reversibel sind, wenn eine entsprechende Mundhygiene wieder aufgenommen wird (THEILADE et al. 1966, LÖE et al. 1965).

\subsection{Erkrankungen der Mundhöhle und oraler Biofilm}

\subsubsection{Klassifikation parodontaler Erkrankungen}

Während eines internationalen Workshops (International Workshop for a Classification of Periodontal Diseases and Conditions)im Herbst 1999 in Oak Brook/Illinois, USA, wurde eine neue Klassifizierung der Parodontalerkrankungen beschlossen. Diese versucht, basierend auf klinischen, radiologischen, anamnestischen und mikrobiologischen Kriterien, die Erscheinungsbilder der Erkrankungen des Zahnhalteapparates zu definieren. Man unterscheidet acht Kategorien in der Klassifizierung der Parodontalerkrankungen. Darüber hinaus sind diese acht Kategorien durch Spezifizierungen weiter unterteilt. Diese umfassen:

I. Gingivale Erkrankungen

A. Plaqueinduzierte gingivale Erkrankungen

B. Nicht plaqueinduzierte gingivale Erkrankungen

Man unterscheidet gingivale Erkrankungen, die infolge von Mangelernährung oder modifiziert durch systemische Einflüsse und Medikamente als ausschließlich plaqueinduziert auftreten können.

II. Chronische Parodontitis
A. Lokalisiert
B. Generalisiert 
Man unterscheidet dabei chronische Parodontitiden, aggressive Parodontitiden und Parodontitiden als Manifestation von Systemerkrankungen, wobei vor allem Bluterkrankungen, genetische Störungen und Stoffwechselerkrankungen eine Rolle spielen. Weiterhin differenziert man nekrotisierende Parodontalerkrankungen, Parodontalabszesse, Parodontitiden im Zusammenhang mit endodontalen Läsionen sowie entwicklungsbedingte oder erworbene Deformationen und Zustände.

III. Aggressive Parodontitis
A. Lokalisiert
B. Generalisiert

IV. Parodontitis als Manifestation einer Systemerkrankung
A. Bluterkrankungen
B. Genetische Störungen
C. Nicht anderwertig spezifiziert

V. Nekrotisierende Parodontalerkrankungen
A. Nekrotisierende ulzerierende Gingivitis (NUG)
B. Nekrotisierende ulzerierende Parodontitis (NUP)

VI. Abszesse des Parodonts
A. Gingivaabszess
B. Parodontalabszess
C. Perikoronarabszess

VII. Parodontitis im Zusammenhang mit endodontalen Läsionen
A. Kombinierte parodontisch-endodontische Läsion

VIII. Entwicklungsbedingte oder erworbene Deformationen und Zustände
A. Lokalisierte zahnbezogene Faktoren, welche die Plaqueretention begünstigen
B. Mukogingivale Verhältnisse
C. Schleimhautveränderungen auf zahnlosen Alveolarkämmen 


\subsection{2. Ätiologie und Pathogenese der Parodontitiden}

Die Parodontitis ist unter Erwachsenen eine häufige Erkrankung mit einer Prävalenz von $50 \%$, wobei etwa $30 \%$ aller Patienten an einer schweren Form der Parodontitis leiden (BROWN und LÖE 2000, MICHEELIS und SCHIFFNER 2006). Trotz wesentlicher Unterschiede im klinischen Verlauf, die auf die multifaktorielle Ätiologie zurückzuführen sind, liegen der Gruppe der entzündlichen Parodontopathien gemeinsame pathogenetische Mechanismen zugrunde (PAGE 1999, PAGE und KORNMAN 1997). Neben der bakteriellen Infektion als Grundvoraussetzung der Erkrankung sind genetische und erworbene endogene und exogene Risikofaktoren modifizierend an der Pathogenese beteiligt (SALVI et al. 1997) (Abb. 1). Andere diskutierte Ätiologiefaktoren sind:

- Rauchen und andere exogene Faktoren wie z. B. Stress

- Störungen des Stoffwechsels, wie z. B. durch Immundefekte, Störungen des Hormonhaushalts, Blut- oder Stoffwechselerkrankungen u.a.

- ernährungsbedingte Schädigungen des Parodonts durch Fehl- oder Mangelernährung

- mechanisch bedingte Traumata, ausgelöst durch gestörte Okklusionsverhältnisse, falsche Putztechniken, derbes oder hoch ansetzendes Lippenbändchen u.a. 


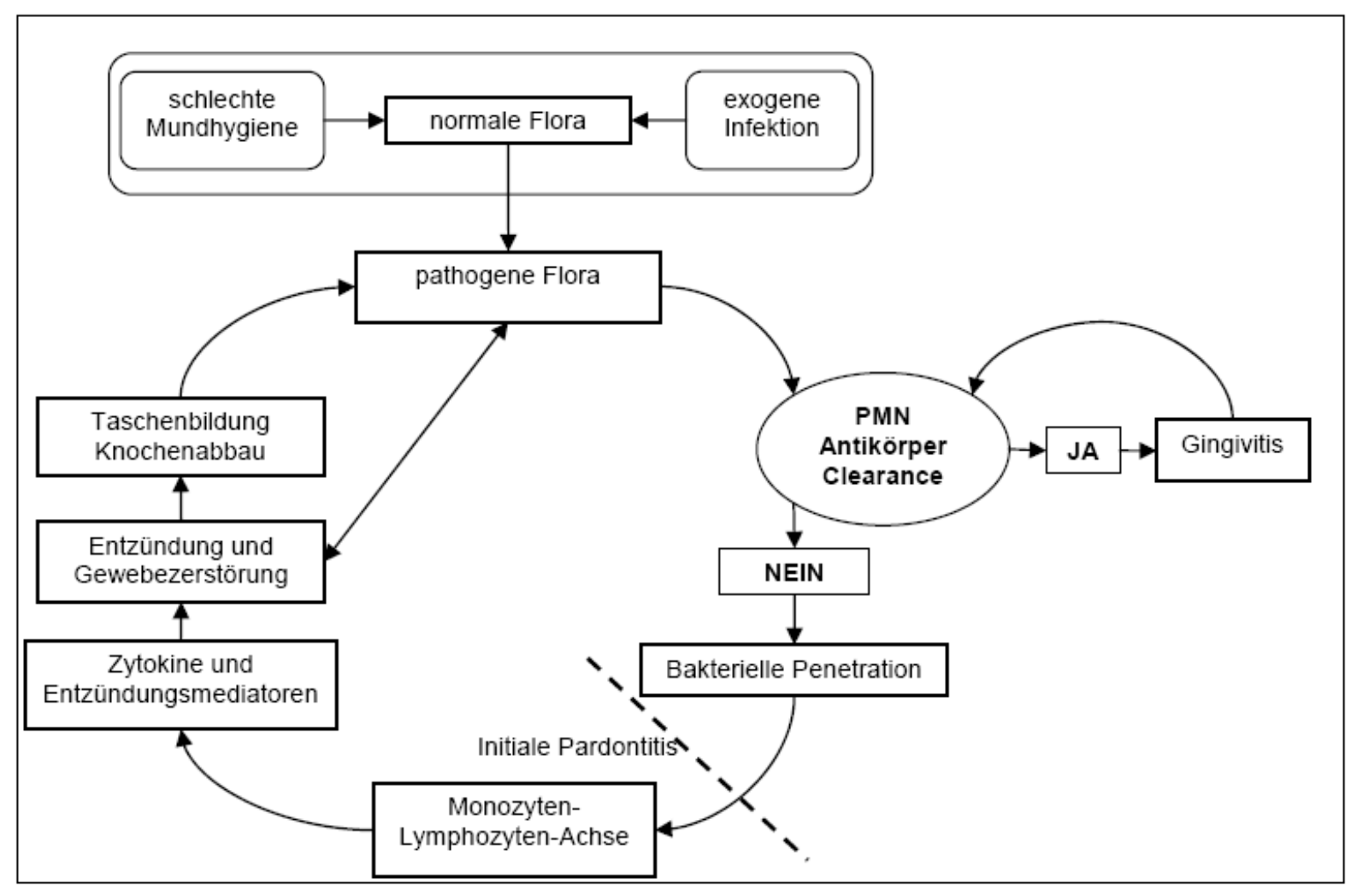

Abbildung 1: Gingivitis-Parodontitis-Modell (modifiziert nach SALVI et al. 1997, S. 178)

Die physiologische Mundflora kann als Folge einer schlechten Mundhygiene oder durch eine exogene Infektion zerstört werden. Die pathogenen Keime können das körpereigene Immunsystem durch spezifische und unspezifische Mechanismen aktivieren. Die hervorgerufene Gingivitis kann entweder durch körpereigene Abwehr bekämpft werden, oder aber die initiale Mundschleimhauterkrankung geht in eine tiefer fortschreitende Parodontitis über. Das ungestörte Vordringen der pathogenen Keime in Parodontalapparat bzw. eine insuffiziente Immunantwort auf eine Gingivitis kann eine initiale Parodontitis verursachen. Diese Prozesse führen zu einer entzündlichen Reaktion des Parodonts mit einer Zerstörung des Zahnhalteapparates und einer Kumulation von noch agressiveren Bakterienstämmen im Entzündungsgebiet. Daraus resultieren die Taschenbildung und ein vertikaler Knochenabbau. Eine suffiziente Immunantwort kann zu einer Eliminierung der hochpathogenen anaeroben gramnegativen Keime bzw. zu einer Chronifizierung der Erkrankung führen. Der Verlust des Parodontalapparates um die betroffenen Zähne führt längerfristig zur Zahnlosigkeit und begünstigt die Entstehung der Osteomyelitis.

Entscheidend für die Entstehung und Erhaltung der Entzündungsreaktion, die in der parodontalen Destruktion resultiert, sind jedoch bakterielle Prozesse. Die anderen genannten Faktoren sind nicht als auslösende, sondern als auf den Krankheitsprozess modellierend einwirkende Parameter zu verstehen. Sie können den Krankheitsverlauf beschleunigen, intensivieren oder Abwehrmechanismen ausschalten (LANG NP et al. 1985).

Die Grundlage für eine andauernde schädigende Wirkung von pathogenen Keimen auf die parodontalen Gewebe ist die Ausbildung einer mikrobiellen Plaque, eines sogenannten 
Biofilms. Die Voraussetzung für die Plaqueanlagerung ist das Vorhandensein von Schmelzpellikeln, die als Proteinschicht die Zahnoberfläche bedecken. Plaque ist ein strukturierter, zäher, verfilzter Zahnbelag (Biofilm) aus Speichelbestandteilen, bakteriellen Stoffwechselprodukten, Nahrungsresten und Bakterienzellen. Die supragingivale Plaque ist primär an den habituell unsauberen Bereichen der Zähne, den sogenannten Kariesprädilektionstellen, lokalisiert. Diese besonders kariesdisponierten Bereiche sind die Zahnfissuren und -grübchen, die Approximalflächen der Zähne, das zervikale Drittel der sichtbaren Zahnkrone und frei liegende Wurzeloberflächen. Die Entwicklung der Zahnplaque vollzieht sich in mehreren Schritten.

Auf einer gründlich gereinigten Zahnoberfläche haftet der unstrukturierter azellulärer Film an, das sogenannte sekundäre Zahnoberhäutchen. Dieses Häutchen ist ca. 0,1 bis $1 \mu \mathrm{m}$ dick und besteht in erster Linie aus Proteinen des Speichels, die aufgrund ihrer Eigenladungen an die Kalzium- und Phosphatgruppen des Apatits der Zahnhartsubstanz elektrostatisch binden können. Die Pellikel ist semipermeabel, d.h., sie steuert in einem gewissen Ausmaß die Austauschvorgänge zwischen Mundhöhlenmilieu, Plaque und Zahn. Sie befeuchtet zudem den Zahn und schützt ihn so beim Essen vor Abrasion. An diese Membran heften sich innerhalb weniger Stunden selektiv zuerst grampositive Kokken (Streptococcus sanguis) und Aktinomyzeten an. Später folgen weitere Streptokokken, Aktinomyzeten und Veillonellen. Stäbchen und Filamente überwiegen in einer sieben bis 14 Tage alten Plaque. Die Plaque wächst dann duch Teilungsvorgänge bzw. Akkumulation weiterer Bakterien über spezifische Adhäsions- und Kohäsionsphänomene, durch direkten Zellkontakt oder mit Hilfestellung durch Plaquematrixkomponenten. Mit zunehmendem Alter gewinnt die Plaque eher anaeroben Charakter. Bakterienadhäsion und Plaquebildung können durch verschiedene Faktoren gehemmt oder gefördert werden. Diese Faktoren können endogener oder exogener Genese sein. Ausgereifte Plaque besteht aus dicht gepackten Bakterien (60-70 Volumenprozent), die in ein amorphes Material, die Plaquematrix, eingebettet sind. Die Plaque ist in diesem Zustand durch die Selbstreinigungskräfte der Mundhöhle nicht mehr vom Zahn zu entfernen. Dabei variiert die bakterielle Besiedelung an verschiedenen Stellen der Mundhöhle und sogar an verschieden Flächen eines Zahnes. Der prozentuale Anteil unterschiedlicher Bakterien in der Plaque unterscheidet sich signifikant von ihrem Anteil im Speichel. Auch die Zusammensetzung der Plaquematrix ist variabel. Sie hängt von Speichelzusammensetzung, Ernährung und Syntheseleistung der verschiedenen 
Plaquebakterien ab. Die völlige Ausreifung der Plaque wird nach etwa einer Woche erreicht, wenn sich Spirochäten etablieren (FLEMMIG 1993).

Die Reaktionen, die ihren Ursprung in der Steigerung der Permeabilität des epithelialen Abschlusses am Zahn haben (Abb. 2) und die später zur Lockerung der kollagenen Strukturen des Weichgewebes beitragen, führen so $\mathrm{zu}$ einer sich ausbreitenden Infiltration mit einer erhöhten Freisetzung von Entzündungsmediatoren wie TNF- $\alpha$ und IL-1ß, gefolgt von den Matrixmetalloproteinasen (MMPs) (PAGE und KORNMAN 1997, LISTGARTEN 1987, ZEE VAN DER et al. 1997).

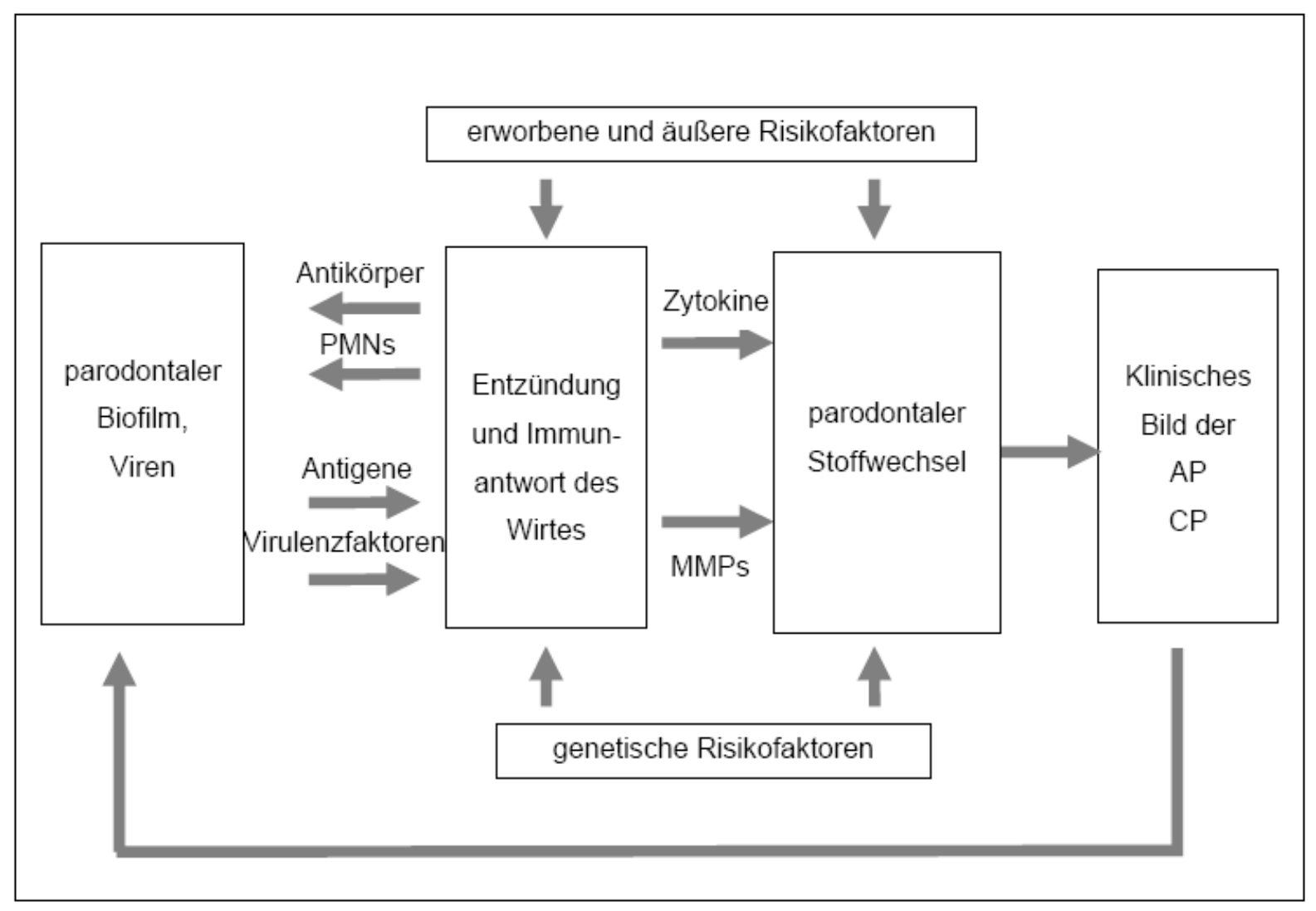

Abbildung 2: Pathogenetisches Modell (modifiziert nach PAGE und KORNMAN 1997, S. 10)

Die Anlagerung der pathogenen Keime an die Zahnoberfläche und die Enstehung von Plaque verursachen über die humorale und zelluläre Immunantwort eine initiale Gingivitis. Das Übergreifen der Gingivitis auf die tiefer gelegenen Parodontien wird durch die von Immunabwehrzellen ausgeschütteten Entzündungsmediatoren begünstigt. Der veränderte parodontale Stoffwechsel präsentiert sich klinisch als eine akute oder chronische Form der Parodontitis. Dabei spielen die erworbenen, äußeren und genetischen Risikofaktoren eine bedeutende Rolle in der Entstehung der Erkrankung. Das Fortbestehen der parodontalen Entzündung führt zu einer Selektion der hochpathogenen Keime in dem betroffenen Gebiet. 
Die Progression einer Parodontitis ist durch einen fortschreitenden Verlust des marginalen Knochens an den betroffenen Zähnen charakterisiert. Verantwortlich für diesen Verlust ist neben der enzymatischen Aktivität zahlreicher Proteasen eine zugunsten der Osteoklasten verschobene Aktivierungsbilanz der Knochenzellen (HOFBAUER et al. 1999). Die Steuerung der Osteoklastendifferenzierung findet über die entzündungsbedingte Aktivierung der T- und der B-Zellen statt. Diese Zellen sezernieren dann den Rezeptoraktivator des nuklearen FaktorkB Liganden (RANKL), der die Zahl der aktiven Osteoklasten gegenüber der der Osteoblasten heraufsetzt (KAWAI et al. 2006, TAUBMAN et al. 2005).

Die Pathogenität der Plaque ist zurückzuführen auf die Gesamtmasse der Bakterien, die Toxine und antigen wirkende Substanzen produzieren und zu Entzündungen führen, aber auch auf das Vorhandensein besonders pathogener Keime, die mit spezifischen Virulenzfaktoren die Gewebe schädigen oder die Wirtsabwehr beeinträchtigen. In dieser Hinsicht unterscheidet man zwei Ansätze: die spezifische und die unspezifische Plaquehypothese. Die unspezifische Plaquehypothese begreift die Gesamtmasse der Plaque als schädigenden Einfluss auf den Wirt (THEILADE 1986). Der Therapieansatz ist deshalb in der Vermeidung und Beseitigung sämtlicher Beläge zu sehen, was durch chemische oder vor allem mechanische Verfahren zu erreichen ist. Dieser Ansatz wird durch das klassische Experiment von LÖE et al. (1965) unterstützt, der nachwies, dass sich bei vernachlässigter Mundhygiene in jedem Fall eine Gingivitis etabliert, die sich jedoch mit Wiederaufnahme der Mundhygienemaßnahmen wieder vollständig zurückbildet. Aus dieser Wechselwirkung zwischen Plaque und Gingivitis lässt sich nicht direkt auf die Beziehung zu parodontalen Erkrankungen schließen. Jedoch wurde in anderen Experimenten auch dieser Zusammenhang belegt (HAUNFELDER 1990). Demgegenüber geht die spezifische Plaquehypothese davon aus, dass parodontale Erkrankungen auf eine bestimmte pathogene Bakterienflora mit typischen Erregern im Sinne der Koch'schen Postulate zurückzuführen sind. Diese müssen gezielt durch Medikamente bekämpft werden. Verschiedene Experimente konnten in diesem Zusammenhang beweisen, dass eine Vielzahl von Bakterienarten in isolierter Form Auslöser für Gingivitis und Parodontitis sein kann (FLEMMIG 1993). Von Bedeutung ist auch die Erkenntnis, dass sich die Mundflora in ihrer Zusammensetzung bei einer Erkrankung im Vergleich zu parodontal gesunden Verhältnissen verändert. Im gesunden Zustand dominieren grampositive aerob wachsende Arten, während sich bei Gingivitis eine aerob-anaerobe Mischflora findet, die sich mit der Etablierung einer Parodontitis in eine gramnegative anaerobe Flora umwandelt (PFISTER 1985). Auf dieser Grundlage konnten für die aggressive Parodontitis spezifische 
Leitkeime identifiziert werden, wie z. B. Actinobacter actinomycetemcomitans, Porphyromonas gingivalis und Prevotella intermedia.

Die Parodontitis wird heute als opportunistische Erkrankung aufgefasst, deren wesentliche Voraussetzungen das Vorhandensein pathogener Keime sowie ein für die Vermehrung der Keime günstiges Milieu darstellen. Das Bestehen einer Gingivitis wird als Grundlage für die Etablierung einer Parodontitis erachtet. Jedoch resultiert eine Gingivitis nicht grundsätzlich in einer Parodontitis. Die Pathogenese der Gingivitis ist durch akute und chronische Entzündungsprozesse geprägt.

Die Ausbildung einer klinisch manifesten Gingivitis verläuft in drei histopathologisch abgrenzbaren Phasen, der Initialläsion, der Frühläsion und der etablierten Läsion. Durch den Einfluss der Plaquemikroorganismen kommt es in der klinisch gesunden Gingiva innerhalb von zwei bis vier Tagen zu einer akuten Entzündung mit Erhöhung der Gefäßpermeabilität, Vasodilatation und Leukozytenmigration. Im Stadium der Initialläsion treten erste Gewebeschädigungen durch den Verlust des perivaskulären Kollagens auf, und die Umwandlung von koronalen Saumepithelabschnitten in Taschenepithel beginnt. Zwischen dem vierten und dem zehnten Tag der Plaquereifung verstärken sich die Entzündungszeichen. Auch die Gewebeschäden nehmen in dieser Phase der Frühläsion weiter zu. Es kommt zum Verlust der Mikrogefäßarchitektur und zur Ausbildung von gefäßreichem Granulationsgewebe. Der Untergang von Kollagenfasern im Bereich des Zahnfleischsaumes setzt sich fort. In der Phase der etablierten Läsion nach zwei bis drei Wochen dauern die entzündlichen Prozesse weiter an. Mit dem Fortschreiten des Bindegewebsverlustes und der Proliferation des Taschenepithels zum Sulkusboden beginnt die sichtbare Taschenbildung. $\mathrm{Zu}$ diesem Zeitpunkt manifestiert sich die Gingivitis klinisch. Diese Phase kann über einen langen Zeitraum unverändert bestehen bleiben, sich jedoch auch in eine Parodontitis mit Knochenverlust umwandeln. Der Übergang von einer Gingivitis zu einer Parodontitis mit allen Faktoren ist jedoch noch nicht vollständig geklärt. Kommt es zur Parodontitismanifestation, dann spricht man von der Phase der fortgeschrittenen Läsion. Die destruktiven Prozesse dehnen sich in Desmodont und Alveolarknochen aus. T-Zellen und Makrophagen werden durch bakterielle Lipopolysaccharide aktiviert. Es kommt daraufhin zur Freisetzung von Zytokinen wie IL 1, IL 6 oder TNF- $\alpha$. Diese stimulieren Osteoklasten, denen der Hauptanteil an den zum Substanzverlust führenden Prozessen, also Kollagenolyse und Knochenresorption, zugeschrieben wird. Die Osteoblastenaktivität ist demgegenüber normal oder verringert, weshalb insgesamt ein Abbau des Alveolarknochens zu verzeichnen ist. 
Tiefer liegende Knochenmarkbereiche und Gingivaanteile können bei fortschreitendem Kollagenverlust fibrosieren. Die Folgen dieser Vorgänge sind schließlich Zahnlockerung und Zahnverlust (FLEMMIG 1993, MERTE 1992).

Die Parodontitis ist ein chronischer Prozess, der jedoch keinen kontinuierlichen Verlauf zeigt. Es wechseln sich Phasen der Stagnation mit Phasen erneuter Exazerbation ab, die als Folge komplexer Wechselwirkungen zwischen Wirtsabwehr, exogenen Einflüssen und den Mikroorganismen zu betrachten sind.

\subsubsection{Therapie}

Bei der Behandlung von entzündlichen parodontalen Erkrankungen steht die Reduktion oder Eliminierung von Bakterien im Vordergrund. Es ist jedoch fraglich, ob nach der Behandlung eine vorhersagbare Bakterienreduktion auf lange Sicht erreicht werden kann. Man unterscheidet dabei die mechanische und die chemische Zahnreinigung voneinander. Die mechanische Zahnreinigung wird mithilfe von Küretten und Scalern durchgeführt und ist sehr effektiv, die Reduktion der Bakterienzahl ist aber bei dieser Therapiemethode ungenügend. Zur chemischen Reinigung werden orale Antiseptika verwendet. Die Bakterienreduktion ist dabei als sehr gut zu bewerten. Mundspüllösungen können jedoch die Plaque nicht effektiv genug durchdringen, sie entfernen oder die Wiederbesiedelung längerfristig verhindern. Aus diesem Grund wird eine Kombination beider Methoden empfohlen, indem zuerst eine professionelle Zahnreinigung und anschließend eine chemische Desinfektion der Mundhöhle durchgeführt werden.

Es konnte gezeigt werden, dass parodontopathogene Keime sich nicht nur auf dem Sulkusepithel und dem Rest der Gingiva etablieren können, sondern auch auf der Zunge und den Tonsillen (VAN DER VELDEN et al. 1986, ASIKAINEN et al. 1991, DANSER et al. 1994 und 1996). Deshalb können Bakterien nach der parodontalen Behandlung erneut eine Infektion des Zahnfleischsulkus hervorrufen. Um das Risiko für eine bakterielle Translokation zu minimieren, entwickelten QUIRYNEN et al. (1995) das Konzept der „one-stage fullmouth-disinfection“ (OSFMD), in der das subgingivale Scaling mit Wurzelglättung in zwei Sitzungen innerhalb von 24 Stunden durchgeführt wurde und von einer supra- und subgingivalen Chlorhexidinanwendung unterstützt wurde. Mit diesem Behandlungsschema wurden in einigen Studien im Vergleich zur konventionellen Therapie signifikante Verbesserungen der klinischen und mikrobiologischen Parameter bei Patienten mit 
fortgeschrittener chronischer Parodontitis erzielt (QUIRYNEN et al. 1995, BOLLEN et al. 1996, VANDEKERCKHOVE et al. 1996, MONGARDINI et al. 1999). Auch bei Patienten mit einer früh beginnenden Parodontitis konnten ähnliche Ergebnisse erzielt werden (MONGARDINI et al. 1999, QUIRYNEN et al. 1999).

Das Vorgehen bei der OSFMD beinhaltet folgende Schritte:

- Scaling und Wurzelglättung an allen Zähnen innerhalb von 24 Stunden (auch unter dem Begriff Full Mouth Scaling bekannt).

- Ausspülung der Zahnfleischtaschen mit $\mathrm{NaCl}, \mathrm{H}_{2} \mathrm{O}_{2}$ oder CHX-Gel

- Mundspülungen mit 0,2\% Chlorhexidin-Lösung; zwei- bis dreimal/Tag über eine Minute: am Abend vor sowie unmittelbar vor der Behandlung, die nächsten Wochen nach der Behandlung

- wiederholte subgingivale Irrigation aller Zahnfleischtaschen (dreimal innerhalb von zehn Minuten) mit CHX-Gel $1 \%$, diese Anwendung wird am achten Tag wiederholt

- Zungenreinigung (Spatel bzw. Bürste mit $\mathrm{H}_{2} \mathrm{O}_{2} 3 \%$ oder CHX-Gel $1 \%$ für eine Minute): unmittelbar nach der chirurgischen Behandlung in der Praxis, Zuhause täglich einmal mit Bürste und Zungenspatel

- Desinfektion von Rachen und Tonsillen: unmittelbar nach der chirurgischen Behandlung in der Praxis mit einem CHX-Spray 0,2\%; Wasserstrahlgeräte (,Mundduschen“) mit entsprechenden Zusätzen tragen zu einer Optimierung bei.

In weiteren Studien wurde die quadrantenweise mechanische Parodontalbehandlung mit der Behandlung innerhalb von 24 Stunden ohne die zusätzliche Anwendung von Chlorhexidin verglichen (APATZIDOU und KINANE 2004, KOSHY et al. 2005, WENNSTRÖM et al. 2005, JERVØE-STORM et al. 2006). In allen Studien gab es sechs Monate nach der Behandlung keine signifikanten Gruppenunterschiede in Bezug auf die klinischen und mikrobiologischen Daten. Eine Studie konnte auch keine Unterschiede bei der Rekolonisierung nach dem subgingivalen Scaling mit Wurzelglättung innerhalb von 24 Stunden im Vergleich zur Behandlung über mehrere Sitzungen bestätigen (JERVØE-STORM et al. 2006). Dennoch führten beide Behandlungsmodalitäten zu deutlichen Reduktionen der Zielbakterien nach sechs Monaten. 
Der Erfolg einer parodontalen Behandlung hängt von der Reduktion der pathogenen Bakterien im dentalen Biofilm ab, die auf Zahnoberflächen und anderen ökologischen Nischen in der Mundhöhle zu finden sind (SLOTS 1979, BOLLEN et al. 1998, SLOTS und TING 2002). Die mechanische Behandlung, die in einem subgingivalen Scaling mit Wurzelglättung besteht, ist in der Regel der erste empfohlene Schritt gegen parodontale Infektionen (COBB 1996). Tägliche Mundhygienemaßnahmen durch den Patienten, wie Zähneputzen und die Anwendung von Zahnseide, in Kombination mit professioneller Entfernung harter und weicher supra- und subgingivaler Beläge, ist sehr effektiv zur Kontrolle der meisten Formen von parodontalen Erkrankungen. Eine Reihe von Studien aus den 1970er-Jahren konnte das Potenzial einer initialen Behandlung demonstrieren, die eine Entfernung supra- und subgingivaler Beläge beinhaltete (SUOMI et al. 1971, AXELSSON und LINDHE 1978 und 1981, KNOWLES et al. 1979). In den 1980er-Jahren gab es umfangreiche Studien über die nicht chirurgische mechanische Parodontalbehandlung (MORRISON et al. 1980, BADERSTEN et al. 1981, 1984 und 1987, PROYE et al. 1982, LOOS et al. 1988, HAMMERLE et al. 1991, CLAFFEY und EGELBERG 1994). Durch eine subgingivale Reinigung kann ein gesundes orales Milieu wiederhergestellt werden, da es zu einer Verschiebung des bakteriellen Gleichgewichts in Richtung nicht pathogener, nützlicher Bakterien kommt. Es wurde von den durchschnittlichen Weichgewebsveränderungen nach einem Scaling mit Wurzelglättung an Frontzähnen und Prämolaren berichtet (DRISKO 2001). Es wurden mittlere Reduktionen der Sondierungstiefe von 1,29 mm und 2,16 mm und Attachmentgewinne von $0,55 \mathrm{~mm}$ und $1,19 \mathrm{~mm}$ hauptsächlich bei Taschen mit einer Sondierungstiefe von 4 bis $6 \mathrm{~mm}$ und $>6 \mathrm{~mm}$ gefunden. Die Furkationen der Molaren sprachen jedoch nicht so gut auf die nicht chirurgische mechanische Behandlung an (NORDLAND et al. 1987, LOOS et al. 1988). Diese Studien unterstreichen die Wichtigkeit des subgingivalen Scalings in der Behandlung parodontaler Erkrankungen.

Aber auch die Anwendung von antiseptischen Mundspüllösungen als Ergänzung der täglichen Mundhygiene oder als Bestandteil einer OSFMD spielt bei der Behandlung von Mundschleimhauterkrankungen oder bei Verletzungen in der Mundregion eine wichtige Rolle. So reduzierte die Anwendung einer Mundspüllösung zweimal pro Tag mit der antibakteriellen Wirkstoffkombination Aminfluorid/Zinnfluorid (Meridol ${ }^{\circledR}$ ) im Rahmen einer 12-wöchigen klinischen Studie bei Patienten mit aggressiver Parodontitis den Zahnbelag sowie Entzündungen des Zahnfleisches. GUARNELLI (2004) wies nach, dass durch die Anwendung der Meridol ${ }^{\circledR}$-Mundspüllösung als Ergänzung zum täglichen Zähneputzen Plaque besonders auch an den hinteren Molaren und in den Approximalräumen gehemmt wird. 
Anhand zahlreicher Studien (MICHEELIS und REICH 1999, MICHEELIS und SCHIFFNER 2006) konnte für die letzten zehn bis 15 Jahre eine deutliche Verbesserung der oralen Gesundheit belegt werden. Der Erfolg basierte auf dem Einsatz von Fluoriden, der Verbesserung der häuslichen Mundhygiene sowie einer Lenkung der Ernährung. Bedeutsam ist in diesem Zusammenhang auch die Einführung der Fissurenversiegelung als kassenzahnärztliche Regelleistung. Im Zusammenhang mit einer verbesserten Mundhygiene wird auch immer wieder über die Bedeutung von Mundspüllösungen als Ergänzung der mechanischen Gebissreinigung diskutiert (KOWOLLIK 1994, SCHIFFNER 1998 und 2000). Zum Nachweis der Wirksamkeit solcher Mundspüllösungen wurden verschiedene Vorgehensweisen im Studiendesign benutzt, bei denen die Dauer (Tage bis Monate) der Anwendung und die Wirkstoffe variierten.

\subsection{Orale Antiseptika}

Der Markt bietet eine umfangreiche Produktpalette mit unterschiedlichen Wirkstoffen für den Einsatz im dentalen Bereich. Damit eine Substanz in vivo effektiv gegen Mikroorganismen wirkt, muss sie während der Applikation in einer biologisch aktiven Form vorliegen und über einen ausreichend langen Zeitraum verfügbar sein. Der Effekt antimikrobieller Substanzen auf den Vitalitätsgrad der Keime in der Plaque hängt natürlich auch stark von ihrer Konzentration an Ort und Stelle ab. Meistens liegen die Wirkstoffe anfangs für kurze Zeit in relativ hohen Konzentrationen (MIC-Bereich) in der Mundhöhle vor. Durch Ausspucken und/oder Herunterschlucken geht je nach Verabreichungsform viel verloren. Den weiteren Effekt bestimmt dann die Konzentration der Substanz, die an Oberflächen der Mundhöhle adsorbiert und langsam freigesetzt wird (sub-MIC). Zum Beispiel kann ein Stoff in hohen Dosierungen Mikroorganismen in Speichel und Plaque reduzieren. Er wirkt also bakterizid. Wird jedoch die Vermehrung der Keime gehemmt, liegt ein bakteriostatischer Effekt vor. Sehr niedrige Konzentrationen können immerhin noch zu einer Einschränkung der Säureproduktion oder einer Störung der Aktivität relevanter Enzyme führen. In vivo können große Unterschiede zwischen Substanzen mit ähnlichen MIC-Werten bezüglich ihrer klinischen Wirkung auftreten. Unter anderem spielen das Eindringen des Wirkstoffes in die Plaque und die dort herrschenden Bedingungen eine wesentliche Rolle. Die oralen Antiseptika sollen des Weiteren nicht nur die Bakterien in der Plaque bzw. Mundhöhle bekämpfen und somit Karies vorbeugen, sondern auch die Mundschleimhaut nicht angreifen und nach Möglichkeit einen schützenden bzw. einen die Wundheilung fördernden Effekt haben. 


\subsubsection{Indikationen zur Mundhöhlenantiseptik}

Zielsetzung der Mundhöhlenantiseptik ist die Abtötung, Inaktivierung und/oder Entfernung unerwünschter Mikroorganismen sowie die Verhinderung einer unerwünschten mikrobiellen Kolonisation (KRAMER und PITTEN 2000). Mit der Mundhöhlenantiseptik soll vor allem der endogenen Infektion entgegengewirkt werden.

Die wichtigsten Indikationen sind:

- antiseptische Mundspülungen vor zahnärztlichen Eingriffen (RAHN et al. 1994)

- Pneumonieprophylaxe bei Beatmungspatienten (DERISO et al. 1996)

- Prophylaxe und Therapie der chemo- oder radiotherapieinduzierten Mukositis (RAHN et al. 1996)

- Verbesserung der Mundhöhlenhygiene bei immunsupprimierten Patienten (MCGAW und BELCH 1985, FERRETTI et al. 1987, 1988 und 1990)

- antiseptische Mundspülung nach akzidenzieller Aufnahme infektiösen Materials in die Mundhöhle ( KRAMER und PITTEN 1998)

- $\quad$ vor und ggf. nach operativen Eingriffen (KRAMER et al. 1997/98)

- antiseptische Mundpflege bei Kieferfrakturen mit intermaxillärer Immobilisation (KRAMER et al. 1993)

- Wurzelkanalantiseptik (KRAMER et al. 1993).

Gerade bei Beatmungspatienten und Patienten, die unter Zytostatikatherapie in eine Leukopenie kommen, spielt die langfristige Antiseptik eine entscheidende Rolle, um hier eine Infektionsprophylaxe zu erreichen (KRAMER et al. 1993). In der Mundhöhle erfolgt die prophylaktisch-therapeutische Antiseptik unter anderem durch intraorale Spülungen. Bei der Wirkstoffauswahl des Antiseptikums muss auf die Besonderheiten des Anwendungsbiotops, die systemische Verträglichkeit und die notwendige Einwirkzeit geachtet werden. Die Wirksamkeit eines Antiseptikums ist von dessen Art, der zugeführten Menge, der Konzentration und der Kontaktzeit mit dem Zielort abhängig (RAHN et al. 1994).

In Abhängigkeit vom Antiseptikum sind Keimzahlreduzierungen bis zu $3 \mathrm{lg}$ möglich (KRAMER et al. 1990 und 1997/98). Die Transientflora wird hierbei stärker reduziert als die Standortflora, da sie ohnehin zahlenmäßig unterlegen ist (PRICKLER 1980, KRAMER et al. 1990). Eine selektive Keimzahlreduzierung bestimmter Mikroorganismen konnte dagegen nicht nachgewiesen werden (NAUMANN 1983). 


\subsubsection{Anforderungen an orale Antiseptika}

Zur Unterstützung der mechanischen Mundhygiene werden Mundspüllösungen angeboten, die eine Reduktion der dentalen Plaque, eine Qualitätssteigerung der Zahnhartgewebe (z. B. mit Fluoriden) sowie eine Steigerung der Regenerationseigenschaften der Weichgewebe (z. B. Pflanzenextrakte) bewirken. Die Mundspüllösungen zur Plaquekontrolle verfügen in der Regel über bakteriostatische bzw. bakterizide Eigenschaften und können darüber hinaus durch ihre Oberflächenaktivität Einfluss auf den Akkumulationsprozess der dentalen Plaque nehmen. Die bakteriziden Eigenschaften der verfügbaren Präparate lassen sich auf eine Inhibierung bestimmter Stoffwechselwege in der Bakterienzelle zurückführen. Diese Wirkung darf auf keinen Fall bei den körpereigenen Zellen vorhanden sein. Aufgrund dieser Anforderung ist die Verfügbarkeit bzw. die Zahl effektiver Präparate zur Verwendung als Mundspüllösungen eingeschränkt. Wegen verschiedener Nebenwirkungen eignen sich bestimmte Mundspüllösungen nicht zur dauerhaften Anwendung. Sie werden deshalb vor allem dann empfohlen, wenn aufgrund von operativen Eingriffen die Zähne nicht mit der Zahnbürste gereinigt werden können oder um die häusliche Mundhygiene bei Mundschleimhauterkrankungen vorübergehend $\mathrm{zu}$ unterstützen. Zum Einsatz kommen antibakteriell wirkende Substanzen, an die folgende Erwartungen gestellt werden (SCHIFFNER 1995):

- Bakteriozidie

- Hemmung des bakteriellen Stoffwechsels, resultierend in einer Bakteriostase

- Hemmung der Bakterienanlagerung an orale Strukturen.

Die Effektivität oraler Mundspüllösungen wird durch deren Wirksamkeit sowie durch die Verweildauer in der Mundhöhle bestimmt (GAFFAR et al. 1994). Dabei muss das ökologische Gleichgewicht des Biotops Mundhöhle gewahrt bleiben, um die natürliche Abwehr zu erhalten. LANG NP und BRECX (1986) charekterisieren die Anforderungen an die Wirkung eines oralen Chemotherapeutikums wie folgt:

- Spezifität gegenüber oralen Mikroorganismen

- Effizienz in ihrer antibakteriellen Wirkung

- Substantivität, d.h. remanente Wirkung durch Adsorption an oralen Flächen

- Sicherheit im Sinne einer möglichst geringen toxischen Wirkung für die Mundschleimhaut und für den Körper allgemein

- Stabilität während der Lagerzeit wie auch in situ. 
Die Substantivität beinhaltet die Retention der Substanz in der Mundhöhle sowie eine ausreichende Adhäsion der Wirksubstanz an Zahnhart- und Weichgeweben mit der Folge einer längeren Verweildauer des Wirkstoffes in der Mundhöhle in antibakteriell wirksamer Konzentration (NETUSCHIL et al. 1997). Entsprechend ihrer Substantivität werden antibakterielle Wirkstoffe in „Generationen“ eingeteilt (NETUSCHIL 1991). Besitzt eine Mundspüllösung ausreichende Effizienz und Spezifität, jedoch nur unzureichende Substantivität, wird sie der ersten Generation zugeordnet (NETUSCHIL 1991). Zu den Antiseptika der ersten Generation gehören z. B. Listerin, Sanguinarin, Hexetidin und PVPJod. Der typische Vertreter der zweiten Generation ist Chlorhexidin (LANG und BRECX 1986). Es zeichnet sich durch Effizienz, Spezifität und ausreichende Substantivität aus (NETUSCHIL et al. 1997). Das Wirkprinzip der dritten Generation besteht nicht in einer antibakteriellen Wirkung, sondern in ihrer Eigenschaft zur Adhäsionsverminderung der oralen Mikroflora auf der Schmelzoberfläche; als Beispiel sei auf Octapinol verwiesen (BRECX et al. 1987).

\subsubsection{Antiseptische Wirkstoffe der ersten Generation}

Wirkstoffe der ersten Generation zeigen in vitro eine antibakterielle Wirkung, die jedoch in vivo nicht nachgewiesen werden kann. Diese Substanzen haben eine zu geringe Substantivität, als dass sie unter den in der Mundhöhle herrschenden Bedingungen eine maßgebliche Wirkung entfalten könnten. Beispiele für Wirkstoffe der ersten Generation sind Enzyme, Hexitidin, Sanguinarin, Cetylpyridiniumchlorid (CPC), ätherische Öle oder PVP-Jod (NETUSCHIL et al. 2002).

Enzymen wird eine vorteilhafte Wirkung bei der Biofilmbekämpfung zugeschrieben, wobei insbesondere Amylasen und Proteasen eine gute Biofilmreduktion erreichen sollen (SHAVER und SCHIFF 1970). Der Vergleich zwischen Zahnpasta mit Enzymen (Amyloglucosidase, Glucoseoxidase) und konventionellen Fluoridzahnpasten ohne Enzyme hat gezeigt, dass hinsichtlich der Biofilm- und Gingivitisentwicklung kein signifikanter Unterschied feststellbar war (MORAN et al. 1989). Auch Dextranasen und Mutanasen konnten aufgrund widersprüchlicher Ergebnisse keinen Einzug in die Gingivitisprophylaxe halten (CALDWELL et al. 1971, KELSTRUP et al. 1978). In einer Mundspüllösung reduzierte P113, ein 12-Aminosäure-Histatinbasierendes Peptid sowohl den Biofilm und die Gingivitis als auch die Gingivablutung im Modell der experimentellen Gingivitis nach MICHELS und 
TARNOW (2001). Nebenwirkungen traten nicht auf und sind auch nicht durch die Anwendung von anderen Enzymen bekannt.

Hexetidin ist ein mit verzweigten Alkylketten substituiertes Pyrimidin-Derivat mit antibakterieller Wirkung gegen grampositive und gramnegative Bakterien und Pilze (ROBERTS und ADDY 1981, ASHLEY 1984). Die antibakterielle Wirkung kann durch Zusatz von Metallsalzen wie z. B. Zink oder Kupfer verstärkt werden (GIERTSEN et al. 1989). Da Hexetidin im Wasser kaum löslich ist, hat es eine lange Verweildauer auf der Schleimhaut des Mund- und Rauchenraumes (FRITZSCHE und SAXER 1989). Die Keimzahl im Speichel erreicht jedoch bereits 90 Minuten nach der Spülung wieder ihren Ausgangswert, also relativ schnell im Vergleich zu der ca. sieben Stunden anhaltenden Wirkung von Chlorhexidin (ROBERTS und ADDY 1981). In einer klinischen Studie konnte durch Hexitidin im Vergleich zu Chlorhexidin eine ähnlich hohe Biofilm- und Gingivitisreduktion erzielt werden (WILLERSHAUSEN et al. 1990). Dies konnte auch durch eine weitere Studie belegt werden, in der die Biofilm- und Gingivitisreduktion durch Hexetidin untersucht wurde und Chlorhexidin die positive Kontrolle darstellte (SHARMA et al. 2003). Die Nebenwirkungen entsprechen denen von Chlorhexidin, wobei es jedoch zu verstärktem Mundschleimhautbrennen kommen kann.

Sanguinarin ist ein Alkaloidextrakt der Pflanze Sanguinaria canadensis (Blutwurz) und ist im Handel nur in Kombination mit Zinkionen (0,03\% Sanguinarin zu 0,2\% Zinkchlorid) als Mundspüllösung erhältlich (z. B. Veadent ${ }^{\circledR}$ und Periogard ${ }^{\circledR}$, Colgate, Hamburg). Die Wirkstoffkombination besitzt ein breites Aktivitätsspektrum gegen Bakterien (DZINK und SOCRANSKY 1985), da es zur Reduktion der glykolytischen Enzymaktivität kommt und die bakterielle Anlagerung an Hydroxylapatit inhibiert wird (GIERTSEN et al. 1989). Ob die bakteriziden Eigenschaften dem Pflanzenextrakt oder den Metallionen zuzuordnen sind, zeigte eine Studie, in der Veadent ${ }^{\circledR}$ mit und ohne Sanguinarin-Wirkstoff im Vergleich zu einer Chlorhexidin-Lösung angewendet wurde. Die vollständige Veadent ${ }^{\circledR}$-Lösung wies zwar im Vergleich zur Chlorhexidin-Kontrolle eine geringere biofilmhemmende Wirkung auf, jedoch war gegenüber der reduzierten Lösung eine um $10 \%$ erhöhte Biofilmreduktion zu beobachten (QUIRYNEN und MARECHAL 1990). Diese Studie verdeutlicht, dass die Antiplaquewirkung offensichtlich durch den Sanguinarin-Wirkstoff bestimmt wird. In einer Kurzzeitstudie wies eine sanguinarinhaltige Mundspüllösung (Veadent ${ }^{\circledR}$ ) bezüglich der Biofilmhemmung eine ähnliche Wirksamkeit wie Listerine ${ }^{\circledR}$ auf (RAMBERG et al. 1992). In klinischen Langzeitstudien konnte nach Anwendung von Sanguinarin im Vergleich zu einer chlorhexidinhaltigen Mundspüllösung eine geringere Biofilm- und Gingivitisreduktion 
(GROSSMANN et al. 1989) und im Vergleich zu einem Placebo (Wasser) kein signifikanter Unterschied festgestellt werden (WILLERSHAUSEN et al. 1990). Jedoch kann Sanguinarin die Wirkung von kurzzeitig eingesetzem Chlorhexidin (zwei Wochen) optimieren. Es beugt einer Gingivitis für einen Zeitraum von etwa zwölf Wochen vor, wenn anschließend eine Kombination aus sanguinarinhaltiger Mundspüllösung und Zahnpasta verwendet wird. Die Nebenwirkungen wie Schleimhautbrennen und Verfärbungen durch das Chlorhexidin können damit vermindert werden (TENENBAUM et al. 1999). Dennoch wurden nach Anwendung von Sanguinarin zumeist Schleimhautbrennen und schlechter Geschmack beschrieben (CIANCIO 1992).

Das Cetylpyridiniumchlorid wird als Ersatz bei Chlorhexidin-Intoleranz diskutiert. Es besitzt zwar ein breites antimikrobielles Spektrum, wirkt jedoch nicht gegen gramnegative Bakterien (PITTEN und KRAMER 2001, RENTON-HARPER et al. 1996). Seine schwächere Wirkung wird auch der niedrigeren Verweildauer zugeschrieben, die nur fünf Stunden beträgt (ELWORTHY et al. 1996). Aber wie auch beim CHX sollte zwischen Spülen und der Anwendung von Zahnpasta ein zeitlicher Abstand von ca. 60 Minuten eingehalten werden. Es scheint hier Interaktionen mit den plaquehemmenden Inhaltsstoffen der Zahnpasta zu geben (SHEEN et al. 2003). Neben den medizinisch wirksamen Inhaltsstoffen ist häufig auch Alkohol in Mundspüllösungen enthalten. Für Kinder und Menschen mit Alkoholproblemen sind diese Produkte nicht geeignet. Außerdem wird ein schädigender Einfluss auf den Aufbau der Zellstruktur diskutiert (POGGI et al. 2003).

Die größte antibakterielle Wirksamkeit von Mundspüllösungen der ersten Generation wird den ätherischen Ölen (Listerine ${ }^{\circledR}$ als bekanntester Vertreter) zugeschrieben (MORAN et al. 1997, RIEP et al. 1999). Allerdings muss hier auf eventuell bestehende Allergien geachtet werden. Die ätherischen Öle sind für die Störung bzw. die Veränderung der Zellmembran (TEUSCHER et al. 1990) pathogener Keime wie Aggregatibacter actinomycetemcomitans oder Candida albicans schon nach einer Einwirkzeit von nur 30 Sekunden (KUBERT et al. 1993) und für die Hemmung der Prostaglandinbiosynthese (WAGNER und WIESNER 1988) verantwortlich. Zusätzlich kann in der Plaque die Glykolyse bzw. die Glykosyltransferase gehemmt werden. BERNIMOULIN und DESCHER (1995) berichteten außerdem von einer antiinflammatorischen und cyclooxygenasehemmenden Aktivität der ätherischen Öle.

Die Verweildauer der Wirksubstanzen in der Mundhöhle, ihre Substantivität, scheint aber gering zu sein. Weiterhin ist nicht hinreichend geklärt, inwiefern der als Lösungsmittel dienende Alkohol, der denaturiert auf die Bakterienzelle einwirkt, zum antibakteriellen Effekt beiträgt. Aber aufgrund der o. g. Effekte konnten BALBUENA et al. (1998) eine Stunde nach 
einmaliger Spülung eine signifikante Reduktion der Bakterienzahl registrieren. Der plaquehemmenden Wirkung von Listerine ${ }^{\circledR}$ liegt laut SCHEIE (2003) ein deutlicher bakterizider Effekt zugrunde. PAN et al. (1999) zeigten, dass Listerine ${ }^{\circledR}$ gegenüber oralen Mikroorganismen wie $S$. mutans und Prevotella eine signifikant stärkere Aktivität entfaltet als eine $\mathrm{AmF} / \mathrm{SnF}_{2}$-Lösung, unabhängig davon, ob sich die Mikroorganismen in einem planktonischen Zustand oder in einem Biofilm befanden.

An zahlreichen Lang- und Kurzzeitstudien konnte durch mikrobiologische und klinische Untersuchungen der plaque- und gingivitisinhibierende Effekt der Listerine ${ }^{\circledR}$-Lösung mit unterschiedlichen Befunden dokumentiert werden (LÖE et al. 1976, YANKELL et al. 1988, ROSS et al. 1989, FINE et al. 1992, BRECX et al. 1992, MORAN et al. 1997, RIEP et al. 1999, CIANCIO 2003, BERNIMOULIN 2003, OUHAYOUN 2003 und 2004, SANTOS 2003). Die Plaquereduktion durch Listerine ${ }^{\circledR}$ betrug dabei zwischen $19 \%$ und $56 \%$. Die Resultate der Gingivitisreduktionen schwankten zwischen $29 \%$ und $36 \%$. In den Studien von GORDEN et al. (1985), LAMSTER et al. (1983), OVERHOLSTER et al. (1990), CHARLES et al. (2001) sowie DEPAOLA et al. (1989) wurden die Probanden aufgefordert, zweimal täglich zu spülen. Die üblichen Mundhygieneaktionen wurden über einen Zeitraum von sechs bis neun Monaten beibehalten. Verglichen mit einem Placebo, blieb die Plaquerekolonisation zwischen $19 \%$ und $34 \%$ (p < 0,01 bzw. p < 0,001) reduziert. PLISCHKE (2001) konnte bei ihren Untersuchungen mit Listerine ${ }^{\circledR}$ eine 19-prozentige Plaquereduktion nachweisen. Bei der metrischen Bewertung der Plaquefläche fiel die Plaquehemmung gegenüber einem Placebo mit $40 \%$ sogar noch deutlich stärker aus.

Die Dauer der Studien variierte zwischen eineinhalb und neun Monaten (AXELSSON und LINDHE 1987, GORDON et al. 1985, FINE et al. 2005), wobei ein nachlassender antibakterieller Effekt bei Ausdehnung der Studienzeit sichtbar wurde, wie es auch im Vergleich mit anderen Substanzen auffiel. Der additive Effekt der Mundspüllösung wurde gleichfalls bei Kombination mit mechanischer Plaquekontrolle nachgewiesen (CHARLES et al. 2001, SHARMA et al. 2004, FINE et al. 1985). FINE et al. (2005) zeigten z. B. an 78 Probanden bei Nutzung von Listerine ${ }^{\circledR}$ über einen Zeitraum von neun Monaten eine deutliche Plaquereduktion von $59 \%$, die sie durch Bestimmung des Proteingehaltes der Plaque verifizierten.

Bei keiner der Studien konnten Nebenwirkungen registriert werden. SCHIFFNER (1999) stellte jedoch fest, dass Zahnverfärbungen und Geschmacksirritationen auftreten können. Die Wirkung von Listerine®-Mundspüllösung auf die humanen Gingiva-Fibroblasten macht die Studie von FLEMINGSON et al. (2008) deutlich. In dieser Arbeit wurde die Toxizität der drei 
Mundspüllösungen Chlorhexidin, PVP-Jod und Listerine ${ }^{\circledR}$ in Abhängigkeit von der Konzentration und der Einwirkzeit der Substanzen auf die Bindegewebsvorläuferzellen der Mundschleimhaut untersucht. Bei der Behandlung der Zellen mit Listerine ${ }^{\circledR}$ war in allen Versuchen eine proliferationshemmende Wirkung der Mundspüllösung festzustellen. Die stark verdünnte Listerine ${ }^{\circledR}$-Lösung (1\% bzw. $2 \%$ ) war toxischer als die CHX- und PVP-JodLösungen bei gleicher Verdünnung. Die Ergebnisse waren konzentrationsabhängig signifikant unterschiedlich, die Abhängigkeit der zellschädigenden Wirkung von der Einwirkzeit wies jedoch keine Signifikanz auf.

Ein weiterer Vertreter der ersten Generation von oralen Antiseptika ist Povidon-Jod (PVPJod). PVP-Jod (Handelsname Betaisodona ${ }^{\circledR}$ ) ist ein wasserlöslicher Komplex von Jod mit Polyvinylpyrrolidon (PVP, Povidon), der als Desinfektionsmittel bzw. Antiseptikum verwendet wird. Povidon-Jod ist eine Verbindung aus der Gruppe der Jodophore, d.h. komplexer organischer Verbindungen, aus denen molekulares Jod freigesetzt wird.

Das 1811 von einem Pariser Apotheker namens Bernard Courtois entdeckte Element Jod wird nunmehr seit über 150 Jahren zur Behandlung von Infektionen und Wunden benutzt. Schon 1839 erkannten französische Chirurgen die antiseptische Wirkung von Jod, das damals in Form von Jodtinkturen zur Therapie von Kriegswunden eingesetzt wurde (GÖRTZ und HÄRING 1986).

Antibakteriell wirksames elementares Jod $\left(\mathrm{I}_{2}\right)$ ist nur schwer wasserlöslich und findet daher seit über 30 Jahren als sogenanntes Jodophor in Kombination mit Polyvinylpyrrolidon (PVP) Anwendung. PVP dient hierbei als Trägersubstanz, die Iod über Wasserstoffbrücken in Form von Triiodid binden und dadurch in wässrige Lösung bringen kann. Hier herrscht dann folgendes Reaktionsgleichgewicht (GÖRTZ und HÄRING 1986, SCHREIER et al. 1997):

$$
[\mathrm{PVPH}+] \mathrm{I}_{3}{ }^{-} \leftrightarrow[\mathrm{PVPH}+] \mathrm{I}^{-}+\mathrm{I}_{2}
$$

Da nur nicht gebundenes molekulares Jod eine antimikrobielle Wirksamkeit zeigt (SCHUBERT 1985, HEEG und CHRISTIANSEN 1993), erreicht man mittels höhergradiger Verdünnung eine Verschiebung zu dessen Gunsten und damit eine raschere antiseptische Wirkung. Dies gilt aber nur bis zu einem Mischverhältnis von 1:100, da bei stärkerer Verdünnung die antiseptische Wirkung infolge eines verminderten Jodgehalts wieder abnimmt (GÖRTZ und HÄRING 1986).

PVP-Jod zeichnet sich durch ein breites Wirkspektrum aus, das nicht nur grampositive und gramnegative Bakterien, sondern auch Viren, Protozoen, Sporen und Pilze umfasst (REIMER et al. 2002, WUTZLER et al. 2003). Diese Wirkung beruht zum einen auf dem starken 
oxidativen Potenzial von Jod (SCHREIER et al. 1997) und zum anderen darauf, dass die Freisetzung zahlreicher Pathogenitätsfaktoren wie z. B. der Exotoxine gehemmt wird (KÖNIG et al. 1997, WUTZLER et al. 2003). Auch einer zu starken Freisetzung entzündungsfördernder Mediatoren wie z. B. der Zytokine oder gewebszerstörender Enzyme kann hierdurch entgegengewirkt werden (KÖNIG et al. 1997, KRAMER et al. 2002). Zu beachten ist dabei, dass die Wirksamkeit durch Blut oder Serum eingeschränkt (sog. Zehrung oder Eiweißfehler) bzw. die Einwirkungszeit verlängert wird. Darüber hinaus führt PVP-Jod nach heutigem Wissensstand nicht zur Resistenzbildung (LANKER KLOSSNER et al. 1997, REIMER et al. 2000, SCHREIER et al. 1997, WUTZLER et al. 2000), die durch den Gebrauch zahlreicher Antibiotika ein immer größer werdendes Problem bei der Bekämpfung von Mikroorganismen darstellt (VALENCIA et al. 2004). Im Allgemeinen zeichnen sich lokal anwendbare PVP-Jod-Präparate durch eine gute Verträglichkeit und ein geringes Risiko der Allergisierung bzw. Toxizität aus (REIMER et al. 2002).

Kontaktallergien sind älteren Studien zufolge mit einer Wahrscheinlichkeit von unter 3 \%o zu erwarten (KIRCHMAYR 1957, BÖCKERS und BORK 1986). Dennoch kann es aber bei entsprechend sensibilisierten Patienten zum Auftreten von Quincke-Ödemen, Urtikaria oder gar einem anaphylaktischen Schock kommen. Ferner sind, abhängig von der Anwendungsdauer und der Größe der behandelten Wundfläche, Schilddrüsenfunktionsstörungen durch systemische Jodaufnahme möglich, die von hypothyreoten Zuständen vor allem beim Neugeborenen (SCHÖNBERGER und GRIMM 1982) bis hin zu hyperthyreoten Zuständen reichen. Vor diesem Hintergrund ist bei bekannter Jodüberempfindlichkeit sowie bei Patienten, die bereits an einer Schilddrüsenüberfunktion oder Dermatitis herpetiformis Duhring leiden oder die sich einer Radioiod-Therapie zu unterziehen haben, Vorsicht bei der Verabreichung iodhaltiger Präparate geboten, um der Induktion einer lebensbedrohlichen thyreotoxischen Krise vorzubeugen. PVP-Jod findet in zahlreichen medizinischen Fachgebieten Verwendung. Dazu ist vor allem seine Benutzung bei der Vorbereitung des Operationsfeldes, bei der Haut- und Schleimhautantiseptik (RUDOLPH et al. 2000), der Spülung von Körperhöhlen und Fistelgängen und bei der Wundbehandlung zu zählen. Darüber hinaus zeigt es auch gute Wirksamkeit bei der Behandlung von Augeninfektionen wie der bakteriell oder viral bedingten Keratokonjunktivitis (WUTZLER et al. 2000). Weiterhin gab es zahlreiche Untersuchungen zur Effektivität von PVP-Jod im Rahmen der Mundhöhlenantiseptik vor zahnärztlichen Eingriffen, um die Bakteriämierate zu senken (SCOPP und ORVIETO 1971, JOKINEN 1978, 
MACFARLANE et al. 1984, RECHMANN et al. 1989, YAMALIK et al. 1992, RAHN et al. 1994).

Umstritten ist aber seit einiger Zeit, ob sich PVP-Jod negativ auf die Wundheilung auswirkt. Dank der stark oxidierenden Wirkung von Jod werden nämlich nicht nur Krankheitserreger, sondern auch körpereigene Zellen (NIEDNER 1997) und hier vor allem das regenerierende Epithel (GÖRTZ und HÄRING 1986) angegriffen. In den 80er-Jahren konnte anhand von Invitro- und In-vivo-Untersuchungen eine zytotoxische Wirkung von PVP-Jod (RODEHEAVER et al. 1982, LINEWEAVER et al. 1985, FLEMINGSON et al. 2008) gezeigt werden, die unter anderem dosisabhängig auftrat. Andere Autoren hingegen postulieren trotz allem eine insgesamt die Wundheilung fördernde Wirkung (HAUPTMANN et al. 1992). So zeigt die liposomale Zubereitung von Povidon-Jod bei gleicher Wirksamkeit eine deutlich bessere Gewebeverträglichkeit mit zumindest in vitro tendenziell nachweisbarer Proliferationsförderung.

\subsubsection{Antiseptische Wirkstoffe der zweiten Generation}

Wirkstoffe der zweiten Generation verfügen über eine ausgeprägte Substantivität. Ihre antibakterielle Wirkung konnte sowohl in vitro als auch in vivo nachgewiesen werden. Vertreter dieser Gruppe sind Triclosan, Xylitol, Chlorhexidin und die Wirkstoffkombination Aminflourid/Zinnflourid (Meridol ${ }^{\circledR}$ ) (NETUSCHIL et al. 2002).

Eine Vielzahl antimikrobieller Wirkstoffe wird zur Mundhöhlenantiseptik angewendet. Um in vivo eine Wirkung gegen die Mikroorganismen zu erzielen, muss die Substanz während der Applikation in einer biologisch aktiven Form vorliegen und über einen ausreichend langen Zeitraum verfügbar sein. Weiterhin hängt die Effektivität auch von der Wirkstoffkonzentration am Wirkort sowie der Absorption und der nachhaltigen Freisetzung durch die Oberflächen der Mundhöhle ab (LINDAU 1997).

Das Phenolderivat Triclosan besitzt nur eine leichte antibakterielle Wirkung gegenüber den meisten Plaquebakterien. Zur Wirkungssteigerung kann Triclosan mit einem Copolymer (PVA/MA) kombiniert werden (Colgate Total). Dies bewirkt eine höhere Retention im Mund. Jedoch bleibt die antimikrobielle Wirkung schwächer als bei den anderen beschriebenen Produkten (MORAN et al. 1992, PITTEN und KRAMER 2001, RENTON-HARPER et al. 1996). 
Dem Zuckeralkohol Xylitol wurden in den 90er-Jahren antikariogene und auch therapeutische Fähigkeiten zugeschrieben, da er von den meisten Mikroorganismen im Mund nicht verstoffwechselt werden kann und damit die Säurebildung in der Plaque hemmt. Es wurde berichtet, Xylitol reduziere die Anzahl von S. mutans, senke die Plaqueformationsrate und hemme ebenso die Entwicklung von Gingivitis. Allerdings sind diese Fähigkeiten nicht unumstritten (HOPPENBROUWERS et al. 1986).

Als Standardpräparat in der Prävention und Therapie oraler Entzündungen hat sich der Wirkstoff Chlorhexidin etabliert. Tatsächlich ist es das effektivste und am meisten verbreitete antimikrobielle Mittel für den intraoralen Gebrauch (STELZEL 2002). Chlorhexidin gehört zur Gruppe der Bisbiguanide (1,6-bis-4-Chlorphenol-diguanidohexan) mit der Summenformel $\mathrm{C}_{22} \mathrm{H}_{30} \mathrm{Cl}_{2} \mathrm{~N}_{10}$. Das Chlorhexidin-Molekül ist stark basisch und besitzt lipophile und hydrophile Gruppen. Nach seiner Entwicklung 1954 von DAVIES et al. untersuchten LÖE und SCHIÖTT (1970) die Wirksamkeit von Chlorhexidindigluconat zur Beeinflussung der Plaquebildung. Dieses Chlorhexidinsalz zeigte im Vergleich zu anderen Salzen (Acetat, Chlorid) die konzentrationsabhängig ausgeprägtesten bakterioziden und bakteriostatischen Eigenschaften. Im Ergebnis zahlreicher Studien zählt Chlorhexidin zu den effektivsten Wirkstoffen für die antiseptische Mundspülung. Die Keimzahlverminderungen in Mundspülflüssigkeiten bis $>2 \mathrm{lg}$ und die Effektivitätszunahme nach 5 bis 120 Minuten unterstreichen die Wirksamkeit von CHX gegenüber anderen oralen Antiseptika (ROBERTS und ADDY 1981, KRAMER et al. 1990).

Chlorhexidin ist gegen gramnegative und grampositive Mikroorganismen wirksam, wobei die Effektivität gegen grampositive Bakterien höher ist (MHK 0,5-64 $\mu \mathrm{g} / \mathrm{mL}$ ) als gegen gramnegative Bakterien (MHK 1-500 $\mu \mathrm{g} / \mathrm{mL}$ ). Auch gegen Candida albicans ist die Wirkung hoch (MHK 20-40 $\mu \mathrm{g} / \mathrm{mL}$ ) (KRAMER und WALLHÄUSSER 1993). Diese remanente Wirkung beruht auf der Affinität zu anionischen Gruppen (Sulfat-, Carboxyl- und Phosphatreste). Die antimikrobielle Wirkung ist auf die Interaktion des positiv geladenen Chlorhexidinmoleküls mit den negativ geladenen Gruppen der Bakterienwand zurückzuführen. Dadurch wird die bakterielle Zellwand verändert (Permeabilität), was bei geringeren Konzentrationen zur Störung des Metabolismus der Bakterien und zur Bakteriostase führt (GJERMO 1978). Bei höheren Konzentrationen kommt es zur Perforation der zytoplasmatischen Membran, sodass Chlorhexidin in die Bakterienzelle eindringt und sie zur Lysis bringt (LANGE 1995). So wirkt Chlorhexidin in Abhängigkeit von der Konzentration bakteriostatisch oder bakteriozid. $\mathrm{Zu}$ den besonders empfindlichen 
Mikroorganismen gegenüber Chlorhexidin zählen Staphylococcus spp., Streptococcus mutans (HEFTI und HUBER 1987, CIANCIO 1995), Streptococcus salivarius, E.coli und Candida albicans. Weniger sensibel reagieren Streptococcus sanguis, Proteus spp., Pseudomonas und Klebsiella spp. (CIANCIO 1995).

Bei der Mundspülung mit Chlorhexidin werden die Moleküle an saure Makromoleküle der oralen Oberflächen (Schleimhaut) gebunden (GJERMO 1978). Das so gebundene Chlorhexidin wird nach und nach innerhalb von acht bis zwölf Stunden wieder freigesetzt (CIANCIO 1995, NETUSCHIL et al. 1989, STELZEL 2002, ADDY und WRIGHT 1978). Dadurch wird ein gewisses Niveau der Chlorhexidinkonzentration über einen längeren Zeitraum in der Mundhöhle erhalten, was ausreicht, den bakteriostatischen Effekt aufrechtzuerhalten. Die Effektivität der antiseptischen Wirkstoffe ist unterschiedlich und stark eingeschränkt, wenn die Frage nach dem infektionsprophylaktischen bzw.- therapeutischen Aspekt im Vordergrund steht, da die antimikrobielle Langzeitwirkung eine entscheidende Rolle spielt. Diese Langzeitwirkung ist ein großer Vorteil gegenüber anderen Mundspüllösungen. Zahlreiche Studien belegen die antiseptische Wirksamkeit zur Verbesserung der Mundhygiene durch Plaque- und Gingivitisreduktion (LÖE und SCHIÖTT 1970, ALBERS und MAAS 1985, BRINER et al. 1986, HEFTI und HUBER 1987, MARUNIAK et al. 1992). Weiterhin vergleichen die Arbeiten von BERGENHOLZ und HÄNSTRÖM (1974), ADDY und WRIGHT (1978), ROBERTS und ADDY (1981), KRAMER et al. (1990), SCHREIL (1991) sowie BRECX et al. (1993) die antimikrobielle Wirksamkeit verschiedener Präparate mit Chlorhexidin. In allen Studien wird deutlich, dass Chlorhexidin eine effektivere Wirkung bezüglich Plaqueinhibition und Beeinflussung der Gingivitis besitzt als die anderen untersuchten Präparate.

Der kationische Charakter des CHX birgt jedoch auch Nachteile. CHX kann durch das anionische Natriumlaurylsulfat, das in den meisten Zahnpasten als Tensid dient, neutralisiert werden (BARKVOLL et al. 1988). Gleiches gilt für Natriummonofluorphosphat, das allerdings nur noch in wenigen Zahnpasten verwendet wird. Aus diesen Erkenntnissen resultiert die Empfehlung an die Patienten, zwischen den Anwendungen einer Zahnpasta mit einer der beiden genannten Substanzen und Chlorhexidin eine halbe bis eine Stunde verstreichen zu lassen (BARKVOLL et al. 1988, STELZEL 2002). Zur Vereinfachung des Gebrauchs könnte bei Anwendung von Chlorhexidin zu einer Zahnpasta gewechselt werden, die diese Stoffe nicht enthält. Das sind z. B. alle Pasten mit Aminfluorid, die kein zusätzliches Tensid benötigen, da das Aminfluorid selbst oberflächenaktiv wirkt. Die DGZMK empfiehlt den Einsatz von Chlorhexidin als therapeutisch wirksame Substanz bei entsprechender 
Indikation: prä- und postoperativ, während der kieferorthopädischen Behandlung, nach Kieferbruchschienung, während der Schwangerschaft, bei umfangreichen Zahn- oder Parodontalsanierungen oder bei Behinderten.

Chlorhexidin besitzt bei Langzeitanwendung das Risiko von Nebenwirkungen wie schwarzbraunen Verfärbungen der Zähne, der Kunststofffüllungen und des Zungenrückens (LÖE et al. 1976, GREENSTEIN et al. 1986), die sich aber durch professionelle mechanische Zahnreinigung entfernen lassen. Weiterhin kann es zu Geschmacksstörungen, Desqamationen und Mundschleimhautläsionen kommen (FLÖTRA et al. 1971, RUSTHON 1977, SKOGLUND und HOLST 1982). Auch Wundheilungsstörungen wurden nach sofortiger Applikation post operationem beschrieben (BASSETTI und KALLENBERGER 1980). Diese Begleiterscheinungen lassen sich bei geringerer Konzentration reduzieren, ohne dass ein signifikanter Unterschied in der klinischen Wirksamkeit hinsichtlich Infektionsprophylaxe, Plaque- und Gingivitishemmung zu verzeichnen ist. Aus diesem Grund wird aktuell die Konzentration von 0,1\% empfohlen (FLÖTRA et al. 1972, CUMMING und LÖE 1973, RIETHE und STOLL 1977, KREMERS und LAMPERT 1979, SKOGLUND und HOLST 1982, JENKINS et al. 1994, LANGE 1995).

Sollte eine höhere Wirksamkeit bei klinisch kritischen Situationen erforderlich sein, kommt der Einsatz höher konzentrierter Lösungen in Betracht (BAY 1978, LANGE 1995). Chlorhexidin kann als Spüllösung in einer Konzentration von $0,1 \%$ bis $0,2 \%$ wirklich als „chemische Zahnbürste“ eingesetzt werden, wenn eine mechanische Zahnreinigung vorübergehend nicht möglich ist, wie z. B. nach chirurgischen Eingriffen oder bei einer hochakuten Gingivitis (ADDY 1986).

Die Wirkung von Chlorhexidin bei Knochenmarktransplantionspatienten wurde in verschiedenen Doppelblindstudien untersucht. FERRETTI et al. (1988 und 1990) verglichen Chlorhexidin 0,12\% mit einem Placebo. In der Chlorhexidingruppe trat eine geringere Mukositis auf als in der Kontrollgruppe. In einer Studie von WEISDORF et al. (1989) fand sich dagegen kein Unterschied zwischen Chlorhexidin und dem Placebo. Auch andere Studien (MCGAW und BELCH 1985, SPJKERVET et al. 1989, RUTKAUSKAS und DAVIS 1999) zeigen unterschiedliche Ergebnisse. Als Folge gibt es bis heute keine Richtlinien für die regelmäßige Anwendung eines bestimmten oralen Antiseptikums bei neutropenen Patienten. Im Allgemeinen ist es den Patienten freigestellt, mit Salbeitee oder handelsüblichen Antiseptika zu spülen.

Obwohl die systemische Toxizität als weitgehend gering beschrieben wird, sollte doch eine strenge Indikationstellung beachtet und von einer dauerhaften täglichen Anwendung 
abgeraten werden (GJERMO 1989). Die Anwendungsdauer von Chlorhexidin sollte aufgrund der bekannten Nebenwirkungen 14 Tage nicht überschreiten (SCHMIDT 1988, SPLIETH und KRAMER 2000).

Zur dauerhaften Anwendung eignet sich die Chlorhexamed ${ }^{\circledR}$ Lösung 0,06 \% + F. Diese zeigte im 6-Monatsvergleich eine Verfärbungstendenz, die lediglich auf dem Niveau einer handelsüblichen aminfluorid-/zinnfluoridhaltigen Lösung lag. Die antibakterielle Wirkung von Chlorhexamed ${ }^{\circledR}$ ist unumstritten und mit den oben genannten Studien eindeutig belegt. Die Toxizität dieses Präparates in Bezug auf die Zellen der Mundschleimhaut und des Parodontalapparates ist bis jetzt jedoch sehr wenig untersucht. Die proliferationshemmende Wirkung von CHX wurde sowohl in der Studie von FLEMINGSON et al. (2008) als auch in der Untersuchung von MARIOTTI und RUMPF (1999) auf die humanen GingivaFibroblasten beschrieben. Die beiden Studien zeigten eine signifikante konzentrationsabhängige Toxizität von $\mathrm{CHX}$ auf die Zellen in vitro sowie eine Hemmung der Kollagen- und Non-Kollagen-Protein-Synthese, was einen negativen Effekt auf die Wundheilung haben kann.

In letzter Zeit sind fluoridhaltige Präparate, insbesondere eine Kombination von Aminfluorid (Olaflur, AmF) mit Zinnfluorid $\left(\mathrm{SnF}_{2}\right)$, wie sie in der Mundspüllösung Meridol ${ }^{\circledR}$ enthalten ist, als entzündungs- und plaquehemmend erkannt worden. Entsprechend den Empfehlungen der DGZMK gehört die Anwendung von Fluoriden zu den drei Eckpfeilern zahnmedizinischer Prävention. Allerdings handelt es sich dabei nicht immer um die kostengünstigste Variante. Die tägliche Verwendung fluoridhaltiger Spüllösungen ist der wöchentlichen Anwendung von Fluoridgelee gleichwertig, bedeutet allerdings einen höheren zeitlichen und finanziellen Aufwand. Die Angabe des Fluoridgehalts kann sowohl in Milligramm/Liter als auch in parts per million (ppm) erfolgen; die Werte beider Einheiten entsprechen einander. Zur Beeinflussung von Plaque und Gingivitis durch Fluoride wurden zahlreiche Studien durchgeführt (ALBERS und MAAS 1985, TRACHSLER 1988, FLORES-DE-JACOBY 1991).

Fluoride wirken auf den bakteriellen Stoffwechsel, indem sie indirekt den Zuckertransport durch die Zellmembran beeinflussen und die Aktivität einiger essenzieller SulfhydrylGruppen enthaltender Enzyme (insbesondere der Enolase) der mikrobiellen Glykolyse hemmen (HAMILTON und BOWDEN 1996). Die Enolase katalysiert die Umwandlung von 2-Phosphoglycerat in Phosphoenolpyruvat (FRUNDER 1984). Zusätzlich wirken Fluoride auf den Kohlenhydratstoffwechsel und damit direkt gegen die mikrobielle Säurebildung (MARSH 
2004). Durch die Eigenschaft der Plaque, Fluoridionen zu kumulieren, kann eine ausreichende Fluoridkonzentration in der Plaque angereichert werden (GUGGENHEIM 1983, JENKINS und EDGAR 1977). In Kombinationspräparaten dient das Aminfluorid als Komplexbildner für das Zinnfluorid. Nach dem Einbringen des $\mathrm{AmF} / \mathrm{SnF}_{2}-\mathrm{Komplexes}$ in die Mundhöhle kommt es durch die tensidähnliche Oberflächenaktivität des Präparates zu einer raschen Verteilung in der Mundhöhle und der Anlagerung an orale Strukturen (WALKER 1988). Dieser Wirkmechanismus der Fluoridkombination wird dem Kation Zinn und dem organischen Amin zugesprochen. Das Zinn-Ion kann seine Wirkung nur in stabiler, gelöster Form entfalten, was durch den Zusatz des oberflächenaktiven Aminfluorids erzielt wird. In der Kombination ergeben sich dann die ausgeprägten Affinitäten zur Oberfläche der Plaquebakterien, zur Mundschleimhaut und zum Zahnschmelz (SCHMID 1983). In Anwesenheit von Ca-Ionen aus dem Speichel wird das Zinn-Ion aus seiner Komplexbindung herausgelöst und liegt dann in seiner aktiven Form vor. Jetzt kann das Zinn-Ion in den Stoffwechsel der Plaquebakterien eingreifen. Durch die beschriebenen Eigenschaften ist $\mathrm{AmF}_{\mathrm{SnF}}$ in der Lage, die Adhäsion von Mikroorganismen auf der Zahnoberfläche zu behindern (GÄNGLER 2005, STÖSSER 2006). Die außergewöhnlichen antibakteriellen

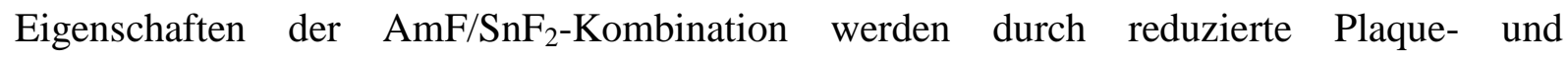
Gingivitisindizes deutlich belegt (SCHULZ L und SCHULZ E 1989, STÖSSER et al. 1992, NETUSCHIL et al. 2003, BRECX et al. 2003, GUARNELLI 2004, TROMBELLI et al. 2003).

Bei TROMBELLI et al. (2003) wurden zu Beginn der Studie bei 39 Teilnehmern ein Testund ein Kontrollbereich im Mund festgelegt. Im Testbereich fand 21 Tage lang keine Mundhygiene statt, um experimentelle Gingivitis zu erzeugen. Für die Bewertung der Plaquebildung und das Fortschreiten der Gingivitis wurden klinische Parameter zu Beginn und zum Ende der Studie erhoben. Dabei zeigte sich, dass trotz einer ähnlichen Plaqueansammlung bei allen Teilnehmern die Gingivitiswerte sehr stark variierten. Anhand dieser Beobachtungen unterteilten die Autoren die Teilnehmer in Gruppen mit starker und geringer Entzündungsantwort. Im anschließenden Untersuchungszeitraum von drei Wochen putzten die Teilnehmer mit Meridol ${ }^{\circledR}$-Zahnpasta und wendeten zusätzlich die Meridol ${ }^{\circledR}$ Mundspüllösung an. Die Parameter der Plaquebildung und Gingivitis gingen dabei in beiden Gruppen deutlich zurück, wiesen aber auf die Dispositionsunterschiede der Entzündungsreaktion hin, die Grundlage der Gruppenbildung gewesen war. MADLENA et al. (2005) belegten an 42 Probanden nach Anwendung einer $\mathrm{AmF} / \mathrm{SnF}_{2}$-haltigen Zahnpaste eine signifikante Plaquereduktion, die aber in einer zweiten Gruppe bei Kombination mit einer 
AmF/SnF ${ }_{2}$-haltigen Mundspüllösung noch stärker ausfiel (50\%). Die 30-sekündige Verabreichung erfolgte über vier Wochen.

Studien von HUDELMAIER (1987), STÖSSER et al. (1990), STRÜBING und GÜLZOW (1991) haben für die Fluoridkombination $\mathrm{AmF}_{\mathrm{SnF}}$ einen antimikrobiellen Effekt in Abhängigkeit von der Konzentration, jedoch aufgrund der schnellen Clearance der Amin/Zinnfluorid-Mundspüllösung keine Langzeitwirkung nachgewiesen. FRITZSCHE und SAXER (1989) bestätigten eine rasche Clearence für $\mathrm{AmF} / \mathrm{SnF}_{2}$. Sie zeigten jedoch aufgrund der hohen Anfangskonzentration von $250 \mathrm{ppm}$ F noch nach 60 Minuten einen Effekt. Untersuchungen von NETUSCHIL et al. (1997) ergaben, dass Meridol ${ }^{\circledR}$ seine stärkste antibakterielle Wirkung in situ nach zwei bis vier Stunden (Abnahme der Vitalität der Plaqueflora bis zu $40 \%$ nach zwei bis drei Stunden) erreicht. Auch nach acht Stunden sollen die Ausgangswerte noch nicht wieder erreicht sein. In einer anderen Studie konnte Aminfluorid/Zinnfluorid bis zu acht Stunden in antibakteriell wirksamer Konzentration im Biofilm nachgewiesen werden (BOWEN 1990). Die quantitativen und qualitativen Nebenwirkungen sind bei Aminfluorid-/Zinnfluorid-Lösungen weniger von Bedeutung (SCHREIL 1991), sodass sie als Adjuvans zur mechanischen Zahnreinigung eingesetzt werden können (BANOCZY und NEMES 1989, BRECX et al. 1992 und 1993). Die Wirkung Aminfluorid-/Zinnfluorid-Mundspüllösungen in Bezug auf ihre Toxizität auf die Zellen der Mundschleimhaut und des Parodontalapparates ist in der Literatur nicht eindeutig beschrieben. Die vorliegende Arbeit hat sich daher zum Ziel gesetzt, dieser Frage nachzugehen.

\subsubsection{Antiseptische Wirkstoffe der dritten Generation}

Chemotherapeutika der dritten Generation haben Eigenschaften zur Adhäsionsminderung der oralen Mikroflora auf der Schmelzoberfläche (LANG NP et al. 1998). Es wird sich jedoch erst in Zukunft zeigen, inwieweit man ihre Eigenschaften nutzen kann. Die ersten Präparate sind derzeit neu im Handel erhältlich. Beispiele für diese Substanzgruppe sind Octenidol ${ }^{\circledR}$ und Delmopinol $^{\circledR}$.

Die oberflächenaktiven Substanzen werden bevorzugt als Netzmittel in Zahnpasten eingesetzt und führen durch Reduktion der Oberflächenspannung zu einer Verringerung der mikrobiellen Kohäsion und somit zu einer Auflösung der Bakterienverbände (CIANCIO 1992). Die oberflächenaktiven Substanzen sind Detergenzien wie Stearat und 
Natriumlaurylsulfat, die seit Langem Anwendung als Zusätze in Zahnpasten finden. Natriumlaurylsulfat gehört zu den oberflächenaktiven anionischen Substanzen. In-vitroStudien haben die Wirksamkeit gegenüber S. mutans und S. sobrinus gezeigt. Eine Hemmung der Plaqueentwicklung konnte ebenfalls nachgewiesen werden. Verschiedene Faktoren scheinen dafür verantwortlich zu sein: Störung bestimmter Enzymreaktionen, Denaturierung von Proteinen sowie Verhinderung der Adsorption von Bakterien auf der Zahnoberfläche. In Kombination mit Zinksalzen erhöht sich die Wirkung. Natriumlaurylsulfat bewirkt das Aufschäumen beim Zähneputzen (VAN DYKE 1992), inaktiviert auch bakterielle Enzyme und erreicht somit eine Bakteriostase (SCHACHTELE 1975). Da es aufgrund seiner Proteinaffinität nicht nur Bakterienenzyme denaturiert, sondern auch interzelluläre Verbindungen in der Mundschleimhaut angreift, ist eine möglichst geringe Konzentration anzustreben, um eine verstärkte Desquamation oberflächlicher Epithelzellen zu vermeiden (FLORES-DE-JACOBY et al. 1975).

Auch oxigenierende Substanzen wie $\mathrm{H}_{2} \mathrm{O}_{2}$ und Perborate als oberflächenaktive Substanzen sind in Mundspüllösungen und Zahnpasten enthalten. Sie werden durch gewebe- bzw. bakteriengebundene Enzyme aktiviert und hinterlassen Sauerstoff in Kombination mit einem aufschäumenden Effekt. Als Desinfizientien besitzen sie entzündungshemmende Eigenschaften und bewirken vorübergehend eine geringere Blutungsneigung des Gewebes. Die eigentliche bakterielle Ursache des Krankheitsprozesses wird jedoch nicht reduziert (CIANCIO 1992). Klinische Kurzzeitstudien liefern widersprüchliche Ergebnisse bezüglich der Effektivität von Peroxiden, jedoch scheint eine ausreichende Reduktion des Biofilms und der Bakterien nicht möglich (GREENWELL et al. 1983, PHILSTROM et al. 1987). Außerdem zeigte sich, dass die Anwendung einer 3-prozentigen $\mathrm{H}_{2} \mathrm{O}_{2}$-Lösung den Heilungsprozess bereits vorhandener Wunden in der Mundschleimhaut stört (REES und ORTH 1986). Delmopinol (Propylheptyl-morpholinethanol-hydrochloride) ist eine oberflächenaktive Substanz mit einem breiten antibakteriellen Wirkungsspektrum, die in Mundspüllösungen enthalten ist. Zum einen wird durch die Herabsetzung der Oberflächenspannung eine Verringerung der Kohäsion von Biofilm und Bakterien erreicht (RUNDEGREN et al. 1992), zum anderen konnte in vitro eine Inhibierung des bakteriellen Glukosestoffwechsels nachgewiesen werden (SIMONSSON et al. 1991). Dies konnte in klinischen Kurzzeitstudien bestätigt werden, da im Vergleich zu Chlorhexidin eine fast äquivalente antimikrobielle Wirksamkeit und eine gute Gingivitis- und Biofilmreduktion vorlagen (COLLAERT et al. 1992 und 1993, RUNDEGREN et al. 1992). 
In einer Metaanalyse konnte herausgestellt werden, dass Delmopinol mit seiner biofilminhibitorischen Wirkung und seiner Gingivitisreduktion in Form einer 0,2-prozentigen Mundspüllösung eine Alternative zum Chlorhexidin für viele Patienten darstellt (ADDY et al. 2007). Dagegen konnte in klinischen Langzeitstudien zwar eine Biofilmreduktion erreicht werden, jedoch führte dies nicht zu einer signifikanten Gingivititisreduktion (ABBOTT et al. 1994, HASE et al. 1995). Es wurde vermutet, dass eine negative Beeinflussung zwischen Delmopinol und der im Speichel enthaltenen antimikrobiell wirksamen Peroxidase vorliegt und diese Hemmung zu einer verminderten Konzentration des Speichelenzyms und somit zu einer reduzierten lokalen Abwehrreaktion führt (TENOVUO et al. 1995). Als Nebenwirkung ist einzelnen Berichten zufolge beim Gebrauch von Mundspüllösungen mit Delmopinol eine vorübergehende Anästhesie der Mundschleimhaut beobachtet worden (HASE et al. 1995).

Ein anderer Vertreter der oralen Antiseptika der dritten Generation ist Octenidin. Octenidin(dihydrochlorid) ist ein oberflächenaktiver Wirkstoff (kationaktives Bispyridin), der für die Antiseptik in Kombination mit 2-prozentigen Phenoxyethanol eingesetzt wird. Das Wirkungsspektrum umfasst grampositive und gramnegative Bakterien, Pilze sowie eine Reihe von Virusarten. Bei der Anwendung auf Wunden war keine Resorption nachweisbar, sodass nach derzeitigem Stand des Wissens resorptiv-toxische Risiken auszuschließen sind. Noch nicht vollständig geklärt ist die Frage einer im Vergleich zu den Jodophoren oder zu Polihexanid erhöhten Zytotoxizität. Gute klinische Erfahrungen liegen vor bei der Erstversorgung von Schürf-, Biss- und Schnittwunden sowie mit 1:1 verdünnter Lösung bei Verbrennungswunden. Kontraindikationen sind Spülungen der Bauchhöhle und der Harnblase sowie die Anwendung am Trommelfell. Die Kontraindikation der Anwendung bei Kindern unter acht Jahren wurde 2003 von der Zulassungsbehörde zurückgenommen.

Octenidin besitzt ein breites antimikrobielles Wirkspektrum und eine geringe systemische Toxizität, eine gute lokale Verträglichkeit an Haut und Schleimhäuten. Dieses Antiseptikum ist seit 1995 als Octenisept ${ }^{\circledR}$ in Deutschland für die Schleimhautdesinfektion zugelassen. Es zeichnete sich bisher besonders in der Gynäkologie und Urologie durch sehr gute Verträglichkeit und Wirksamkeit aus (ENZELSBERGER et al. 1995). In-vitro-Versuche zeigten die abtötende Wirkung von Octenisept ${ }^{\circledR}$ auf grampositive und gramnegative Bakterien innerhalb von 30 Sekunden (GORONCY-BERMES 1990). Dabei hat der Wirkstoff Octenidinhydrochlorid keinen negativen Einfluss auf die Wundheilung (HARKE et al. 1997). Von KALTEIS et al. (2003) wurde Octenidin in einer In-vivo-Studie ebenfalls eine geringe Toxizität bestätigt. 
Seit 2008 ist eine neue Mundspüllösung auf der Basis von Octenidin (Octenidol ${ }^{\circledR}$ ) im Handel erhältlich. Diese Lösung wird zur Regeneration von entzündlichen Erkrankungen im Mundraum, bei eingeschränkter Mundhygienefähigkeit, zur unterstützenden Behandlung von MRSA-Patienten, bei Parodontitis und Gingivitis, in der (Kinder-)Onkologie, in der Intensivpflege von beatmeten Patienten und begleitend zur Strahlentherapie angewendet. Octenidol $^{\circledR}$ ist hochwirksam gegenüber den Leitkeimen der infektiösen Erkrankungen aus dem Formkreis der Parodontitis und Gingivitis (odontogene Infektionen). Das Präparat erreicht bereits bei einer Einwirkzeit von 30 Sekunden eine Keimreduktion um 4,7 bis 8 lgStufen. Da die tatsächliche Keimzahl der geprüften gramnegativen und grampositiven anaeroben und microaerophilen Erregerarten bei einer aggressiven oder chronischen Form der Parodontitis in einem Bereich zwischen $10^{2}$ und $10^{5}$ liegt, im Fall von P. micros in einem Bereich von $10^{4}$, ist eine sichere Keimreduktion erreichbar (MUTTERS et al. 2007).

In einem Suspensionsversuch gegen Aggregatibacter actinomycetemcomitans und Micromonas micros konnte bei einer Ausgangskeimzahl von $10^{8} \mathrm{KBE} / \mathrm{ml}$ eine vollständige Abtötung der Testorganismen bereits nach 30 Sekunden Einwirkzeit erzielt werden (KAMMA et al. 2006).

In einem quantitativen Suspensionsversuch unter ,dirty conditions “ gemäß DGHMMethodenbuch 2001 wurde die antimikrobielle Wirkung des Präparates Octenidol ${ }^{\circledR}$ Mundspüllösung gegen multiresistente Staphylococcus-aureus-Isolate geprüft. Als Einwirkzeiten wurden 10, 20 und 30 Sekunden gewählt. Bereits nach einer Einwirkzeit von zehn Sekunden wurde eine ausreichende Wirkung gegen alle verwendeten MRSA-Isolate erreicht. Unter Zugrundelegung der ermittelten Ergebnisse ist das Präparat Octenidol ${ }^{\circledR}$ Mundspüllösung zur Sanierung von MRSA-besiedelten Patienten im Mund-Rachen-Raum geeignet (AL-DOORI et al. 2007).

Die Wirkung von Octenidol ${ }^{\circledR}$ auf die Zellen der Munschleimhaut und des Knochens ist bis jetzt nicht untersucht worden, sodass die Frage nach der Vorbeugung der Parodontitiden durch die Octenidin-Mundspüllösung bzw. eine eventuelle Komplikation der Wundheilungsstörung im Sinne einer Nebenwirkung bei der Anwendung dieses Präparates noch völlig offen ist. 


\subsection{Untersuchungsmethoden zur Beschreibung zellulärer Ereignisse}

Die verschiedenen vorhandenen Zellkultursysteme werden zur Identifizierung und Charakterisierung bioaktiver Substanzen und zur Untersuchung ihrer Bioverfügbarkeit eingesetzt sowie zur Abschätzung möglicher unerwünschter Nebenwirkungen (u. a. akute bzw. chronische Toxizität, Kanzerogenität, Mutagenität, Teratogenität bzw. antioxidative, antiinflammatorische Wirkungen). Die dazu angewendeten zellchemischen Nachweisverfahren basieren auf den grundlegenden zellulären Ereignissen: Proliferation, Wachstum, Differenzierung und Zelltod (Apoptose und Nekrose). Die zellchemischen Forschungsergebnisse ermöglichen eine Reduzierung notwendiger Tierversuche sowie eine effiziente Durchführung von klinischen Studien vor dem Einsatz oraler Antiseptika in vivo.

\subsubsection{Zytotoxizität und Antikanzerogenität}

Der Begriff Zytotoxizität fasst alle unerwünschten Effekte zusammen, die eine Substanz auf die Viabilität gesunder Zellen ausübt und die zum Zelltod führen, unabhängig vom zugrunde liegenden Mechanismus (Apoptose oder Nekrose) (HARTMANN und MEISEL 2007). Die Ergebnisse verschiedener Studien zeigten auf, dass eine akute Zytotoxizität, unabhängig vom Zelltyp, unter Einsatz der verschiedensten Methoden, wie WST-1 Test, Neutralrot-Färbung, Zellzählung oder Bestimmung des zellulären Gesamtproteins, nachweisbar ist (BABICH und BORENFREUND 1991, MARTIN und CLYNES 1991, BERRIDGE und TAN 2000). Diese Erkenntnisse flossen in die Europäische Norm 30993-5 (DIN ISO 30993-5) ein, welche die Prüfung der Zytotoxizität mit In-vitro-Methoden zur biologischen Beurteilung von Medizinprodukten regelt. Die Einhaltung der Norm wird durch ein vorgegebenes Prüfverfahren realisiert, unter Angabe der eingesetzten mykoplasmenfreien Zellkultur (anerkannte Zelllinie), den Kulturbedingungen sowie der angewendeten Nachweismethode, des Prüfberichts und einer Ergebnisbeurteilung durch eine kompetente Person (TOMINAGA et al. 1999, BERRIDGE et al. 1996a, FRANCOEUR 1997). Aufgrund dessen sind die unten aufgeführten Methoden normkonform, wenn das vorgegebene Prüfverfahren eingehalten wurde.

Chemische Verbindungen, die die Fähigkeit besitzen, Zellen zu töten, werden als zytotoxisch bezeichnet. In-vitro-Untersuchungen ergaben, dass Chlorhexidin bereits in niedrigen Konzentrationen eine Hemmwirkung auf die Proliferation von Fibroblastenkulturen ausübt (PULCHER und DANIEL 1992) und die Produktion von Kollagen- und NichtKollagenproteinen reduziert (MARIOTTI und RUMPF 1999). Störungen der Wundheilung 
konnten dagegen in klinischen Studien nicht bestätigt werden. Chlorhexidinspülungen bei der Nachsorge parodontalchirurgischer Eingriffe führten vielmehr $\mathrm{zu}$ einem schnelleren Abklingen der Entzündung und zu reduzierten Taschentiefen (SANZ et al. 1989, KOZLOVSKY et al. 2007).

Bei humanen dermalen Fibroblasten setzt Chlorhexidin schon in Konzentrationen von 0,001 \% Mechanismen in Gang, die zum ATP-Verlust der Zelle führen und somit den Zelltod verursachen (HIDALGO und DOMINGUEZ 2001). Humane Gingivafibroblasten reagieren nach einer 24- bzw. 72-stündigen Chlorhexidinexposition mit dem Tod der Zelle (BABICH et al. 1995). Auch zellschädigende Effekte des Chlorhexidins auf andere Zellen sind bekannt. Aktuelle Studien wiesen massive zytotoxische Wirkungen chlorhexidinhaltiger Mundspüllösungen auf humane Osteoblasten nach (PATEL et al. 2006, CABRAL und FERNANDES 2007). Im Versuch konnte eine Zytotoxizität aller Mundspüllösungen auf Gingivafibroblasten erwiesen werden. Eine Verminderung der metabolischen Aktivität um durchschnittlich $90 \%$ nach 18 Stunden nach Einsatz der Mundspüllösungen im Vergleich zur Kontrolle zeigt diese zellschädigende Chlorhexidinwirkung eindrucksvoll. Auch das zur Kontrolle eingesetzte sterile Leitungswasser veränderte die nachgewiesenen enzymatischen Vorgänge der Zellen leicht, was als Stressreaktion der Zellen gewertet werden könnte.

POGGI et al. (2003) wiesen für alkoholhaltige Mundspüllösungen zellschädigende Wirkungen auf Fibroblasten nach. Dazu gehörten dosis- und zeitabhängige Hemmungen der Zelladhäsion, die Verminderung der Vitalität und Veränderungen der zytoskelletalen Strukturen und der zytoplasmatischen Organellen der Fibroblasten. Ein Einfluss des Alkohols konnte durch die ermittelten Ergebnisse jedoch nicht bestätigt werden; die Zytotoxizität der alkoholhaltigen und der alkoholfreien Zusammensetzungen war gleich. Listerine ${ }^{\circledR}$ und Meridol $^{\circledR}$ führten zu Ergebnissen, die im Bereich der Werte der Chlorhexidinlösungen lagen.

Die Abhängigkeit der Zellschäden von den verwendeten Konzentrationen wurde bei der Auswertung des Trypanblau-Exclusion-Tests deutlich. So sank die Zahl der vitalen Fibroblasten von 100 nach Spülung mit sterilem Leitungswasser im Durchschnitt aller Zeitintervalle auf 84,3, nach Anwendung von 0,06\% Chlorhexidin auf 46 Zellen, auf 41 Zellen bei 0,2 \% und auf nur noch 23 vitale Fibroblasten bei 1,0\% Chlorhexidin. Daraus folgt, dass mit Erhöhung der Wirkstoffkonzentration die zytotoxischen Eigenschaften des Chlorhexidins zunehmen.

Zur Untersuchung des Zeitpunktes der Schädigung der Fibroblasten wurde die Zahl der vitalen Zellen nach einer, nach sechs und nach 18 Stunden ermittelt. Die Ergebnisse zeigten eine deutliche Reduktion der vitalen Zellzahl nach einer Stunde. In den Intervallen sechs und 
18 Stunden ergab sich nur eine geringe weitere Verminderung der Zellzahl. Die Schädigung scheint also bei der direkten Exposition der Zellen mit Chlorhexidin aufzutreten und sich nach dessen Entfernen nur in geringem Maß fortzusetzen. Dies bestätigen Studien, die zeigten, dass humane Gingivafibroblasten nach zweistündiger Chlorhexidinexposition auch über 48 Stunden in chlorhexidinfreier Umgebung die Schädigung nicht kompensieren konnten (BABICH et al. 1995).

Plaquekontrolle ist die wichtigste Methode zur Prävention von parodontalen Erkrankungen. Eine gründliche mechanische Plaquereduktion sowie die Vermeidung von parodontitisbegünstigenden Faktoren sollten dabei an erster Stelle stehen. Die adjuvante Anwendung von antibakteriellen Mundspüllösungen wurde in Studien als effektiv nachgewiesen. Aufgrund der zytotoxischen Wirkungen auf Fibroblasten sollte die Behandlung gesunder parodontaler Verhältnisse im Sinne der Prophylaxe durch die getesteten zellschädigenden Mundspüllösungen infrage gestellt werden und unter strenger Indikationsstellung erfolgen. Eingeschränkte physische oder mentale Fähigkeiten, Zustände nach Operationen in der Mundhöhle, intermaxilläre Fixation oder kieferorthopädische Situationen, in denen eine ausreichende Mundhygiene unmöglich ist, können die Anwendung von antibakteriellen Substanzen in Form von Spüllösungen erforderlich machen.

Aus der Therapie entzündlicher Parodontalerkrankungen ist Chlorhexidin ergänzend zur mechanischen Entfernung des Biofilms jedoch kaum wegzudenken. Als Alternativen überzeugen Antibiotika durch ihr begrenztes spezifisches Wirkspektrum, systemische Nebenwirkungen und die Möglichkeit der Resistenzentwicklung nicht. Ihre Anwendung ist auf Problempatienten beschränkt. Andere Mundspüllösungen auf der Basis von Zinnfluorid/Aminfluorid oder ätherischen Ölen erreichen nicht die antibakterielle Potenz des Chlorhexidins. Durch Kurzzeitanwendung niedrig konzentrierter Chlorhexidinspülungen können die antimikrobiellen Eigenschaften des Chlorhexidins genutzt und die zytotoxischen Effekte auf Gingivafibroblasten reduziert werden.

Ein Spezialfall der Zytotoxizität ist die Antikanzerogenität, die dadurch gekennzeichnet ist, dass eine Substanz auf Tumorzellen zytotoxisch wirkt und gleichzeitig keine negative Wirkung auf gesunde Zellen ausübt (DEBATIN 2000). Eine potenziell antikanzerogene Substanz wird durch den Nachweis von Apoptose (jedoch nicht Nekrose) in Tumorzellen identifiziert und den zusätzlichen Nachweis der unbeeinflussten Vitalität gesunder Zellen. 


\subsubsection{Zellviabilität}

Gesunde (viable) Zellen sind zur Aufrechterhaltung ihres physiologischen Metabolismus fähig, wodurch Zellproliferation, -wachstum und -differenzierung realisiert werden. Diese Stadien werden im Zellzyklus zusammengefasst, den gesunde Vertebratenzellen innerhalb von 15 bis 30 Stunden durchlaufen. Tumorzellen hingegen beenden diesen nach 12 bis 20 Stunden (LÖFFLER und PETRIDES 1997, REHNER und DANIEL 1999, CUMMINGS und SCHNELLMANN 2002).

Zelluläre Lebensprozesse sind mit unterschiedlichen Methoden nachweisbar und werden durch bioaktive Substanzen moduliert. Die verschiedenen Zellviabilitäts-Nachweismethoden geben u. a. Aufschluss über die Anzahl gesunder Zellen in einer Probe bzw. deren Veränderung im Zeitverlauf (Proliferation), die Integrität der Zellmembran oder den Differenzierungsgrad. Hierbei werden einerseits unspezifische Merkmale untersucht, die größtenteils unabhängig vom Zelltyp sind: Zelldimensionen (Volumen und Größe), metabolische Aktivität oder Permeabilität der Zellmembranen für spezifische Substanzen (z. B. Farbstoffe). Andererseits werden spezifische Merkmale nachgewiesen durch Einsatz u. a. der ELISA-Technik, der Durchflusszytometrie oder der Fluoreszenzmikroskopie. Zum Nachweis von Zelldifferenzierung wird die Ausprägung zellartspezifischer Merkmale untersucht (HARTMANN und MEISEL 2007).

Zur Überprüfung der Zellviabilität kann eine Zellkoloniezählung unter Einsatz des Umkehrmikroskops oder durch Einzelzellzählung durchgeführt werden. Dazu ist es notwendig, dass adhärent wachsende Zellen (z. B. Fibroblasten und Epithelzellen) zuvor in eine Suspension überführt werden. Dieser Vorgang wirkt teilweise zellzerstörend und hat somit Einfluss auf das Zählergebnis. Anschließend wird die Zellzahl ermittelt: unter dem Mikroskop (Zählkammer ohne/mit Anfärbung, u. a. durch Trypanblau), im Zellcounter (Cellometer ${ }^{\mathrm{TM}}$ ) oder durch die Durchflusszytometrie. Trypanblau dient der Unterscheidung zwischen lebenden und toten Zellen. Die ungeschädigte Zellmembran der lebenden Zellen verhindert das Eindringen von Trypanblau ins Zytosol. Deshalb erscheinen die vitalen Zellen hell, während tote Zellen eine dunkelblaue Färbung aufweisen. Die Verdünnung der Zellsuspension sollte erst direkt vor Befüllung der Zellkammer erfolgen, um den toxischen Effekt von Trypanblau auf die Zellen zu minimieren. Diese Methoden sind hochsensibel und reproduzierbar (SCHÄRFE 2004). Durch mikroskopische Beobachtung lässt sich außerdem die Entwicklung des Zellrasens (Konfluenz) sowie die Morphologie der Einzelzellen bewerten (LINDL und BAUER 1994, PINTO et al. 1983). 
Die Durchflusszytometrie ist eine Untersuchungsmethode, die es erlaubt, verschiedene Eigenschaften einer Zelle gleichzeitig zu messen. Es können die Zellgröße, die Zellgranularität und die Intensität mehrerer Fluorochrome simultan gemessen werden. Die Messungen werden an Zellen durchgeführt, die in einem Flüssigkeitsstrom fokussiert werden und einen Laserstrahl senkrecht passieren. Durch das Licht des Lasers werden die Fluorochrome angeregt, mit deren Hilfe die zu untersuchenden Zellbestandteile zuvor markiert wurden. Der Laser regt die Fluoreszenzfarbstoffe an und registriert gleichzeitig die durch die Anregung entstandenen Streulichtsignale. Auf diese Weise können Zellen einzeln gezählt und zelluläre Parameter über Streulicht- und Fluoreszenzsignale analysiert werden. Die Bindung der Fluorochrome (z. B. FITC) an Antiköper, die gegen das zu untersuchende Antigen gerichtet sind, ermöglicht sowohl die Untersuchung von Strukturen auf der Zelloberfläche als auch im Zytoplasma. Die Fluorochrom-Menge ist proportional zur Anzahl der Bindungsstellen der Antiköper an den Antigenen. Die von den Fluorochromen emittierte Intensität nach der Anregung durch den Laser stellt somit ein Maß für die Anzahl an Bindungsstellen des gewählten Antikörpers dar. Fluorochrome zeichnen sich dadurch aus, dass sie Licht einer charakteristischen Wellenlänge (Anregungs- oder Exzitationsspektrum) absorbieren und, durch Wärmeverlust bedingt, energieärmeres, langwelligeres Licht emittieren (Emissionsspektrum).

Bei Verwendung eines Argonlasers mit der Emissionswellenlänge von 488 nm können solche an Antiköper gekoppelten Fluorochrome verwendet werden, deren Anregungsbereich bei dieser Wellenlänge liegt. Dies trifft u. a. für Fluoresceinisothiocyanat (FITC, Emissionswellenlänge $525 \mathrm{~nm}$ ) und Phycoerythrin (PE, Emissionswellenlänge $575 \mathrm{~nm}$ ) zu. Neben den Fluoreszenzsignalen wird in der Durchflusszytometrie auch das Streulicht des Lasers registriert. Sowohl die Größe als auch Form, Oberfläche und Granularität der Zellen beeinflussen das gestreute Licht, sodass sich vom Charakter der Streuung Rückschlüsse auf die Zelleigenschaften ziehen lassen. Die Lichtstreuung ist zudem vom Winkel des auftreffenden Laserlichts abhängig. Sie wird entlang der Achse des einfallenden Lichts als Vorwärtsstreulicht (Forward Angle Light Scatter), im 90-Winkel zum einfallenden Licht als Seitwärtsstreulicht (Side Scatter) bezeichnet. Das Vorwärtsstreulicht hat die stärkste Intensität und kann, ohne verstärkt zu werden, über eine Photodiode registriert werden. Das Vorwärtsstreulicht informiert über die Querschnittsfläche der gemessenen Zelle; darüber lässt sich die Zellgröße errechnen. Das Seitwärtsstreulicht gibt Informationen über das Reflexionsverhalten, das sich proportional zur Zellgranularität verhält. Für Messungen mittels Durchflusszytometrie wird eine Zellsuspension mit zu charakterisierenden Zellen benötigt. 
Das Gerät zählt die Zellen und sortiert diese nach Größe und Granulationsgrad. Die Zellzahlen können am Gerät auf einen festen Wert eingestellt werden, das Gerät zählt dann diese Zellenzahl ab und bezieht die Ergebnisse darauf.

Die Zellproliferation wird außerdem anhand der zellulären DNA-Syntheseleistung durch den Einsatz handelsüblicher Reagenzien-Kits quantifiziert. Dabei werden die Zellen u. a. mit radioaktiv markiertem Thymidin $([3 \mathrm{H}]-\mathrm{TdR})$ oder mit Uridin (5'-Bromo-2'-Desoxyuridin: BrdU) inkubiert. Diese Basen werden ausschließlich von proliferierenden Zellen ins Genom eingebaut und verbleiben nach Waschschritten in der Probe. Der Nachweis erfolgt anschließend im Szintillationszähler oder durch Einsatz peroxidasegekoppelter Antikörper und geeigneter Substrate im ELISA-Photometer. Anderen Phasen des Zellzyklus werden mithilfe von unterschiedlichen monoklonalen Antikörpern untersucht, die an zellkernassoziierte Proteine binden. Diese Nachweise greifen jedoch nur auf Einzelzellebene (in situ) und beruhen auf immunozytochemischen und -histochemischen Techniken (BHUTIA et al. 2008, TOMINAGA et al. 1999).

Eine Methode zur Bestimmung von Zytotoxizität ist die Untersuchung der zellulären Reduktase-Aktivität (metabolische Aktivität) durch Zugabe eines Tetrazoliumsalzes (MTT und dessen Derivate: u. a. XTT oder WST-1).

FLEMINGSON et al. (2008) überprüfte mittels MTT-Tests die proliferationshemmende Wirkung von CHX, Listerine ${ }^{\circledR}$ und Betaisodona ${ }^{\circledR}$ in verschiedenen Konzentrationen auf die humanen Gingivafibroblasten. Die Einwirkzeit betrug eine, fünf und 15 Minuten. Das Proliferationspotenzial von Fibroblasten war in Bezug auf die Einwirkzeit nicht signifikant reduziert, sondern hochsignifikant abhängig von der Konzentration der oralen Antiseptika. Diese Studie zeigte, dass alle drei Mundspülllösungen toxisch auf die Zellen wirkten, wobei die Proliferationshemmung nach der Behandlung mit CHX am deutlichsten ausgeprägt war. MTT ist der Prototyp, der intrazellulär durch NAD(P)H-abhängige Enzyme der Glycolyse zum wasserunlöslichen Formazan reduziert wird. Die notwendige Solubilisierung des Reaktionsproduktes und die Abhängigkeit des Ergebnisses vom Glucosegehalt des Mediums sind entscheidende Nachteile, die durch Entwicklung weiterer Tetrazoliumsalze (XTT, WST1) ausgeglichen wurden. WST-1 wird in einer gebrauchsfertigen NADH-haltigen Testlösung angeboten und von einer Vielzahl verschiedener Zellarten innerhalb kurzer Zeit (min) zum dunkelroten, wasserlöslichen Formazan reduziert. Dieses Reaktionsprodukt ist ohne weiteren Arbeitsschritt photometrisch detektierbar. Da WST-1 nicht zytotoxisch wirkt, sind Messungen an einer Zellkultur in Zeitabständen (Stunden bis Monate) möglich. Aufgrund dieser einfachen und schnellen Durchführung und Reproduzierbarkeit eignet sich diese Methode für 
Screening-Tests (TOMINAGA et.al. 1999). Der zugrunde liegende Mechanismus ist allerdings noch nicht genau bekannt. Da die Anwesenheit von Mitochondrien oder der Superoxiddismutase die Formazanbildung hemmt, wird angenommen, dass diese Reaktion superoxidabhängig ist und extrazellulär und/oder membrangebunden stattfindet (BERRIDGE et al. 1996b, TOMINAGA et al. 1999).TAN und BERRIDGE (2000) untersuchten den Mechanismus der WST-1-Reduzierung unter Einsatz von 15 verschiedenen Zellkulturen. Die Autoren wiesen zunächst darauf hin, dass die Zellmembranen in komplexer und ständiger Kommunikation mit dem Extra- und Intrazellularraum stehen, wozu eine ständige Reduzierung extrazellulär vorliegender Substanzen notwendig ist. Dazu existieren vermutlich verschiedene komplexe (trans)membrane Enzymsysteme (Oxidoreduktasen), die interagieren. Die Autoren wiesen nach, dass auf den Zellmembranen gesunder teilungsfähiger Zellen eine Oxidoreduktase existiert, die in Anwesenheit von NADH oder anderen in Körperflüssigkeiten natürlicherweise vorliegenden Kofaktoren das WST-1 zu Formazan reduziert. Damit wurde nachgewiesen, dass WST-1 die Zellmembran nicht penetriert (TAN und BERRIDGE 2000). In weiteren Testsystemen wird das Vorhandensein der Kofaktoren NADH und ATP (Primärzellen und Zell-Linien) zur Bestimmung der Zahl lebender Zellen ausgenutzt. Appliziertes Resazurin wird $\mathrm{NAD}^{+}$-abhängig zum pinkfarbenen, fluoreszierenden Resurfin reduziert. Luciferin wird unter ATP-Aufwand und Verbrauch molekularen Sauerstoffs zu Oxyluciferin oxidiert, wobei $\mathrm{CO}_{2}$ und Licht entstehen. Die jeweiligen Signale werden im Fluoreszenz-, Spektralphotometer bzw. Luminometer oder mit einer CCD-Kamera detektiert (Promega GmbH, 2003, 1 Proliferationsassays).

Adhärente Zellen (z. B. Fibroblasten oder Epithelzellen) bilden in Kultur innerhalb kurzer Zeit einen Monolayer. Die Anzahl und Funktionsfähigkeit (Dichtigkeit) der Zell-ZellKontakte (tight junctions) nimmt unter günstigen Kulturbedingungen zeitabhängig zu und ist durch Inkubation mit bioaktiven Substanzen modulierbar. Diese Wirkungen sind u. a. durch wiederholte Messung des transepithelialen elektrischen Widerstandes (TEER) nachweisbar. Der Vorteil dieses Messsystems liegt darin, dass es keinen modulierenden Einfluss auf die Zellvitalität aufweist, sodass Verlaufsuntersuchungen über lange Zeiträume möglich sind. Liegt ein konfluenter Monolayer vor, so steigt der TEER mit der Anzahl und Funktionsfähigkeit der tight junctions an und die parazelluläre Durchlässigkeit für niedermolekulare wasserlösliche Substanzen nimmt ab. Infolgedessen ist die MonolayerIntegrität zusätzlich durch Transportstudien nachweisbar, wobei niedermolekulare wasserlösliche Referenzsubstanzen die tight junctions passieren: u. a. Mannitol, Phenolrot, Lucifer Yellow, [14C] Inulin oder Flourescein (Molekulargewichte: 192, 354, 475, 500). Die 
Substanzsignale werden mithilfe von Photometrie, Flourometrie, Lumineszens- oder Radioaktivitätsmessungen detektiert.

Das Überleben der Fibroblasten bzw. Epithelzellen nach der Behandlung mit den verschiedenen oralen Antiseptika kann auch mittels ATP-Biolumineszenztest (z. B. CellTiterGlo® Luminescent Cell Viability Assay von Promega) untersucht werden. Als Marker für die Zellproliferation und das Überleben der Zellen wurde Adenosintriphosphat (ATP), das nur von lebendigen Zellen produziert werden kann, verwendet. Die ATP-Produktion wurde, wie von CROUCH et al. 1993 beschrieben, dabei mittels der Luciferin-Luciferase-Reaktion quantifiziert. Die Methode basiert auf der Quantifizierung der Zellzahl durch die Menge des produzierten ATP. Die Messung der Lumineszenz kann anschließend im Lumineszenzdetektor erfolgen. Die Hintergrund-Lumineszenz kann detektiert werden, indem lediglich die Kontrollwells ohne Zellen gemessen wurden.

Mithilfe der ATP-Biolumineszenz kann die Anzahl an lebenden Zellen bestimmt werden. Sie erlaubt jedoch keine Unterscheidung zwischen überlebenden Zellen und Zellen, die durch Proliferation neu entstanden sind. Um zwischen Zellen, die lediglich nicht proliferieren, und überlebenden Zellen, die nicht zugrunde gegangen sind, zu unterscheiden, eignet sich die Messung von LDH (z. B. CytoTox $96^{\circledR}$-Assay). LDH wird aus zerstörten Zellen freigesetzt und kann dann im Kulturmedium nachgewiesen werden. In den Kulturen, in denen die Zellen lediglich in ihrer Proliferation stagnieren, findet sich hingegen keine LDH-Aktivität im Kulturmedium. Dieses intrazelluläre Enzym ist ausschließlich nach Zerstörung von Zellmembranen im Kulturüberstand vorhanden und oxidiert Lactat zu Pyruvat, wobei NAD ${ }^{+}$ reduziert wird. In einer zweiten Reaktion wird ein Tetrazoliumsalz (INT) zum colorimetrisch messbaren roten Formazan reduziert. Die Absorption des roten Reaktionsproduktes kann bei $490 \mathrm{~nm}$ bestimmt werden.

Die Neutralrot-Färbung ist eine weitere validierte Referenzmethode für Zytotoxizitätsuntersuchungen (Europäisches Zentrum für Validierung von Alternativen Methoden). Der Farbstoff Neutralrot penetriert Membranen viabler Zellen und wird in Lysosomen akkumuliert. Nach Entfernen nicht transportierter Farbstoffreste werden die Zellen fixiert, lysiert und das Neutralrot freigesetzt. Dieses wird nachfolgend photometrisch detektiert. Die Farbintensität korreliert direkt mit der Zellzahl. 


\subsubsection{Zelltod}

Apoptose und Nekrose sind zwei verschiedene Mechanismen, die zum Zelltod führen. Nekrose tritt nach einer extremen Abweichung von physiologischen Bedingungen auf, z. B. durch Einwirkung physikalischer (starke Hitze, Strahlung), mechanischer (Schlag), chemischer bzw. biochemischer (metabolische Gifte, Sauerstoffmangel, Komplementfaktoren) Noxen auf die Zelle bzw. durch Pathogene (Viren). Die dadurch verursachten Schädigungen betreffen immer mehrere Zellen eines Gewebes. Diese Zellen schwellen aufgrund von Membranschädigungen und Störung des osmotischen Gleichgewichts zunächst an und platzen später. Der freigesetzte Zellinhalt verursacht Entzündungen und immunologische Reaktionen im Organismus. Eine dabei auftretende DNA-Fragmentierung erfolgt immer zufällig (unregelmäßig große DNA-Bruchstücke), und nachfolgend werden diese Fragmente im Organismus phagozytotisch (ohne Energieverbrauch) eliminiert. Die Apoptose ist ein physiologischer Vorgang, der durch autonome Gene differenzierter (apoptosekompetenter) Zellen beeinflusst wird und nach einem festgelegten Programm abläuft. In einem gesunden Gewebe sind grundsätzlich nur bestimmte Zellen von Apoptose betroffen. Der Ablauf des programmierten Zelltodes ist insbesondere an der Nematode Caenorhabditis elegans studiert worden, deren Gene Ced-3 und Ced-4 apoptoseinduzierende Proteine codieren, während das Ced-9-Genprodukt die Apoptose unterdrückt. In Säugetierzellen werden vergleichbare Gene und deren Produkte gefunden, z. B. die Bcl-2Genfamilie, die vergleichbar mit Ced-9 ist. Als Genprodukte werden Proteine synthetisiert, welche die Apoptose fördern (z. B. bad, bak, bax, bik, bclx, c-jun, hrk, p53) oder hemmen (z. B. brag-1, bcl-2, bcl-xL, mcl-1, a1, bfl-1). Diese Proteine interagieren miteinander und bilden Dimere, wobei der überwiegende Proteinanteil darüber entscheidet, ob die Zelle überleben oder absterben wird. Diesen Mechanismus nutzen Viren (z. B. Epstein-Barr-Virus), indem sie die bcl-2-Synthese aktivieren und sich so vor der Immunabwehr des Wirts schützen. Eine Immortalisierung von Zellen erfolgt, wenn das Protein p53 codierende Gen fehlt oder mutiert ist. Dies ist häufig in Tumorzellen der Fall. Ein anderes apoptoseregulierendes Gen ist das c-myc Proto-Onkogen, das im Beisein von Wachstumsförderern die Proliferation stimuliert und das bei deren Fehlen mittels des c-mycProteins die Apoptose induziert (TOMINAGA et al. 1999, LANG D et al. 2002, FESUS et al. 1991).

Die Apoptose wird einerseits genetisch und andererseits durch verschiedenste Signale (z. B. Wachstumsfaktoren, Hormone, Zytokine) reguliert und dient im Organismus der Eliminierung 
funktionslos gewordener Zellen, u. a. während der Ontogenese oder in der laktierenden Milchdrüse. Die Mundschleimhaut wird durch Apoptose vor der permanenten mutagenen Gefahr aus der Nahrung geschützt (BHUTIA et al. 2008, LÖFFLER und PETRIDES 1997, REHNER und DANIEL 1999).

Die Apoptose wird im Verlauf pathophysiologischer Vorgänge oder unter dem Einfluss zytotoxischer Substanzen induziert, z. B. durch UV- oder radioaktive Strahlung, Medikamente (Chemotherapeutika, Glucocorticoide, Retinolsäuren, Thyroxin), bioaktive Substanzen wie z. B. modifizierte Ribonucleoside (MEISEL et al. 1998, HARTMANN et al. 1999) sowie durch $\mathrm{Ca}^{2+}$-Ionophore oder durch Verletzungen, die einen Anstieg der intrazellulären $\mathrm{Ca}^{2+}$-Konzentration verursachen (FESUS et al. 1991).

Der komplexe Ablauf des programmierten Zelltods ist zwar noch nicht vollständig aufgeklärt, es werden jedoch charakteristische morphologische und biochemische Merkmale während der Signal-(Reaktions-)Kaskade ausgebildet, die mit unterschiedlichen Methoden nachweisbar sind. Der Prozess der Apoptose ist innerhalb von ca. vier Stunden abgeschlossen (FESUS et al. 1991).

$\mathrm{Zu}$ den morphologischen Merkmalen einer frühen apoptotischen Phase gehört der Verlust der Oberflächenspezialisierung einer oder weniger individueller Zellen eines Gewebes, die dadurch den Kontakt zur Nachbarzelle verlieren. Gleichzeitig kondensieren zytosolische und Zellkernproteine unter Bildung von peripheren Chromatinkappen sowie Zellkernfragmenten. Außerdem verringert sich das zytosolische Volumen, die Zelle schrumpft. Die Zellorganellen bleiben dabei allerdings intakt. Nachfolgend kommt es zur Abschnürung vesikelartiger apoptotic bodies (apoptotische Körperchen). Diese enthalten Zellkernfragmente, intakte Organellen und zytosolische Bestandteile und sind von einer intakten Zellmembran umgeben. In der Endphase werden die apoptotic bodies aufgrund bestimmter Merkmale, z. B. exponiertes Phosphatidylserin auf der Zelloberfläche, von Nachbarzellen oder Makrophagen erkannt und durch Phagozytose eliminiert. Dabei kommt es im Unterschied zur Nekrose weder zu einer Entzündungs- oder Immunreaktion noch zur Narbenbildung. In vitro wird in einer spätapoptotischen Phase eine als „,sekundäre Nekrose“ bezeichnete Lyse apoptotischer Zellen und deren Fragmente beobachtet (TOMINAGA et al. 1999, FESUS et al. 1991).

Die charakteristischen biochemischen Apoptose-Merkmale werden oftmals begleitet von einer erhöhten intrazellulären $\mathrm{Ca}^{2+}$-Konzentration. Ein Teil der apoptoseinduzierenden Signale wird von Effektorzellen, z. B. aktivierten T-Zellen, natürlichen Killer-(NK) Zellen oder zytotoxischen T-Lymphozyten (CTL), über unterschiedliche Oberflächenrezeptoren an der Zielzelle vermittelt. Ein Beispiel dafür ist das CD95-(Fas-)Rezeptor-Liganden-System. 
Der Fas-Ligand (exprimiert in aktiven T-, NK-Effektorzellen und teilweise solubilisiert durch Metalloproteasen) oder ein Agonist binden an den Fas-Rezeptor. Dadurch wird die intrazelluläre Caspasen-Kaskade aktiviert. Ähnlich agiert der Tumor-Nekrose-Faktor (CTL oder NK sind Effektorzellen). Das granzyme $B$ dagegen gelangt mithilfe von Perforin in die Zelle und aktiviert dort selbst die Kaskade. Zur Familie der Caspasen (Cysteinyl-asparticacidproteases) werden zehn verschiedene Enzyme gezählt, die jeweils durch Zusatz einer Ziffer zwischen 1 und 10 gekennzeichnet werden. Die Caspase 1 (Interleukin-1 $\alpha$-converting Enzyme: ICE) wurde zuerst identifiziert und ist am besten beschrieben. Die verschiedenen Caspasen liegen intrazellulär als inaktive Enzyme vor und interagieren nach ihrer Aktivierung teilweise miteinander. Ein Marker der frühen apoptotische Phase ist die aktivierte Caspase 3 (CPP3), durch welche die Signalkaskade ausgelöst wird und in deren Verlauf die entscheidenden biochemischen Reaktionen ausgelöst werden, die letztendlich zum Zelltod führen (TOMINAGA et al. 1999, LANG D et al. 2002, FESUS et al. 1991, KÜHNEL et al. 2000, MARAVEI et al. 1997, CUMMINGS und SCHNELLMANN 2002, BHUTIA et al 2008). Insbesondere die Caspasen 3 und 7 haben eine zentrale Rolle bei Reaktionen der Zellen auf induzierte Apoptose. Die Bestimmung der Caspase-3/7-Aktivität kann z. B. mit dem Apo-ONE ${ }^{\circledR}$ Homogeneous Caspase-3/7-Assay vom Promega erfolgen. Die Zellen können dabei 24 Stunden lang mit dem Reagens bei Raumtemperatur inkubiert werden. Die Fluoreszenz (Apo-ONE ${ }^{\circledR}$ Assay) kann bei einer Anregungswellenlänge von $485 \mathrm{~nm}$ und einer Emissions-Wellenlänge von $535 \mathrm{~nm}$ im Photometer gemessen werden.

Ein weiteres Merkmal der frühen Apoptose ist der Verlust der Zellmembranasymmetrie. Dabei werden etwa zeitgleich mit der Chromatinkondensation Phosphatidylserinreste von der inneren zur äußeren Membranseite translokalisiert. Diese stellen ein Erkennungsepitop u. a. für Makrophagen dar, welche die Zellfragmente phagozytotisch eliminieren. Außerdem wird die Membran der Mitochondrien verändert. Bei Anwesenheit des bax-bax Dimers gelangt der apoptoseinduzierende Faktor (AIF) ins Zytosol. AIF aktiviert die Caspasen-Kaskade bzw. gelangt in den Zellkern und führt autonom zum Zelltod. Ebenso gelangt Zytochrom C (Apaf2) ins Zytosol, welches die Caspase 9 (Apaf-3) unter Energieaufwand (ATP) aktiviert und u. a. zur Bildung von Apoptosomen führt (TOMINAGA et al. 1999, LANG D et al. 2002, FESUS et al. 1991, KÜHNEL et al. 2000, MARAVEI et al. 1997, CUMMINGS und SCHNELLMANN 2002, BHUTIA et al 2008). Im Verlauf der Kaskade werden außerdem $\mathrm{Ca}^{2+}$-abhängige Transglutaminasen aktiviert. Diese vernetzen Proteine des Zytoskeletts miteinander und stabilisieren dadurch u. a. die Membranen der Zellfragmente (apoptotic bodies) (FESUS et al. 1991). Am Ende der Kaskade werden $\mathrm{Ca}^{2+}$ - und $\mathrm{Mg}^{2+}$-abhängige 
Endonucleasen im Zellkern aktiviert, welche die Chromosomen ausschließlich an der LinkerDNA spalten. Dadurch entstehen Mono- und Oligonucleosomen-Fragmente (180 bis 200 Basenpaare oder ein Vielfaches davon). UV- oder radioaktive Strahlen sowie Chemotherapeutika (z. B. Camptothecin) verursachen dagegen zufällige DNA-Strangbrüche (TRAGANOS et al. 1993). Dadurch werden unterschiedliche DNA-Reparaturenzyme aktiviert, z. B. die Poly-(ADP-Ribose-)Polymerase (PARP). Dieses Enzym (113 kD) wird in apoptotischen Zellen durch die Caspasen 3 und 7 inaktiviert, indem es in ein $89 \mathrm{kD}$ und ein 24 kD Fragment gespalten wird (DAMOUR et al. 1998).

Der Apoptose-Nachweis kann mithilfe einer Vielzahl verschiedener zellchemischer Methoden geführt werden und basiert zumeist auf intrazellulären biochemischen Veränderungen, die im Verlauf des programmierten Zelltods auftreten. Zur Aufklärung des komplexen Mechanismus der Apoptose ist es notwendig, verschiedene Nachweisverfahren parallel durchzuführen, da nicht in jedem Zelltyp und auch nicht nach jedem bekannten Stimulus die Gesamtheit der genannten Apoptosemerkmale ausgebildet wird. Für den Nachweis des zytotoxischen Potenzials einer Substanz genügt ein positives Ergebnis (Apoptose oder Nekrose), hingegen wird eine potenziell antikanzerogene Substanz erst dann nachgewiesen, wenn nachweislich Apoptose und nicht Nekrose zum Zelltod von Tumorzellen geführt hat. Für den möglichen Einsatz einer potenziell antikanzerogenen Substanz ist zusätzlich nachzuweisen, dass diese Substanz keine zytotoxischen Wirkungen auf gesunde Zellen ausübt.

Eine altbewährte, jedoch aufwendige Methode zum Nachweis einer DNA-Fragmentierung ist die Auftrennung der spezifischen Nucleosomenfragmente durch Elektrophorese. Hierbei werden Apoptose bzw. Nekrose durch ein charakteristisches bzw. ungleichmäßiges Muster im Agarose-Gel (sog. Leitermuster, engl. ladder) nachgewiesen. Die DNA-Fragmentierung ist außerdem mithilfe des Tunel-Assays (Terminal Desoxynucleotidyl-Transferase mediated dUTP-X nick end labeling) im Durchflusszytometer oder mit Fluoreszenz bzw. Lichtmikroskopie nachweisbar. Dabei werden lysierte apoptotische Zellen mit DNADoppelstrangbrüchen durch enzymatischen Einbau eines biotinylierten oder fluoresceinmarkierten Nucleotids (dUTP) markiert. Der Nachweis nekrotischer Zellen hingegen erfolgt durch enzymatische Markierung von Einzelstrangbrüchen (In-Situ-NickTranslation-Methode). Die TUNEL-Reaktion markiert spezifisch DNA-Strangbrüche, die während der Apoptose entstehen, sodass eine Unterscheidung zwischen einem Zelltod, der durch Apoptosevorgänge bedingt ist, von einem solchen, der durch Nekrose verursacht wird, getroffen werden kann (GORZYCA et al. 1993, GOLD et al. 1994). 
Der Cell-Death-Detection-ELISAPLUS eignet sich zur Unterscheidung zwischen beiden Formen des Zelltods durch Nachweis vorhandener spezifischer DNA-Fragmentierungen (Nukleosomen) im Zellkulturüberstand und Lysat (Nekrose). Sind die Nukleosomen ausschließlich im Zelllysat nachweisbar, so liegt Apoptose vor. Das Funktionsprinzip basiert auf zwei monoklonalen Antikörpern in Sandwichtechnik. Hierbei sind die ELISA-Platten mit einem Anti-Substanz-Antikörper beschichtet. Die Probe wird aufgetragen, dabei bindet die Substanz aus der Zellsuspension an den Antikörper. Der zweite, mit alkalischer Phosphatase (AP) gekoppelte Antikörper wird zugegeben und setzt sich an die am Erstantikörper fixierte Substanz. AP katalysiert die Reaktion von p-Nitrophenylphosphat zu gelbem p-Nitrophenol, dessen Konzentration photometrisch bei $405 \mathrm{~nm}$ bestimmt werden kann.

MARIOTTI und RUMPF (1999) konnten in ihrer Studie mithilfe des ELISA-Verfahren die Reduktion der Synthese von Kollagen- und Nicht-Kollagenproteine nach der Behandlung der humanen Gingivafibroblasten mit CHX nachweisen. Dieser Effekt war weniger von der Einwirkzeit, sondern mehr von der Substanzkonzentration abhängig.

Die Translokalisierung der Phosphatidylserinreste von der inneren zur äußeren Membranschicht ist ein Merkmal der frühen apoptotischen Phase, die durch die $\mathrm{Ca}^{2+}$ abhängige Bindung von Annexin-V nachweisbar ist. Je nach eingesetztem Annexin-Konjugat erfolgt der Nachweis mit unterschiedlichen Detektionssystemen (u. a. Durchflusszytometer, Fluorometer, Mikroskop). Zur Unterscheidung von Apoptose und Nekrose ist eine Gegenfärbung mit DNA-Farbstoffen (Flourochrom: Propidiumiodid; Lichtmikroskopie: Trypanblau) notwendig. Diese Farbstoffe können die intakte Zellmembran apoptotischer Zellen nicht passieren und binden somit ausschließlich an die DNA nekrotischer Zellen.

Der Caspase-3-Activity-Assay ist ein fluorometric immunosorbent enzyme assay (FIENA). In apoptotischen Zellen wird das intrazellulär vorliegende Proenzym frühzeitig aktiviert, durch Zelllyse freigesetzt und nachfolgend in eine mit Anti-Caspase-3-beschichtete MTP pipettiert. Die aktivierte Caspase 3 bindet an die Beschichtung und spaltet das angebotene Substrat, z. B. Ac-DEVD-AFC. Dabei entsteht ein flourometrisch messbares Produkt, dessen Detektiossignal proportional zur Konzentration der aktivierten Caspase 3 ist (LANG D et al. 2002, BHUTIA et al. 2008).

Mit dem Homogeneous Caspasen Assay ist ein schneller, automatisierbarer fluorometrischer Nachweis der Aktivität verschiedener Caspasen (2, 3, 7 sowie 6, 8, 9, 10) möglich. Hierbei werden die apoptotischen Zellen mit einem Substrat (DEVE-Rhodamin 110) der aktivierten Caspasen inkubiert und gleichzeitig lysiert. In apoptotischen Zellen entsteht dabei das 
fluoreszierende Rhodamin 110. Die Enzymaktivität wird mithilfe einer Standardkurve ermittelt (ROCHE MOLECULAR BIOCHEMICALS, Info-Paket 2001).

Dem M30 CytoDeath Assay liegt die Erkenntnis zugrunde, dass ausschließlich aktivierte Caspasen das intrazellulär vorliegende Cytokreatin 18 spalten und die im Testsystem enthaltenen speziellen Antikörper ausschließlich an dessen Spaltprodukte binden. Diese Bindung ist aufgrund der an den Antikörper gekoppelten Farbstoffe nachweisbar. Die Signaldetektion erfolgt an Einzelzellen oder Geweben, mit FACS oder mikroskopisch (LEER et al. 1999, BANTEL et al. 2000, ROCHE MOLECULAR BIOCHEMICALS, Info-Paket 2001). Durch den Einsatz unterschiedlicher Antikörper (gekoppelt u. a. an Farbstoffe) lassen sich Markerproteine der Apoptose nachweisen, z. B. Bcl-2, p35 oder PARP. Außerdem werden spezifische Caspase-Inhibitoren im Handel angeboten, die eine Aufklärung der Kaskade nach unterschiedlichen Stimuli ermöglichen (SIGMA-ALDRICH: APOPTOSIS, 2002, ROCHE MOLECULAR BIOCHEMICALS, Info-Paket 2001).

\subsection{Versuchsplanung und Zielsetzung}

Ziel der vorliegenden Untersuchung war es, einen Vergleich der toxischen bzw. proliferationshemmenden Wirkung verschiedener auf dem Markt verfügbarer Mundspüllösungen auf die Zellen des Parodontalapparates und der Mundschleimhaut in vitro in Abhängigkeit von der Einwirkzeit der Substanzen durchzuführen. Dabei sollte insbesondere der Unterschied in der zellschädigenden Wirkung zwischen alkoholhaltigen und alkoholfreien oralen Antiseptika dargestellt werden. Desweiteren sollten die zwei unterschiedlichen Auswertungmethoden (MTT-Test und optische Zellzahlbestimmung mittels Cellometer ${ }^{\mathrm{TM}}$ Auto T4) bei der Toxizitätsbestimmung dieser Substanzen untereinander verglichen werden (Versuchsplanung siehe Flußdiagramm Abb. 3). 
primäre humane Gingivafibroblasten

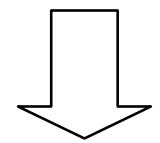

primäre humane nasale Epithelzellen

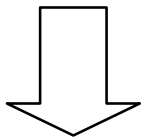

Zellkultur bis Ausgangszellzahl

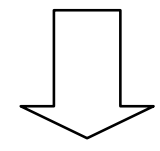

Kontamination mit Mundspüllösungen / PBS
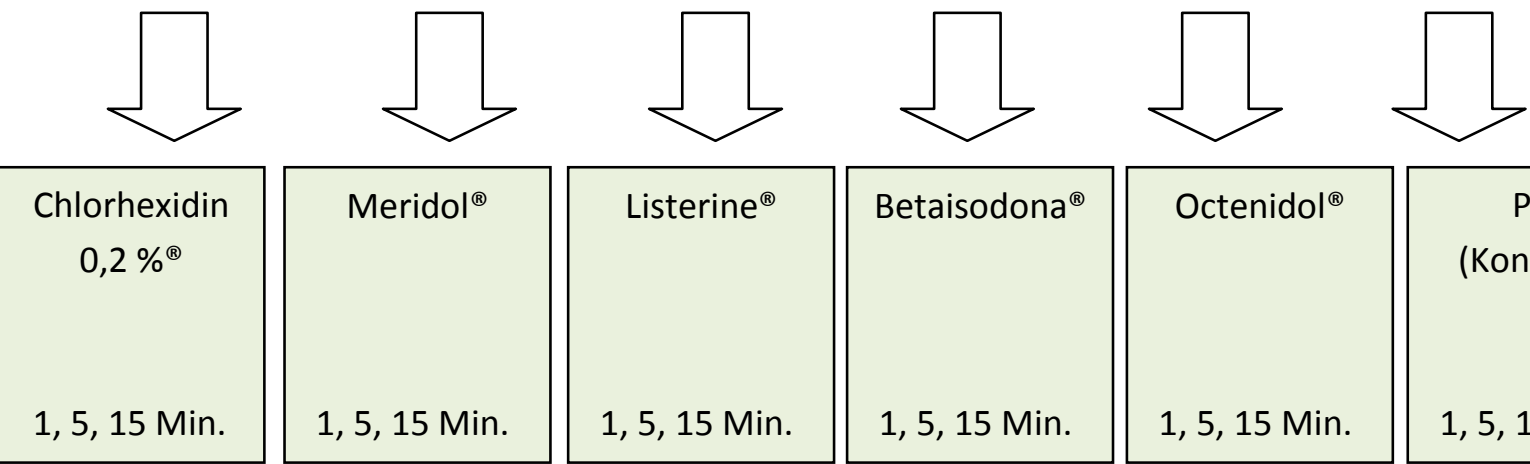

1, 5, 15 Min.

1, 5, 15 Min.

1, 5, 15 Min.

1, 5, 15 Min.

1, 5, 15 Min.
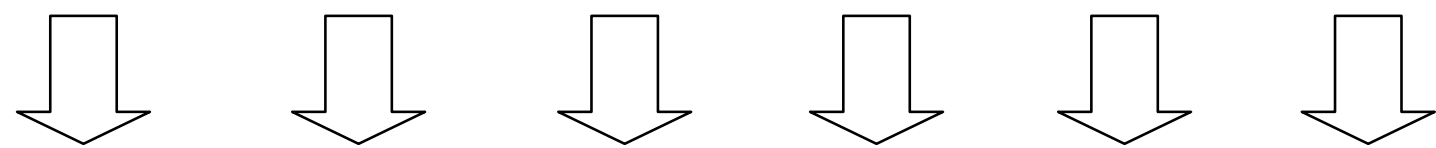

Spülen mit PBS

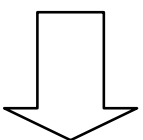

Cellometer ${ }^{\mathrm{TM}}$ Auto T4

(optische Zellzahl, Viabilität und Zelldurchmesser)

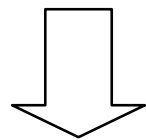

MTT-Test

(metabolische Zellaktivität)

Abbildung 3: Versuchsplanung 


\section{Material und Methoden}

\subsection{Material}

\subsubsection{Die Zellen}

Die Grundlage der vorliegenden Studie bildeten die Zellpopulationen der primären humanen Gingivafibroblasten (HGFIB, Bestell-Nr. 1210412, Provitro GmbH, Berlin, Deutschland) und der primären humanen nasalen Epithelzellen (HNEPC, Bestell-Nr. 1210711, Provitro GmbH, Berlin, Deutschland).

Ein Aliquot der HGFIB mit 5 x 10 $0^{5}$ Zellen, die am 10.04.2001 aus der Mundschleimhaut einer 27-jährigen Frau weißer Abstammung primär isoliert und bis zur dritten Passage in vitro vermehrt wurden, wurde unter standardisierten Einfrierbedingungen in Cryo-SFM-Medium (Bestell-Nr. 2040102, Provitro GmbH, Berlin, Deutschland) in $2 \mathrm{ml}$ Einfrierröhrchen in flüssigem Stickstoff tiefgefroren. Die HGFIB waren bei immunhistochemischer Analyse positiv für Fibroblasten spezifischen Rezeptor CD90/Thy-1. Infektionsseroligisch wurden die Zellen auf die Bakterien, Pilze, Mycoplasmen, HIV-DNA und Hepatitis B/C-DNA geprüft und als negativ eingestuft.

Ein Aliquot der HNEPC mit 5 x $10^{5}$ Zellen, die am 08.09.2003 aus der Nasenschleimhaut eines 43-jährigen Mannes weißer Abstammung primär isoliert wurden und gleich unter standardisierten Einfrierbedingungen in Cryo-SFM-Medium (Bestell-Nr. 2040102, Provitro $\mathrm{GmbH}$, Berlin, Deutschland) in $2 \mathrm{ml}$ Einfrierröhrchen in flüssigem Stickstoff tiefgefroren wurden. Die HNEPC waren immunhistochemisch positiv für Keratin und wiesen entsprechend den HGFIB kein infektiöses Material auf. Die beiden kryokonservierten Zellpopulationen bildeten das Ausgangsmaterial zu den Zellkulturarbeiten der vorliegenden Studie (siehe Anhang 7.1 Materialliste).

\subsubsection{Mundspüllösungen}

Als antibakterielle Wirkstoffe wurden Chlorhexidin $0,2 \%{ }^{\circledR}$, Meridol $^{\circledR}$, Listerine $^{\circledR}$, Betaisodona $^{\circledR}$ und Octenidol $^{\circledR}$ angewendet (siehe Tab. 1 und Abb. 4). Die oralen Antiseptika wurden bis auf Betaisodona ${ }^{\circledR}$ unverdünnt jeweils $1 \mathrm{ml}$ Lösung/well auf die HGFIB bzw. HNEPC appliziert und für jeweils 1, 5 und 15 Minuten auf den Zellen belassen. Lediglich Betaisodona ${ }^{\circledR}$-Mundspüllösung wurde laut Beipackzettel vorher 1:5 mit Bidest-Wasser verdünnt. Der Behandlungsprotokoll war bei allen antibakteriellen Substanzen identisch. 
Tabelle 1: Mundspüllösungen

\begin{tabular}{|l|l|l|}
\hline \multicolumn{1}{|c|}{ Mundspüllösungen } & \multicolumn{1}{|c|}{ Wirkstoff } & \multicolumn{1}{|c|}{ Hersteller } \\
\hline $\begin{array}{l}\text { Chlorhexidindigluconat } \\
\text { Fertiglösung 0,2 \% }\end{array}$ & $\begin{array}{l}\text { Chlorhexidinbis } \\
\text { (D-Gluconat) }\end{array}$ & $\begin{array}{l}\text { Engelhard Arzneimittel GmbH \& Co. } \\
\text { KG, Niederdorfelden, Deutschland }\end{array}$ \\
\hline Meridol $^{\circledR}$ & Amin-/Zinnfluorid & GABA GmbH, Lörrach, Deutschland \\
\hline Listerine $^{\circledR}$ Coolmint & ätherische Öle & $\begin{array}{l}\text { Pfizer Consumer Healthcare GmbH, } \\
\text { Karlsruhe, Deutschland }\end{array}$ \\
\hline Betaisodona $^{\circledR}$ & Povidon-Jod & $\begin{array}{l}\text { Mundipharma GmbH, Limburg (Lahn), } \\
\text { Deutschland }\end{array}$ \\
\hline Octenidol $^{\circledR}$ & Octenidin & $\begin{array}{l}\text { Schülke } \\
\text { Deutschland }\end{array}$ \\
\hline
\end{tabular}

a

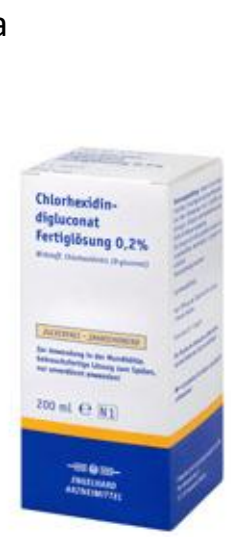

b

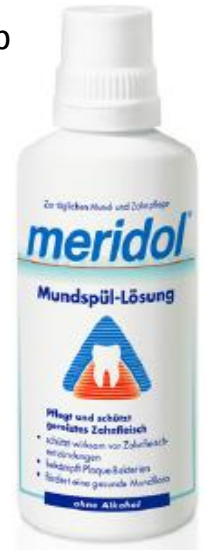

C

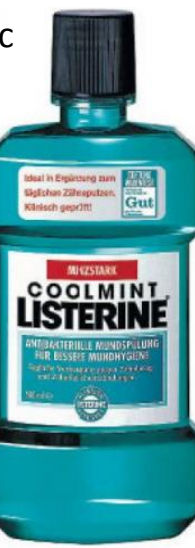

d

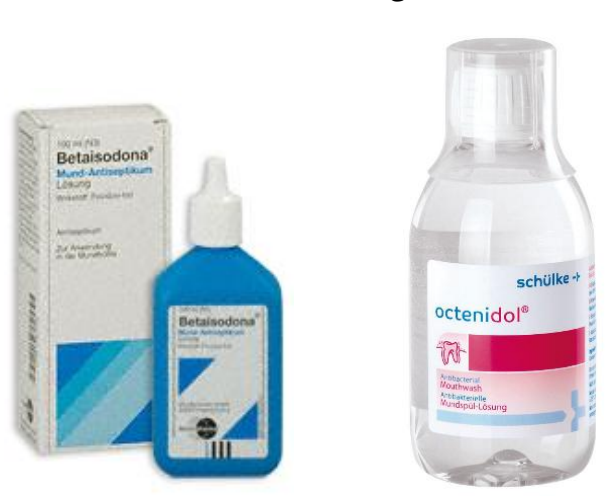

Abbildung 4: Orale Antiseptika: Chlorhexidin 0,2 ${ }^{\circledR}$ (a), Meridol ${ }^{\circledR}$ (b), Listerine $^{\circledR}$ (c), Betaisodona ${ }^{\circledR}$ (d) und Octenidol ${ }^{\circledR}$ (e) 


\subsection{Methoden}

\subsubsection{Zellkultur}

Zellkulturen werden ausgehend von einer aus dissoziiertem Gewebe entstandenen Einzelzellsuspension gezüchtet. Als „primär“ gelten Zellkulturen indes nur solange, bis sie das erste Mal abtrypsiniert und erneut angesät werden. Die Zellzusammensetzung lässt sich u. a. durch die Präparationsmethode, die Wahl des Kulturmediums (Selektionsmedium) und die Dauer der Kultur beeinflussen.

Die in flüssigem Stickstoff asservierten Einfrierröhrchen mit den humanen Gingivafibroblasten bzw. nasalen Epithelzellen wurden nach der Entnahme aus dem Stickstofftank zunächst für etwa 20 Minuten auf Nasseis und anschließend im Wasserbad bei $+37^{\circ} \mathrm{C}$ aufgetaut (Abb. 5). Die anschließenden Zellkulturarbeiten wurden unter sterilen Bedingungen unter einer Reinraumwerkbank durchgeführt (Abb. 6).

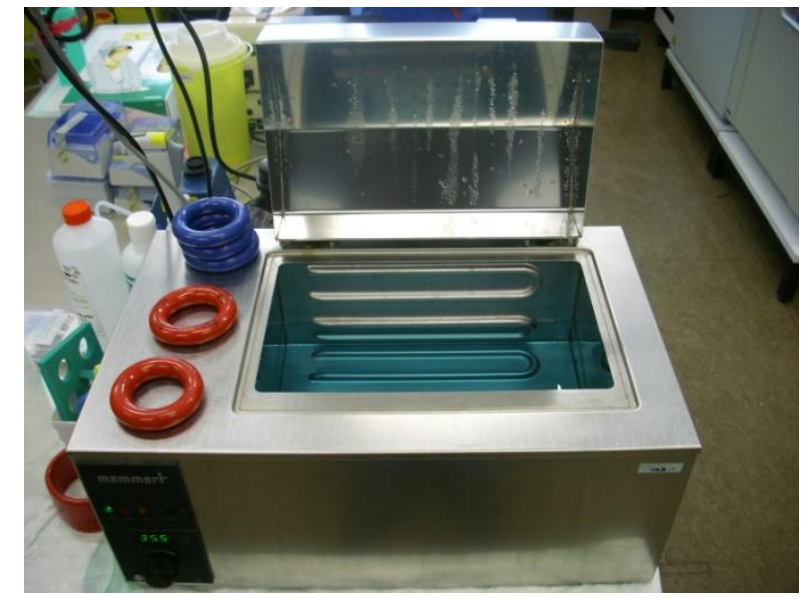

Abbildung 5: Wasserbad

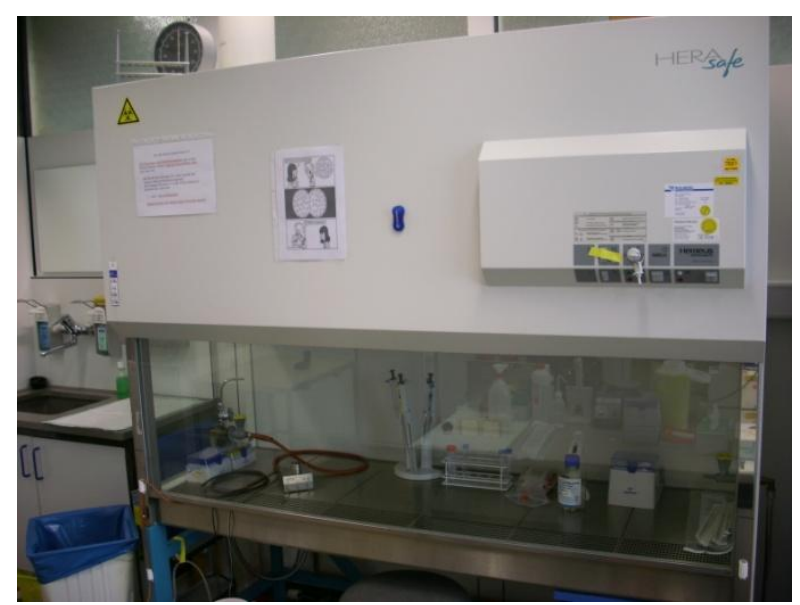

Abbildung 6: Reinraumwerkbank

Die Zellsuspension wurde jeweils in $10 \mathrm{ml}$ Fibroblasten-Anzuchtmedium (Fibroblast growth medium, Bestell-Nr. 2010401, Provitro GmbH, Berlin, Deutschland), das $10 \%$ hitzeinaktiviertes fetales Kälberserum (FCS) enthielt, bzw. in Epithelzellen-Anzuchtmedium (Airway epithelial cell growth medium, Bestell-Nr. 2030701, Provitro GmbH, Berlin, Deutschland) ohne FCS aufgenommen und bei Raumtemperatur für fünf Minuten bei 250xg zentrifugiert (Abb. 7). Nach Verwerfen des Überstands wurde das Zellpellet in $10 \mathrm{ml}$ des der jeweiligen Zellart entsprechenden Kulturmediums resuspendiert und in $75-\mathrm{cm}^{2}$ Zellkulturflaschen überführt (Abb. 8). Das Kulturmedium für HGFIB enthielt neben dem Fibroblasten-Anzuchtmedium $10 \%$ FCS, $50 \mathrm{ng} / \mathrm{ml}$ Amphotericin B und $50 \mu \mathrm{g} / \mathrm{ml}$ 
Gentamicin. Das Kulturmedium für HNEPC bestand neben dem EpithelzellenAnzuchtmedium aus 0,4\% BPE, $5 \mu \mathrm{g} / \mathrm{ml}$ EGF (epidermal growth factor), $0,5 \mu \mathrm{g} / \mathrm{ml}$ Hydrocortison, 0,5 $\mu \mathrm{g} / \mathrm{ml}$ Epinephrin, $10 \mu \mathrm{g} / \mathrm{ml}$ Transferrin, 0,1 ng/ml Retinsäure, $6,7 \mathrm{ng} / \mathrm{ml}$ T3 und $5 \mu \mathrm{g} / \mathrm{ml}$ Insulin (siehe Anhang 7.1 Materialliste). Diese Medien wurden in dieser Zusammensetzung bereits bei der initialen Kultivierung der Zellen verwendet. Die HGFIB wurden entsprechend der Empfehlung von Provitro GmbH mit der Dichte von 4000 Zellen/cm ${ }^{2}$ und die HNEPC von 6000 Zellen/ $/ \mathrm{cm}^{2}$ ausgesät (Abb. 14).

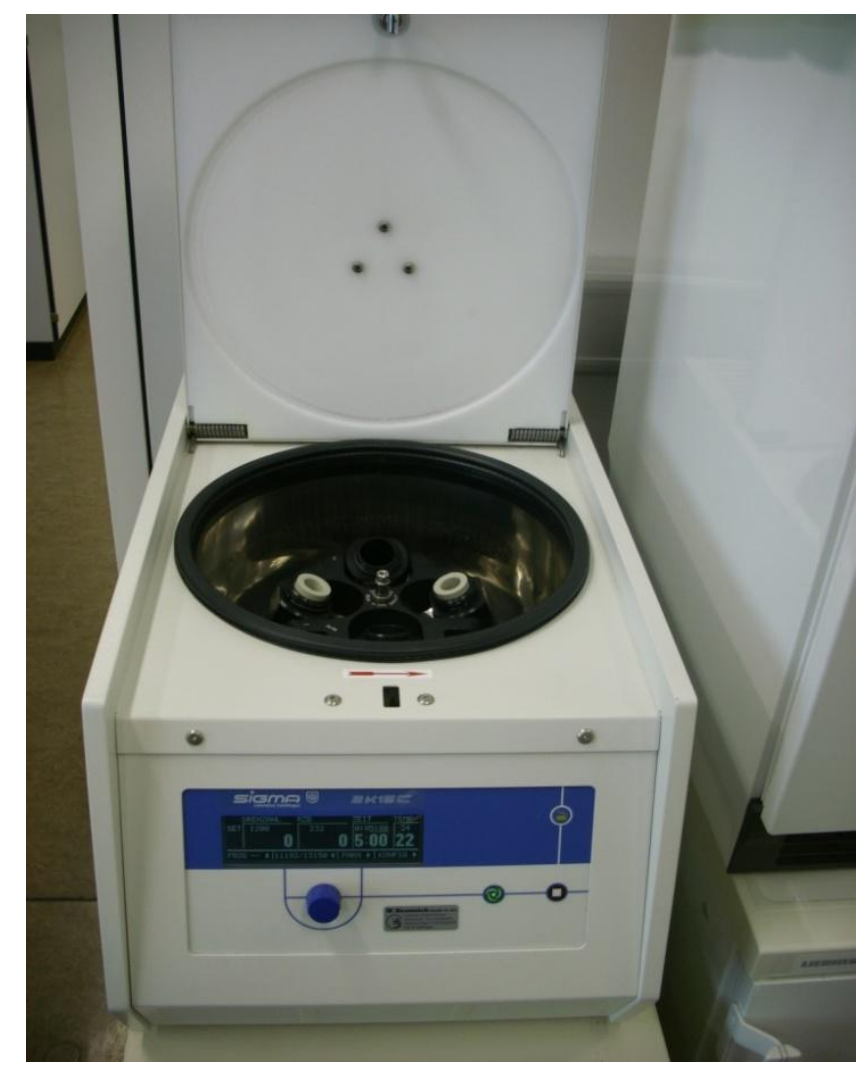

Abbildung 7: Zentrifuge

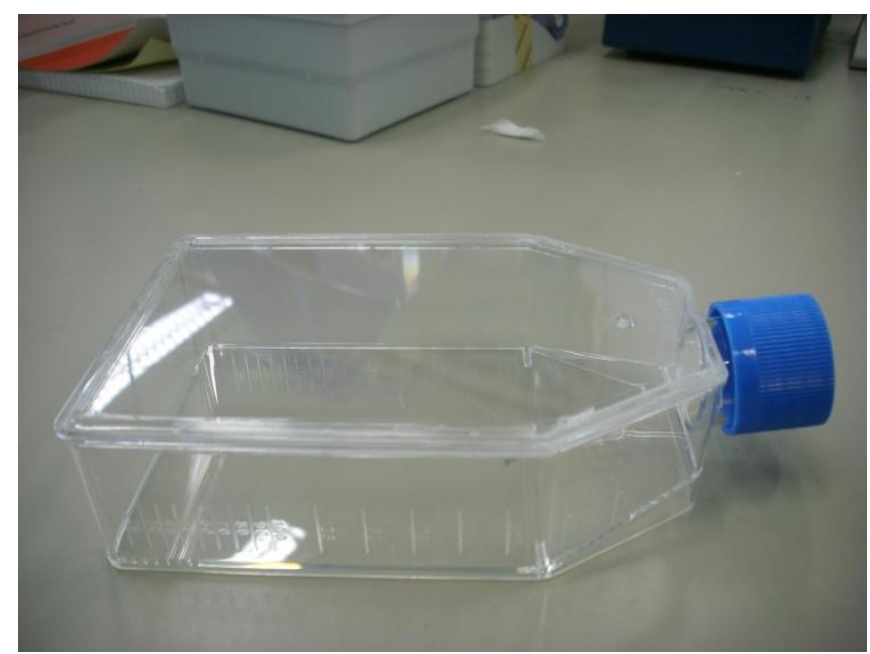

Abbildung 8: Zellkulturflasche 75- $\mathrm{cm}^{2}$-Bodenfläche 
Die Kultivierung der Zellen erfolgte anschließend bei einem konstanten Stickstoffanteil von $5 \%$ bei $+37^{\circ} \mathrm{C}$ und gesättigter Luftfeuchtigkeit in einem $\mathrm{CO}_{2}$-Inkubator (Abb. 9). Der erste Mediumwechsel erfolgte 24 Stunden nach der Aussaat, um die nicht adhärenten Zellen zu entfernen. Anschließend wurde das Kulturmedium alle zwei bis drei Tage mithilfe einer Vakuumpumpe und sterilen Pipetten abgesaugt und durch frisches Nährmedium ersetzt.

Die adhärent wachsenden Zellen wurden nach Erreichen einer Konfluenz von $70 \%$ bis $80 \%$ der Kulturflaschenoberfläche passagiert. Nach Absaugen des Zellkulturmediums wurden die Zellen hierbei mit $5 \mathrm{ml}$ phosphatgepufferter Kochsalzlösung (Phosphate-buffered saline, PBS, pH 7,4) gewaschen. Während die HGFIB nach Entfernen des PBS mit $25 \mu 1 / \mathrm{cm}^{2}$ der sterilen Trypsin-EDTA-Lösung (Passage-Kit 2, Bestell-Nr. 2040002, Provitro GmbH, Berlin, Deutschland) überschichtet und für vier bis sieben Minuten bei $+37^{\circ} \mathrm{C}$ inkubiert wurden, wurden die HNEPC mit $25 \mu 1 / \mathrm{cm}^{2}$ Dispase II (Passage-Kit 3, Bestell-Nr. 2040003, Provitro $\mathrm{GmbH}$, Berlin, Deutschland) behandelt und 15 Minuten lang bei den gleichen Bedingungen inkubiert. Die Trypsinierung wurde im Anschluss durch Zugabe von $25 \mu 1 / \mathrm{cm}^{2}$ neutralisierender Lösung (Passage-Kit 2) und die Behandlung mit Dispase II mit $25 \mu 1 / \mathrm{cm}^{2}$ des Kulturmediums gestoppt. Unter dem Auflichtmikroskop erfolgte eine Kontrolle der Zellablösung (Abb. 10).

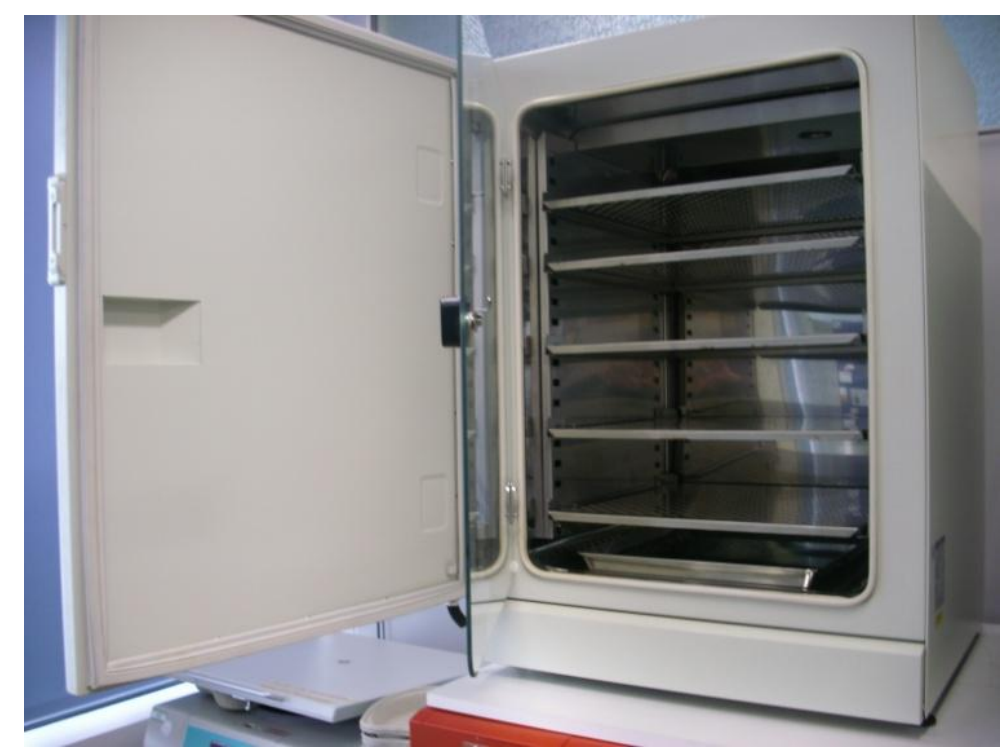

Abbildung 9: $\mathrm{CO}_{2}$-Inkubator 


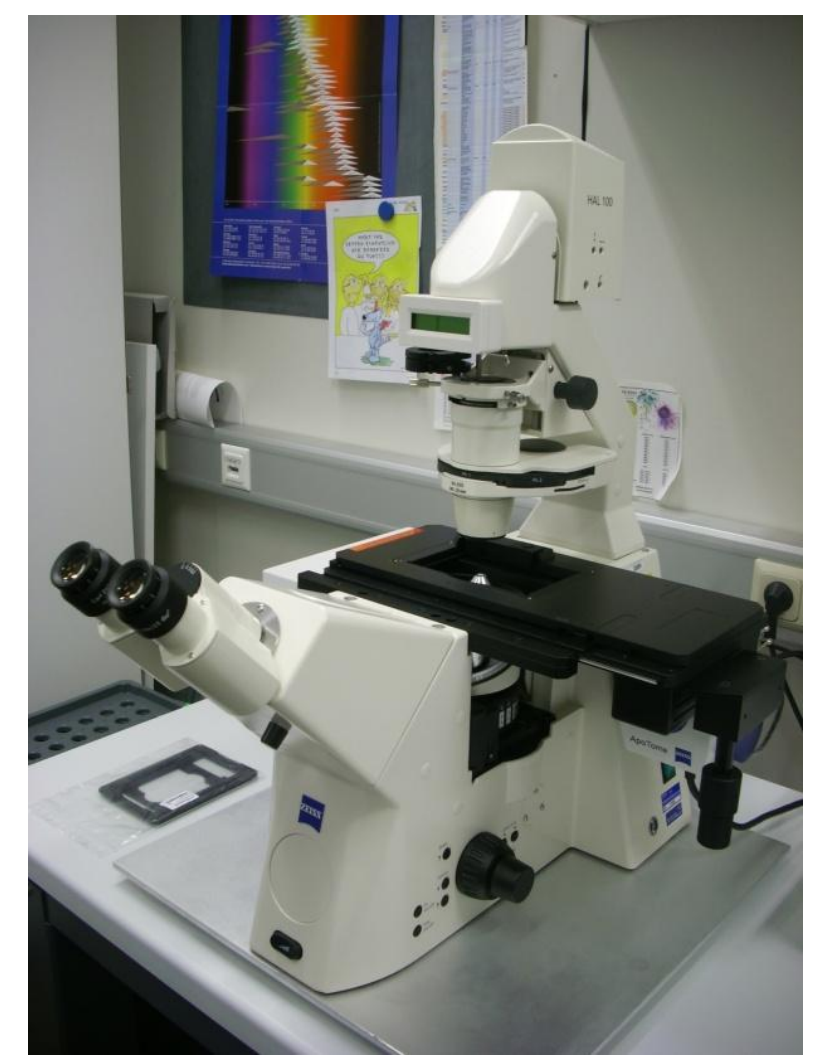

Abbildung 10: Auflichtmikroskop

Die vom Flaschenboden gelösten Zellen wurden mit einer Pipettierhilfe aufgenommen, in ein $15 \mathrm{ml}$ Zentrifugenröhrchen überführt und fünf Minuten bei 250xg und Raumtemperatur zentrifugiert. Der Überstand wurde verworfen und das Zellpellet in $5 \mathrm{ml}$ Kulturmedium resuspendiert. Die Zellzählung erfolgte optisch computergestützt mittels Cellometer ${ }^{\mathrm{TM}}$ Auto T4 (Nexcelom Bioscience LLC, Lawrence, USA) (Abb. 11). Anschließend wurde ein Teil der Zellen für die Durchführung der Versuche in 12-well-Platten (Abb. 12) gegeben und bei einem konstanten Stickstoffanteil von $5 \%$ bei $+37^{\circ} \mathrm{C}$ und gesättigter Luftfeuchtigkeit inkubiert, während ein anderer Anteil für die weitere Expansion in Kulturmedium resuspendiert und in Kulturflaschen verbracht wurde. 


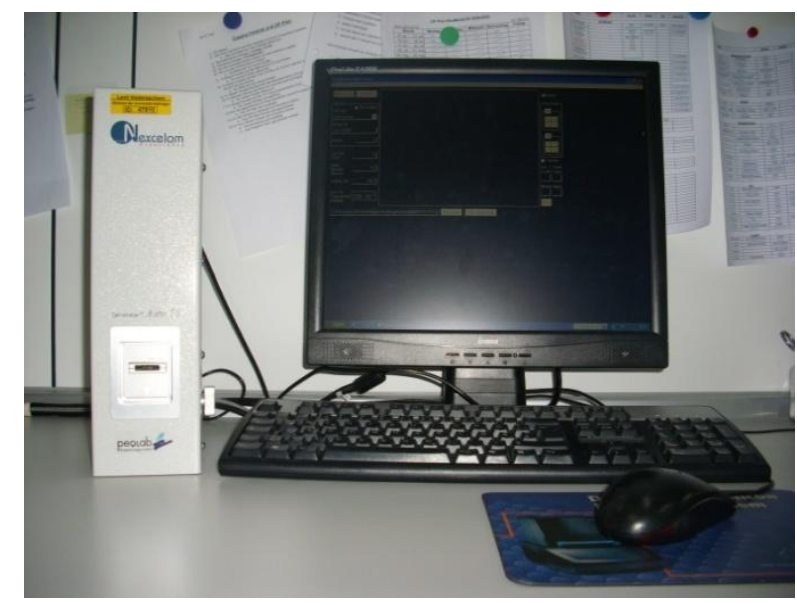

Abbildung 11: Cellometer ${ }^{\mathrm{TM}}$ Auto T4

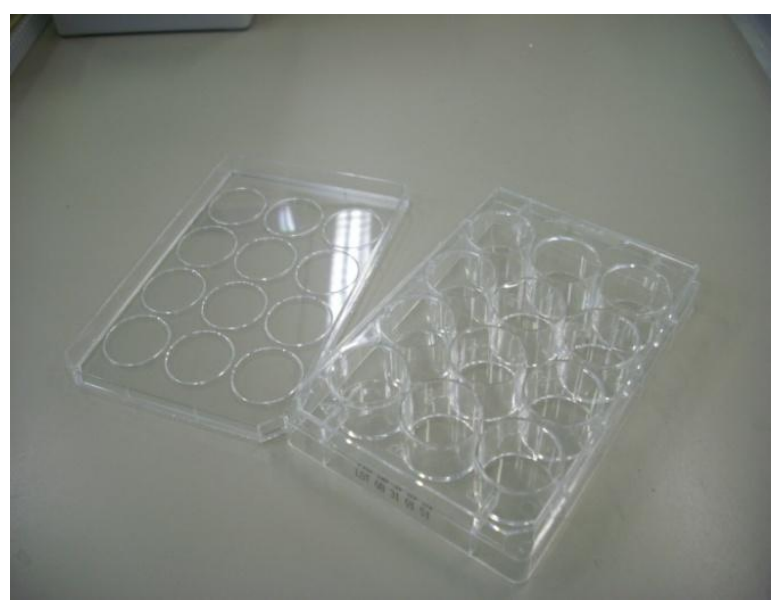

Abbildung 12: 12-well-Platte

Die restlichen Zellen wurden zu Aliquots von je $10^{6}$ Zellen/ml gefroren. Hierfür wurden die Zellen mit $1 \mathrm{ml}$ Cryo-SFM-Medium nach dem fünfminütigen Zentrifugieren bei 250xg und Raumtemperatur resuspendiert und in vorgekühlte $1,5 \mathrm{ml} \mathrm{Nunc-Röhrchen} \mathrm{überführt.} \mathrm{Die}$ Zellen wurden 24 Stunden in einem Isopropanolbad bei $-80^{\circ} \mathrm{C}$ gelagert. Abschließend erfolgte eine Abservierung der Zellen in flüssigem Stickstoff.

\subsubsection{Versuchsaufbau}

Die Ergebnisse dieser Arbeit wurden in jeweils zwei Teilversuchen für die Zellpopulationen der HGFIB und HNEPC ermittelt. Zum einen wurde die Zytotoxizität der Mundspüllösungen auf Fibroblasten bzw. Epithelzellen mittels MTT-Test bestimmt, zum anderen wurde die zytotoxische Wirkung mithilfe der optischen Zellzählung im Cellometer ${ }^{\mathrm{TM}}$ Auto T4 ermittelt. Die Durchführung der Versuche erfolgte immer in gleicher Reihenfolge, mit gleichen Materialien und in gleichen Zeitabständen (Abb. 13). Für die Behandlung mit den antibakteriellen Mundspüllösungen wurden die Zellen nach der Zellzahlbestimmung in frischem Kulturmedium resuspendiert und in 12-well-Platten gegeben. Die Endkonzentration wurde auf 2 × $10^{5}$ Zellen/ml Kulturmedium/well eingestellt. Bei den Versuchen wurden die HGFIB der 6. und 7. Passage und die HNEPC der 4. Passage verwendet. Nach 24 Stunden wurde das Medium mit dem Ziel, die nicht adhärenten schwimmenden Zellen zu entfernen und den Zellen die nötigen Nährstoffe zuzusetzen, gewechselt. Vor und nach jedem Schritt wurden die Zellen lichtmikroskopisch kontrolliert (Abb. 14a und b). 


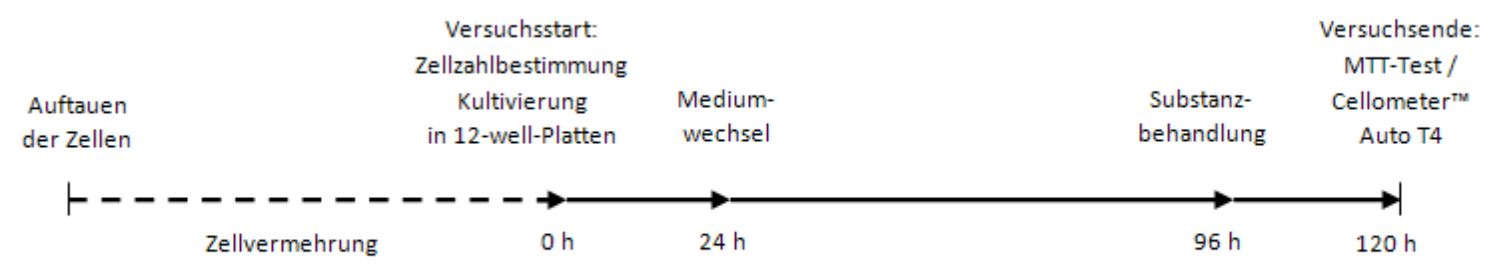

\section{Abbildung 13: Versuchsdurchführung mit HGFIB und HNEPC}

Die kryokonservierten Zellen wurden für die Durchführung der Versuche in Kultur gebracht und innerhalb der drei bis fünf Wochen bei $5 \% \mathrm{CO}_{2},+37^{\circ} \mathrm{C}$ und gesättigter Luftfeutigkeit vermehrt. Am Anfang des Versuchs wurde die Zellzahl der kultivierten Zellen bestimmt und die 12-well-Platten mit je $2 \times 10^{5}$ Zellen/ml Kulturmedium/well präpariert $(0 \mathrm{~h})$. Nach 24 Stunden erfolgte der Mediumwechsel. Drei Tage später wurden die Zellen mit CHX $0,2 \%{ }^{\circledR}$, Meridol ${ }^{\circledR}$, Listerine ${ }^{\circledR}$, Betaisodona $^{\circledR}$, Octenidol ${ }^{\circledR}$ und reinem PBS für die Kontrolle jeweils 1, 5 und 15 Minuten behandelt (96 h). Am nächsten Tag wurde der Versuch beendet, indem die präparierten wells mittels eines MTTTests und der Zellzahlbestimmung mit der Hilfe des Cellometer ${ }^{\mathrm{TM}}$ Auto T4 ausgewertet wurden (120 h). 

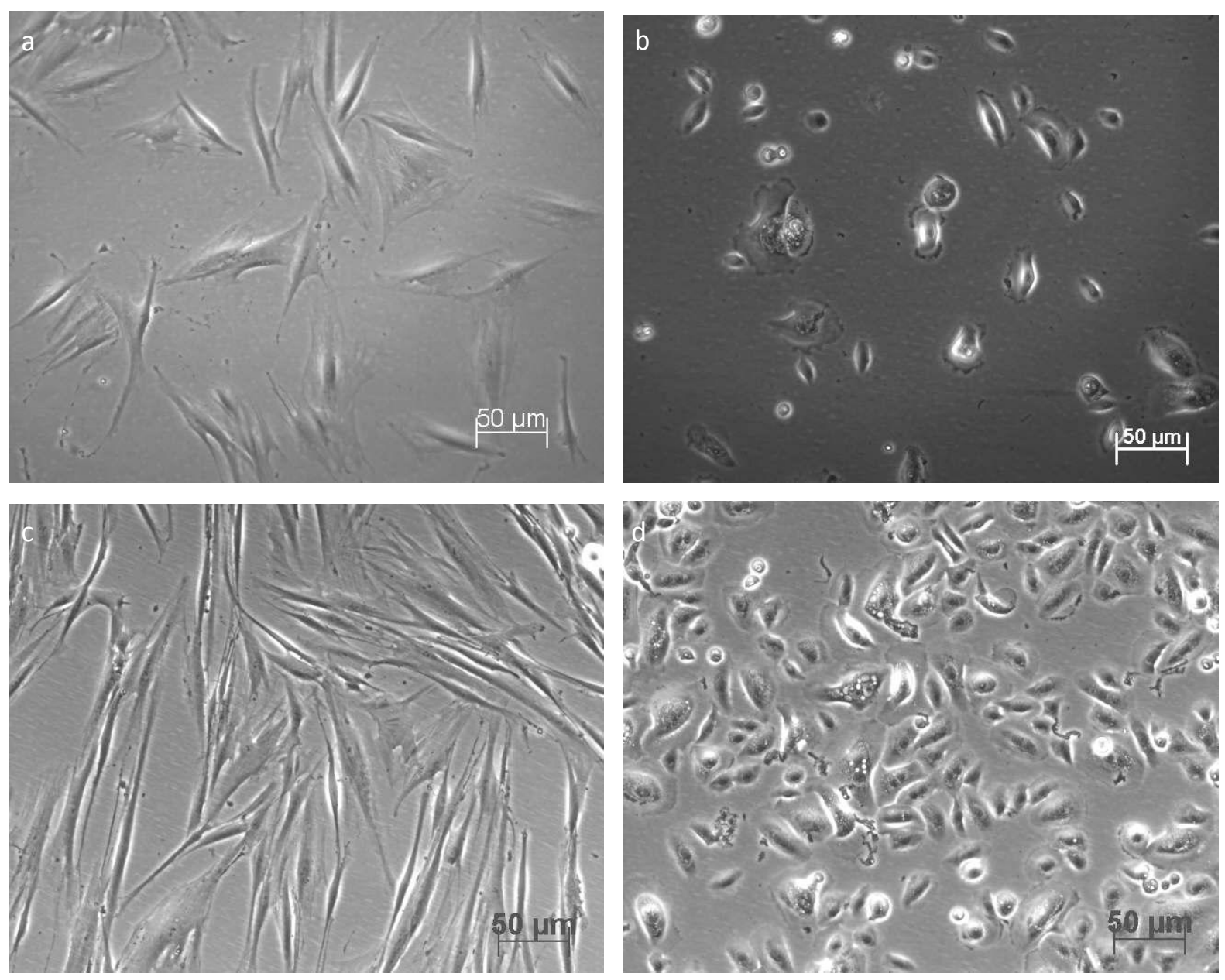

\section{Abbildung 14: Primäre humane Gingivafibroblasten und nasale Epithelzellen in vitro 24 Stunden (a und b) bzw. 96 Stunden (c und d) nach der Aussaat}

24 Stunden nach der Aussaat wurden die nicht adhärenten Zellen infolge des Mediumwechsels entfernt. Die verbliebenen, am Schallenboden haftenden Fibroblasten stehen über viele irreguläre zytoplasmatische Fortsätze miteinander in Verbindung (a). Die HNEPC weisen zwar auch die Plastikadhärenz auf, bilden aber viel weniger Zell-Zell-Kontakte untereinander (b). Für die Behandlung der Zellen mit den handelsüblichen oralen Antiseptika wurde eine 75-prozentige Konfluenz angestrebt (c und d).

Am vierten Tag nach der Aussaat (96 Stunden, Abb. 14c und d) wurden die Zellen mit oralen Antiseptika: Chlorhexidin (CHX) als Chlorhexidin-digluconat Fertiglösung $0,2 \%{ }^{\circledR}$ (Engelhard Arzneimittel GmbH \& Co. KG, Niederdorfelden, Deutschland), Amin/Zinnfluorid $\left(\mathrm{AmF}_{\mathrm{SnF}}\right)$ als Meridol ${ }^{\circledR}\left(\mathrm{GABA} \mathrm{GmbH}\right.$, Lörrach, Deutschland), Listerine ${ }^{\circledR}$ Coolmint als eine Kombination aus ätherischen Ölen, Metylsalicylat, Natriumzitrat und Benzoesäure (Pfizer Consumer Healthcare GmbH, Karlsruhe, Deutschland), Povidon-Jod (PVP-Jod) als Betaisodona ${ }^{\circledR}$ (Mundipharma GmbH, Limburg/Lahn, Deutschland) und

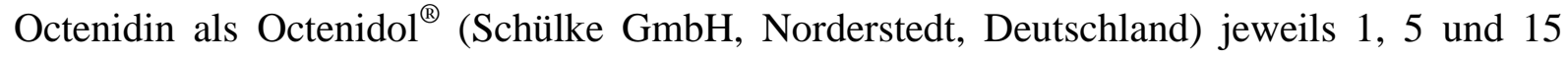


Minuten behandelt. Die Lösungen wurden steril filtriert und nach Angaben des Herstellers unverdünnt bzw. in der vorgeschriebenen Konzentration für den Gebrauch in vivo eingesetzt. Dabei folgte der Entnahme des Kulturmediums von den Wells mit einer Pasteurpipette die Zugabe von $1 \mathrm{ml}$ Mundspüllösung/well. Alle Versuche erfolgten in Doppelbestimmung. In die letzten zwei Wells wurde zur Kontrolle anstatt der Antiseptika PBS pipettiert. Um Mundbedingungen zu simulieren, verblieb jede Lösung für jeweils 1, 5 bzw. 15 Minuten bei $+37^{\circ} \mathrm{C}$ und $5 \% \mathrm{CO}_{2}$ auf den Zellen. Abschließend wurden die Wirkstofflösungen abgesaugt, die Wells mit je $1 \mathrm{ml}$ PBS 30 Sekunden lang gespült und mit je $1 \mathrm{ml}$ frischem Kulturmedium aufgefüllt. Die Zellen wurden bei einem konstanten Stickstoffanteil von $5 \%$ bei $+37^{\circ} \mathrm{C}$ und gesättigter Luftfeuchtigkeit für weitere 24 Stunden im Inkubator kultiviert. Am fünften Tag (120 Stunden) nach der Aussaat erfolgte die Auswertung der präparierten Platten mittels MTT-Test und parallel dazu eine computergestützte optische Zellzählung mithilfe des Cellometer ${ }^{\mathrm{TM}}$ Auto T4.

\subsubsection{MTT-Test}

Der MTT-Test ist ein Wachstumsassay, der bereits 1983 erwähnt wurde und der im Rahmen dieser Arbeit für Untersuchungen an Fibroblasten und Epithelzellen zur Anwendung kam. Basierend auf der Messung der metabolischen Aktivität lebender Zellen, sollte der Einfluss der Testverbindungen auf die Viabilität der Zellen ermittelt werden. Hierbei erfolgt in den Mitochondrien eine Umwandlung des gelben Tetrazoliumsalzes MTT (3-(4,5-Dimethylthiazol-2-yl-)2,5-diphenyl-2H-tetrazoliumbromid) durch mitochondriale Dehydrogenasen zu reduziertem Formazan, das violette Kristalle ausbildet (Abb. 15). Die Menge an gebildetem Formazan wird über die optische Dichte für die Zellpopulation der HGFIB bei $555 \mathrm{~nm}$ gegenüber einer Referenzwellenlänge von $690 \mathrm{~nm}$ bzw. für die Zellpopulation der HNEPC bei $550 \mathrm{~nm}$ und einer Referenzwellenlänge von $700 \mathrm{~nm}$ im Spektralphotometer (Abb. 16) bestimmt und korreliert mit der Gesamtaktivität der mitochondrialen Dehydrogenasen und daraus abgeleitet der Biomasse der überlebenden Zellen. 

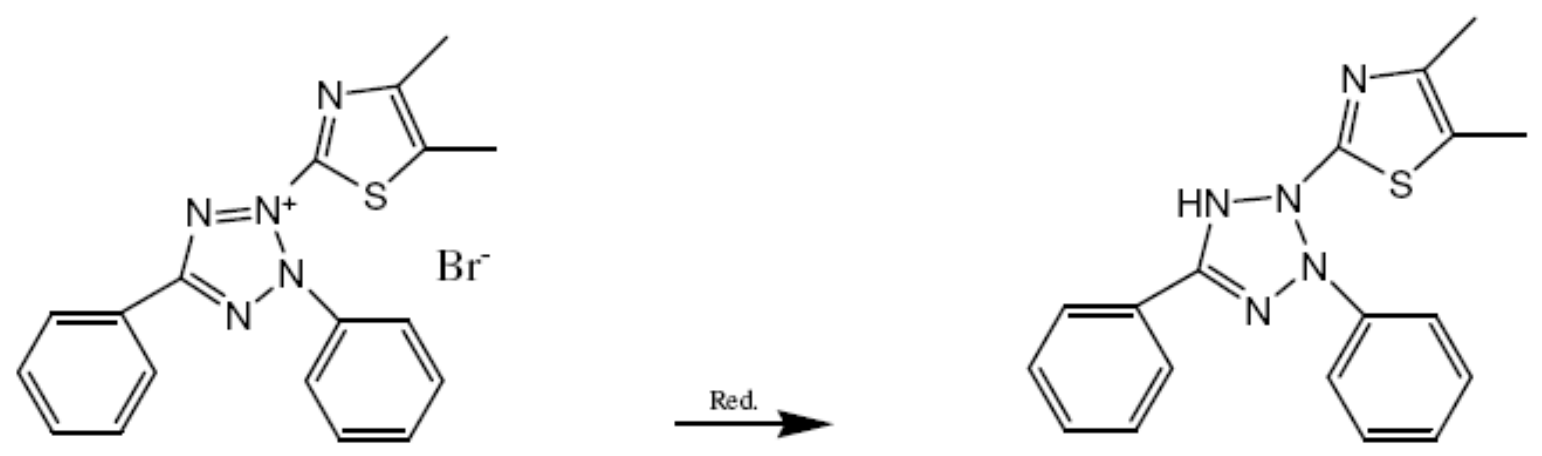

Abbildung 15: Reduzierung des gelben MTT zu violettem Formazan

Der MTT-Test wurde angewandt, um den Einfluss ausgewählter Verbindungen auf die Viabilität der Zellen zu ermitteln. Die Auswertung erfolgte über die Bildung des violetten Formazan-Salzes, das nur in lebenden, intakten Mitochondrien gebildet werden kann. Je wirksamer eine Substanz ist, desto mehr wird die Aktivität der mitochondrialen Dehydrogenasen gehemmt und desto weniger Farbbildung tritt auf, die ihrerseits wiederum über die Absorption ermittelbar ist. Über diese Absorption kann die Proliferation bzw. Viabilität erhalten werden, indem das prozentuale Wachstum, bezogen auf die substanzunbehandelten Zellen, grafisch aufgetragen wird.

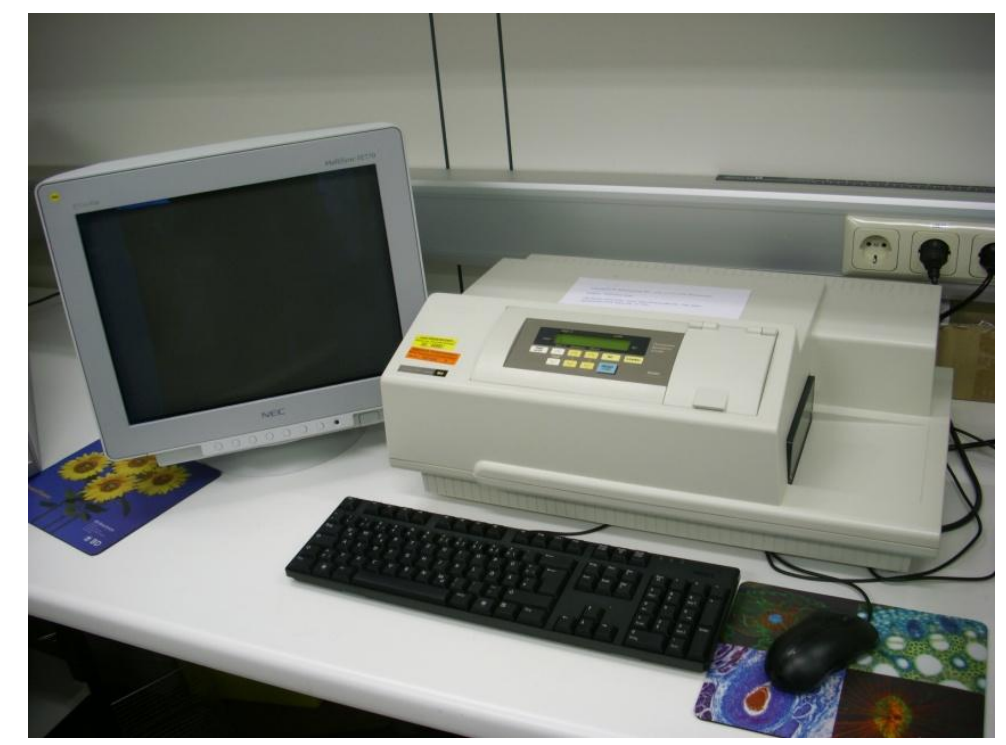

Abbildung 16: Spektralphotometer

24 Stunden nach der Behandlung der Zellen mit den antibakteriellen Mundspüllösungen und der Inkubation im Brutschrank bei $5 \% \mathrm{CO}_{2},+37^{\circ} \mathrm{C}$ und gesättigter Luftfeuchtigkeit wurden $250 \mu 1$ MTT-Lösung pro Well zu dem Medium gegeben. Die 12-well-Platten wurden für weitere zwei Stunden bei gleichen Bedingungen inkubiert. Die Bildung von Kristallen wurde lichtmikroskopisch kontrolliert. Des Weiteren wurde das Medium mit der MTT-Lösung vorsichtig abgesaugt und jedes Well mit $1 \mathrm{ml}$ DMSO zum Lösen der Kristalle versehen. 
Anschließend wurden die Platten weitere 15 Minuten im Brutschrank inkubiert. Die während der Inkubationszeit aus dem MTT gebildeten violetten Farbkristalle wurden in dieser Zeit gelöst. Mithilfe des Spektralphotometers wurde die Exzitation der Lösungen der einzelnen Wells bei einer Wellenlänge für HGFIB von $555 \mathrm{~nm}$ sowie einer Referenzwellenlänge von $690 \mathrm{~nm}$ gemessen. Für die Zellpopulation der HNEPC wurden eine Excitationswellenlänge von $550 \mathrm{~nm}$ und eine Referenzwellenlänge von $700 \mathrm{~nm}$ genommen.

Für die Auswertung wurden die Ergebnisse bei den Referenzwellenlängen von den Ergebnissen bei den Excitationswellenlängen subtrahiert und bei zwei zusammengehörenden Wells jeweils gemittelt. Die Ergebnisse der Kontrollwells jeder Platte wurden ebenfalls gemittelt und als $100 \%$ ausgegeben, da hier die Zellen anstatt der Mundspüllösungen lediglich mit dem reinen PBS behandelt wurden und folglich ihr optimales Wachstum zeigen sollten. Die Ergebnisse der mit den oralen Antiseptika behandelten Wells wurden anschließend als Prozentwert der Kontrollwells ausgegeben.

\subsubsection{Optische Zellzahlbestimmung}

Parallel zu dem MTT-Test wurde die Zellzahlbestimmung mittels Cellometer ${ }^{\mathrm{TM}}$ Auto T4 durchgeführt. Cellometer ${ }^{\mathrm{TM}}$ Auto T4 ist ein bildbasiertes automatisches Zellzählsystem (siehe Abb. 11). Ein softwaregestütztes Programm erlaubt die gleichzeitige Bestimmung der Anzahl der lebenden Zellen in Relation zur Gesamtzellzahl (Viabilität) mithilfe der TrypanblauFärbung. Die Zellkonzentration wurde automatisch unter der Berücksichtigung des Verdünnungsfaktors angegeben. Durch die Einstellungen des Zelltyps konnte die Zellzählung mit einer hohen Reproduzierbarkeit und Genauigkeit durchgeführt werden.

Die Dichte des Zellrasens auf dem Boden der 12-well-Platten wurde lichtmikroskopisch kontrolliert. Das verbrauchte Medium wurde mithilfe einer Pasteurpipette abgesaugt. Anschließend wurde der Zellrasen mit $1 \mathrm{ml}$ PBS pro Well gespült. Nach dem Absaugen des PBS wurden $200 \mu 1$ Trypsin-EDTA-Lösung pro Well gleichmäßig auf dem Zellrasen verteilt. Des Weiteren wurden die 12-well-Platten im Brutschrank fünf bis sieben Minuten bei $5 \%$ $\mathrm{CO}_{2},+37^{\circ} \mathrm{C}$ und gesättigter Luftfeuchtigkeit inkubiert. Durch Zugabe von $1 \mathrm{ml}$ Kulturmedium pro Well, das 10\% FCS enthält, wurde der Prozess des Ablösens der Zellen gestoppt. Die abgelösten Zellen samt Medium wurden von den jeweils zwei zusammengehörenden Wells in ein Reagenzröhrchen gegeben. Die Wells wurden noch einmal mit $1 \mathrm{ml}$ Kulturmedium pro Well gespült, und die gewonnene Suspension wurde zu den anderen Zellen gegeben. Nach einer lichtmikroskopischen Kontrolle der 12-well-Platten, die 
sicherzustellen sollte, dass alle Zellen aus dem Well abgenommen wurden, wurden die Reagenzröhrchen fünf Minuten lang bei 250xg und Raumtemperatur zentrifugiert. Der Überstand wurde vorsichtig abgesaugt und das Zellpellet in $1 \mathrm{ml}$ Kulturmedium resuspendiert. Anschließend wurde $20 \mu \mathrm{l}$ Zellsuspension aus jedem Reagenzröhrchen in jeweils eine Zellkammer pipettiert (Abb. 17). Die Zellkammer wurde in das Cellometer ${ }^{\mathrm{TM}}$ Auto T4 platziert und automatisch ausgewertet (siehe Abb. 11). Zuvor wurden folgende Daten in das Programm eingegeben: Verdünnungsfaktor 1, Zelltyp HGFIB bzw. HNEPC und Zelldurchmesser $10-50 \mu \mathrm{m}$. Die gewonnen Daten (Zellzahl, Viabilität und mittlerer Zelldurchmesser) wurden mithilfe des Programms Microsoft Excel ${ }^{\circledR}$ ausgewertet.
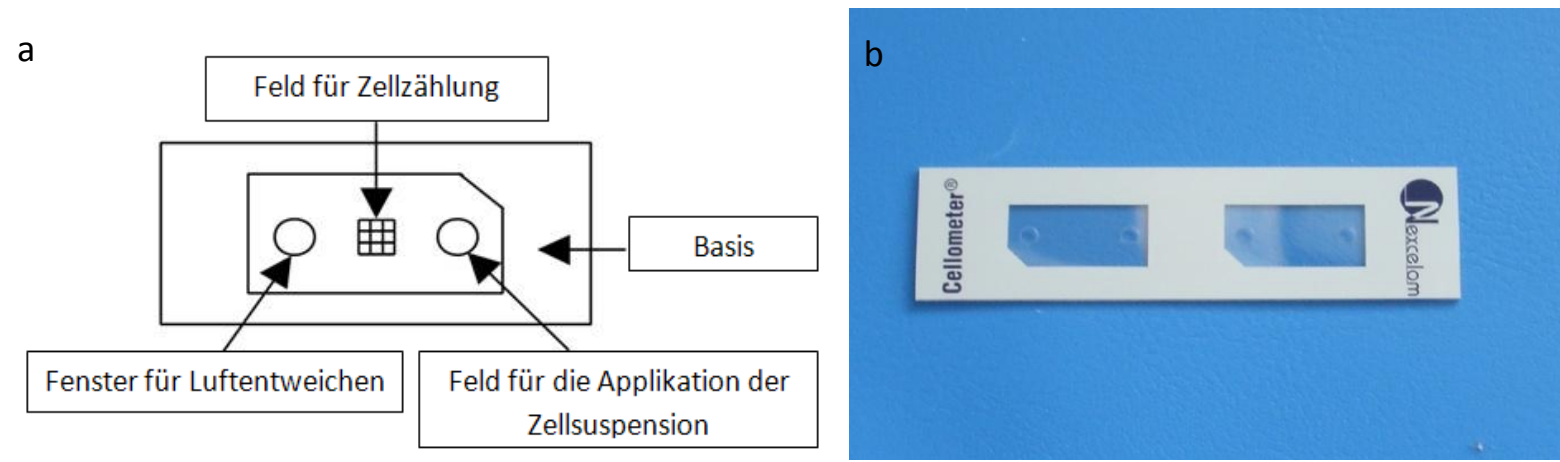

\section{Abbildung 17: Zellkammer}

Eine schematische Darstellung einer Zellkammer (a) und eine Zellkammer für Cellometer ${ }^{\mathrm{TM}}$ Auto T4 (b). Die Basis besteht aus Kunstoff. Die Zellkammer verfügt über zwei Öffnungen. In eine Öffnung wird die Zellsuspension langsam pipettiert. Die Luft entweicht dabei aus der anderen Öffnung. Anschließend können die Zellen im Feld zwischen den beiden Öffnungen automatisch ausgezählt werden.

\subsubsection{Statistische Auswertungen}

Der Einfluss der Spüllösung und der Einwirkzeit sowie der Wechselwirkungseffekt dieser beiden Faktoren auf die verschiedenen Messgrößen wurden, getrennt nach den beiden Zelltypen, mit zweifaktoriellen Varianzanalysen untersucht. Im Falle eines signifikanten Einflusses der Lösung wurde anschließend jede der Spüllösungen mit der Kontrolle verglichen (Dunnett-Vergleiche). Zusätzlich wurden alle Spüllösungen mit t-Tests paarweise untereinander verglichen. Der Zusammenhang zwischen MTT-Messung und Zellzahl wurde mit Pearsons Korrelationskoeffizient rho untersucht. Als Signifikanzniveau wurde für alle Tests $\alpha=5 \%$ festgelegt. Bei den paarweisen Vergleichen der Spüllösungen wurde ein 
signifikanter Unterschied nur bei einem p-Wert unterhalb des Bonferroni-adjustierten Signifikanzniveaus von $0,05 / 10=0,005$ angenommen. Alle Analysen wurden mit SAS (Version 9.1, SAS Institute) berechnet. Die Grafiken wurden mit der freien Software R (Version 2.8, www.r-project.org) erstellt. 


\section{Ergebnisse}

Im Idealfall ist anzunehmen, dass bei der für die Anwendung fertigen, unverdünnten Lösung $(100 \%)$ und realistischer Einwirkzeit (z. B. 1, 5 und 15 Minuten) keine Zellschädigung auftritt. Bei unrealistischen Einwirkzeiten ist für die unverdünnte Lösung eine Zellschädigung nicht erwünscht. Das Auftreten einer Zellschädigung unter diesen Bedingungen ist jedoch mit hoher Wahrscheinlichkeit nicht von klinischer Bedeutung. Längere Einwirkzeiten (30 Minuten, 1 Stunde) der unverdünnten Mundspüllösung sind in vivo unwahrscheinlich. Eine Zellschädigung bei dieser Kombination ist daher mit hoher Wahrscheinlichkeit klinisch nicht relevant.

\subsection{Versuche mit primären humanen Gingivafibroblasten (HGFIB)}

Die primären humanen Gingivafibroblasten bilden als bedeutender Bestandteil mehrerer Gewebe im Bereich der Mundhöhle eine Grundlage für die Untersuchung der Wirkung von handelsüblichen oralen Antiseptika auf die Mundschleimhaut und den Parodontalapparat. Die primären Zellen wurden in Kultur unter standardisierten Bedingungen gezüchtet und vermehrt.

\subsubsection{Bestimmung der Toxizität von oralen Antiseptika mittels MTT-Tests}

Die metabolische Aktivität von lebenden Zellen wurde mithilfe des MTT-Tests bestimmt. Aus den Ergebnissen dieses Wachstumsassays konnten Rückschlüsse auf die Viabilität der Zellen gezogen werden.

\subsubsection{Ergebnisse der einzelnen Antiseptika nach Einwirkzeiten}

In Tabelle 2 sind die Mittelwerte mit den dazugehörigen Standardfehlern der Messung der metabolischen Aktivität der HGFIB mittels des MTT-Tests angegeben. Die Viabilität war nach der Behandlung der Zellen mit den fünf handelsüblichen Mundspüllösungen (CHX 0,2 $\%{ }^{\circledR}$, Meridol ${ }^{\circledR}$, Listerine ${ }^{\circledR}$, Betaisodona ${ }^{\circledR}$ und Octenidol ${ }^{\circledR}$ ) bei allen Versuchsreihen $(1,5$ und 15 Minuten) im Vergleich zur Kontrolle $(0,3648 \pm 0,0181$ OD) signifikant reduziert $(\mathrm{p}<$ 0,0001). OD = Lm1(Exzitation $)-\operatorname{Lm} 2($ Emission $)$ 
Tabelle 2: Mittelwerte und Standardfehler der MTT-Messungen (OD) nach der Behandlung mit oralen Antiseptika bei Fibroblasten

\begin{tabular}{|c|c|c|c|}
\hline & \multicolumn{3}{|c|}{ Einwirkzeit } \\
\hline Mundspüllösung & 1 Minute & 5 Minuten & 15 Minuten \\
\hline CHX 0,2 \% ${ }^{\circledR}$ & $0,0190 \pm 0,0021$ & $0,0184 \pm 0,0020$ & $0,0154 \pm 0,0016$ \\
\hline Meridol $^{\circledR}$ & $0,0188 \pm 0,0020$ & $0,0177 \pm 0,0022$ & $0,0171 \pm 0,0014$ \\
\hline Listerine $^{\circledR}$ & $0,0176 \pm 0,0022$ & $0,0176 \pm 0,0021$ & $0,0173 \pm 0,0017$ \\
\hline Betaisodona $^{\circledR}$ & $0,0206 \pm 0,0041$ & $0,0208 \pm 0,0040$ & $0,0192 \pm 0,0040$ \\
\hline Octenidol $^{\circledR}$ & $0,0219 \pm 0,0023$ & $0,0205 \pm 0,0026$ & $0,0181 \pm 0,0018$ \\
\hline
\end{tabular}

\subsubsection{Einfluss der Einwirkzeit}

Der Vergleich beschreibt die Zellwirkung der einzelnen Mundspüllösungen in Abhängigkeit von der Einwirkzeit. Wegen der besseren Übersichtlichkeit werden die Vergleiche in den Diagrammen 1 bis 5 separat ohne Angabe des Standardfehlers dargestellt. Die Standardfehler sind der Tabelle 2 zu entnehmen.

Die CHX-Versuchsreihe weist eine Reduktion der metabolischen Aktivität der HGFIB in Abhängigkeit von der Einwirkzeit der Mundspüllösung auf. Je länger das Antiseptikum auf den Zellen verbleibt, desto stärker werden die Zellen in ihrer Aktivität gehemmt. Während nach einer Minute 0,0190 \pm 0,0021 OD gemessen wurde, wurden nach 5 bzw. 15 Minuten $0,0184 \pm 0,0020$ OD bzw. $0,0154 \pm 0,0016$ OD registriert. 


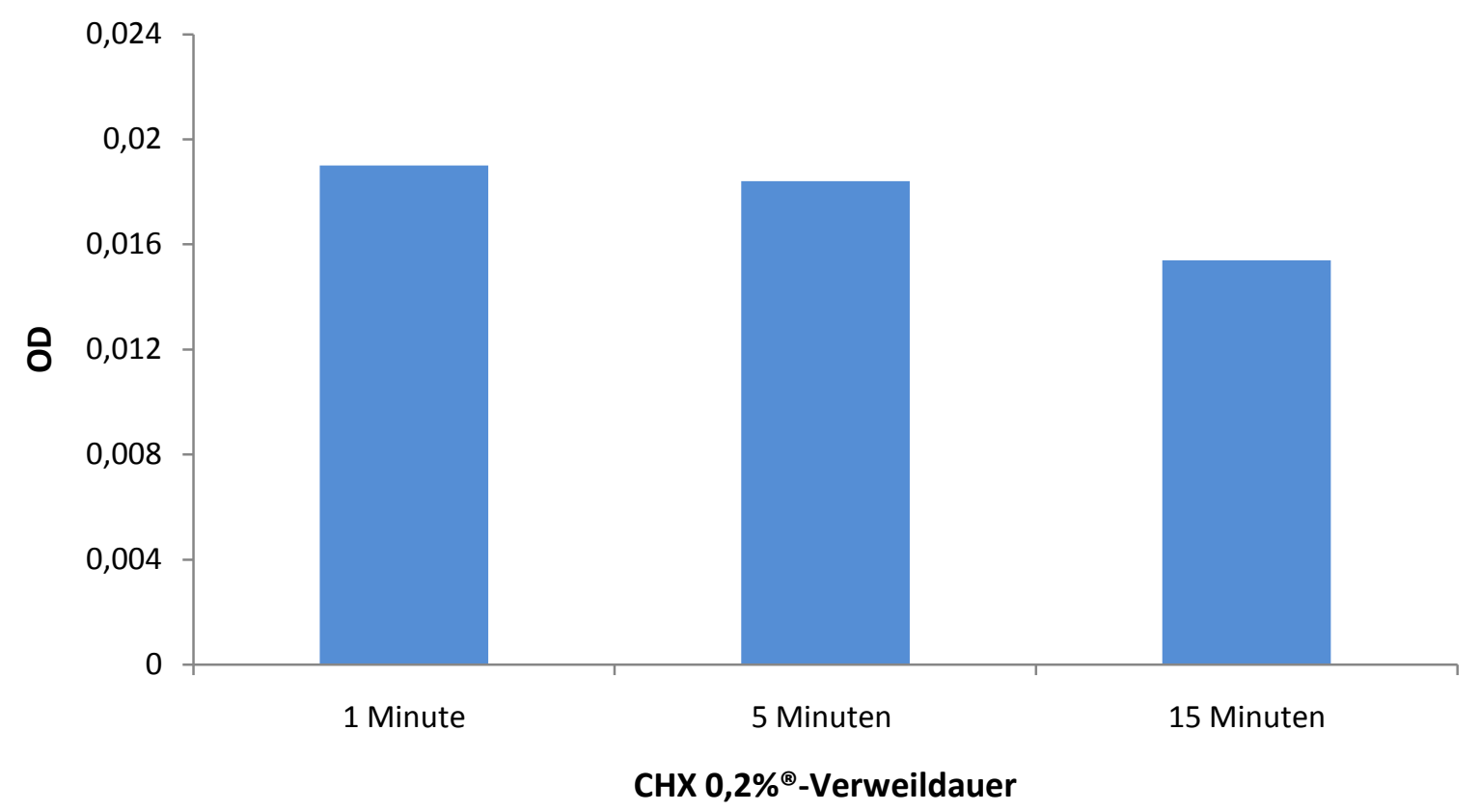

Diagramm 1: Einfluss der CHX-Mundspüllösung auf die HGFIB in Abhängigkeit von der Einwirkzeit

Ganz ähnliche Ergebnisse wurden infolge der Behandlung der humanen Gingivafibroblasten mit Meridol ${ }^{\circledR}$ erzielt. Das MTT-Testergebnis betrug nach einer Minute 0,0188 \pm 0,0020 OD, nach fünf Minuten 0,0177 $\pm 0,0022$ OD und nach 15 Minuten 0,0171 \pm 0,0014 OD.

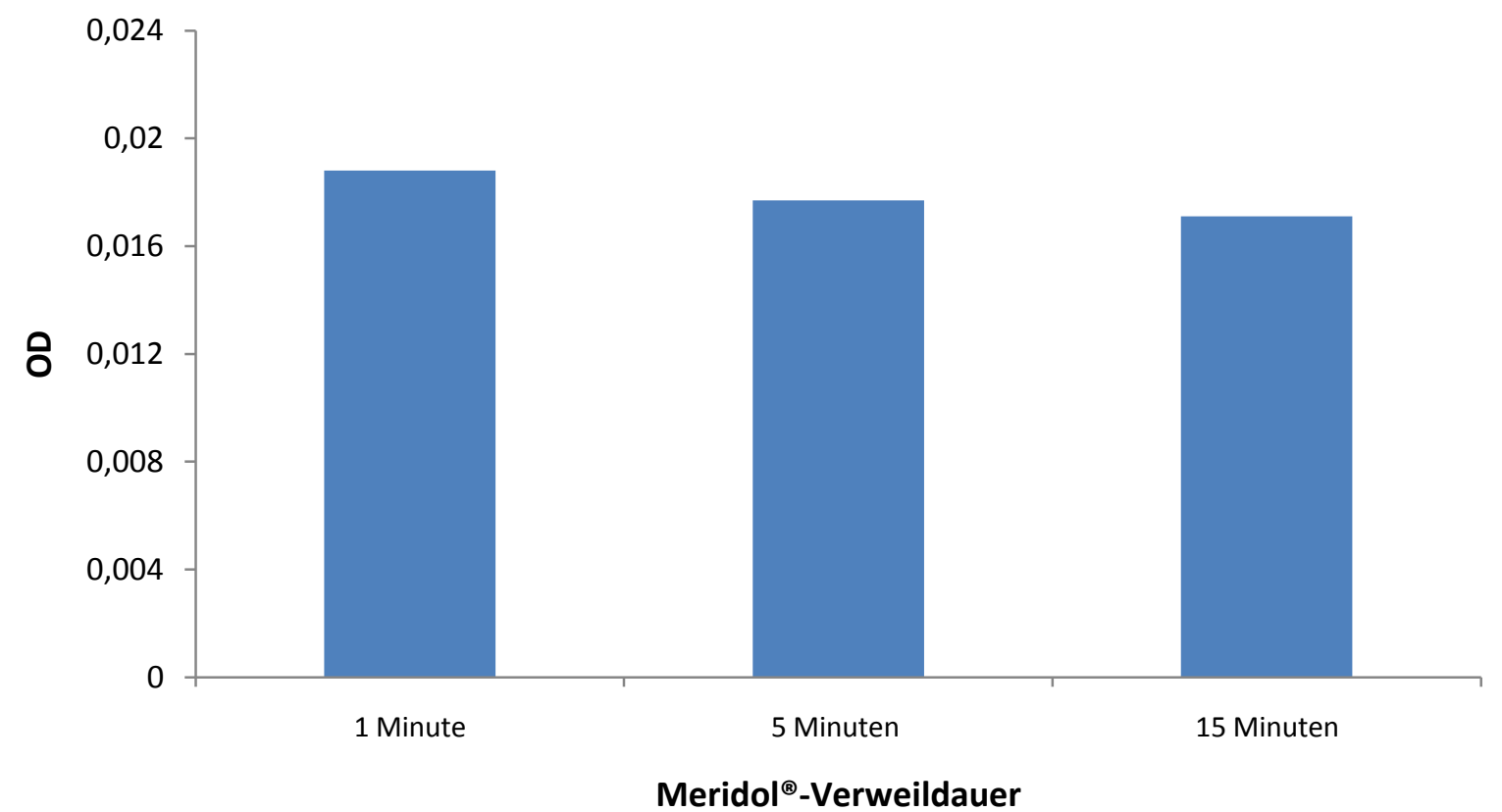

Diagramm 2: Einfluss von Meridol ${ }^{\circledR}$ auf die HGFIB in Abhängigkeit von der Einwirkzeit 
Die MTT-Messungen bei den Versuchen mit der Listerine ${ }^{\circledR}$-Lösung wiesen keine wesentlichen Unterschiede zu den oben gezeigten Experimenten auf. Die Werte nach einer bzw. nach fünf Minuten waren bis auf Standardfehler gleich; sie betrugen 0,0176 $\pm 0,0022$ OD bzw. 0,0176 \pm 0,0021 OD. Nach 15-minütiger Behandlung mit Listerine ${ }^{\circledR}$ war die metabolische Aktivität der HGFIB noch niedriger als nach einer bzw. nach fünf Minuten Einwirkzeit $(0,0173 \pm 0,0017 \mathrm{OD})$.

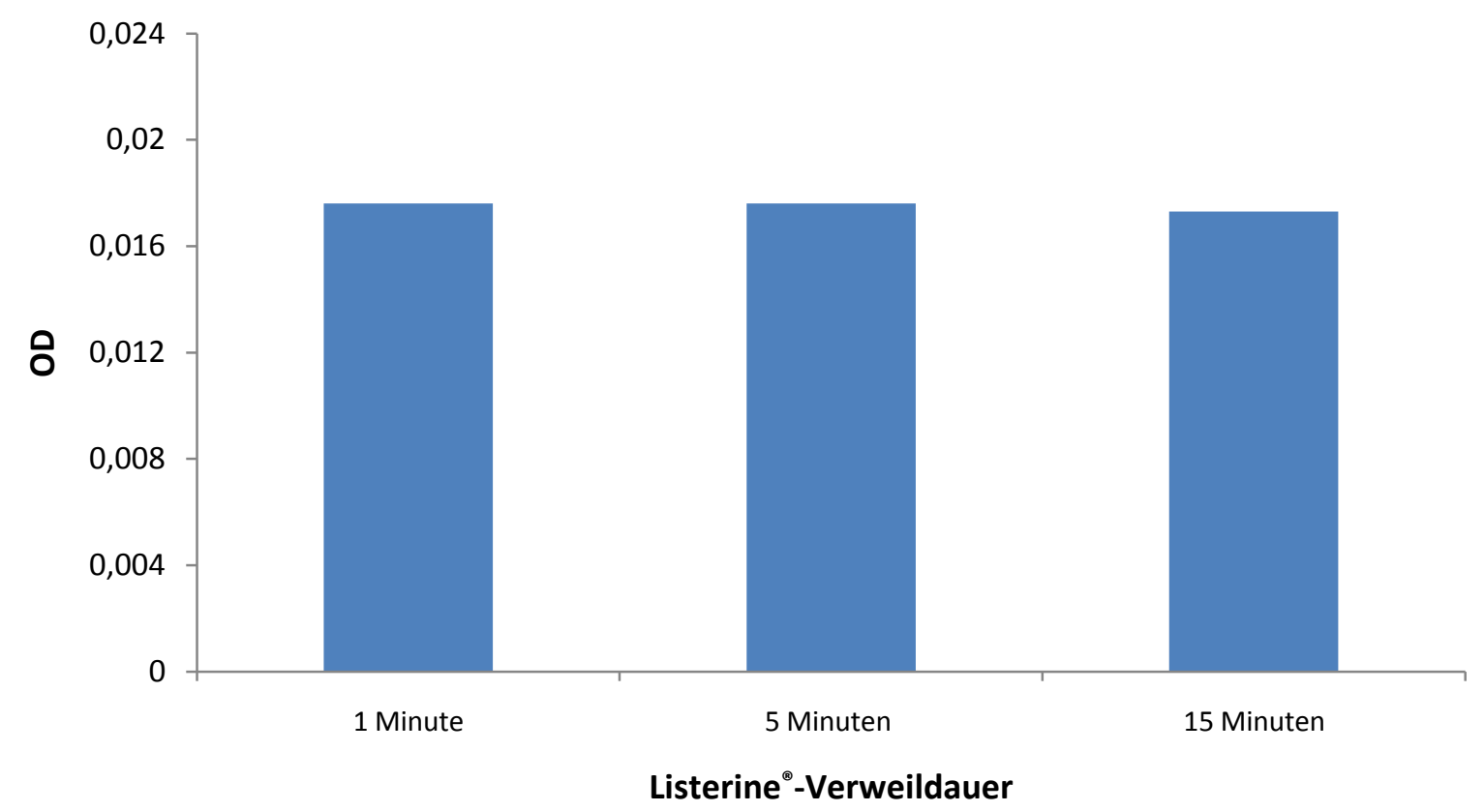

Diagramm 3: Einfluss von Listerine ${ }^{\circledR}$ auf die HGFIB in Abhängigkeit von der Einwirkzeit

Während nach einer Minute Einwirkzeit $\left(0,0206 \pm 0,0041\right.$ OD) der Betaisodona ${ }^{\circledR}$ Mundspüllösung auf die HGFIB die ermittelten Werte mit den Ergebnissen der 5-MinutenVersuche $(0,0208 \pm 0,0040$ OD) weitgehend übereinstimmten, war nach 15 Minuten eine deutliche Reduktion der Fibroblastenaktivität festzustellen (0,0192 \pm 0,0040 OD). 


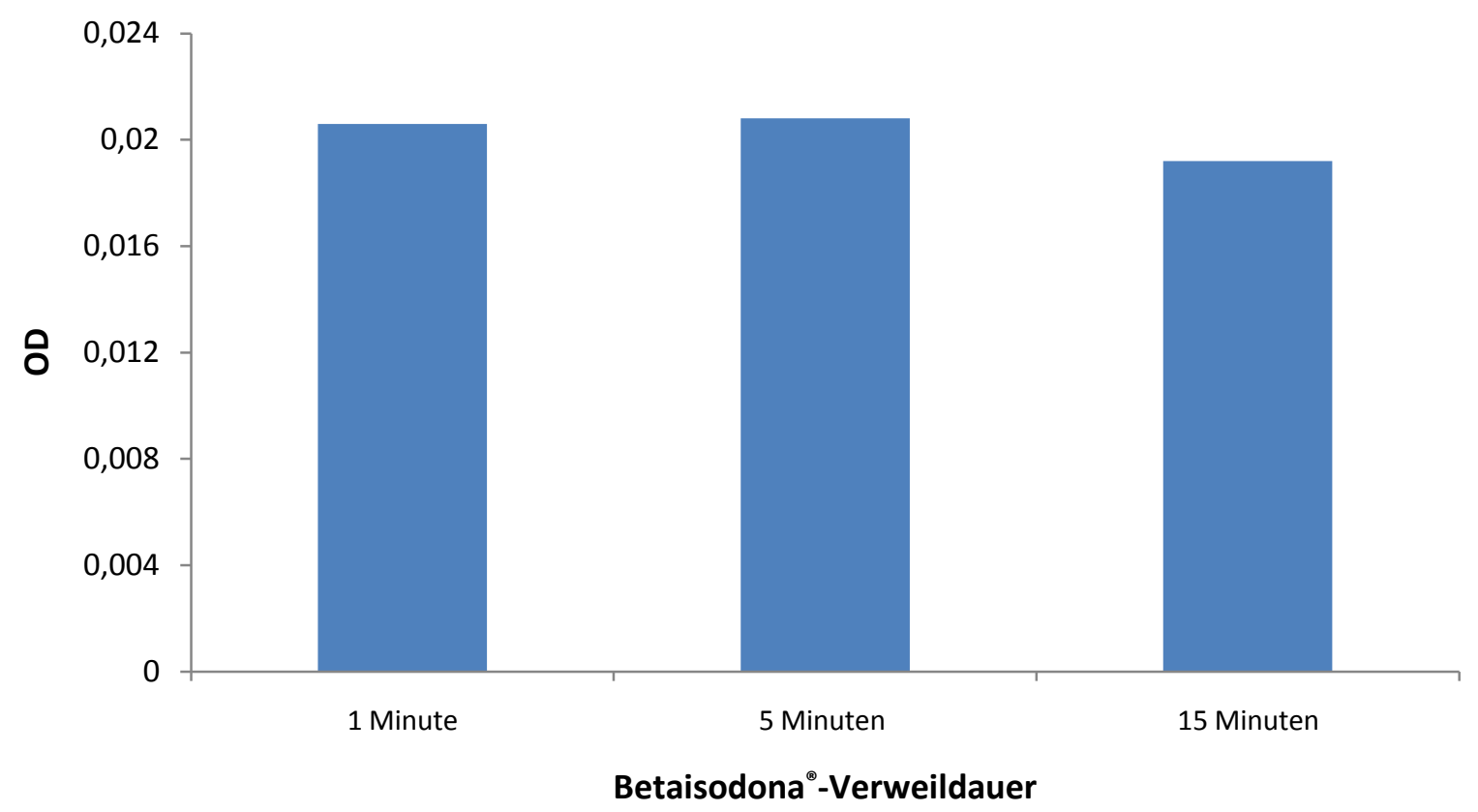

Diagramm 4: Einfluss von Betaisodona ${ }^{\circledR}$-Mundspüllösung auf die HGFIB in Abhängigkeit von der Einwirkzeit

Die Octenidol ${ }^{\circledR}$-Versuche wiesen wiederum eine deutliche Abhängigkeit der metabolischen Fibroblastenaktivität von der Einwirkzeit der Mundspüllösung auf. Die Dauer der Einwirkung von Octenidol ${ }^{\circledR}$ beeinflusste die Zellen negativ (1 Minute: 0,0219 \pm 0,0023 OD; 5 Minuten: 0,0205 $\pm 0,0026$ OD; 15 Minuten: 0,0181 $\pm 0,0018$ OD).

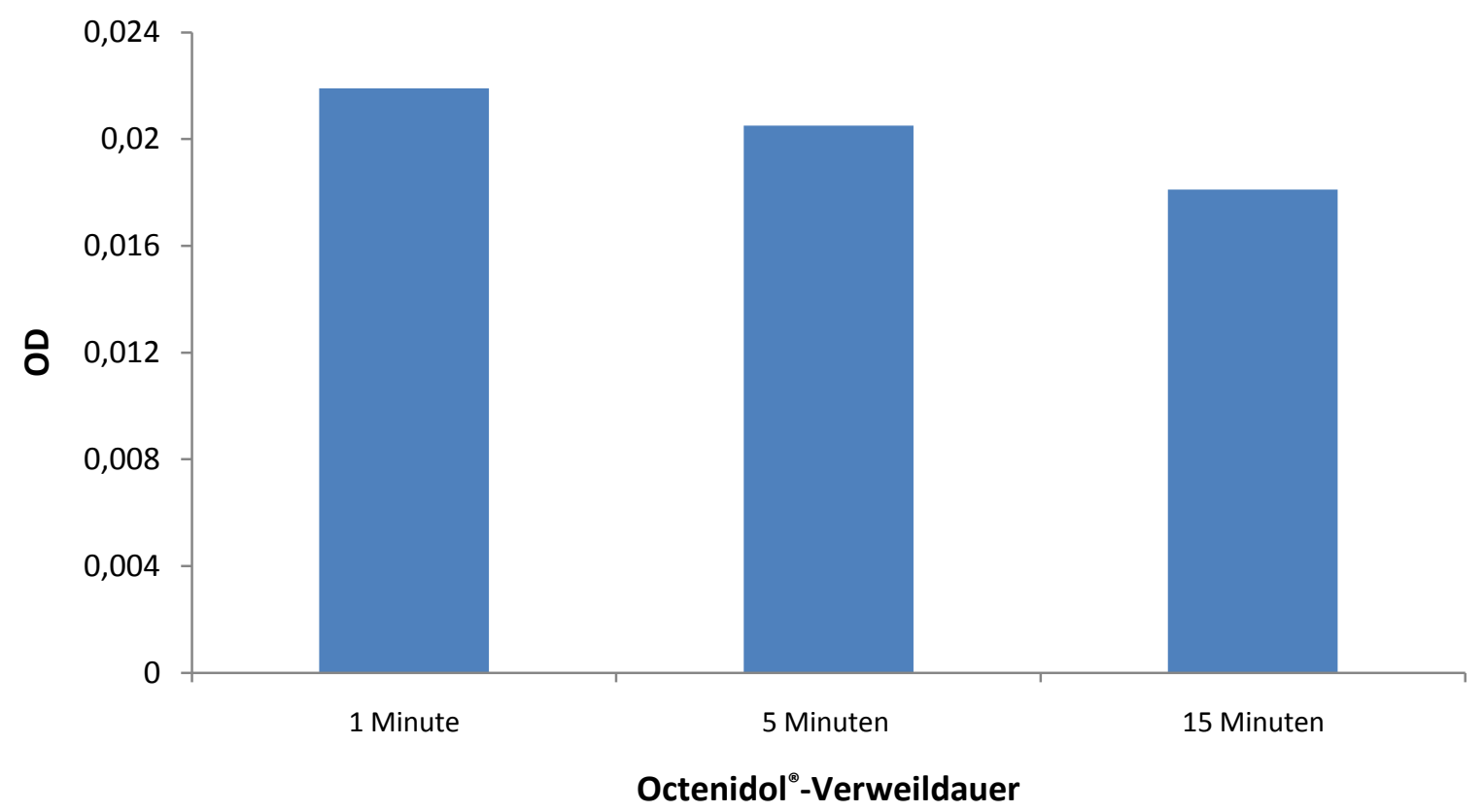

Diagramm 5: Einfluss von Octenidol ${ }^{\circledR}$ auf die HGFIB in Abhängigkeit von der Einwirkzeit 


\subsubsection{Vergleich der Mundspüllösungen untereinander}

Der Vergleich beschreibt die Zellwirkung der einzelnen Mundspüllösungen untereinander bei den unterschiedlichen Einwirkzeiten. Tabelle 3 bietet eine Übersicht aller Vergleiche. Diagramm 6 stellt die entsprechenden Unterschiede zwischen den einzelnen Mundspüllösungen grafisch dar. In der Regel liegen die Messwerte bei den fünf Mundspüllösungen immer niedriger als diejenigen der Kontrollmessungen (Diagramm 6). Außerdem sinken in den meisten Fällen die Messwerte mit zunehmender Einwirkzeit. Ein deutlicher Unterschied zwischen den einzelnen Lösungen in ihrer negativen Wirkung auf HGFIB konnte beim MTT-Test nicht festgestellt werden.

Tabelle 3: Paarweiser Vergleich der Mundspüllösungen in Abhängigkeit von der Einwirkzeit (Signifikanzen)

\begin{tabular}{|c|c|c|c|c|}
\hline & \multicolumn{3}{|c|}{ Einwirkzeit } \\
\hline & & 1 Minute & 5 Minuten & 15 Minuten \\
\hline \multirow{10}{*}{ 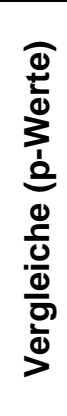 } & $\mathrm{CHX}^{(\Theta)}$ vs. Meridol ${ }^{\Theta}$ & 0,9539 & 0,8137 & 0,4335 \\
\hline & $\mathrm{CHX}^{(\Theta)}$ vs. Listerine ${ }^{(\Theta)}$ & 0,6506 & 0,7890 & 0,4288 \\
\hline & $\mathrm{CHX}^{(\beta)}$ vs. Betaisodona $\left.{ }^{(}\right)$ & 0,7275 & 0,5923 & 0,3971 \\
\hline & $\mathrm{CHX}^{\Theta}$ vs. Octenidol ${ }^{\Theta}$ & 0,3530 & 0,5252 & 0,2738 \\
\hline & Meridol $^{(\Theta}$ vs. Listerine ${ }^{(\Theta}$ & 0,6818 & 0,9783 & 0,9403 \\
\hline & Meridol $^{\otimes}$ vs. Betaisodona ${ }^{\Theta}$ & 0,6977 & 0,4975 & 0,6341 \\
\hline & Meridol $^{\circledR}$ vs. Octenidol ${ }^{\circledR}$ & 0,3145 & 0,4110 & 0,6749 \\
\hline & Listerine $^{(\otimes)}$ Vs. Betaisodona $\left.{ }^{(}\right)$ & 0,5251 & 0,4836 & 0,6676 \\
\hline & Listerine $^{(\Theta)}$ vs. Octenidol ${ }^{(\Theta)}$ & 0,1856 & 0,3919 & 0,7476 \\
\hline & Betaisodona $^{(\Theta}$ vs. Octenidol ${ }^{\Theta}$ & 0,7801 & 0,9451 & 0,8017 \\
\hline
\end{tabular}

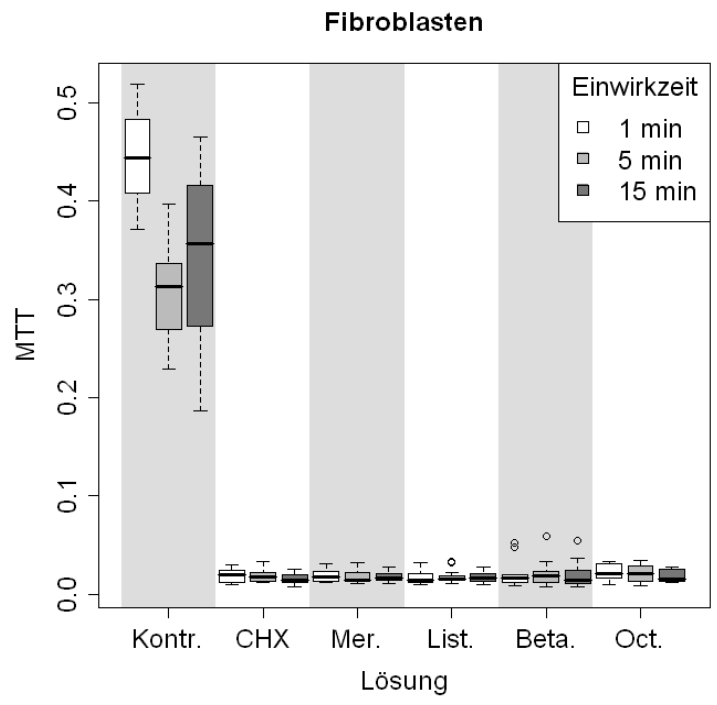

Diagramm 6: Vergleich der Mundspüllösungen in Abhängigkeit von der Einwirkzeit 


\subsubsection{Wechselwirkung}

Bei den Varianzanalysen zeigt sich für alle Messgrößen ein signifikanter Einfluss der Lösungsart sowie der Einwirkzeit (Tab. 4). Eine signifikante Wechselwirkung zwischen Lösungsart und Einwirkzeit war bei den MTT-Messungen für HGFIB zu erkennen, d. h., die Stärke des Lösungseffekts ist je nach Einwirkzeit unterschiedlich ausgeprägt.

Tabelle 4: Einfluss der Lösung sowie der Einwirkzeit auf die Messwerte des MTT-Tests bei den HGFIB

\begin{tabular}{|l|c|}
\hline \multicolumn{1}{|c|}{ Effekt } & p-Wert \\
\hline Lösung & $<0,0001$ \\
\hline Einwirkzeit & 0,0002 \\
\hline Wechselwirkung & $<0,0001$ \\
\hline
\end{tabular}

\subsubsection{Optische Zellzählung mittels Cellometer ${ }^{\mathrm{TM}}$ Auto T4}

Die optische Zellzählung nach dem Prinzip der Trypan-Blau-Färbung wurde parallel zum MTT-Test bei jedem Versuch durchgeführt. Die Anfärbung sowie die Gesamtzellzahlbestimmung der HGFIB geschah vollautomatisch unter Verwendung des Cellometer ${ }^{\mathrm{TM}}$ Auto T4 in einer Zellkammer.

\subsubsection{Ergebnisse der einzelnen Antiseptika nach Einwirkzeiten}

Tabelle 5 zeigt die Mittelwerte mit den dazugehörigen Standardfehlern für die Gesamtzellzahlbestimmung mittels Cellometer ${ }^{\mathrm{TM}}$ Auto T4. Die Zellzahl war nach der Behandlung der Zellen mit den fünf handelsüblichen Mundspüllösungen (CHX 0,2\% ${ }^{\circledR}$, Meridol $^{\circledR}$, Listerine $^{\circledR}$, Betaisodona $^{\circledR}$ und Octenidol $\left.^{\circledR}\right)$ bei allen Versuchsreihen $(1,5$ und 15 Minuten) im Vergleich zur Kontrolle $\left(6,53 \pm 0,32 \times 10^{5}\right.$ Zellen/ml) signifikant reduziert ( $\mathrm{p}<$ $0,0001)$. 
Tabelle 5: Mittelwerte und Standardfehler für die Zellzahlbestimmung (x10 Zellen/ml) nach der Behandlung mit oralen Antiseptika bei Fibroblasten

\begin{tabular}{|c|c|c|c|}
\hline & \multicolumn{3}{|c|}{ Einwirkzeit } \\
\hline Mundspüllösung $^{\mid}$ & 1 Minute & 5 Minuten & 15 Minuten \\
\hline CHX 0,2 \% $^{\circledR}$ & $4,1 \pm 0,12$ & $3,9 \pm 0,08$ & $3,4 \pm 0,07$ \\
\hline Meridol $^{\circledR}$ & $4,2 \pm 0,08$ & $3,9 \pm 0,10$ & $3,7 \pm 0,08$ \\
\hline Listerine $^{\circledR}$ & $3,8 \pm 0,08$ & $3,8 \pm 0,10$ & $3,6 \pm 0,08$ \\
\hline Betaisodona $^{\circledR}$ & $4,6 \pm 0,11$ & $4,5 \pm 0,12$ & $4,2 \pm 0,07$ \\
\hline Octenidol $^{\circledR}$ & $4,8 \pm 0,10$ & $4,6 \pm 0,07$ & $3,9 \pm 0,13$ \\
\hline
\end{tabular}

\subsubsection{Einfluss der Einwirkzeit}

Der Vergleich beschreibt die Auswirkung der antiseptischen Therapie mit verschiedenen Mundspüllösungen auf die HGFIB-Gesamtzellzahl in Abhängigkeit von der Einwirkzeit. Wegen der besseren Übersichtlichkeit werden die Vergleiche in den Diagrammen 7 bis 11 separat ohne Angabe des Standardfehlers dargestellt. Die Standardfehler sind der Tabelle $5 \mathrm{zu}$ entnehmen.

Die CHX-Versuchsreihe weist eine Reduktion der Gesamtzellzahl in Abhängigkeit von der Einwirkzeit der Mundspüllösung auf. Je länger das Antiseptikum auf den Zellen verbleibt, desto weniger Zellen überleben und können schließlich gezählt werden. Während nach einer Minute 4,1 $\pm 0,12 \times 10^{5}$ Zellen/ml identifiziert konnten, wurden nach 5 und 15 Minuten 3,9 \pm $0,08 \times 10^{5}$ und $3,4 \pm 0,07 \times 10^{5}$ Zellen/ml gezählt. 


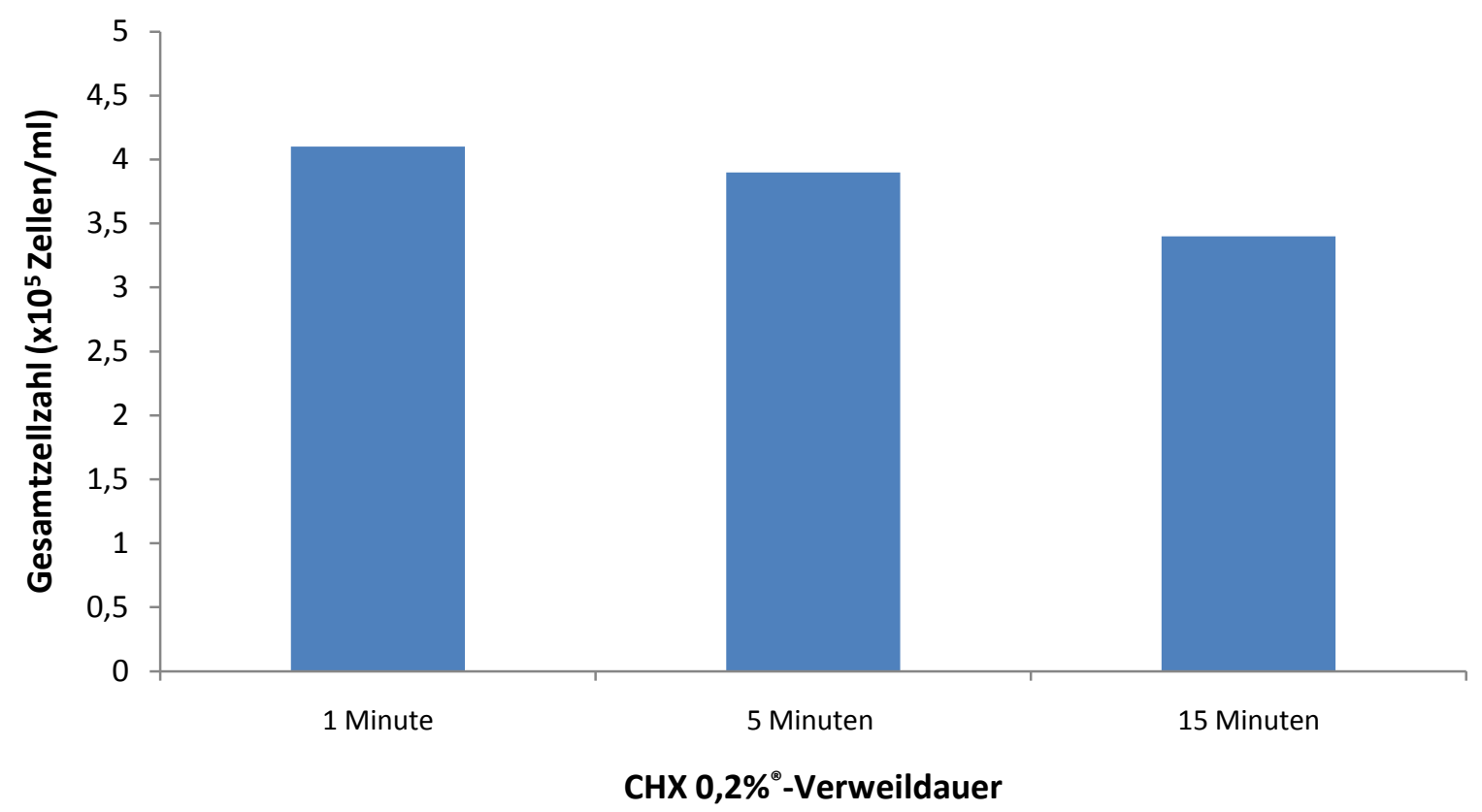

Diagramm 7: Einfluss von CHX $0,2 \%{ }^{\circledR}$-Mundspüllösung auf die Gesamtzellzahl von HGFIB in Abhängigkeit von der Einwirkzeit

Ahnliche Ergebnisse wurden nach der Behandlung der humanen Gingivafibroblasten mit Meridol $^{\circledR}$ erzielt. Nach einer Minute konnten 4,2 $\pm 0,08 \times 10^{5}$ Zellen/ml, nach fünf Minuten $3,9 \pm 0,10 \times 10^{5}$ Zellen/ml und nach 15 Minuten 3,7 $\pm 0,08 \times 10^{5}$ Zellen/ml identifiziert werden.

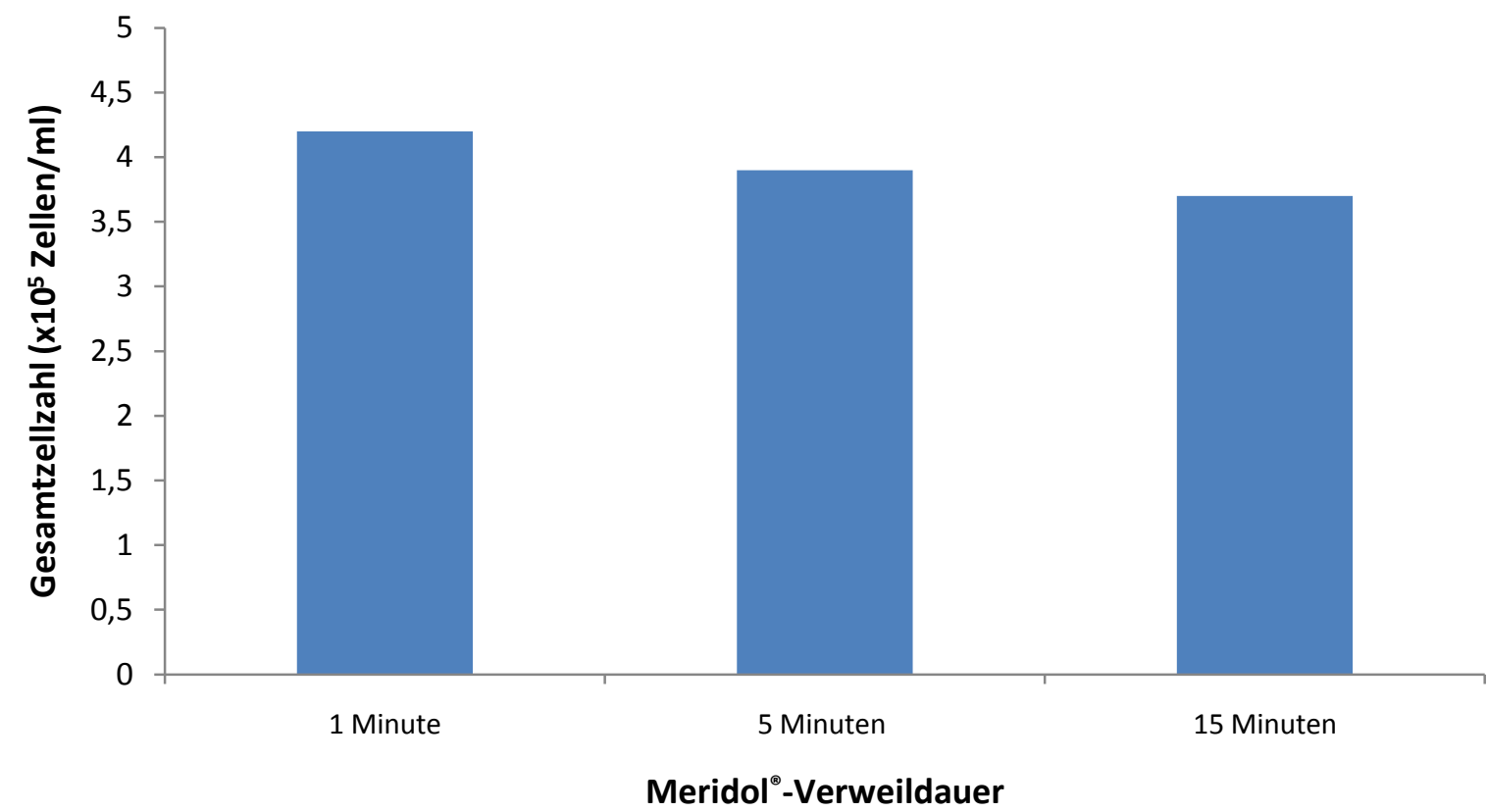

Diagramm 8: Einfluss von Meridol ${ }^{\circledR}$ auf die Gesamtzellzahl von HGFIB in Abhängigkeit von der Einwirkzeit 
Die Bestimmung der Gesamtzellzahlen bei den Versuchen mit der Listerine ${ }^{\circledR}$-Lösung wiesen keine wesentlichen Unterschiede zu den oben dargestellten Experimenten auf. Die Werte nach einer bzw. nach fünf Minuten waren bis auf Standardfehler identisch und betrugen 3,8 \pm 0,08 bzw. 3,8 $\pm 0,10 \times 10^{5}$ Zellen/ml. Nach 15 Minuten Behandlung mit Listerine ${ }^{\circledR}$ war die Anzahl der HGFIB noch niedriger als nach einer bzw. nach fünf Minuten Einwirkzeit $(3,6 \pm 0,08 x$ $10^{5}$ Zellen/ml).

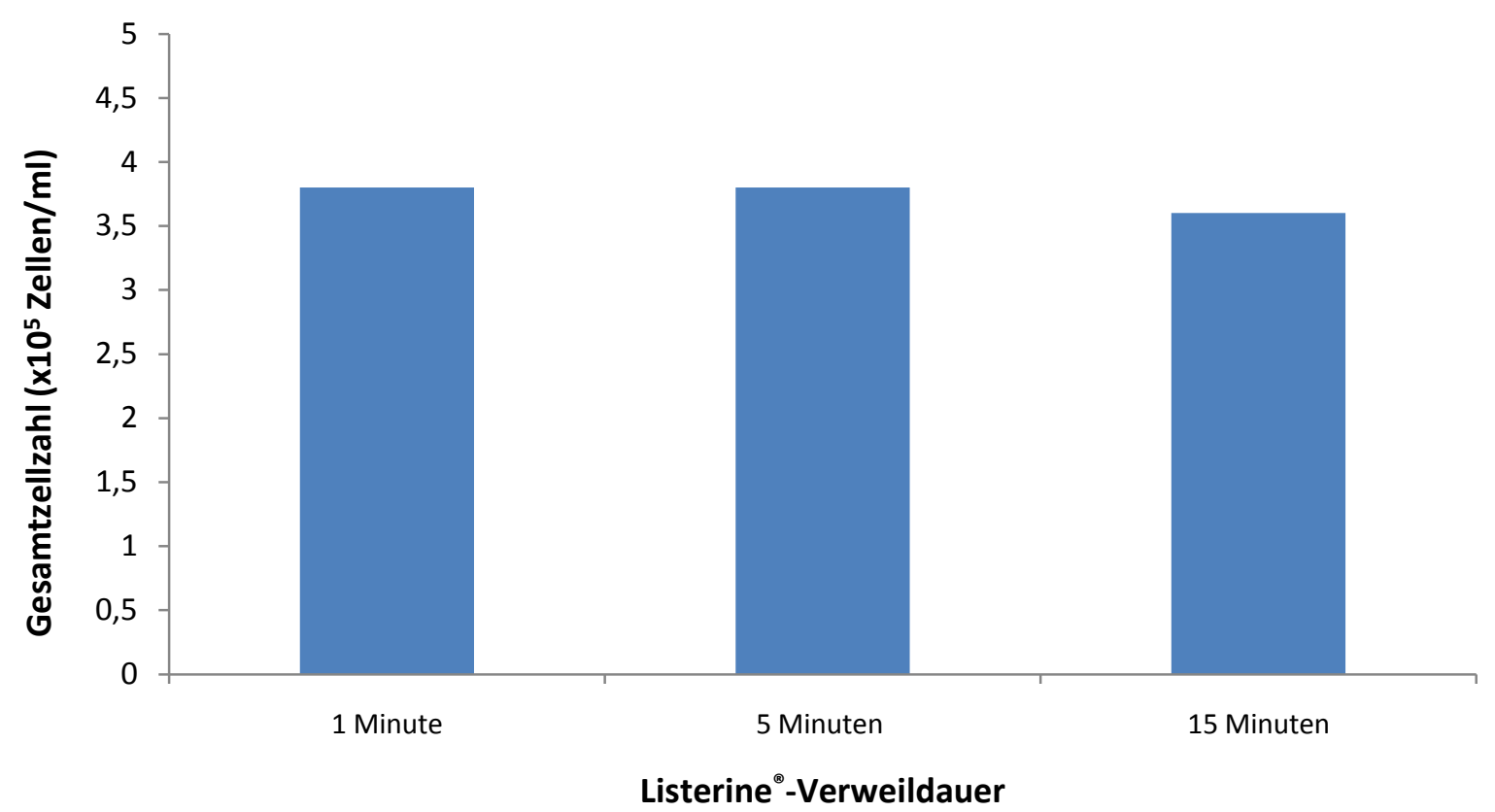

Diagramm 9: Einfluss von Listerine ${ }^{\circledR}$ auf die Gesamtzellzahl von HGFIB in Abhängigkeit von der Einwirkzeit

Während nach einer Minute Einwirkzeit der Betaisodona ${ }^{\circledR}$-Mundspüllösung auf die HGFIB 4,6 $\pm 0,11 \times 10^{5}$ Zellen/ml gezählt wurden, wiesen die 5-Minuten-Proben leicht erniedrigte Gesamtzellzahlen von 4,5 $\pm 0,12 \times 10^{5}$ Zellen/ml auf. Bei den 15-Minuten-Versuchen war eine noch weitere Reduktion der Fibroblastenzahl festzustellen $\left(4,2 \pm 0,07\right.$ x $10^{5}$ Zellen/ml). 


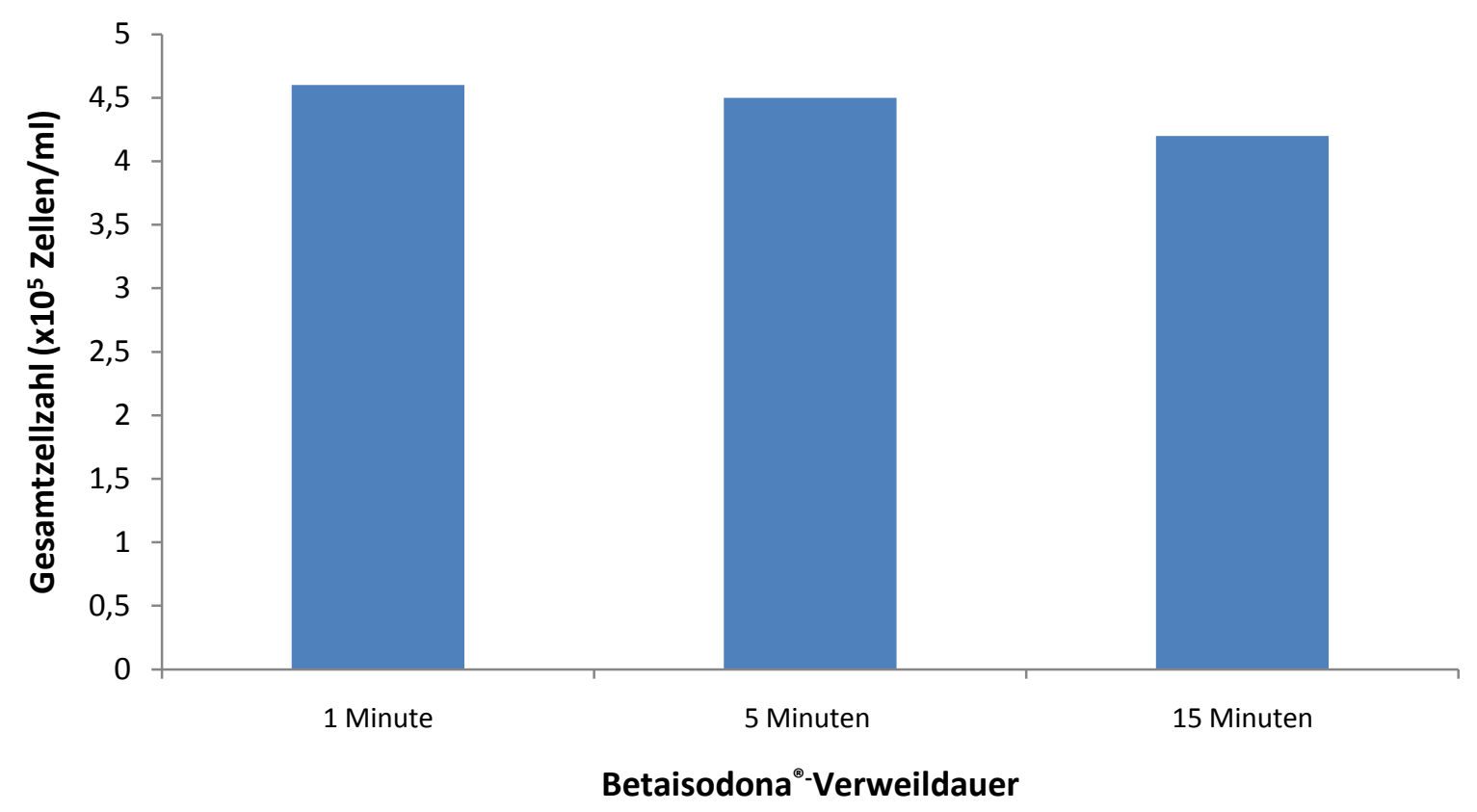

Diagramm 10: Einfluss von Betaisodona ${ }^{\circledR}$ auf die Gesamtzellzahl von HGFIB in Abhängigkeit von der Einwirkzeit

Octenidol $^{\circledR}$ wies wiederum eine deutliche Abhängigkeit der Gesamtzellzahl von der Einwirkzeit der Mundspüllösung auf. Die längere Einwirkzeit von Octenidol ${ }^{\circledR}$ beeinflusste die Zellen negativ ( 1 Minute: 4,8 $\pm 0,10 \times 10^{5}$ Zellen/ml; 5 Minuten: 4,6 $\pm 0,07$ x $10^{5}$ Zellen/ml; 15 Minuten: $3,9 \pm 0,13 \times 10^{5}$ Zellen/ml).

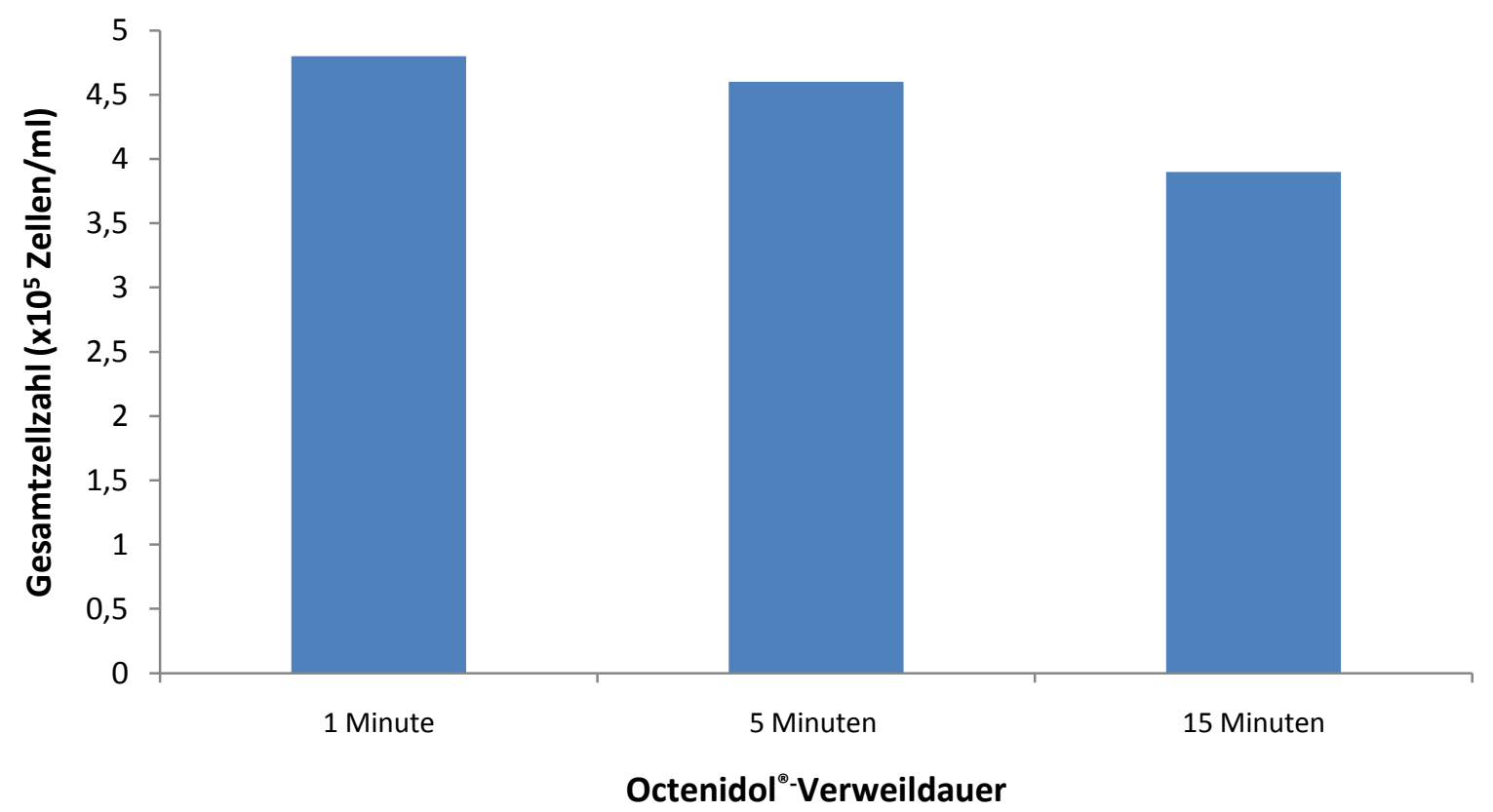

Diagramm 11: Einfluss von Octenidol ${ }^{\circledR}$ auf die Gesamtzellzahl von HGFIB in Abhängigkeit von der Einwirkzeit 


\subsubsection{Vergleich der Mundspüllösungen untereinander}

Der Vergleich beschreibt die Zellwirkung der einzelnen Mundspüllösungen untereinander bei unterschiedlichen Einwirkzeiten. Tabelle 6 bietet eine Übersicht über alle Vergleiche. Diagramm 12 stellt die entsprechenden Unterschiede zwischen den einzelnen Mundspüllösungen grafisch dar.

Die Messwerte bei den fünf untersuchten Mundspüllösungen liegen immer niedriger als bei den Kontrollmessungen (Diagramm 12). Außerdem sinken in den meisten Fällen die Messwerte mit zunehmender Einwirkzeit. Während bei der Anwendung von CHX 0,2 \% ${ }^{\circledR}$, Meridol $^{\circledR}$ und Listerine ${ }^{\circledR}$ die Anzahl der HGFIB unabhängig von der Einwirkzeit deutlich reduziert war, war die negative Wirkung der antiseptischen Therapie mit Betaisodona ${ }^{\circledR}$ und Octenidol $^{\circledR}$ weniger stark ausgeprägt. Die Octenidol ${ }^{\circledR}$-Reihe wies deutlich mehr Zellen bei der optischen Zellzahlbestimmung auf. Listerine ${ }^{\circledR}$ wirkte am negativsten auf die Gesamtzellzahl der humanen Gingivafibroblasten.

Tabelle 6: Paarweiser Vergleich der Mundspüllösungen in Abhängigkeit von der Einwirkzeit (Signifikanzen)

\begin{tabular}{|c|c|c|c|c|}
\hline & \multicolumn{3}{|c|}{ Einwirkzeit } \\
\hline & & 1 Minute & 5 Minuten & 15 Minuten \\
\hline \multirow{10}{*}{ 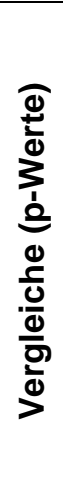 } & $\mathrm{CHX}^{(}{ }^{(}$vs. Meridol ${ }^{\circledR}$ & 0,4902 & 0,7098 & 0,0094 \\
\hline & $\mathrm{CHX}^{(\mathbb{B}}$ vs. Listerine $\left.{ }^{(}\right)$ & 0,0883 & 0,5159 & 0,2518 \\
\hline & $\mathrm{CHX}^{(}$vs. Betaisodona ${ }^{\circledR}$ & 0,0014 & 0,0003 & 0,0000 \\
\hline & $\mathrm{CHX}^{(}{ }^{\text {vs. Octenidol }}{ }^{\circledR}$ & 0,0001 & 0,0000 & 0,0063 \\
\hline & Meridol $\left.^{(}\right)$vs. Listerine ${ }^{\circledR}$ & 0,0042 & 0,3613 & 0,1228 \\
\hline & Meridol $^{\circledR}$ vs. Betaisodona ${ }^{\circledR}$ & 0,0018 & 0,0011 & 0,0006 \\
\hline & Meridol $\left.^{(}\right)$vs. Octenidol ${ }^{(\circledR)}$ & 0,0000 & 0,0000 & 0,3610 \\
\hline & Listerine ${ }^{\circledR}$ vs. Betaisodona ${ }^{\circledR}$ & 0,0000 & 0,0001 & 0,0000 \\
\hline & Listerine $^{(\circledR)}$ vs. Octenidol ${ }^{(}$ & 0,0000 & 0,0000 & 0,0432 \\
\hline & Betaisodona $^{(B)}$ vs. Octenidol ${ }^{(B)}$ & 0,2730 & 0,7260 & 0,0607 \\
\hline
\end{tabular}




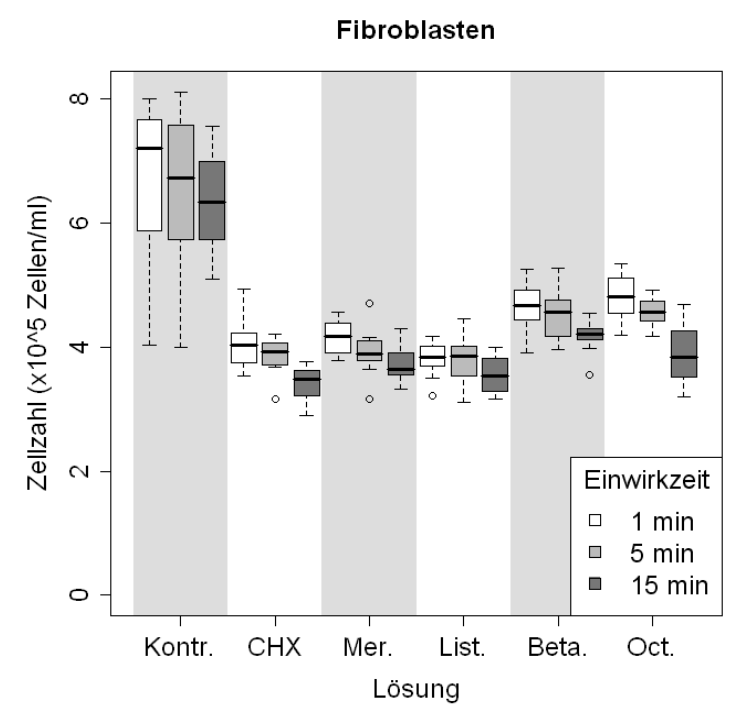

Diagramm 12: Vergleich der Mundspüllösungen in Abhängigkeit von der Einwirkzeit

\subsubsection{Wechselwirkung}

In den Varianzanalysen zeigt sich für alle Messgrößen ein signifikanter Einfluss der Lösungsart sowie der Einwirkzeit (Tab. 7). Eine signifikante Wechselwirkung zwischen Lösungsart und Einwirkzeit war bei der Zellzahlbestimmung nicht zu erkennen, d. h., die Stärke des Lösungseffekts war je nach Einwirkzeit gleich ausgeprägt.

Tabelle 7: Einfluss der Lösung sowie der Einwirkzeit auf die Messwerte bei der optischen Zellzahlbestimmung mittels Cellometer ${ }^{\mathrm{TM}}$ Auto T4 bei den HGFIB

\begin{tabular}{|l|c|}
\hline \multicolumn{1}{|c|}{ Effekt } & p-Wert \\
\hline Lösung & $<0,0001$ \\
\hline Einwirkzeit & $<0,0001$ \\
\hline Wechselwirkung & 0,7337 \\
\hline
\end{tabular}

\subsubsection{Bestimmung der Viabilität}

Die Bestimmung der Viabilität von primären humanen Gingivafibroblasten, d. h. der Anzahl der lebenden Zellen im Verhältnis zu den toten Zellen, wurde parallel zur optischen Zellzählung mithilfe des Cellometer ${ }^{\mathrm{TM}}$ Auto T4 durchgeführt. Das Gerät erlaubt die gleichzeitige Bestimmung beider Parameter ohne zusätzlichen Aufwand. 


\subsubsection{Ergebnisse der einzelnen Antiseptika nach Einwirkzeiten}

In Tabelle 8 sind die Mittelwerte mit den dazugehörigen Standardfehlern für die Viabilitätsbestimmung mittels Cellometer ${ }^{\mathrm{TM}}$ Auto T4 angegeben. Die Viabilität der HGFIB war nach der Behandlung der Zellen mit den fünf handelsüblichen Mundspüllösungen (CHX $0,2 \%{ }^{\circledR}$, Meridol ${ }^{\circledR}$, Listerine ${ }^{\circledR}$, Betaisodona ${ }^{\circledR}$ und Octenidol $\left.{ }^{\circledR}\right)$ bei allen Versuchsreihen $(1,5$ und 15 Minuten) im Vergleich zur Kontrolle $(95,6 \pm 0,5 \%)$ signifikant reduziert ( $\mathrm{p}<0,0001)$.

Tabelle 8: Mittelwerte und Standardfehler für die Viabilitätsbestimmung (in \%) nach der Behandlung mit den oralen Antiseptika beim Zelltyp Fibroblasten

\begin{tabular}{|c|c|c|c|}
\hline & \multicolumn{3}{|c|}{ Einwirkzeit } \\
\hline Mundspüllösung & 1 Minute & 5 Minuten & 15 Minuten \\
\hline CHX 0,2 \% ${ }^{\circledR}$ & $76,1 \pm 0,8$ & $73,1 \pm 0,8$ & $63,7 \pm 0,8$ \\
\hline Meridol $^{\circledR}$ & $76,1 \pm 0,8$ & $71,9 \pm 1,6$ & $62,5 \pm 1,5$ \\
\hline Listerine $^{\circledR}$ & $75,9 \pm 0,8$ & $72,8 \pm 1,6$ & $65,3 \pm 1,2$ \\
\hline Betaisodona $^{\circledR}$ & $79,9 \pm 1,5$ & $76,2 \pm 1,1$ & $70,7 \pm 0,5$ \\
\hline Octenidol $^{\circledR}$ & $80,0 \pm 1,6$ & $76,6 \pm 1,2$ & $68,3 \pm 1,6$ \\
\hline
\end{tabular}

\subsubsection{Einfluss der Einwirkzeit}

Der Vergleich beschreibt die Auswirkung der antiseptischen Therapie mit verschiedenen Mundspüllösungen auf die Viabilität von HGFIB in Abhängigkeit von der Einwirkzeit. Wegen der besseren Übersichtlichkeit werden die Vergleiche in den Diagrammen 13 bis 17 separat ohne Angabe des Standardfehlers dargestellt. Die Standardfehler sind der Tabelle $8 \mathrm{zu}$ entnehmen.

Die $\mathrm{CHX}^{\circledR}$-Versuchsreihe weist eine Reduktion der Viabilität in Abhängigkeit von der Einwirkzeit der Mundspüllösung auf. Je länger das Antiseptikum auf den Zellen verbleibt, desto weniger Zellen überleben und desto kleiner wird das Verhältnis von lebenden zu toten Zellen. Während nach einer Minute 76,1 $\pm 0,8 \%$ der Fibroblasten vital bleiben, ist eine Viabilität von $73,1 \pm 0,8 \%$ nach 5 Minuten bzw. von $63,7 \pm 0,8 \%$ nach 15 Minuten zu verzeichnen. 


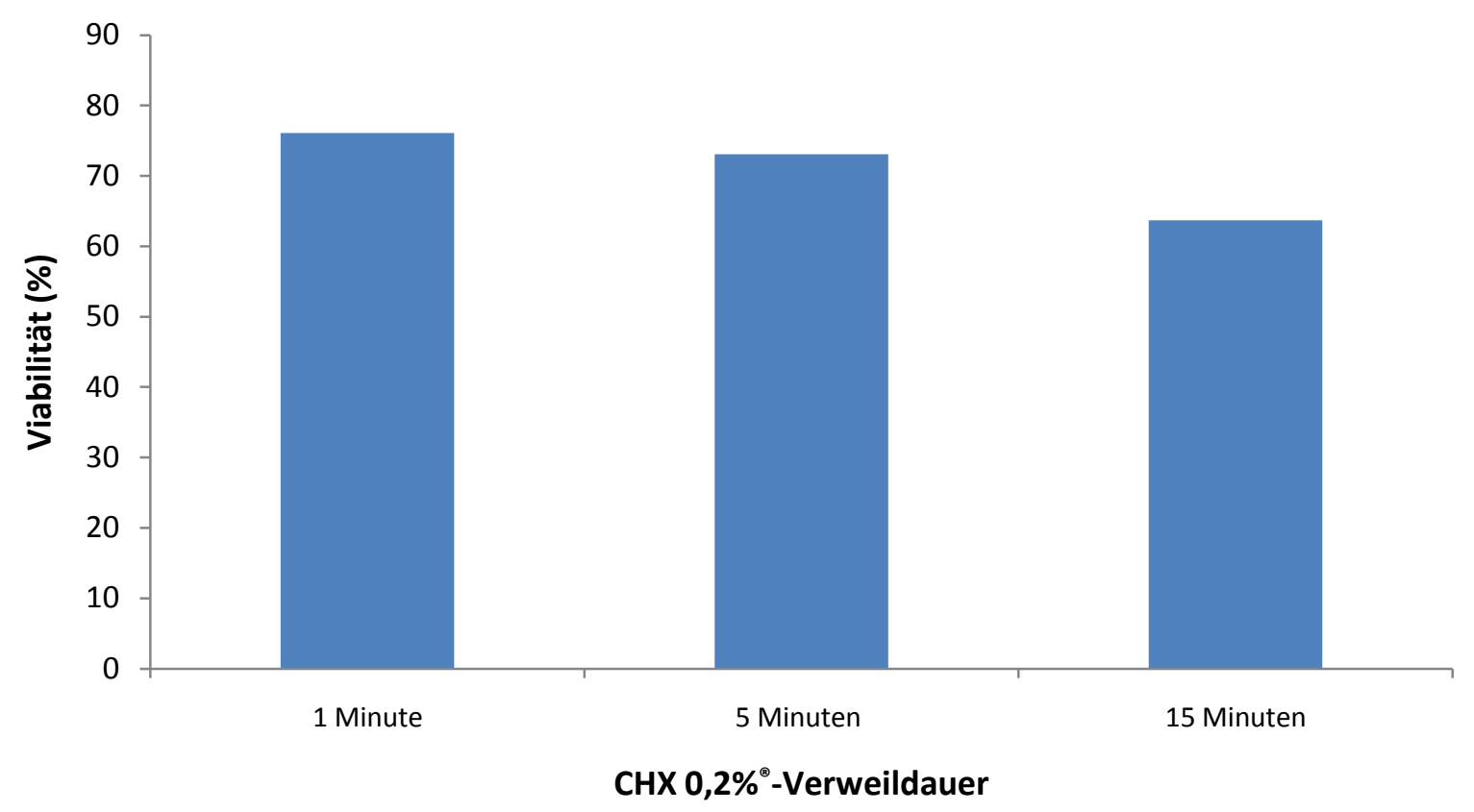

Diagramm 13: Einfluss von $\mathrm{CHX}^{\circledR}$ auf die Viabilität von HGFIB in Abhängigkeit von der Einwirkzeit

Ähnliche Ergebnisse wurden nach der Behandlung der humanen Gingivafibroblasten mit Meridol $^{\circledR}$ erzielt. Nach einer Minute konnten 76,1 $\pm 0,8 \%$, nach fünf Minuten 71,9 $\pm 1,6 \%$ und nach 15 Minuten $62,5 \pm 1,5 \%$ vitale Zellen identifiziert werden.

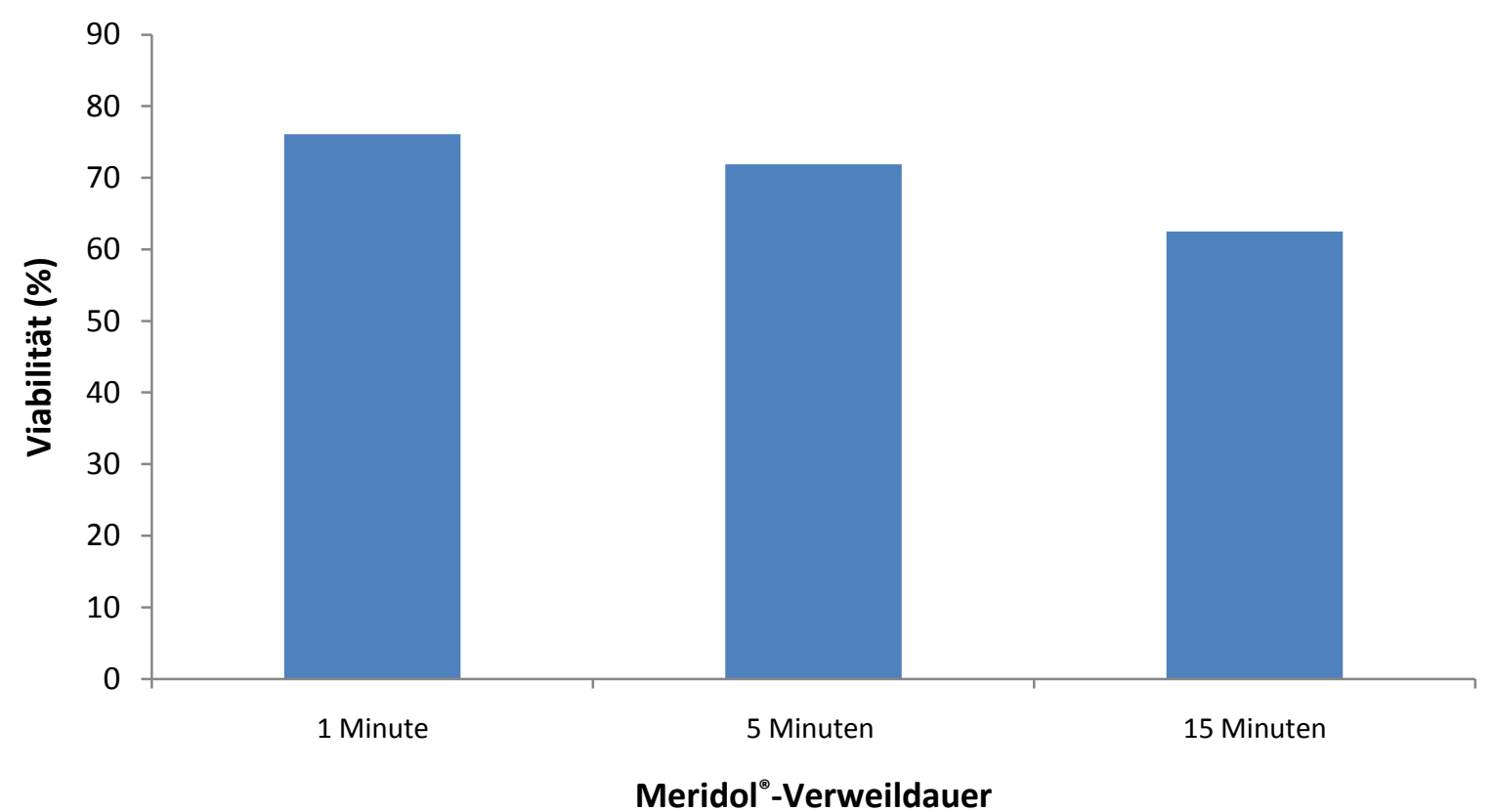

Diagramm 14: Einfluss von Meridol ${ }^{\circledR}$ auf die Viabilität von HGFIB in Abhängigkeit von der Einwirkzeit 
Die Viabilitätsbestimmungen bei den Versuchen mit der Listerine ${ }^{\circledR}$-Lösung wiesen keine wesentlichen Unterschiede zu den oben gezeigten Experimenten auf. Die Werte für eine Minute betrugen 75,9 \pm 0,8 \% und für 5 Minuten 72,8 $\pm 1,6 \%$ der Zellen. Nach 15-minütiger Behandlung mit Listerine ${ }^{\circledR}$ war die Viabilität der HGFIB noch niedriger als nach einer bzw. fünf Minuten Einwirkzeit (65,3 \pm 1,2 \% der Zellen).

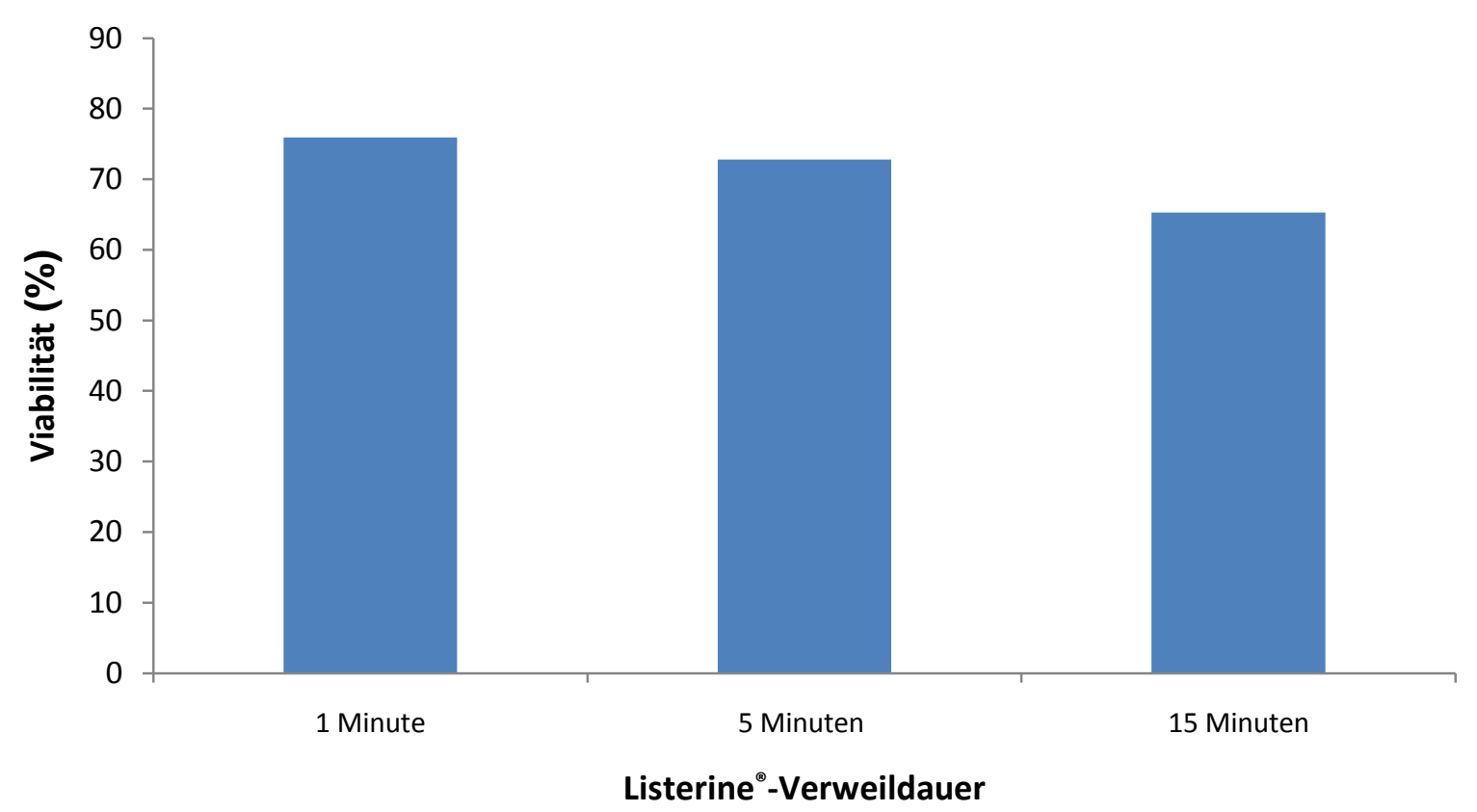

Diagramm 15: Einfluss von Listerine ${ }^{\circledR}$ auf die Viabilität von HGFIB in Abhängigkeit von der Einwirkzeit

Während nach einer Minute Einwirkzeit der Betaisodona ${ }^{\circledR}$-Mundspüllösung auf die HGFIB eine Viabilität von 79,9 $\pm 1,5 \%$ bestimmt wurde, wiesen die 5-Minuten-Proben eine leicht erniedrigte Anzahl von lebenden Fibroblasten (76,2 $\pm 1,1 \%)$ auf. Bei den 15-MinutenVersuchen war eine noch weitere Reduktion der Viabilität festzustellen $(70,7 \pm 0,5 \%)$. 


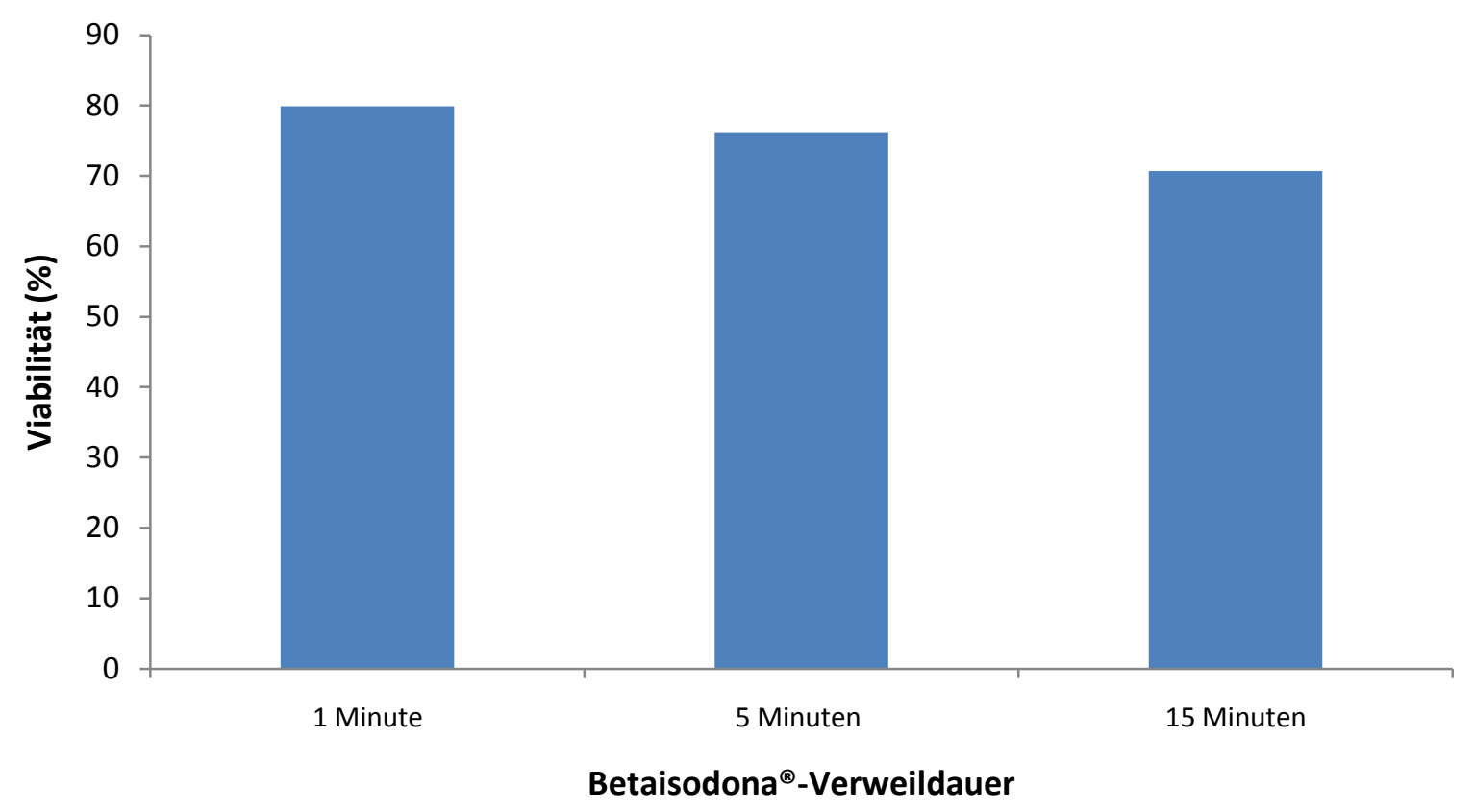

Diagramm 16: Einfluss von Betaisodona ${ }^{\circledR}$ auf die Viabilität von HGFIB in Abhängigkeit von der Einwirkzeit

Die Octenidol ${ }^{\circledR}$-Versuchsreihe wies wiederum eine deutliche Abhängigkeit der Viabilität von der Einwirkzeit der Mundspüllösung auf. Die längere Einwirkzeit von Octenido ${ }^{\circledR}$ beeinflusste die Zellen negativ (1 Minute: 80,0 \pm 1,6\%; 5 Minuten: 76,6 $\pm 1,2 \%$; 15 Minuten: 68,3 \pm $1,6 \%)$.

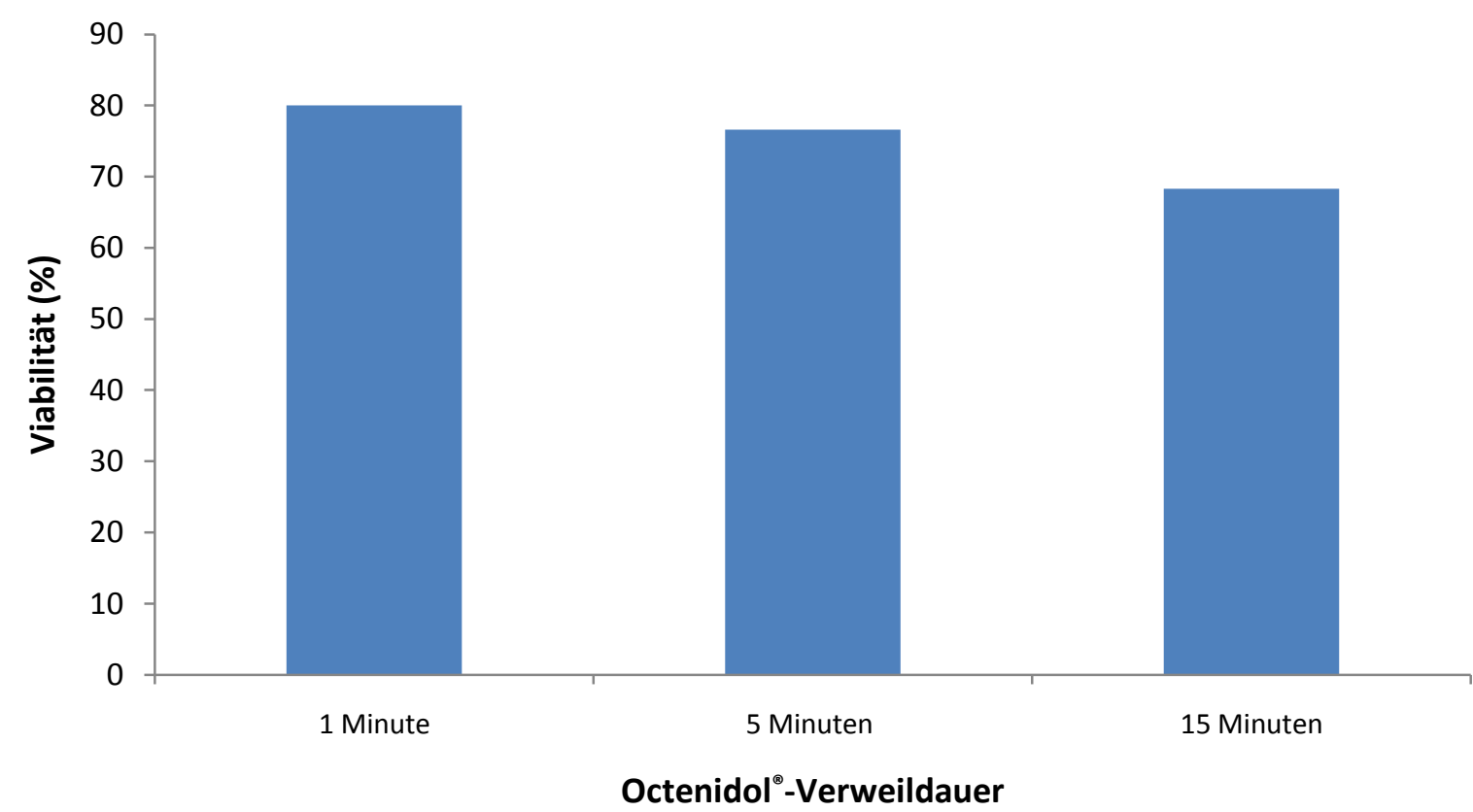

Diagramm 17: Einfluss von Octenidol ${ }^{\circledR}$ auf die Viabilität von HGFIB in Abhängigkeit von der Einwirkzeit 


\subsubsection{Vergleich der Mundspüllösungen untereinander}

Dieser Vergleich beschreibt die Zellwirkung der einzelnen Mundspüllösungen untereinander bei unterschiedlichen Einwirkzeiten. Tabelle 9 gibt eine Übersicht über alle Vergleiche. Diagramm 18 stellt die entsprechenden Unterschiede zwischen den einzelnen Mundspüllösungen grafisch dar.

In der Regel liegen die Messwerte bei den fünf Mundspüllösungen immer niedriger als diejenigen der Kontrollmessungen (Diagramm 18). Außerdem sinken in den meisten Fällen die Messwerte mit zunehmender Einwirkzeit. Wie auch bei den Gesamtzellzahlbestimmung war die Viabilität der HGFIB bei der Anwendung von CHX 0,2 \% ${ }^{\circledR}$, Meridol ${ }^{\circledR}$ und Listerine ${ }^{\circledR}$ unabhängig von der Einwirkzeit deutlich reduziert. Die negative Wirkung der antiseptischen Therapie mittels Betaisodona ${ }^{\circledR}$ und Octenidol ${ }^{\circledR}$ war weniger stark ausgeprägt. Die Octenidol ${ }^{\circledR}$ Reihe wies deutlich mehr vitale Zellen im Vergleich zu den anderen Mundspüllösungen auf.

Tabelle 9: Paarweiser Vergleich der Mundspüllösungen in Abhängigkeit von der Einwirkzeit (Signifikanzen)

\begin{tabular}{|c|c|c|c|c|}
\hline & \multicolumn{3}{|c|}{ Einwirkzeit } \\
\hline & & 1 Minute & 5 Minuten & 15 Minuten \\
\hline \multirow{10}{*}{ 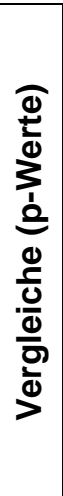 } & $\mathrm{CHX}^{(B}$ vs. Meridol ${ }^{\circledR}$ & 0,9943 & 0,5182 & 0,4763 \\
\hline & $\mathrm{CHX}^{(}{ }^{(}$vs. Listerine $\left.{ }^{(}\right)$ & 0,8343 & 0,8699 & 0,2743 \\
\hline & $\mathrm{CHX}^{(B)}$ vs. Betaisodona ${ }^{(B)}$ & 0,0350 & 0,0320 & 0,0000 \\
\hline & $\mathrm{CHX}^{(\circledR}$ vs. Octenidol ${ }^{\circledR}$ & 0,0492 & 0,0251 & 0,0175 \\
\hline & Meridol $^{\circledR}$ vs. Listerine ${ }^{\circledR}$ & 0,8327 & 0,7038 & 0,1556 \\
\hline & Meridol $^{(}$vs. Betaisodona $\left.{ }^{(}\right)$ & 0,0369 & 0,0366 & 0,0001 \\
\hline & Meridol $^{(\mathbb{R}}$ vs. Octenidol $\left.^{(}\right)$ & 0,0512 & 0,0280 & 0,0133 \\
\hline & Listerine $^{(B)}$ vs. Betaisodona ${ }^{(B)}$ & 0,0267 & 0,0945 & 0,0010 \\
\hline & Listerine $^{(}$vs. Octenidol ${ }^{\circledR}$ & 0,0386 & 0,0727 & 0,1468 \\
\hline & Betaisodona $\left.^{(}\right)$vs. Octenidol $\left.{ }^{(}\right)$ & 0,9820 & 0,8180 & 0,1622 \\
\hline
\end{tabular}




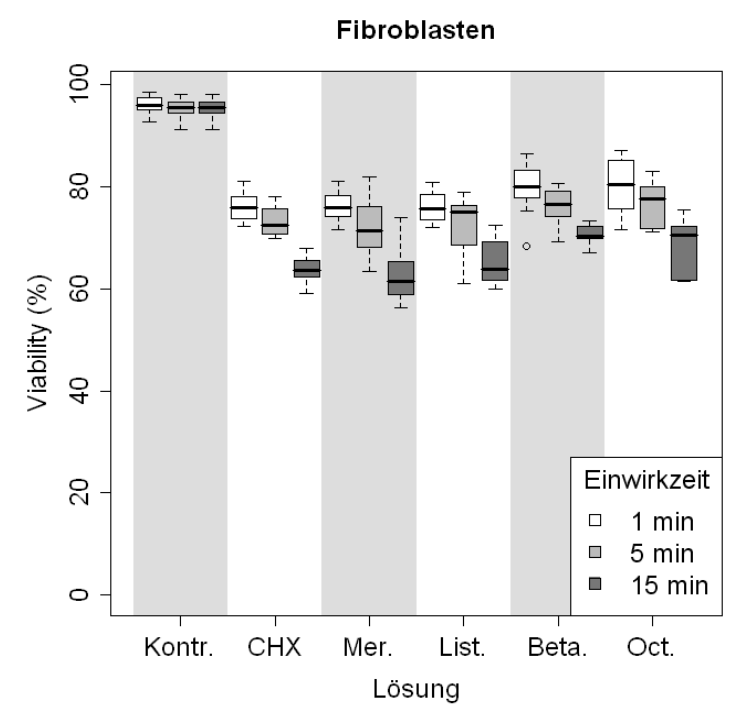

Diagramm 18: Vergleich der Mundspüllösungen in Abhängigkeit von der Einwirkzeit

\subsubsection{Wechselwirkung}

In den Varianzanalysen zeigt sich für alle Messgrößen ein signifikanter Einfluss der Lösungsart sowie der Einwirkzeit (Tab. 10). Eine signifikante Wechselwirkung zwischen Lösungsart und Einwirkzeit war bei Viabilitätsbestimmung zu erkennen, d. h., die Stärke des Lösungseffekts war je nach Einwirkzeit unterschiedlich ausgeprägt.

Tabelle 10: Einfluss der Lösung sowie der Einwirkzeit auf die Messwerte bei der Viabilitätsbestimmung mittels Cellometer ${ }^{\mathrm{TM}}$ Auto T4 bei den HGFIB

\begin{tabular}{|l|c|}
\hline \multicolumn{1}{|c|}{ Effekt } & p-Wert \\
\hline Lösung & $<0,0001$ \\
\hline Einwirkzeit & $<0,0001$ \\
\hline Wechselwirkung & $<0,0001$ \\
\hline
\end{tabular}

\subsubsection{Durchmesser der HGFIB nach Antiseptikabehandlung}

Die Bestimmung der mittleren Zelldurchmesser von primären humanen Gingivafibroblasten wurde parallel zur optischen Zellzählung bzw. Viabilitätsbestimmung mit dem Cellometer ${ }^{\mathrm{TM}}$ Auto T4 durchgeführt. Das Gerät erlaubt die gleichzeitige Bestimmung aller drei Parameter ohne zusätzlichen Aufwand. 


\subsubsection{Ergebnisse der einzelnen Antiseptika nach Einwirkzeiten}

Tabelle 11 gibt die Mittelwerte mit den dazugehörigen Standardfehlern für die Bestimmung des mittleren Zelldurchmessers mittels Cellometer ${ }^{\mathrm{TM}}$ Auto T4 an. Der Durchmesser der HGFIB war nach der Behandlung der Zellen mit den fünf handelsüblichen Mundspüllösungen $\left(\right.$ CHX 0,2 \% ${ }^{\circledR}$, Meridol $^{\circledR}$, Listerine ${ }^{\circledR}$, Betaisodona ${ }^{\circledR}$ und Octenidol $\left.{ }^{\circledR}\right)$ bei allen Versuchsreihen (1, 5 und 15 Minuten) im Vergleich zur Kontrolle (19,93 \pm 0,15 micron) signifikant reduziert $(\mathrm{p}<0,0001)$.

Tabelle 11: Mittelwerte und Standardfehler für die Bestimmung des mittleren Zelldurchmessers (in micron) nach der Behandlung mit den oralen Antiseptika beim Zelltyp Fibroblasten

\begin{tabular}{|c|c|c|c|}
\hline & \multicolumn{3}{|c|}{ Einwirkzeit } \\
\hline Mundspüll̈̈̈sung & 1 Minute & 5 Minuten & 15 Minuten \\
\hline CHX 0,2 \% $^{\circledR}$ & $16,8 \pm 0,20$ & $16,4 \pm 0,15$ & $15,8 \pm 0,10$ \\
\hline Meridol $^{\circledR}$ & $17,0 \pm 0,12$ & $16,5 \pm 0,12$ & $15,9 \pm 0,14$ \\
\hline Listerine $^{\circledR}$ & $16,8 \pm 0,09$ & $16,6 \pm 0,13$ & $16,0 \pm 0,13$ \\
\hline Betaisodona $^{\circledR}$ & $17,8 \pm 0,14$ & $17,6 \pm 0,14$ & $17,1 \pm 0,12$ \\
\hline Octenidol $^{\circledR}$ & $18,0 \pm 0,11$ & $17,6 \pm 0,10$ & $16,9 \pm 0,13$ \\
\hline
\end{tabular}

\subsubsection{Einfluss der Einwirkzeit}

Der Vergleich beschreibt die Auswirkung der antiseptischen Therapie mit verschiedenen Mundspüllösungen auf den mittleren Durchmesser der HGFIB in Abhängigkeit von der Einwirkzeit. Wegen der besseren Übersichtlichkeit werden die Vergleiche in den Diagrammen 19 bis 23 separat ohne Angabe des Standardfehlers dargestellt. Die Standardfehler sind der Tabelle $11 \mathrm{zu}$ entnehmen.

Die $\mathrm{CHX}^{\circledR}$-Versuchsreihe weist eine Reduktion des mittleren Zelldurchmessers in Abhängigkeit von der Einwirkzeit der Mundspüllösung auf. Je länger das Antiseptikum auf den Zellen verbleibt, desto kleiner werden die Fibroblasten im Durchmesser. Während nach einer Minute der Durchmesser der HGFIB im Durchschnitt 16,8 \pm 0,20 micron betrug, betrug er nach fünf Minuten 16,4 $\pm 0,15$ micron und nach 15 Minuten 15,8 $\pm 0,10$ micron. 


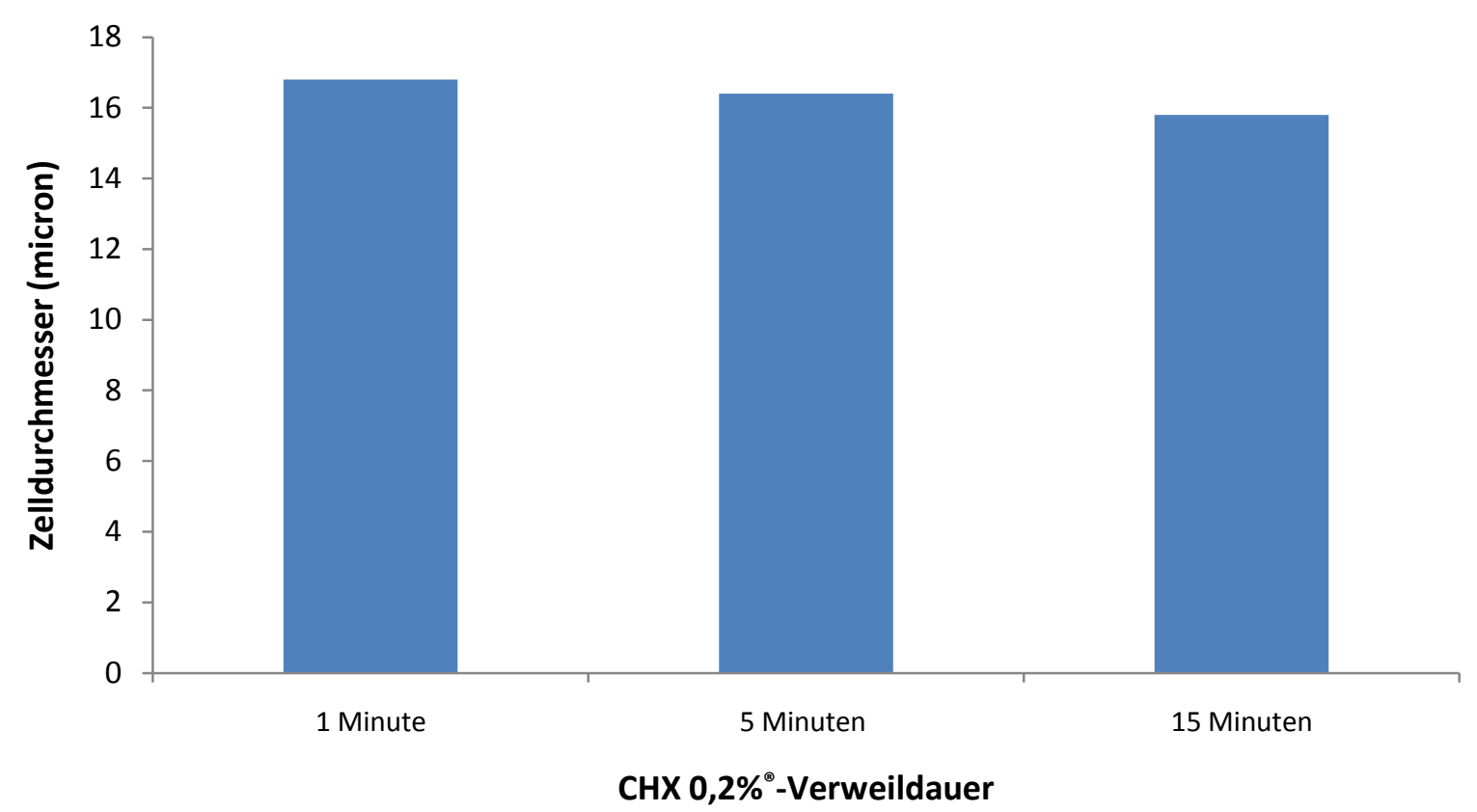

Diagramm 19: Einfluss von CHX $0,2 \%{ }^{\circledR}$ auf den mittleren Durchmesser der HGFIB in Abhängigkeit von der Einwirkzeit

Ähnliche Ergebnisse wurden nach der Behandlung der humanen Gingivafibroblasten mit Meridol $^{\circledR}$ erzielt. Nach einer Minute Einwirkzeit von Meridol ${ }^{\circledR}$ konnte ein Zelldurchmesser von 17,0 \pm 0,12 micron gemessen werden, nach fünf Minuten von 16,5 $\pm 0,12$ micron und nach 15 Minuten von 15,9 $\pm 0,14$ micron.

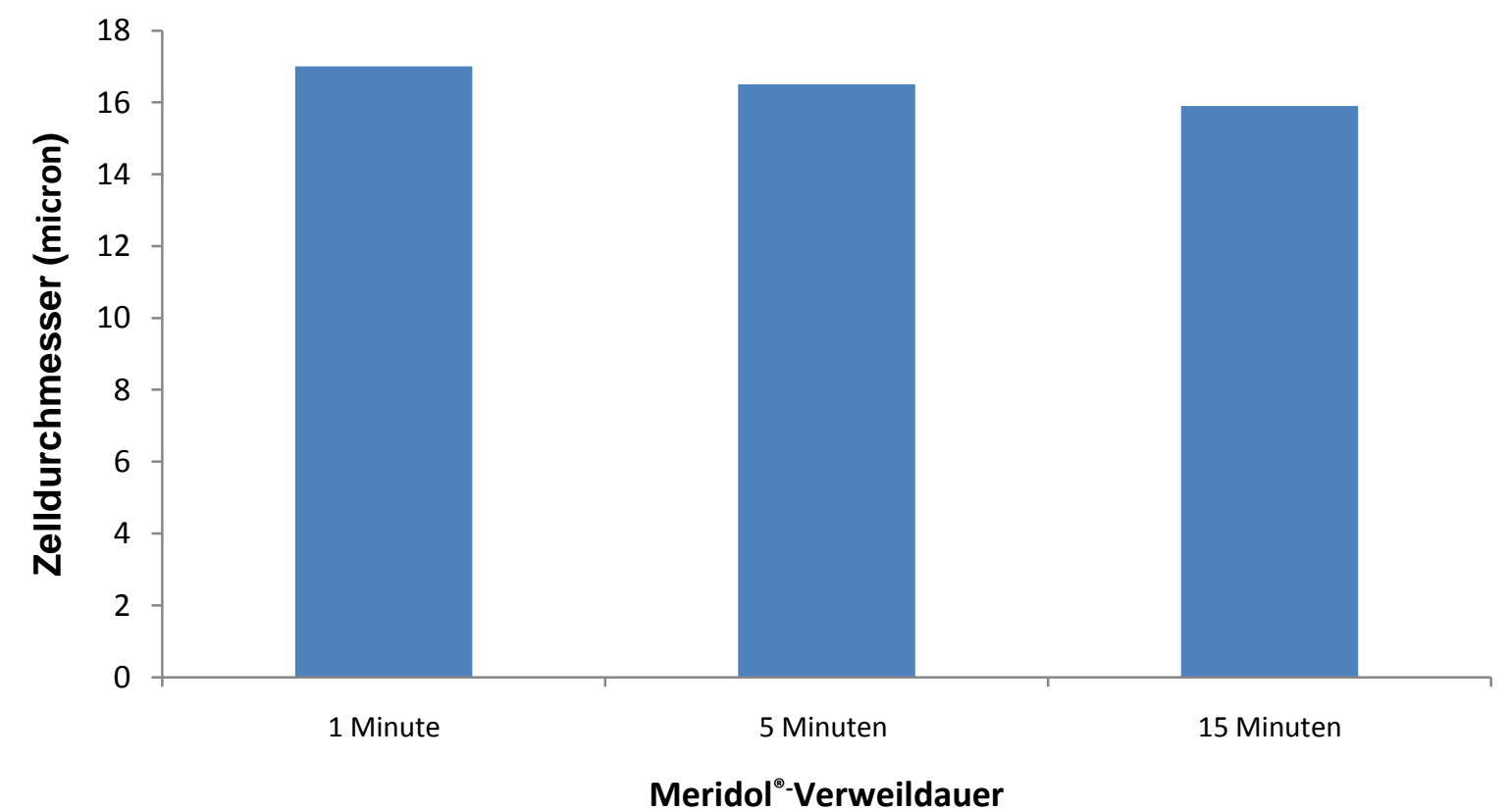

Diagramm 20: Einfluss von Meridol ${ }^{\circledR}$ auf den mittleren Zelldurchmesser der HGFIB in Abhängigkeit von der Einwirkzeit 
Die Bestimmungen des mittleren Zelldurchmessers bei den Versuchen mit der Listerine ${ }^{\circledR}$ Lösung wiesen keine wesentlichen Unterschiede zu den oben gezeigten Experimenten auf. Der Wert betrug nach einer Minute 16,8 \pm 0,09 micron, nach fünf Minuten lag er bei 16,6 \pm 0,13 micron. Nach 15-minütiger Behandlung mit Listerine ${ }^{\circledR}$ war der mittlere Zelldurchmesser der HGFIB noch niedriger als nach einer bzw. fünf Minuten Einwirkzeit (16,0 $\pm 0,13$ micron).

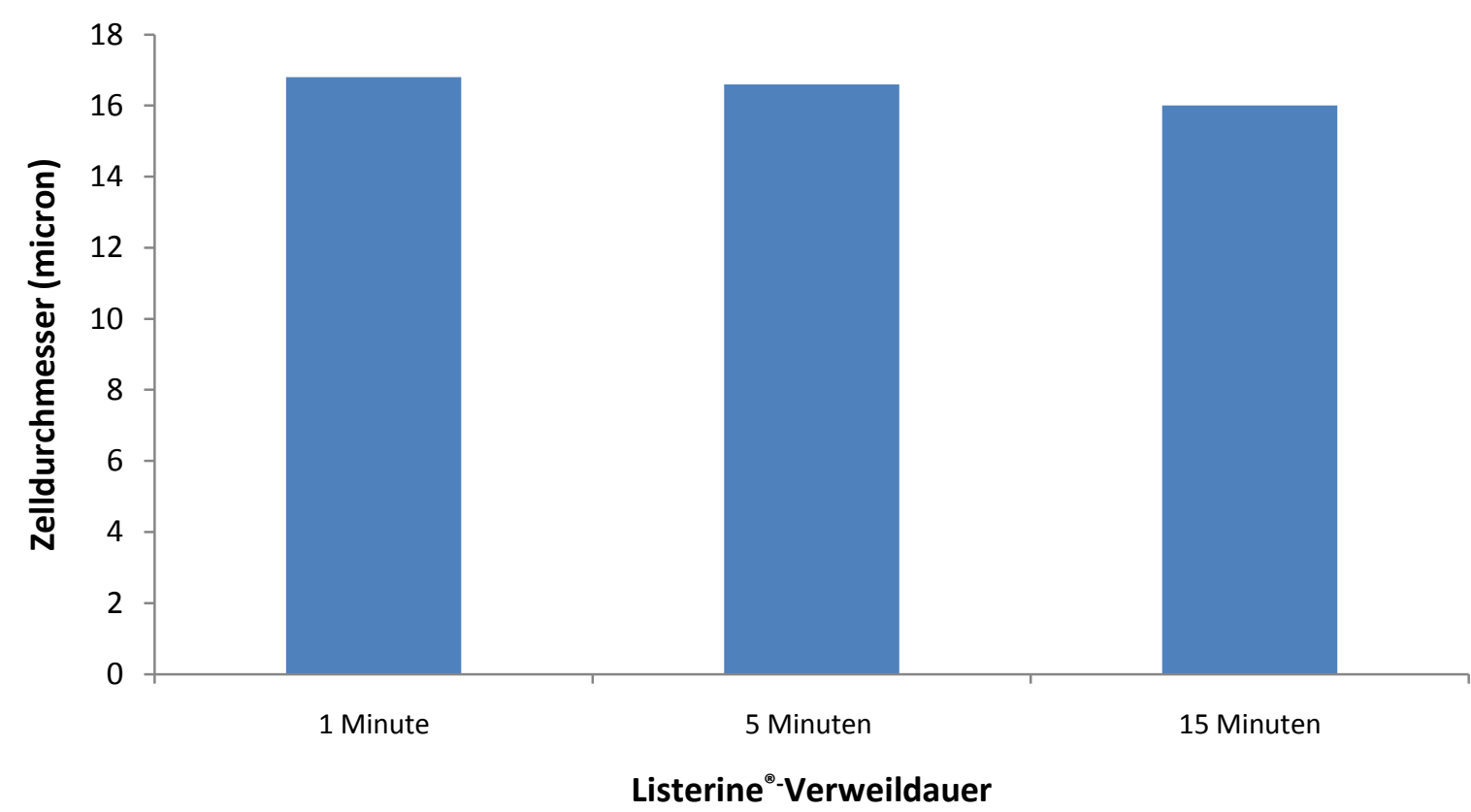

Diagramm 21: Einfluss von Listerine ${ }^{\circledR}$ auf den mittleren Zelldurchmesser der HGFIB in Abhängigkeit von der Einwirkzeit

Während nach einer Minute Einwirkzeit der Betaisodona ${ }^{\circledR}$-Mundspüllösung auf die HGFIB ein mittlerer Zelldurchmesser von 17,8 \pm 0,14 micron bestimmt wurde, wiesen die 5-MinutenProben leicht erniedrigte mittlere Fibroblastendiameter (17,6 \pm 0,14 micron) auf. Bei den 15Minuten-Versuchen war eine noch weitere Reduktion des Zelldurchmessers festzustellen $(17,1 \pm 0,12$ micron $)$. 


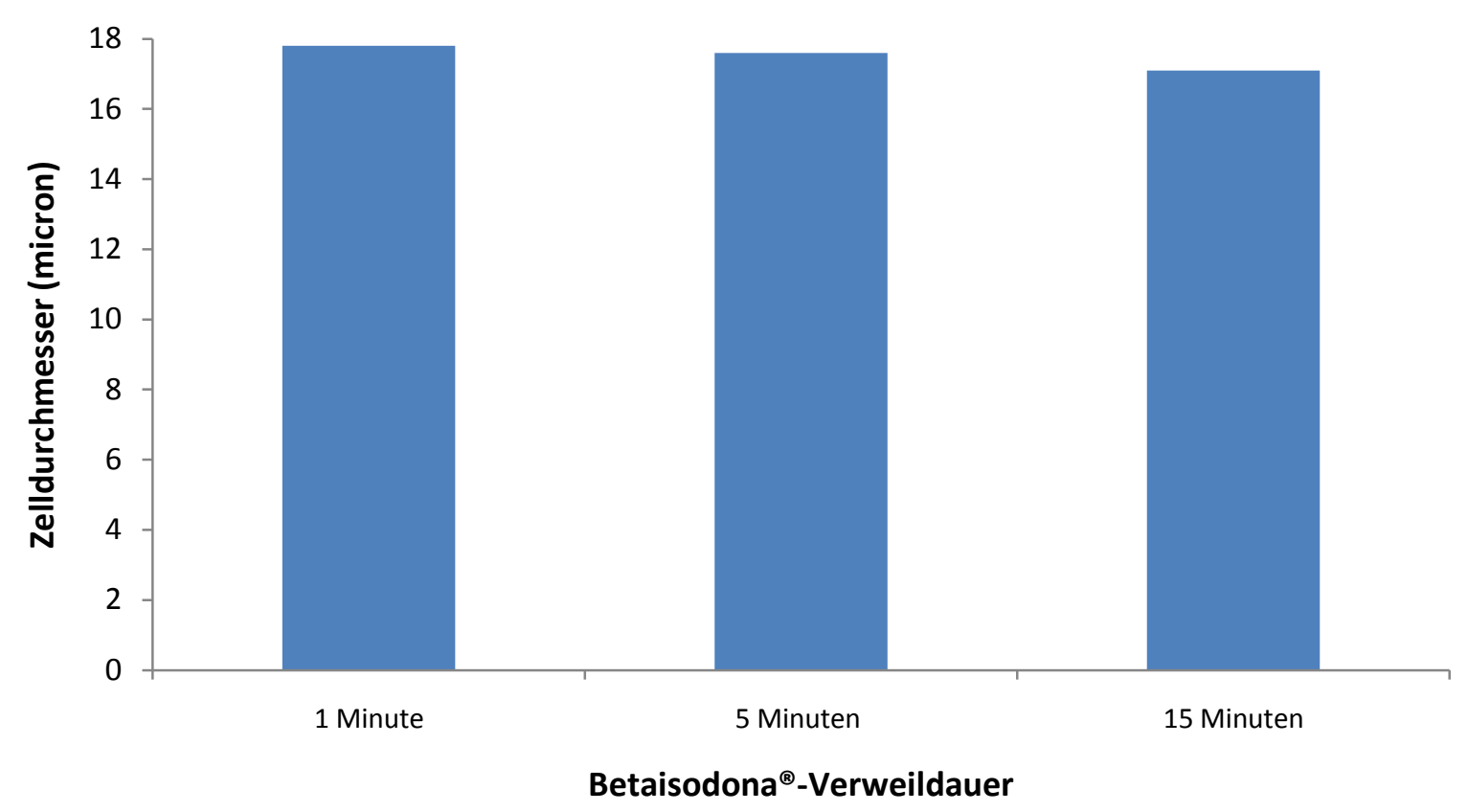

Diagramm 22: Einfluss von Betaisodona ${ }^{\circledR}$ auf den mittleren Zelldurchmesser der HGFIB in Abhängigkeit von der Einwirkzeit

Die Octenidol $^{\circledR}$-Versuchsreihe wies eine deutlich höhere Abhängigkeit des mittleren Zelldurchmessers von der Einwirkzeit der Mundspüllösung auf. Die längere Einwirkzeit von Octenidol $^{\circledR}$ beeinflusste den Zelldurchmesser negativ (1 Minute: 18,0 \pm 0,11 micron; 5 Minuten: 17,6 $\pm 0,10$ micron; 15 Minuten: 16,9 $\pm 0,13$ micron).

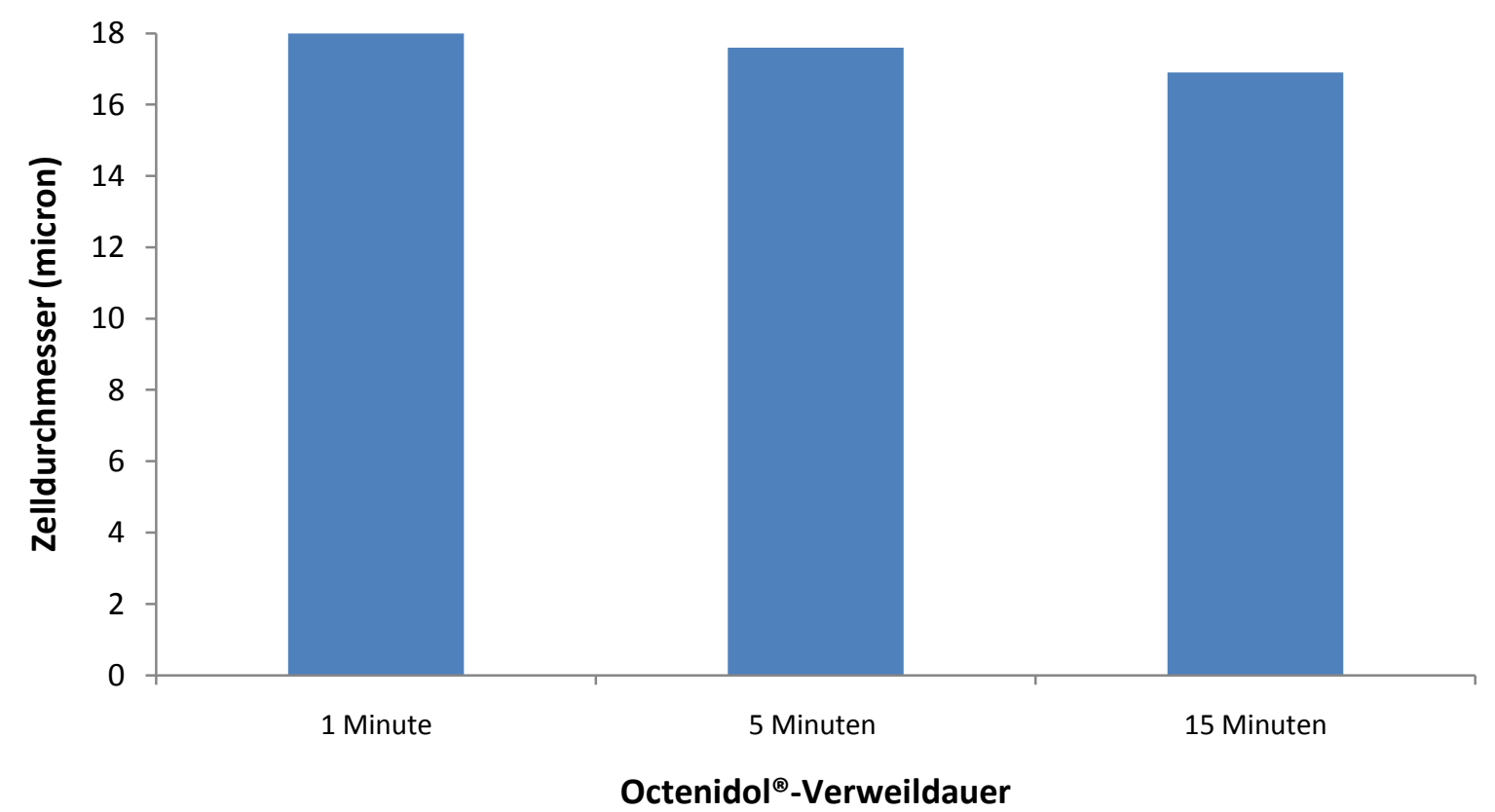

Diagramm 23: Einfluss von Octenidol ${ }^{\circledR}$ auf den mittleren Zelldurchmesser der HGFIB in Abhängigkeit von der Einwirkzeit 


\subsubsection{Vergleich der Mundspüllösungen untereinander}

Der Vergleich beschreibt die Zellwirkung der einzelnen Mundspüllösungen untereinander bei den unterschiedlichen Einwirkzeiten. Tabelle 12 liefert eine Übersicht über alle Vergleiche. Diagramm 24 stellt die entsprechenden Unterschiede zwischen den einzelnen Mundspüllösungen grafisch dar.

In der Regel liegen die Messwerte bei den fünf Mundspüllösungen immer niedriger als diejenigen der Kontrollmessungen (Diagramm 24). Außerdem sinken in den meisten Fällen die Messwerte mit zunehmender Einwirkzeit. Wie auch bei der Gesamtzellzahl- und der Viabilitätsbestimmung war der mittlere Zelldurchmesser der HGFIB bei der Anwendung von CHX 0,2 \% ${ }^{\circledR}$, Meridol ${ }^{\circledR}$ und Listerine ${ }^{\circledR}$ unabhängig von der Einwirkzeit deutlich reduziert. Die negative Wirkung der antiseptischen Therapie mit Betaisodona ${ }^{\circledR}$ und Octenidol ${ }^{\circledR}$ war weniger ausgeprägt.

Tabelle 12: Paarweiser Vergleich der Mundspüllösungen in Abhängigkeit von der Einwirkzeit (Signifikanzen)

\begin{tabular}{|c|c|c|c|c|}
\hline & \multicolumn{3}{|c|}{ Einwirkzeit } \\
\hline & & 1 Minute & 5 Minuten & 15 Minuten \\
\hline \multirow{10}{*}{ 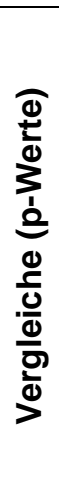 } & $\mathrm{CHX}^{(\mathbb{R}}$ vs. Meridol $\left.{ }^{(}\right)$ & 0,4660 & 0,8288 & 0,4963 \\
\hline & $\mathrm{CHX}^{(}{ }^{(}$vs. Listerine $\left.{ }^{(}\right)$ & 0,8250 & 0,4600 & 0,2461 \\
\hline & $\mathrm{CHX}^{(B)}$ vs. Betaisodona $\left.{ }^{(}\right)$ & 0,0006 & 0,0000 & 0,0000 \\
\hline & $\mathrm{CHX}^{(}{ }^{\text {vs. Octenidol }}{ }^{\circledR}$ & 0,0001 & 0,0000 & 0,0000 \\
\hline & Meridol $^{(B)}$ vs. Listerine ${ }^{(B)}$ & 0,4177 & 0,5541 & 0,6891 \\
\hline & Meridol $\left.{ }^{(}\right)$vs. Betaisodona ${ }^{(B)}$ & 0,0002 & 0,0000 & 0,0000 \\
\hline & Meridol $^{(B)}$ vs. Octenidol ${ }^{(B)}$ & 0,0000 & 0,0000 & 0,0001 \\
\hline & Listerine $^{(\circledR)}$ vs. Betaisodona $\left.{ }^{(}\right)$ & 0,0000 & 0,0001 & 0,0000 \\
\hline & Listerine $^{\circledR}$ vs. Octenidol ${ }^{\circledR}$ & 0,0000 & 0,0000 & 0,0001 \\
\hline & Betaisodona $^{(B)}$ vs. Octenidol $\left.{ }^{(}\right)$ & 0,3389 & 1,0000 & 0,2194 \\
\hline
\end{tabular}




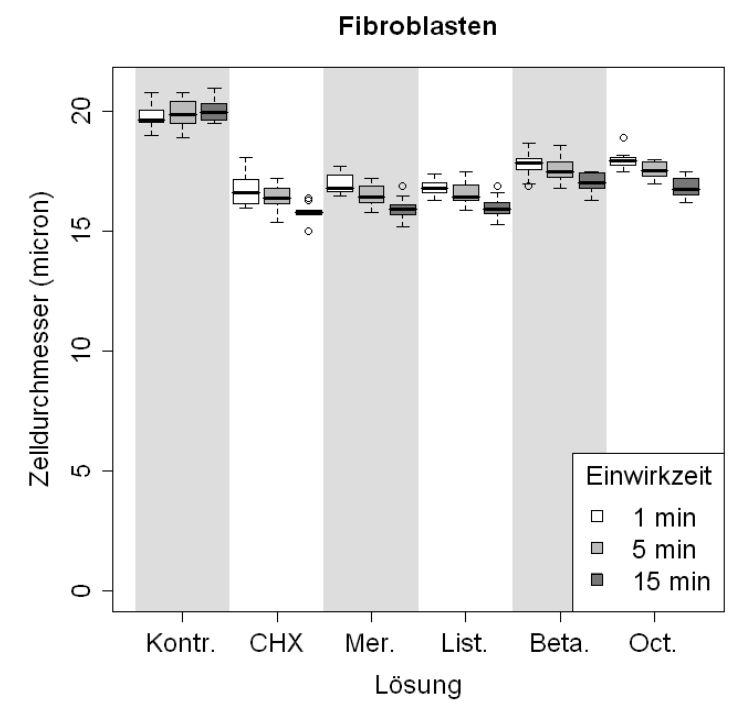

Diagramm 24: Vergleich der Mundspüllösungen in Abhängigkeit von der Einwirkzeit

\subsubsection{Wechselwirkung}

In den Varianzanalysen zeigt sich für alle Messgrößen ein signifikanter Einfluss der Lösungsart sowie der Einwirkzeit (Tab. 13). Eine signifikante Wechselwirkung zwischen Lösungsart und Einwirkzeit war bei der Bestimmung des mittleren Zelldurchmessers der HGFIB nach der antiseptischen Therapie zu erkennen, d. h., die Stärke des Lösungseffekts war je nach Einwirkzeit unterschiedlich ausgeprägt.

Tabelle 13: Einfluss der Lösung sowie der Einwirkzeit auf die Messwerte bei der Bestimmung des mittleren Zelldurchmessers der HGFIB mittels Cellometer ${ }^{\mathrm{TM}}$ Auto T4

\begin{tabular}{|l|c|}
\hline \multicolumn{1}{|c|}{ Effekt } & p-Wert \\
\hline Lösung & $<0,0001$ \\
\hline Einwirkzeit & $<0,0001$ \\
\hline Wechselwirkung & 0,0002 \\
\hline
\end{tabular}

\subsubsection{Vergleich des MTT-Tests und der optischen Zellcharakterisierung mittels Cellometer ${ }^{\mathrm{TM}}$ Auto T4}

Der MTT-Test basiert auf einer fotometrischen Bestimmung der metabolischen Aktivität von der zu untersuchenden Zellen. Die Gesamtzellzahl, die Viabilität und der mittlere Zelldurchmesser wurden in der vorliegenden Studie optisch mittels Cellometer ${ }^{\mathrm{TM}}$ Auto T4 
bestimmt. Dabei wurde der Frage nachgegangen, ob die beiden Methoden miteinander korrelieren.

Da die Kontrollmessungen stets stark von den Messungen bei den anderen Lösungen abwichen, wurden sie nicht in die Korrelationsberechnungen zwischen MTT-Test und Zellzahlbestimmung mit einbezogen (Diagramm 25). Zwischen beiden Methoden wurde bei den Fibroblasten ein signifikant positiver Zusammenhang ermittelt $(r h o=0,28, p<0,01)$.

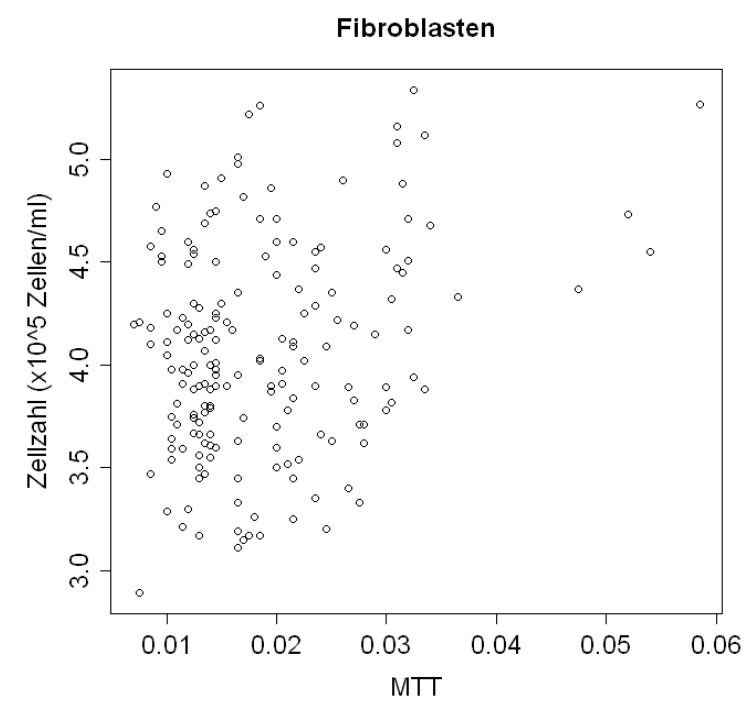

Diagramm 25: Korrelationsbestimmung zwischen MTT-Test und Zellzahlbestimmung mittels Cellometer ${ }^{\mathrm{TM}}$ Auto T4 für HGFIB

\subsection{Versuche mit primären humanen nasalen Epithelzellen (HNEPC)}

Die humanen Epithelzellen kleiden alle Körperhöhlen aus und schützen damit das darunter liegende Gewebe von den äußeren Einflüssen. Da die Epithelzellen der Mundschleimhaut als Auskleidung der Mundhöhle und die nasalen Epithelzellen als oberflächliche Zellschicht der Nasenschleimhaut sehr ähnliche Strukturen und Eigenschaften aufweisen, wurden die HNEPC für den zweiten Teil der Untersuchung der Wirkung handelsüblicher Mundspüllösungen als sehr geeignet bewertet. Da bei jeder antiseptischen Therapie im Bereich der Mundhöhle und des Parodontalapparates die HNEPC dem unmittelbaren Kontakt mit den Lösungen ausgesetzt sind, war es von großem Interesse, deren Wirkung auf die Epithelzellen zu untersuchen. Die primären Zellen wurden in Kultur unter standardisierten Bedingungen gezüchtet und vermehrt. 


\subsubsection{Bestimmung der Toxizität von oralen Antiseptika mittels MTT-Test}

Die metabolische Aktivität von lebenden Zellen wurde unter Verwendung des MTT-Tests bestimmt. Aus den Ergebnissen dieses Wachstumsassays konnten Rückschlüsse auf die Viabilität der Zellen gezogen werden.

\subsubsection{Ergebnisse der einzelnen Antiseptika nach Einwirkzeiten}

In Tabelle 14 sind die Mittelwerte mit den dazugehörigen Standardfehlern für die Messung der metabolischen Aktivität der HNEPC mittels MTT-Test angegeben. Die Viabilität war nach der Behandlung der Zellen mit den fünf handelsüblichen Mundspüllösungen (CHX 0,2 $\%^{\circledR}$, Meridol $^{\circledR}$, Listerine ${ }^{\circledR}$, Betaisodona ${ }^{\circledR}$ und Octenidol ${ }^{\circledR}$ ) bei allen Versuchsreihen $(1,5$ und 15 Minuten) im Vergleich zur Kontrolle $(0,1900 \pm 0,0074$ OD) signifikant reduziert $(\mathrm{p}<$ 0,0001). OD = Lm1(Excitation $)-\operatorname{Lm} 2($ Emission $)$

Tabelle 14: Mittelwerte und Standardfehler für die MTT-Messungen (OD) nach der Behandlung mit oralen Antiseptika bei Epithelzellen

\begin{tabular}{|c|c|c|c|}
\hline & \multicolumn{3}{|c|}{ Einwirkzeit } \\
\hline Mundspüllı̈sung & 1 Minute & 5 Minuten & 15 Minuten \\
\hline CHX 0,2 \% $^{\circledR}$ & $0,0213 \pm 0,0014$ & $0,0233 \pm 0,0009$ & $0,0194 \pm 0,0007$ \\
\hline Meridol $^{\circledR}$ & $0,0175 \pm 0,0012$ & $0,0164 \pm 0,0008$ & $0,0146 \pm 0,0014$ \\
\hline Listerine $^{\circledR}$ & $0,0195 \pm 0,0006$ & $0,0180 \pm 0,0006$ & $0,0160 \pm 0,0005$ \\
\hline Betaisodona $^{\circledR}$ & $0,0200 \pm 0,0047$ & $0,0187 \pm 0,0041$ & $0,0161 \pm 0,0050$ \\
\hline Octenidol $^{\circledR}$ & $0,0239 \pm 0,0011$ & $0,0184 \pm 0,0004$ & $0,0190 \pm 0,0011$ \\
\hline
\end{tabular}

\subsubsection{Einfluss der Einwirkzeit}

Der Vergleich beschreibt die Zellwirkung der einzelnen Mundspüllösungen in Abhängigkeit von der Einwirkzeit. Wegen der besseren Übersichtlichkeit werden die Vergleiche in den Diagrammen 26 bis 30 separat ohne Angabe des Standardfehlers dargestellt. Die Standardfehler sind der Tabelle 14 zu entnehmen.

Die $\mathrm{CHX}^{\circledR}$-Versuchsreihe weist eine Reduktion der metabolischen Aktivität der HNEPC in Abhängigkeit von der Einwirkzeit der Mundspüllösung auf. Während nach einer Minute $0,0213 \pm 0,0014$ OD gemessen wurde, konnte nach fünf Minuten Einwirkzeit ein leichter 
Anstieg der metabolischen Aktivität auf 0,0233 $\pm 0,0009$ OD festgestellt werden. Nach 15 Minuten wurde wiederum ein Abfall auf 0,0194 $\pm 0,0007$ OD registriert.

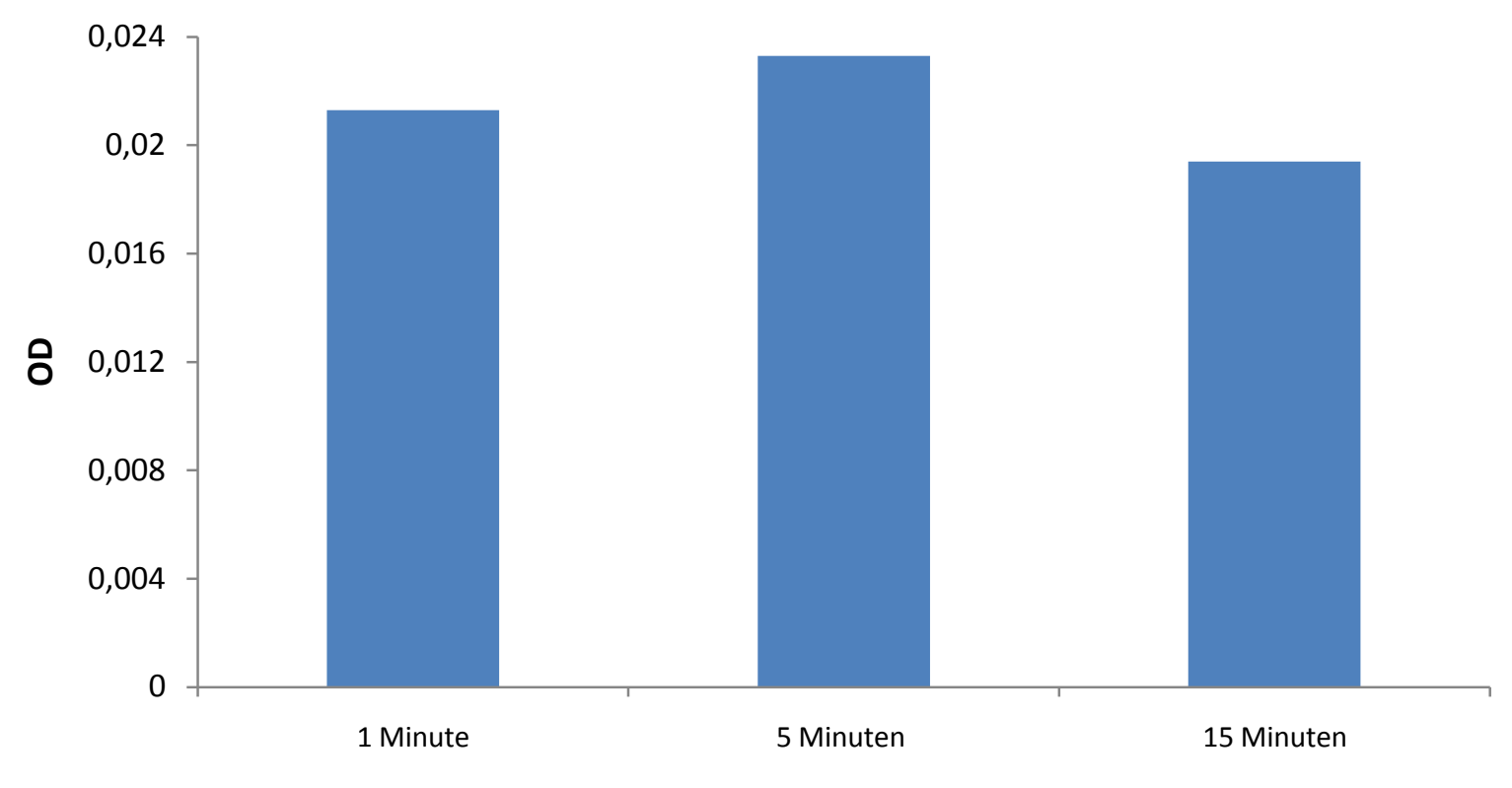

CHX 0,2\% ${ }^{\circledR}$-Verweildauer

Diagramm 26: Einfluss von CHX 0,2 \% ${ }^{\circledR}$ auf die HNEPC in Abhängigkeit von der Einwirkzeit

Bei den Versuchen mit Meridol ${ }^{\circledR}$ wurde festgestellt, dass die Zellen in ihrer Aktivität umso stärker gehemmt werden, je länger das Antiseptikum auf den Zellen verbleibt. Das MTTTestergebnis nach einer Minute lag bei 0,0175 \pm 0,0012 OD, nach fünf Minuten bei 0,0164 \pm 0,0008 OD und nach 15 Minuten bei 0,0146 $\pm 0,0014$ OD.

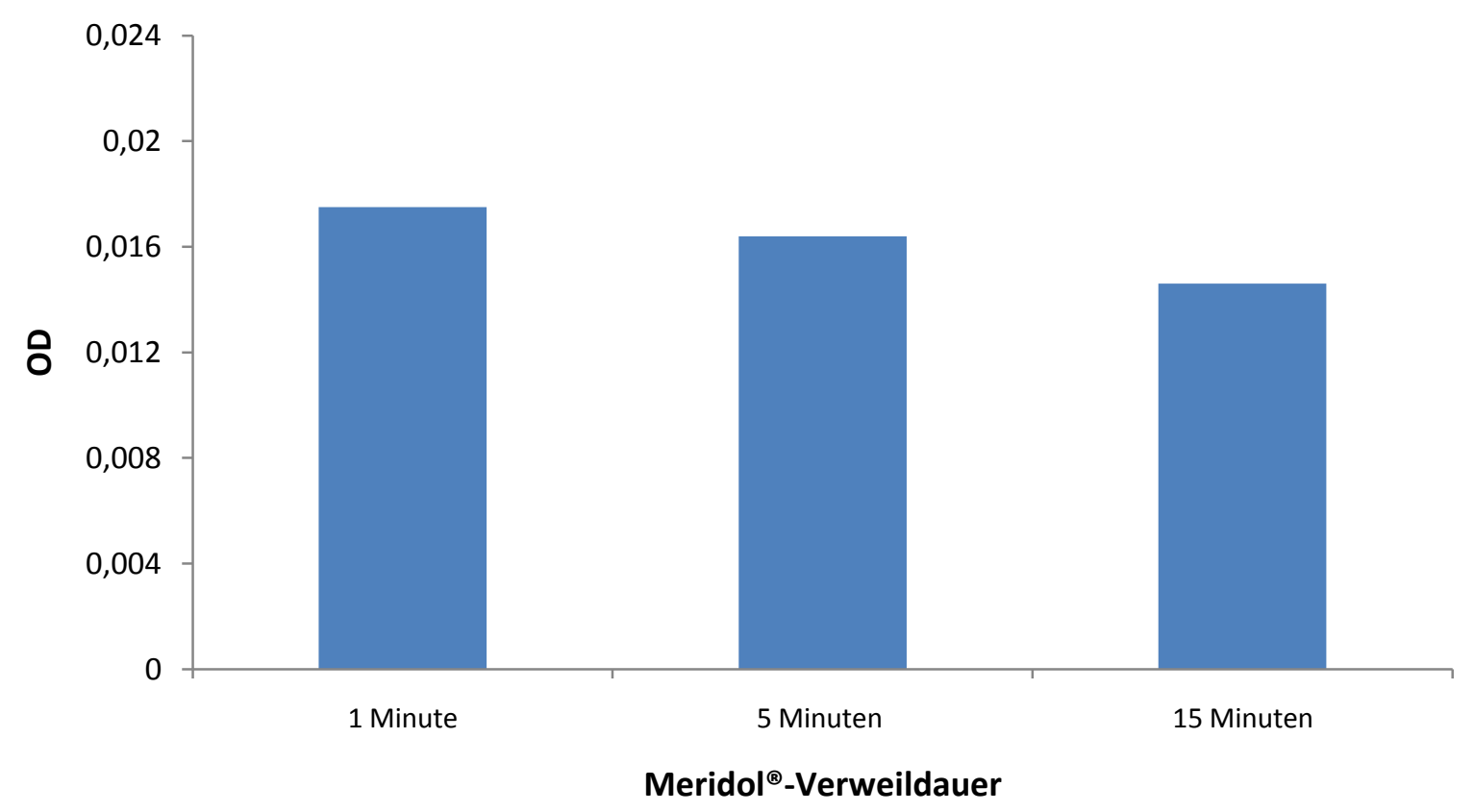

Diagramm 27: Einfluss von Meridol $^{\circledR}$ auf die HNEPC in Abhängigkeit von der Einwirkzeit 
Die MTT-Messungen bei den Versuchen mit der Listerine ${ }^{\circledR}$-Lösung wiesen keine wesentlichen Unterschiede zu den oben gezeigten Experimenten auf. Die Werte nach einer bzw. fünf Minuten betrugen 0,0195 \pm 0,0006 OD bzw. 0,0180 \pm 0,0006 OD. Nach 15 Minuten Behandlung mit Listerine ${ }^{\circledR}$ war die metabolische Aktivität der HNEPC noch niedriger als nach einer bzw. fünf Minuten Einwirkzeit (0,0160 $\pm 0,0005$ OD).

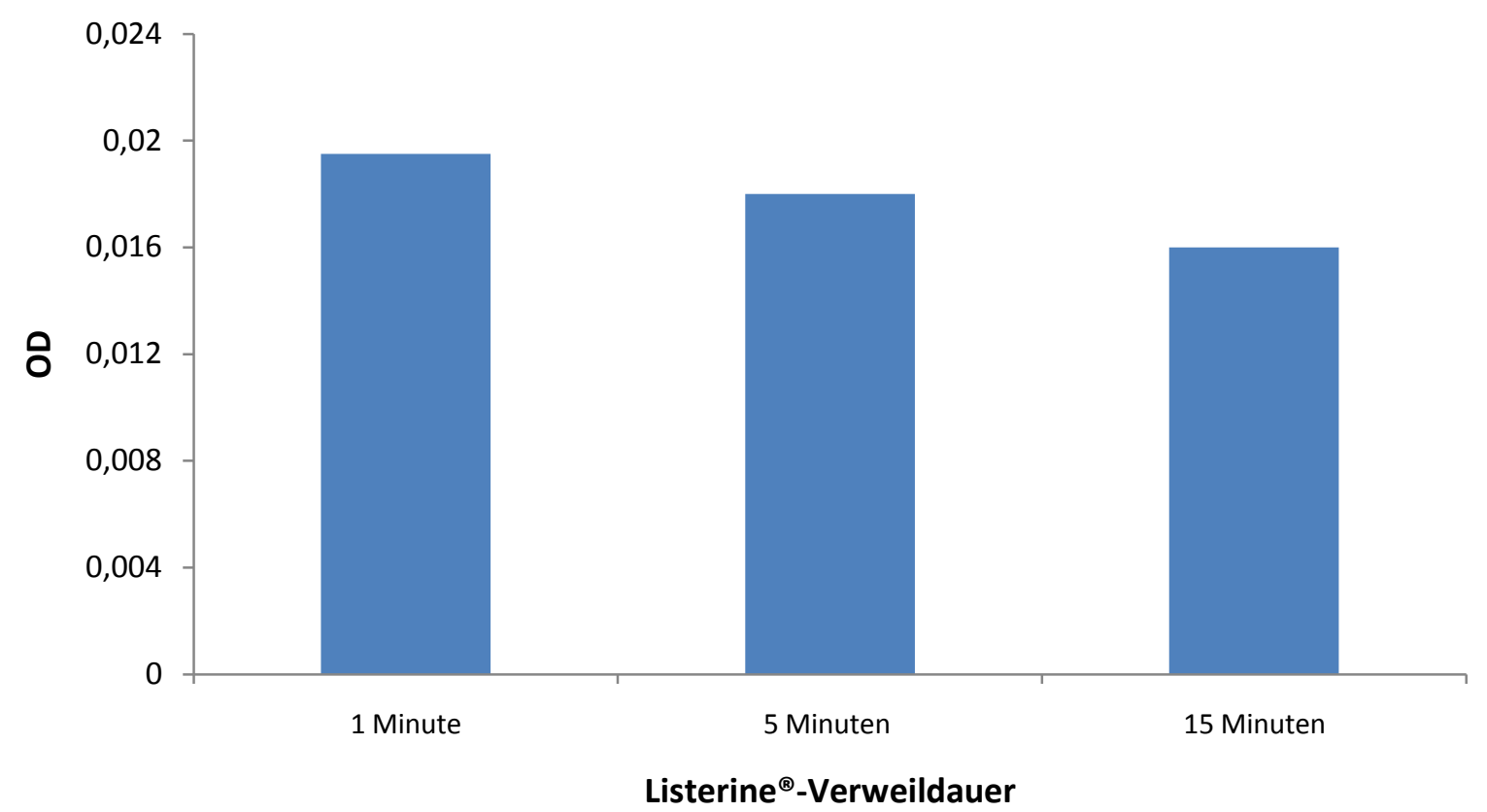

Diagramm 28: Einfluss von Listerine ${ }^{\circledR}$ auf die HNEPC in Abhängigkeit von der Einwirkzeit

Während die Werte der Betaisodona ${ }^{\circledR}$-Mundspüllösung nach einer Minute Einwirkzeit auf die HNEPC 0,0200 \pm 0,0047 OD betrugen, konnte bei den 5-Minuten-Versuchen 0,0187 $\pm 0,0041$ OD gemessen werden. Nach 15 Minuten wurde eine stärkere Reduktion der Epithelzellenaktivität festgestellt $(0,0161 \pm 0,0050$ OD). 


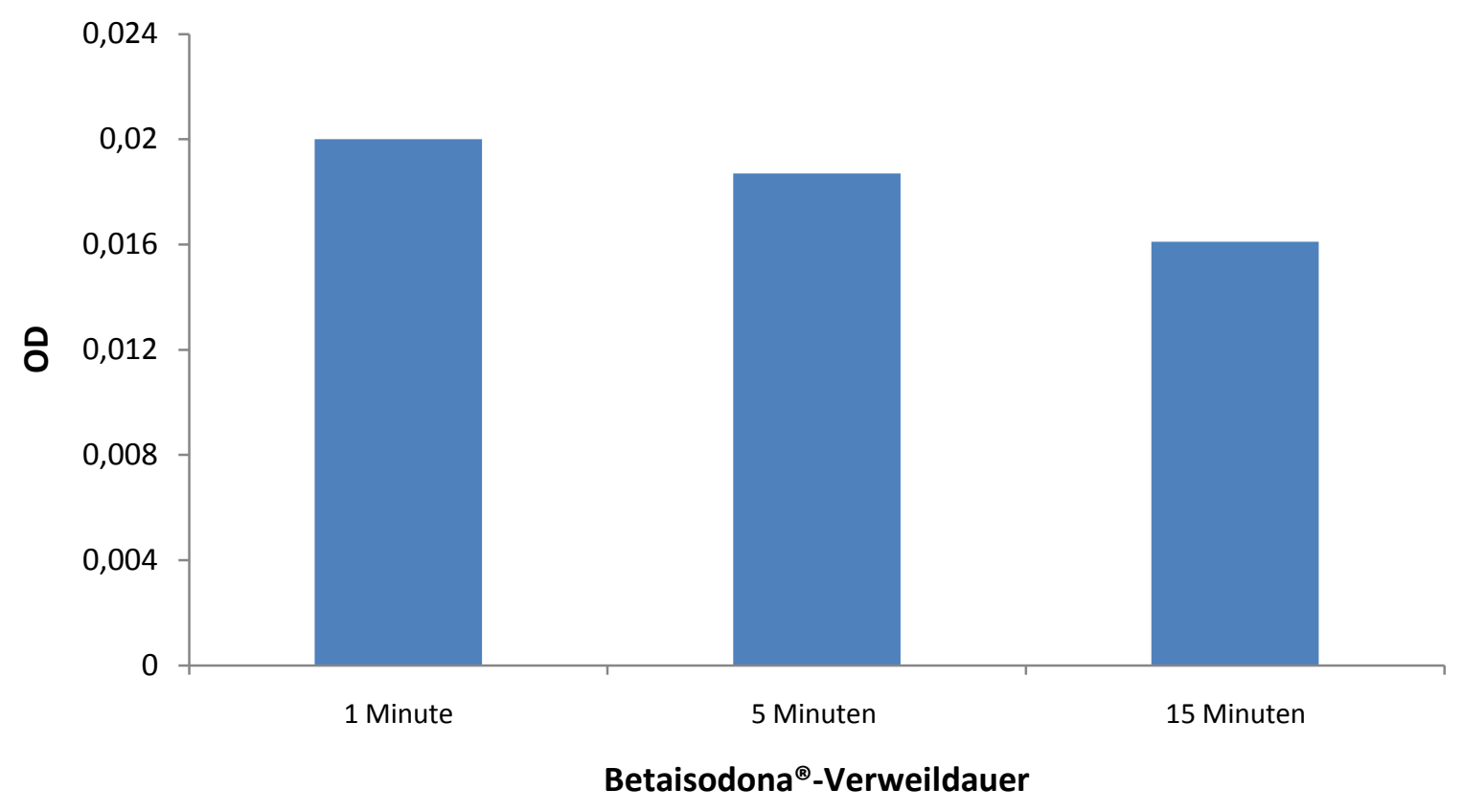

Diagramm 29: Einfluss von Betaisodona ${ }^{\circledR}$ auf die HNEPC in Abhängigkeit von der Einwirkzeit Die Octenidol ${ }^{\circledR}$-Versuchsreihe wies eine deutliche Abhängigkeit der metabolischen Aktivität der Epithelzellen von der Einwirkzeit der Mundspüllösung auf. Die Dauer der Einwirkung

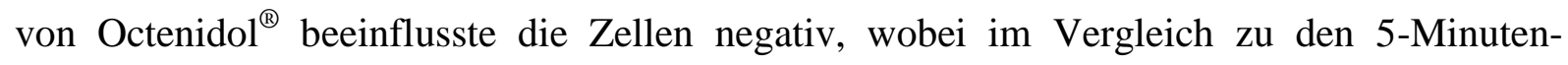
Versuchen nach 15 Minuten Einwirkzeit ein leichter Anstieg der Zellaktivität festgestellt werden konnte ( 1 Minute: 0,0239 \pm 0,0011 OD; 5 Minuten: 0,0184 \pm 0,0004 OD; 15 Minuten: $0,0190 \pm 0,0011$ OD).

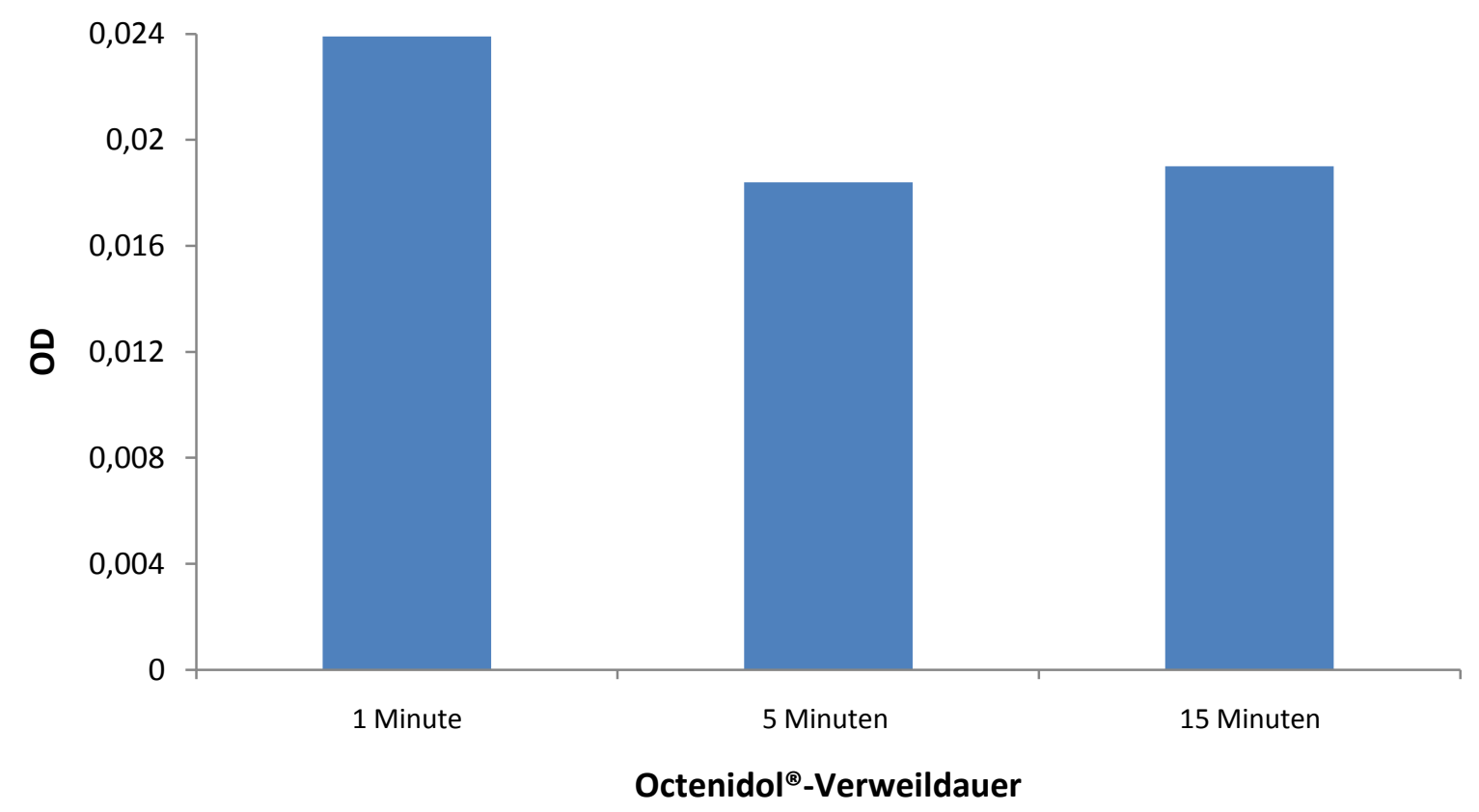

Diagramm 30: Einfluss von Octenidol ${ }^{\circledR}$ auf die HNEPC in Abhängigkeit von der Einwirkzeit 


\subsubsection{Vergleich der Mundspüllösungen untereinander}

Der Vergleich beschreibt die Zellwirkung der einzelnen Mundspüllösungen untereinander bei den unterschiedlichen Einwirkzeiten. Tabelle 15 gibt eine Übersicht über alle Vergleiche. Diagramm 31 stellt die entsprechenden Unterschiede zwischen den einzelnen Mundspüllösungen grafisch dar.

In der Regel liegen die Messwerte bei den fünf Mundspüllösungen immer niedriger als diejenigen der Kontrollmessungen (Diagramm 31). Außerdem sinken in den meisten Fällen die Messwerte mit zunehmender Einwirkzeit. Ein deutlicher Unterschied zwischen den einzelnen Lösungen in ihrer negativen Wirkung auf die HNEPC konnte beim MTT-Test nicht festgestellt werden.

Tabelle 15: Paarweiser Vergleich der Mundspüllösungen in Abhängigkeit von der Einwirkzeit (Signifikanzen)

\begin{tabular}{|c|c|c|c|c|}
\hline & \multicolumn{3}{|c|}{ Einwirkzeit } \\
\hline & & 1 Minute & 5 Minuten & 15 Minuten \\
\hline \multirow{10}{*}{ 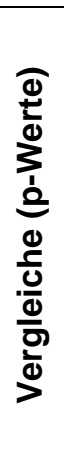 } & $\mathrm{CHX}^{\circledR}$ vs. Meridol ${ }^{\circledR}$ & 0,0428 & 0,0000 & 0,0008 \\
\hline & $\mathrm{CHX}^{\circledR}$ vs. Listerine ${ }^{\circledR}$ & 0,6622 & 0,0000 & 0,0000 \\
\hline & $\mathrm{CHX}^{\circledR}$ vs. Betaisodona ${ }^{\circledR}$ & 0,9206 & 0,5848 & 0,9808 \\
\hline & $\mathrm{CHX}^{\circledR}$ vs. Octenidol ${ }^{(}$ & 0,0620 & 0,0000 & 0,1444 \\
\hline & Meridol $^{\circledR}$ vs. Listerine ${ }^{\circledR}$ & 0,0262 & 0,4206 & 0,4614 \\
\hline & Meridol $^{\circledR}$ vs. Betaisodona ${ }^{\circledR}$ & 0,4960 & 0,3474 & 0,2355 \\
\hline & Meridol $^{\circledR}$ vs. Octenidol ${ }^{\circledR}$ & 0,7559 & 0,3304 & 0,0205 \\
\hline & Listerine $^{(}$vs. Betaisodona ${ }^{\circledR}$ & 0,9727 & 0,4440 & 0,3101 \\
\hline & Listerine $^{\circledR}$ vs. Octenidol ${ }^{\circledR}$ & 0,0352 & 0,0302 & 0,0140 \\
\hline & Betaisodona $^{\circledR}$ vs. Octenidol ${ }^{\circledR}$ & 0,5578 & 0,2529 & 0,6926 \\
\hline
\end{tabular}

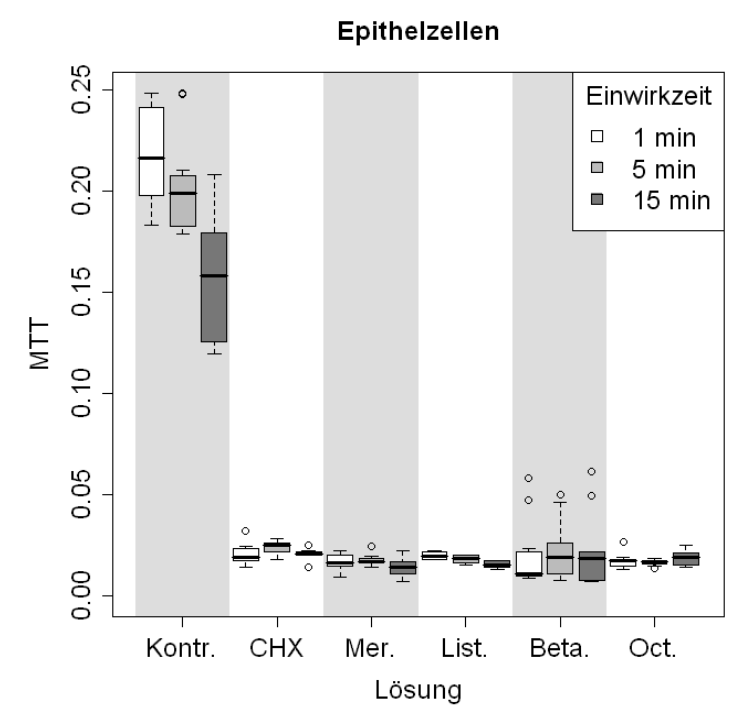

Diagramm 31: Vergleich der Mundspüllösungen in Abhängigkeit von der Einwirkzeit 


\subsubsection{Wechselwirkung}

In den Varianzanalysen zeigt sich für alle Messgrößen ein signifikanter Einfluss der Lösungsart sowie der Einwirkzeit (Tab. 16). Eine signifikante Wechselwirkung zwischen Lösungsart und Einwirkzeit war bei den MTT-Messungen für die HNEPC zu erkennen, d. h., die Stärke des Lösungseffekts ist je nach Einwirkzeit unterschiedlich ausgeprägt.

Tabelle 16: Einflüsse der Lösung sowie der Einwirkzeit auf die Messwerte des MTT-Tests bei den HNEPC

\begin{tabular}{|l|c|}
\hline \multicolumn{1}{|c|}{ Effekt } & p-Wert \\
\hline Lösung & $<0,0001$ \\
\hline Einwirkzeit & $<0,0001$ \\
\hline Wechselwirkung & $<0,0001$ \\
\hline
\end{tabular}

\subsubsection{Optische Zellzählung mittels Cellometer ${ }^{\mathrm{TM}}$ Auto T4}

Die optische Zellzählung nach dem Prinzip der Trypan-Blau-Färbung wurde parallel zum MTT-Test bei jedem Versuch durchgeführt. Die Anfärbung sowie die Gesamtzellzahlbestimmung der HNEPC geschah vollautomatisch mit dem Cellometer ${ }^{\mathrm{TM}}$ Auto T4 in einer Zellkammer.

\subsubsection{Ergebnisse der einzelnen Antiseptika nach Einwirkzeiten}

In Tabelle 17 sind die Mittelwerte mit dazugehörigen Standardfehlern für die Gesamtzellzahlbestimmung mittels Cellometer ${ }^{\mathrm{TM}}$ Auto T4 angegeben. Die Gesamtzellzahl war nach der Behandlung der Zellen mit den fünf handelsüblichen Mundspüllösungen (CHX $0,2 \%{ }^{\circledR}$, Meridol ${ }^{\circledR}$, Listerine ${ }^{\circledR}$, Betaisodona ${ }^{\circledR}$ und Octenidol $\left.{ }^{\circledR}\right)$ bei allen Versuchsreihen $(1,5$ und 15 Minuten) im Vergleich zur Kontrolle $\left(5,47 \pm 0,19 \times 10^{5}\right.$ Zellen/ml) signifikant reduziert $(\mathrm{p}<0,0001)$. 
Tabelle 17: Mittelwerte und Standardfehler für die Zellzahlbestimmung (x10 Zellen/ml) nach der Behandlung mit den oralen Antiseptika bei Epithelzellen

\begin{tabular}{|c|c|c|c|}
\hline & \multicolumn{3}{|c|}{ Einwirkzeit } \\
\hline Mundspüllösung & 1 Minute & 5 Minuten & 15 Minuten \\
\hline CHX 0,2 \% ${ }^{\circledR}$ & $3,8 \pm 0,07$ & $3,9 \pm 0,10$ & $3,4 \pm 0,06$ \\
\hline Meridol $^{\circledR}$ & $3,7 \pm 0,10$ & $3,7 \pm 0,12$ & $3,7 \pm 0,10$ \\
\hline Listerine $^{\circledR}$ & $3,8 \pm 0,05$ & $3,7 \pm 0,07$ & $3,6 \pm 0,06$ \\
\hline Betaisodona $^{\circledR}$ & $4,2 \pm 0,10$ & $4,0 \pm 0,14$ & $3,7 \pm 0,13$ \\
\hline Octenidol $^{\circledR}$ & $4,2 \pm 0,18$ & $3,9 \pm 0,13$ & $3,8 \pm 0,05$ \\
\hline
\end{tabular}

\subsubsection{Einfluss der Einwirkzeit}

Der Vergleich beschreibt die Auswirkung der antiseptischen Therapie mit verschiedenen Mundspüllösungen auf die Zellzahl von HNEPC in Abhängigkeit von der Einwirkzeit. Wegen der besseren Übersichtlichkeit werden die Vergleiche in den Diagrammen 32 bis 36 separat ohne Angabe des Standardfehlers dargestellt. Die Standardfehler sind der Tabelle 17 zu entnehmen.

Die $\mathrm{CHX}^{\circledR}$-Versuchsreihe weist eine Reduktion der Gesamtzellzahl in Abhängigkeit von der Einwirkzeit der Mundspüllösung. Je länger das Antiseptikum auf den Zellen verbleibt, desto weniger Zellen überleben und können schließlich gezählt werden. Die Ergebnisse nach einer bzw. fünf Minuten wiesen keine deutlichen Unterschiede auf. Während nach einer Minute 3,8 $\pm 0,07 \times 10^{5}$ Zellen/ml identifiziert werden konnten, wurden nach fünf bzw. 15 Minuten 3,9 \pm $0,10 \times 10^{5}$ Zellen/ml bzw. 3,4 $\pm 0,06 \times 10^{5}$ Zellen/ml gezählt. 


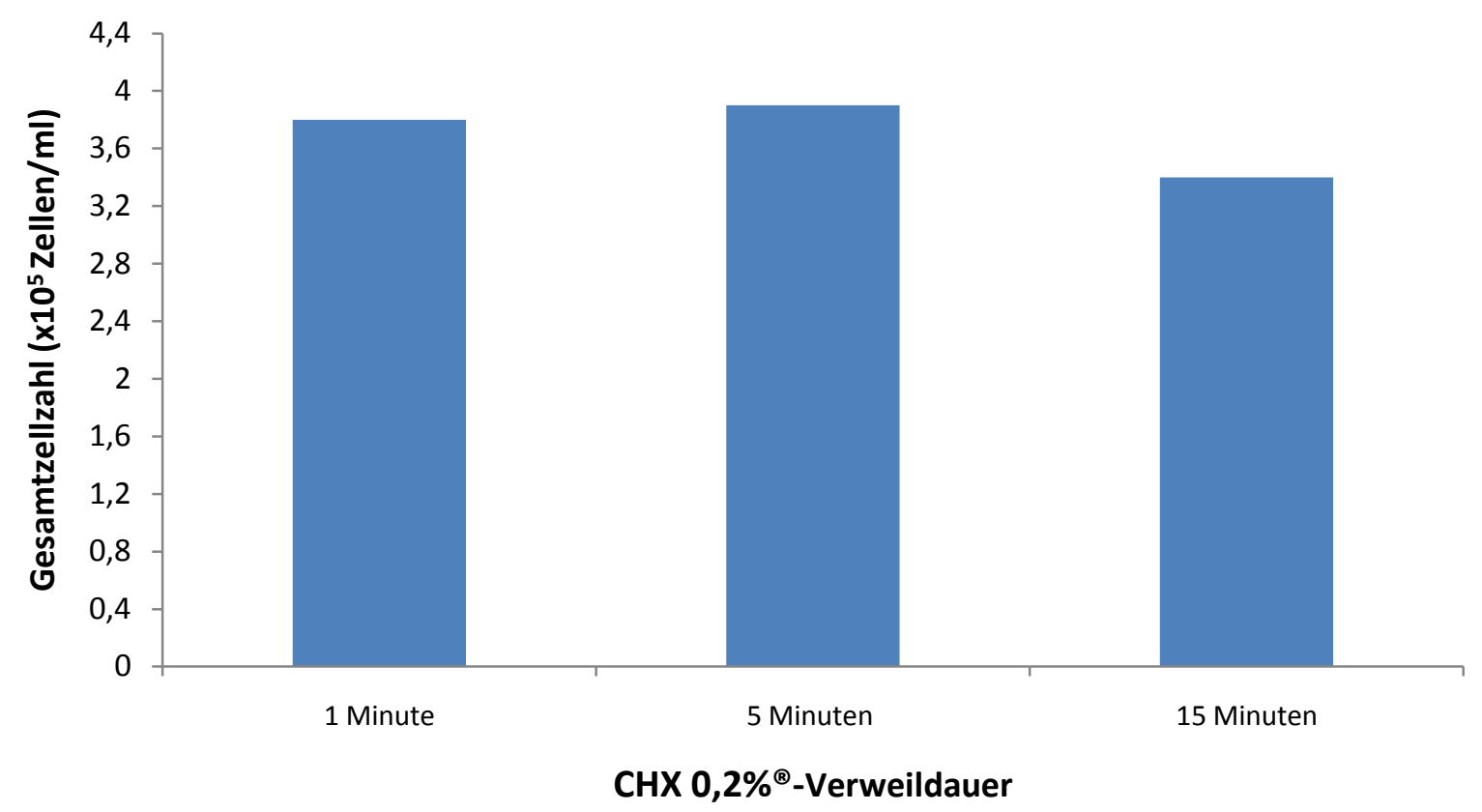

Diagramm 32: Einfluss von CHX 0,2\% ${ }^{\circledR}$ auf die Zellzahl von HNEPC in Abhängigkeit von der Einwirkzeit

Die Zellzahlen nach der Behandlung der humanen nasalen Epithelzellen mit Meridol ${ }^{\circledR}$ waren bis auf Standardfehler identisch. Folglich wiesen sie keine Abhängigkeit von der Einwirkzeit auf. Nach einer Minute konnten 3,7 $\pm 0,10 \times 10^{5}$ Zellen/ml, nach fünf Minuten 3,7 $\pm 0,12 \times$ $10^{5}$ Zellen/ml und nach 15 Minuten 3,7 $\pm 0,10 \times 10^{5}$ Zellen/ml identifiziert werden.

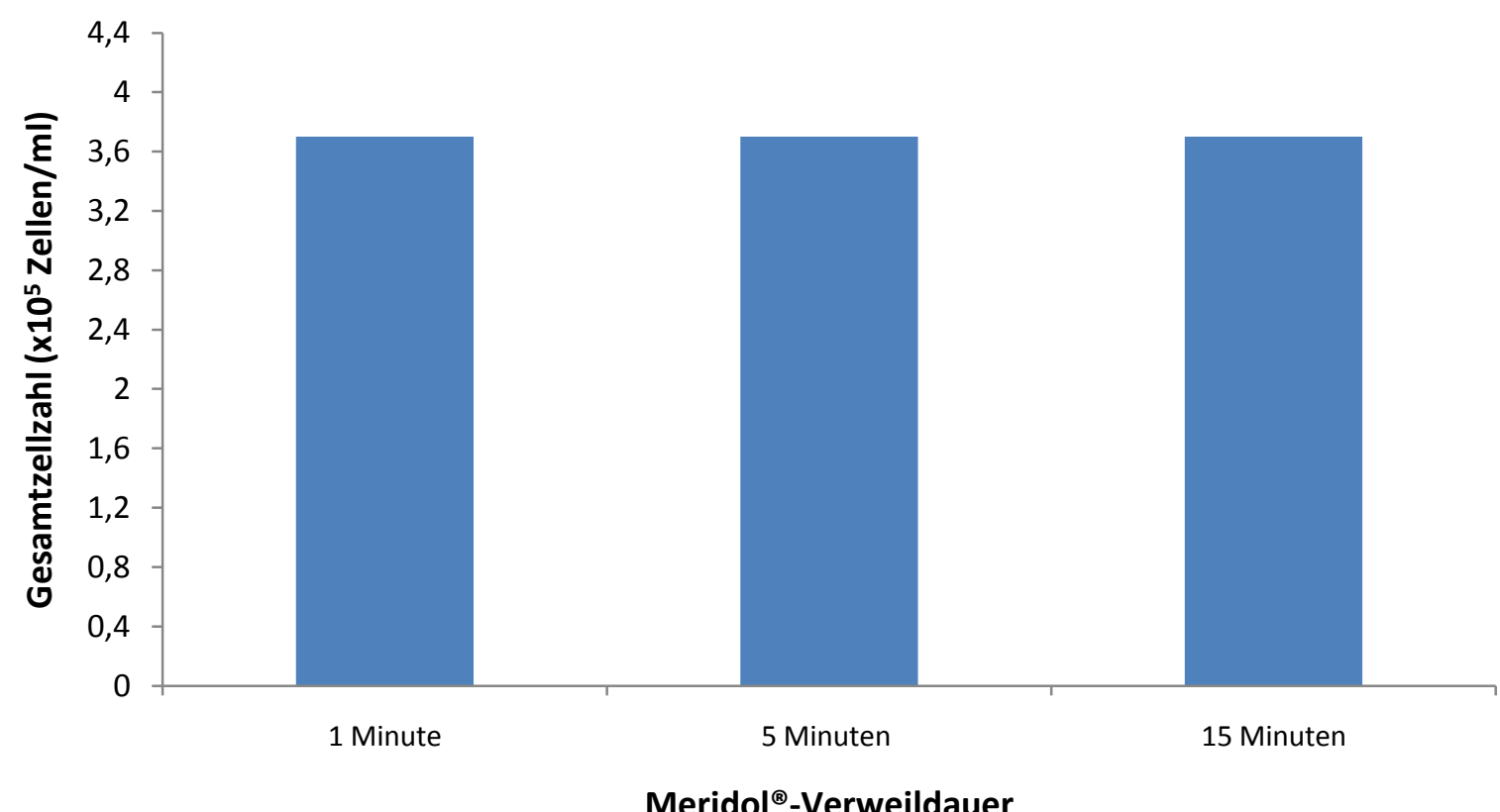

Diagramm 33: Einfluss von Meridol $^{\circledR}$ auf die Zellzahl von HNEPC in Abhängigkeit von der Einwirkzeit 
Die Gesamtzellzahlbestimmungen bei den Versuchen mit der Listerine ${ }^{\circledR}$-Lösung wiesen eine deutliche Abhängigkeit von der Einwirkzeit auf. So waren die Zellzahlen nach einer Minute am höchsten $\left(3,8 \pm 0,05 \times 10^{5}\right.$ Zellen/ml). Die Werte nach fünf Minuten Einwirkzeit betrugen $3,7 \pm 0,07 \times 10^{5}$ Zellen/ml. Nach 15-minütiger Behandlung mit Listerine ${ }^{\circledR}$ war die Anzahl der HNEPC noch niedriger als nach einer bzw. fünf Minuten Einwirkzeit $\left(3,6 \pm 0,06 \times 10^{5}\right.$ Zellen/ml).

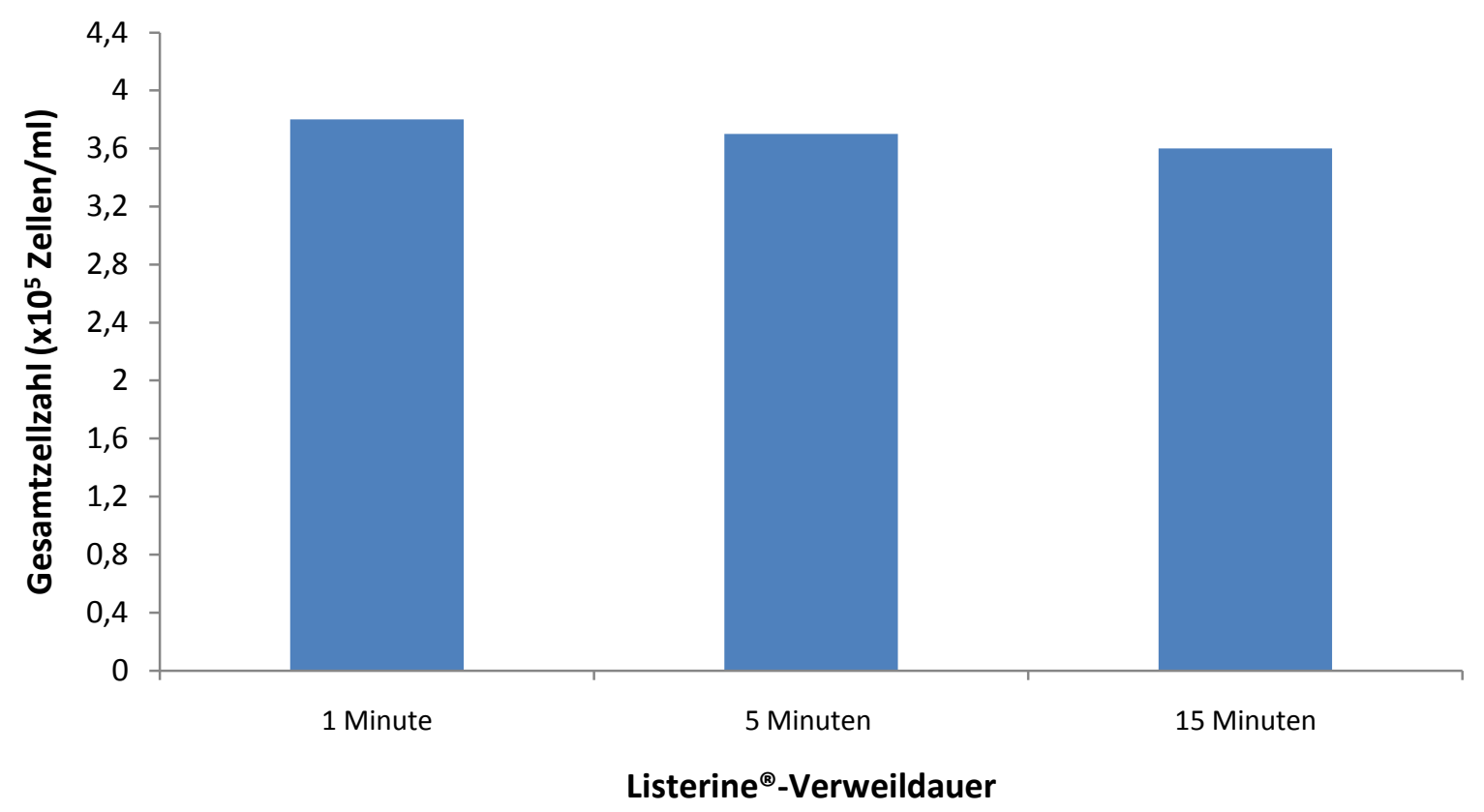

Diagramm 34: Einfluss von Listerine ${ }^{\circledR}$ auf die Zellzahl von HNEPC in Abhängigkeit von der Einwirkzeit

Während nach einer Minute Einwirkzeit der Betaisodona ${ }^{\circledR}$-Mundspüllösung auf die HNEPC $4,2 \pm 0,10 \times 10^{5}$ Zellen/ml gezählt wurden, wiesen die 5-Minuten-Proben eine leicht erniedrigte Gesamtzellzahl von 4,0 $\pm 0,14$ x $10^{5}$ Zellen/ml auf. Bei den 15-MinutenVersuchen war eine noch weitere Reduktion der Epithelzellenzahl festzustellen $(3,7 \pm 0,13 \mathrm{x}$ $10^{5}$ Zellen/ml). 


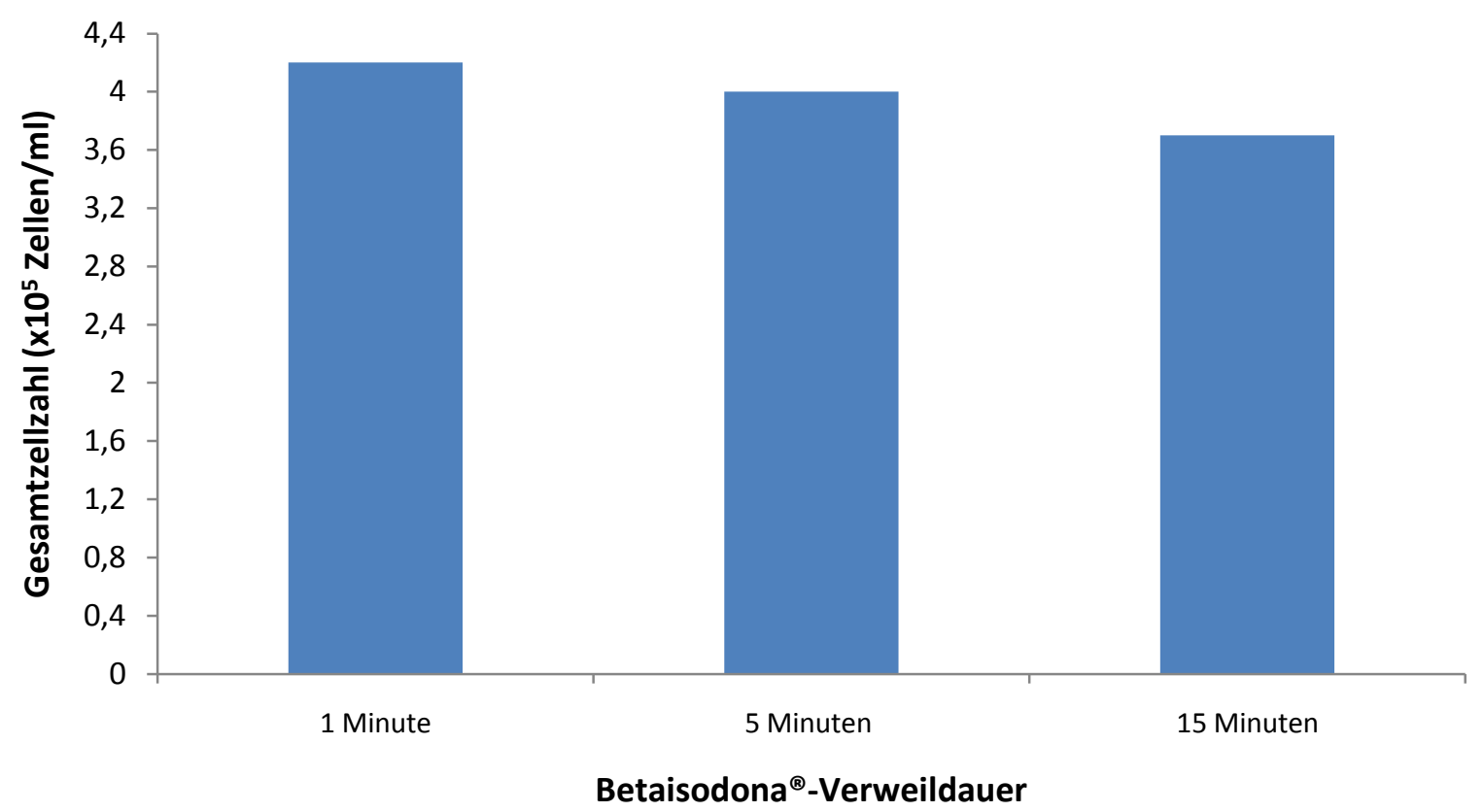

Diagramm 35: Einfluss von Betaisodona ${ }^{\circledR}$ auf die Zellzahl von HNEPC in Abhängigkeit von der Einwirkzeit

Die Octenidol ${ }^{\circledR}-$ Versuchsreihe wies eine in etwa gleich starke Abhängigkeit der Gesamtzellzahl von der Einwirkzeit der Mundspüllösung auf, wie sie auch die Betaisodona ${ }^{\circledR}$ Versuche ergeben hatten. Die längere Einwirkzeit von Octenidol ${ }^{\circledR}$ beeinflusste die Zellen negativ (1 Minute: 4,2 $\pm 0,18 \times 10^{5}$ Zellen/ml; 5 Minuten: $3,9 \pm 0,13 \times 10^{5}$ Zellen/ml; 15 Minuten: $3,8 \pm 0,05 \times 10^{5}$ Zellen/ml).

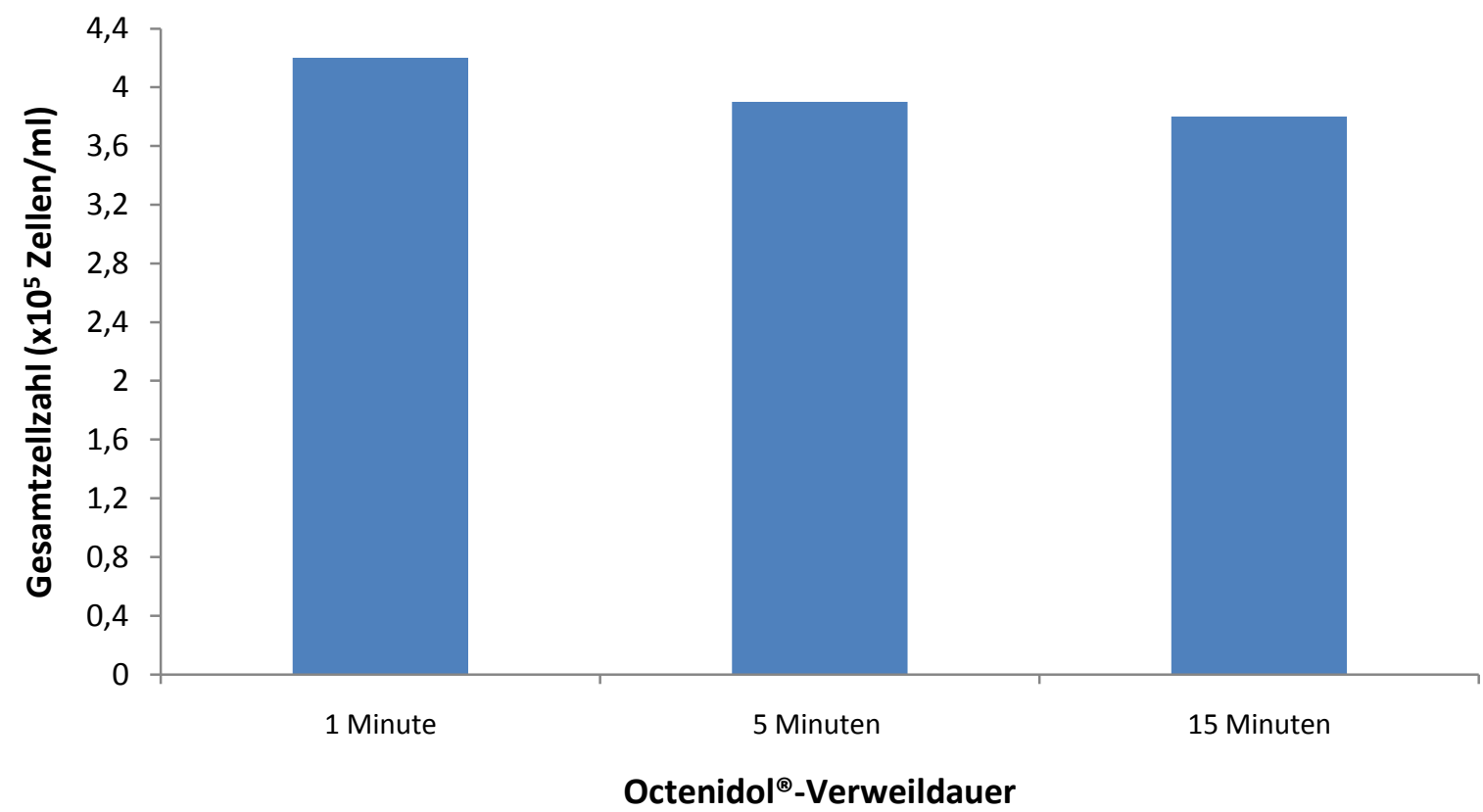

Diagramm 36: Einfluss von Octenidol ${ }^{\circledR}$ auf die Zellzahl von HNEPC in Abhängigkeit von der Einwirkzeit 


\subsubsection{Vergleich der Mundspüllösungen untereinander}

Der Vergleich beschreibt die Zellwirkung der einzelnen Mundspüllösungen untereinander bei den unterschiedlichen Einwirkzeiten. Tabelle 18 gibt eine Übersicht über alle Vergleiche. Diagramm 37 stellt die entsprechenden Unterschiede zwischen den einzelnen Mundspüllösungen grafisch dar.

In der Regel liegen die Messwerte bei den fünf Mundspüllösungen immer niedriger als diejenigen der Kontrollmessungen (Diagramm 37). Außerdem sinken in den meisten Fällen die Messwerte mit zunehmender Einwirkzeit. Während bei der Anwendung von CHX 0,2 \% ${ }^{\circledR}$, Meridol $^{\circledR}$ und Listerine ${ }^{\circledR}$ die Anzahl der HNEPC unabhängig von der Einwirkzeit deutlich reduziert war, war die negative Wirkung der antiseptischen Therapie mit Betaisodona ${ }^{\circledR}$ und Octenidol $^{\circledR}$ weniger stark ausgeprägt. Die Octenidol ${ }^{\circledR}$-Reihe wies mehr Zellen bei der optischen Zellzahlbestimmung auf. Die niedrigste Zellzahl konnte nach 15 Minuten $\mathrm{CHX}^{\circledR}$ Behandlung gemessen werden.

Tabelle 18: Paarweiser Vergleich der Mundspüllösungen in Abhängigkeit von der Einwirkzeit (Signifikanzen)

\begin{tabular}{|c|c|c|c|c|}
\hline & \multicolumn{3}{|c|}{ Einwirkzeit } \\
\hline & & 1 Minute & 5 Minuten & 15 Minuten \\
\hline \multirow{10}{*}{ 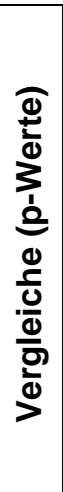 } & $\mathrm{CHX}^{(\circledR}$ vs. Meridol ${ }^{\circledR}$ & 0,2478 & 0,2883 & 0,0144 \\
\hline & $\left.\mathrm{CHX}^{(}\right)$vs. Listerine $\left.{ }^{(}\right)$ & 0,9925 & 0,1282 & 0,0882 \\
\hline & $\mathrm{CHX}^{(B)}$ vs. Betaisodona $\left.{ }^{(}\right)$ & 0,0109 & 0,4088 & 0,0281 \\
\hline & $\mathrm{CHX}^{(B)}$ vs. Octenidol $\left.{ }^{(}\right)$ & 0,0735 & 0,8904 & 0,0001 \\
\hline & Meridol ${ }^{\circledR}$ vs. Listerine ${ }^{\circledR}$ & 0,2101 & 0,8678 & 0,1878 \\
\hline & Meridol ${ }^{(}$vs. Betaisodona ${ }^{(}$ & 0,0022 & 0,1034 & 0,8683 \\
\hline & Meridol $\left.^{(}\right)$vs. Octenidol $\left.{ }^{(}\right)$ & 0,0222 & 0,2806 & 0,5488 \\
\hline & Listerine $\left.^{(}\right)$vs. Betaisodona $\left.{ }^{(}\right)$ & 0,0076 & 0,0478 & 0,2046 \\
\hline & Listerine $\left.^{(}\right)$vs. Octenidol ${ }^{\circledR}$ & 0,0685 & 0,1520 & 0,0099 \\
\hline & Betaisodona $\left.^{(}\right)$vs. Octenidol ${ }^{(\circledR)}$ & 0,8942 & 0,5196 & 0,7672 \\
\hline
\end{tabular}




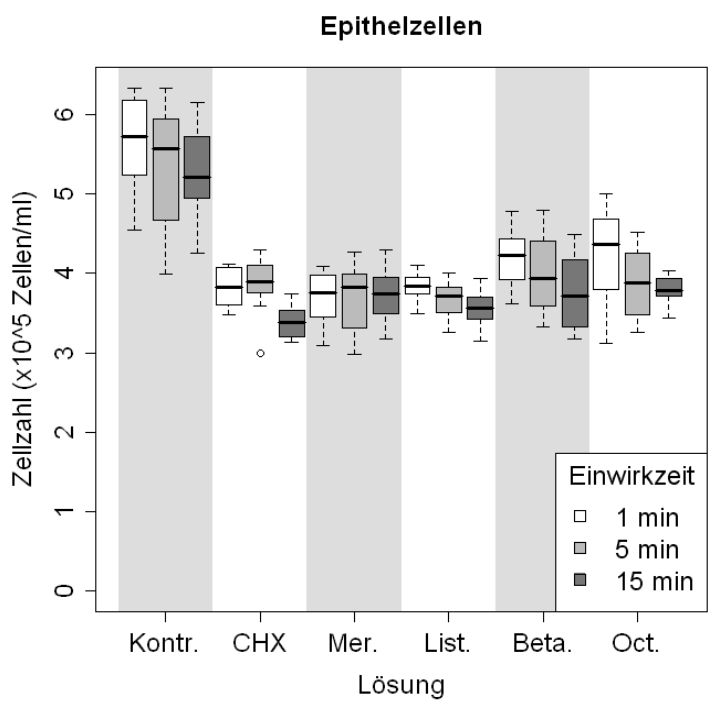

Diagramm 37: Vergleich der Mundspüllösungen in Abhängigkeit von der Einwirkzeit

\subsubsection{Wechselwirkung}

In den Varianzanalysen zeigt sich für alle Messgrößen ein signifikanter Einfluss der Lösungsart sowie der Einwirkzeit (Tab. 19). Eine signifikante Wechselwirkung zwischen Lösungsart und Einwirkzeit war bei der Zellzahlbestimmung nicht zu erkennen, d. h., die Stärke des Lösungseffekts war je nach Einwirkzeit gleich ausgeprägt.

Tabelle 19: Einflüsse der Lösung sowie der Einwirkzeit auf die Messwerte bei der optischen Zellzahlbestimmung mittels Cellometer ${ }^{\mathrm{TM}}$ Auto T4 bei den HNEPC

\begin{tabular}{|l|c|}
\hline \multicolumn{1}{|c|}{ Effekt } & p-Wert \\
\hline Lösung & $<0,0001$ \\
\hline Einwirkzeit & $<0,0001$ \\
\hline Wechselwirkung & 0,4826 \\
\hline
\end{tabular}

\subsubsection{Bestimmung der Viabilität}

Die Bestimmung der Viabilität von primären humanen nasalen Epithelzellen, d. h. der Anzahl der lebenden Zellen im Verhältnis zu den toten Zellen, wurde parallel zur optischen Zellzählung mit dem Cellometer ${ }^{\mathrm{TM}}$ Auto T4 durchgeführt. 


\subsubsection{Ergebnisse der einzelnen Antiseptika nach Einwirkzeiten}

Tabelle 20 gibt die Mittelwerte mit den dazugehörigen Standardfehlern für die Viabilitätsbestimmung mittels CellometerTM Auto T4 an. Die Viabilität der HNEPC war nach der Behandlung der Zellen mit den fünf handelsüblichen Mundspüllösungen (CHX 0,2 \% ${ }^{\circledR}$, Meridol $^{\circledR}$, Listerine ${ }^{\circledR}$, Betaisodona ${ }^{\circledR}$ und Octenidol ${ }^{\circledR}$ ) bei allen Versuchsreihen $(1,5$ und 15 Minuten) im Vergleich zur Kontrolle $(96,2 \pm 0,6 \%)$ signifikant reduziert $(\mathrm{p}<0,0001)$.

Tabelle 20: Mittelwerte und Standardfehler für die Viabilitätsbestimmung (in \%) nach der Behandlung mit oralen Antiseptika bei Epithelzellen

\begin{tabular}{|c|c|c|c|}
\hline & \multicolumn{3}{|c|}{ Einwirkzeit } \\
\hline Mundspüllösung & 1 Minute & 5 Minuten & 15 Minuten \\
\hline CHX 0,2 \% ${ }^{\circledR}$ & $75,4 \pm 1,3$ & $75,5 \pm 1,5$ & $72,5 \pm 2,1$ \\
\hline Meridol $^{\circledR}$ & $88,8 \pm 0,8$ & $87,9 \pm 1,2$ & $83,2 \pm 1,4$ \\
\hline Listerine $^{\circledR}$ & $77,7 \pm 1,0$ & $75,5 \pm 1,0$ & $68,6 \pm 0,8$ \\
\hline Betaisodona $^{\circledR}$ & $85,3 \pm 1,1$ & $79,3 \pm 1,1$ & $72,2 \pm 1,3$ \\
\hline Octenidol $^{\circledR}$ & $82,9 \pm 0,7$ & $80,4 \pm 0,8$ & $75,9 \pm 1,3$ \\
\hline
\end{tabular}

\subsubsection{Einfluss der Einwirkzeit}

Der Vergleich beschreibt die Auswirkung der antiseptischen Therapie mit den verschiedenen Mundspüllösungen auf die HNEPC-Viabilität in Abhängigkeit von der Einwirkzeit. Wegen der besseren Übersichtlichkeit werden die Vergleiche in den Diagrammen 38 bis 42 separat ohne Angabe des Standardfehlers dargestellt. Die Standardfehler sind der Tabelle 20 zu entnehmen.

Die $\mathrm{CHX}^{\circledR}$-Versuchsreihe weist eine Reduktion der Viabilität in Abhängigkeit von der Einwirkzeit der Mundspüllösung auf. Je länger das Antiseptikum auf den Zellen verbleibt, desto weniger Zellen überleben und desto kleiner wird das Verhältnis von den lebenden zu den toten Zellen. Die Werte nach einer bzw. fünf Minuten unterschieden sich nicht wesentlich voneinander. Während nach einer Minute 75,4 $\pm 1,3 \%$ der Epithelzellen vital bleiben, ist nach fünf Minuten eine Viabilität von 75,5 $\pm 1,5 \%$ und nach 15 Minuten eine Viabilität von $72,5 \pm 2,1 \%$ zu verzeichnen. 


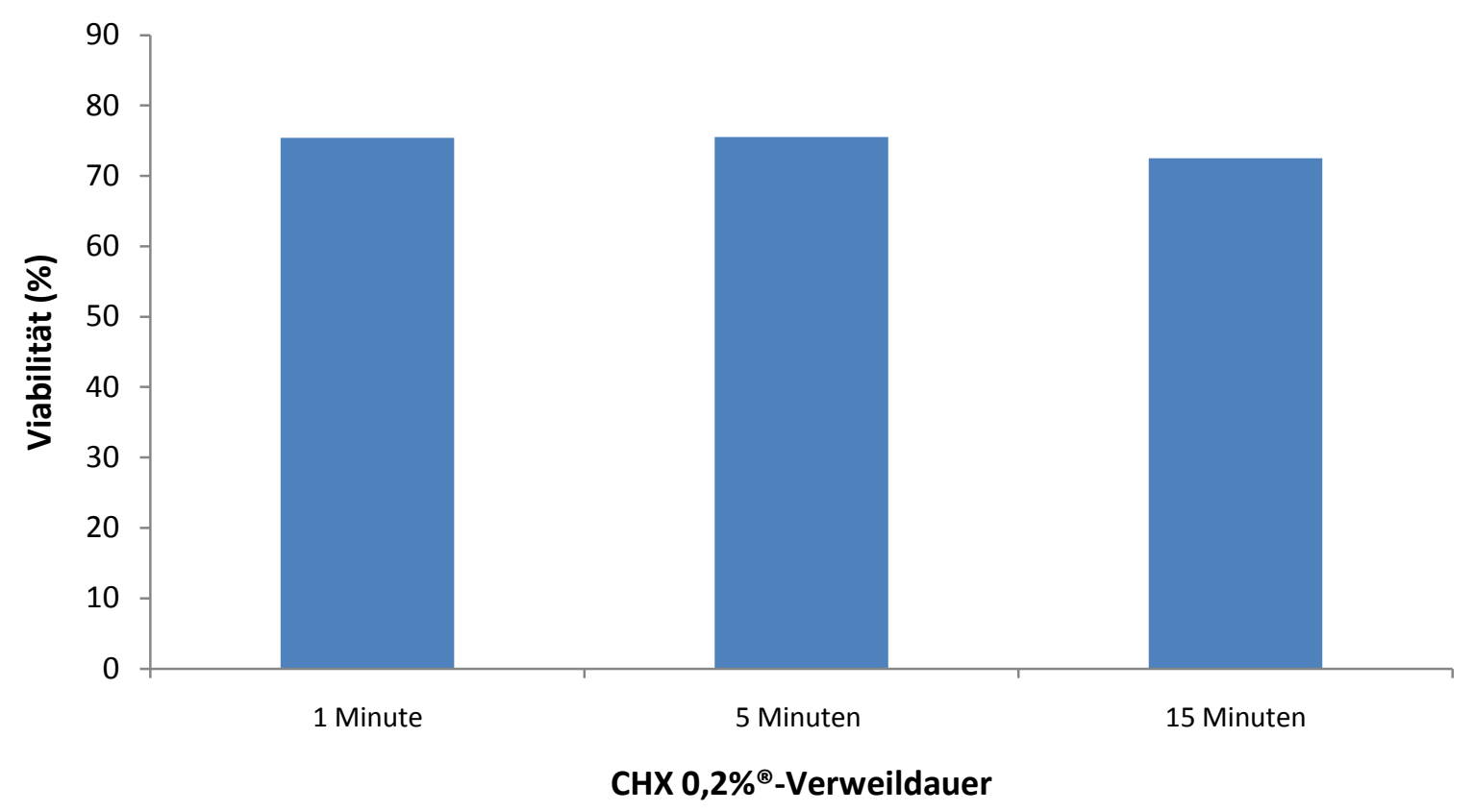

Diagramm 38: Einfluss der $\mathrm{CHX}^{\circledR}$-Mundspüllösung auf die Viabilität von HNEPC in Abhängigkeit von der Einwirkzeit

Einen ähnlichen Abfall der Viabilitätswerte wurde auch nach der Behandlung der humanen nasalen Epithelzellen mit Meridol ${ }^{\circledR}$ erzielt. Nach einer Minute konnten $88,8 \pm 0,8 \%$, nach fünf Minuten 87,9 $\pm 1,2 \%$ und nach 15 Minuten $83,2 \pm 1,4 \%$ vitale Zellen identifiziert werden.

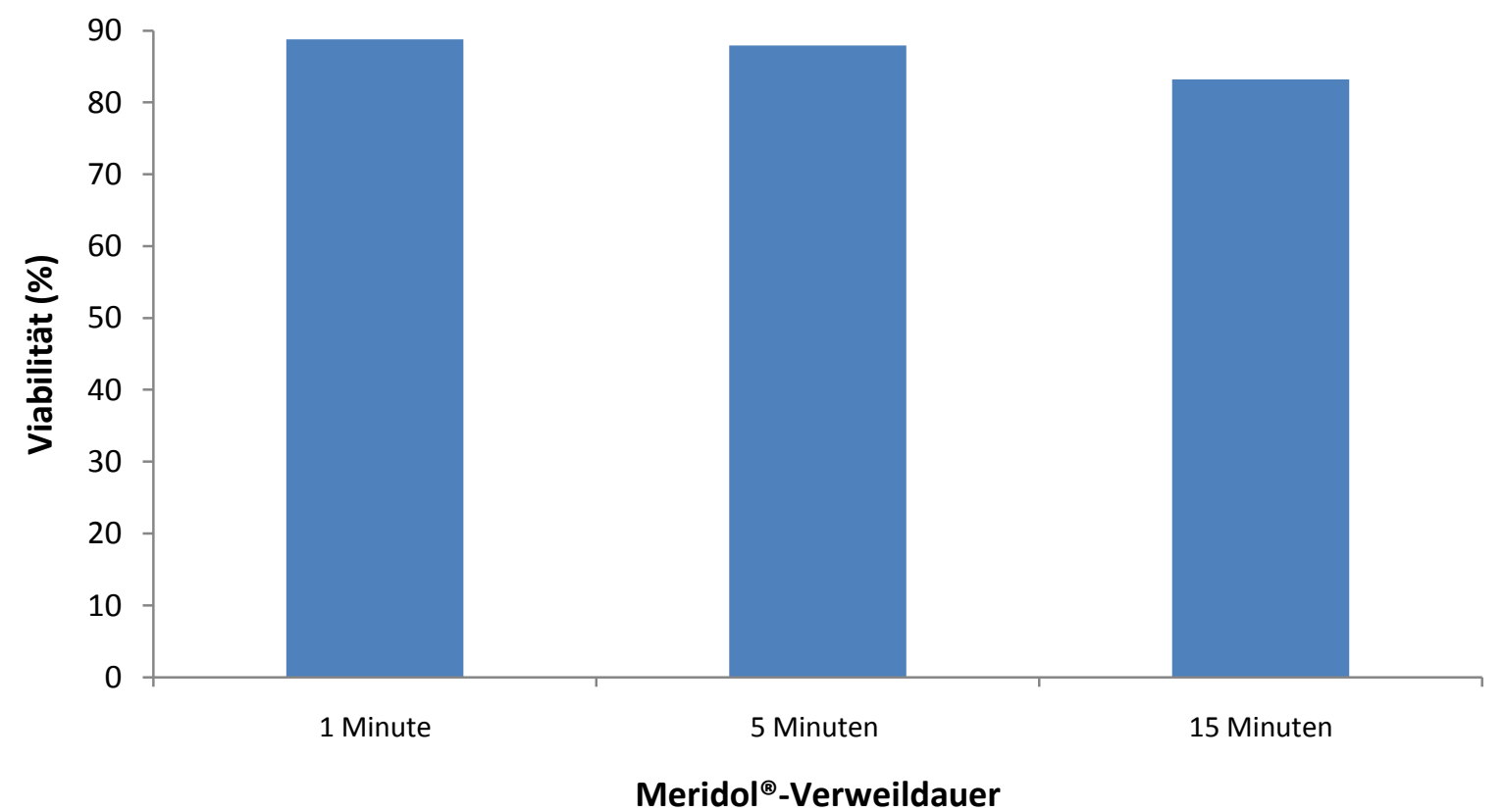

Diagramm 39: Einfluss von Meridol ${ }^{\circledR}$ auf die Viabilität von HNEPC in Abhängigkeit von der Einwirkzeit 
Die Viabilitätsbestimmungen bei den Versuchen mit der Listerine ${ }^{\circledR}$-Lösung wiesen keine wesentlichen Unterschiede zu den oben gezeigten Experimenten auf. Die Werte betrugen nach einer Minute 77,7 $\pm 1,0 \%$, nach fünf Minuten 75,5 $\pm 1,0 \%$ der Zellen. Nach 15minütiger Behandlung mit Listerine ${ }^{\circledR}$ war die Viabilität der HNEPC noch niedriger als nach einer bzw. fünf Minuten Einwirkzeit (68,6 $\pm 0,8 \%$ der Zellen).

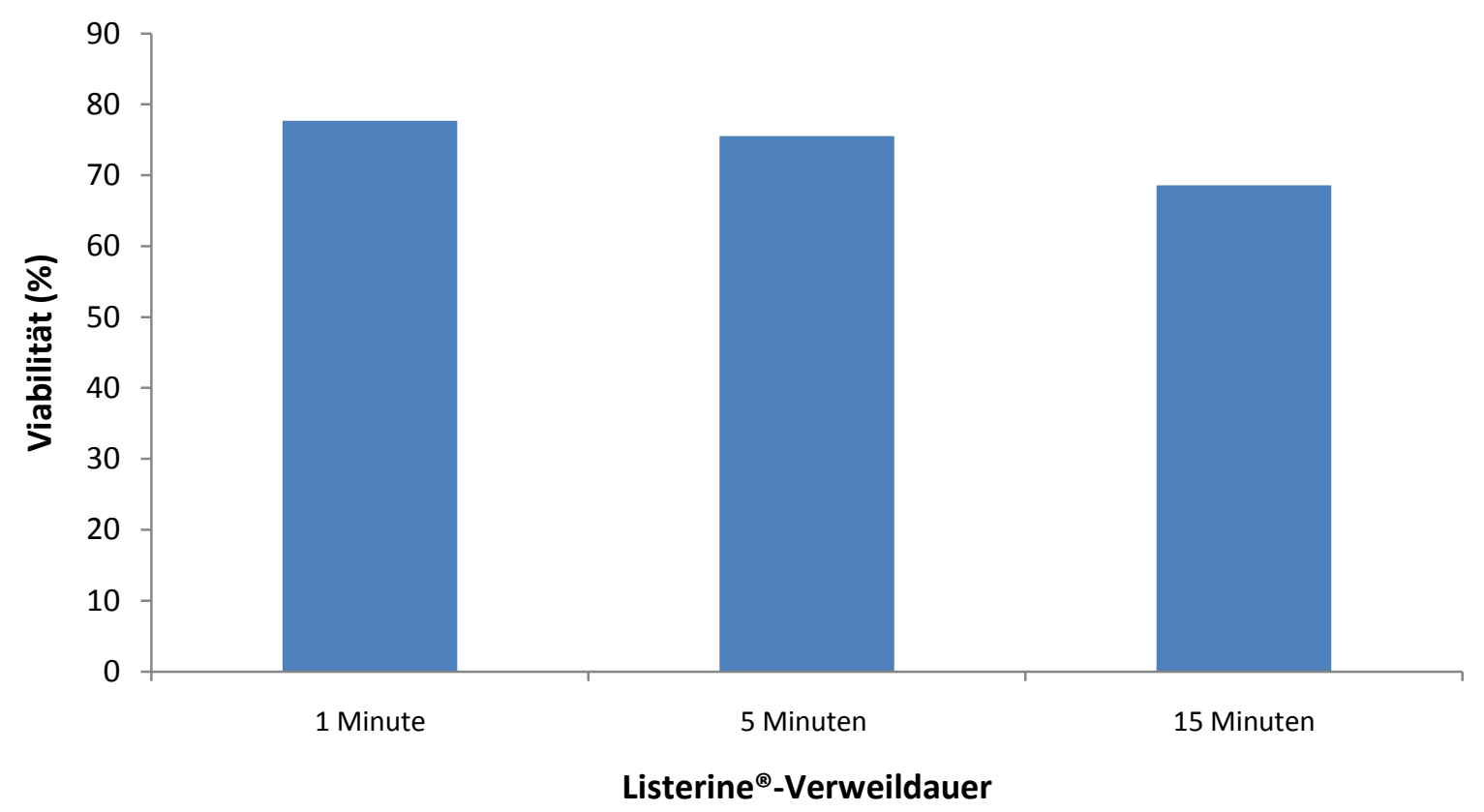

Diagramm 40: Einfluss von Listerine ${ }^{\circledR}$ auf die Viabilität von HNEPC in Abhängigkeit von der Einwirkzeit

Während nach einer Minute Einwirkzeit der Betaisodona ${ }^{\circledR}$-Mundspüllösung auf die HNEPC eine Viabilität von $85,3 \pm 1,1 \%$ bestimmt wurde, wiesen die 5-Minuten-Proben eine leicht erniedrigte Anzahl lebender Epithelzellen (79,3 \pm 1,1 \%) auf. Bei den 15-Minuten-Versuchen war eine noch weitere Reduktion der Viabilität festzustellen $(72,2 \pm 1,3 \%)$. 


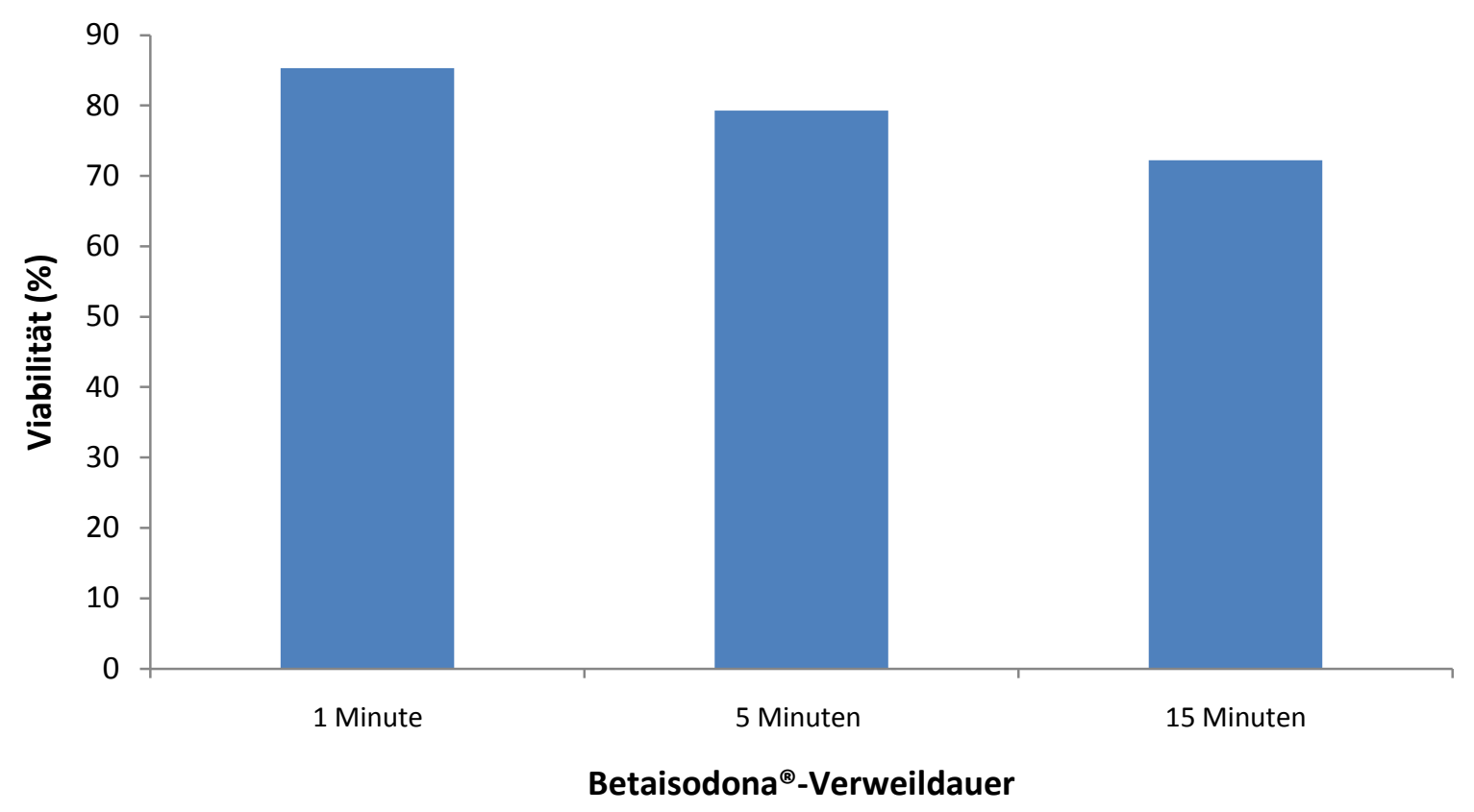

Diagramm 41: Einfluss der Betaisodona ${ }^{\circledR}$-Mundspüllösung auf die Viabilität von HNEPC in Abhängigkeit von der Einwirkzeit

Die Octenidol ${ }^{\circledR}$-Versuchsreihe wies eine ähnliche Abhängigkeit der Viabilität von der Einwirkzeit der Mundspüllösung auf. Eine längere Octenidol ${ }^{\circledR}$-Einwirkzeit beeinflusste die Zellen negativ (1 Minute: 82,9 \pm 0,7 \%; 5 Minuten: 80,4 $\pm 0,8 \%$; 15 Minuten: 75,9 $\pm 1,3 \%$ ).

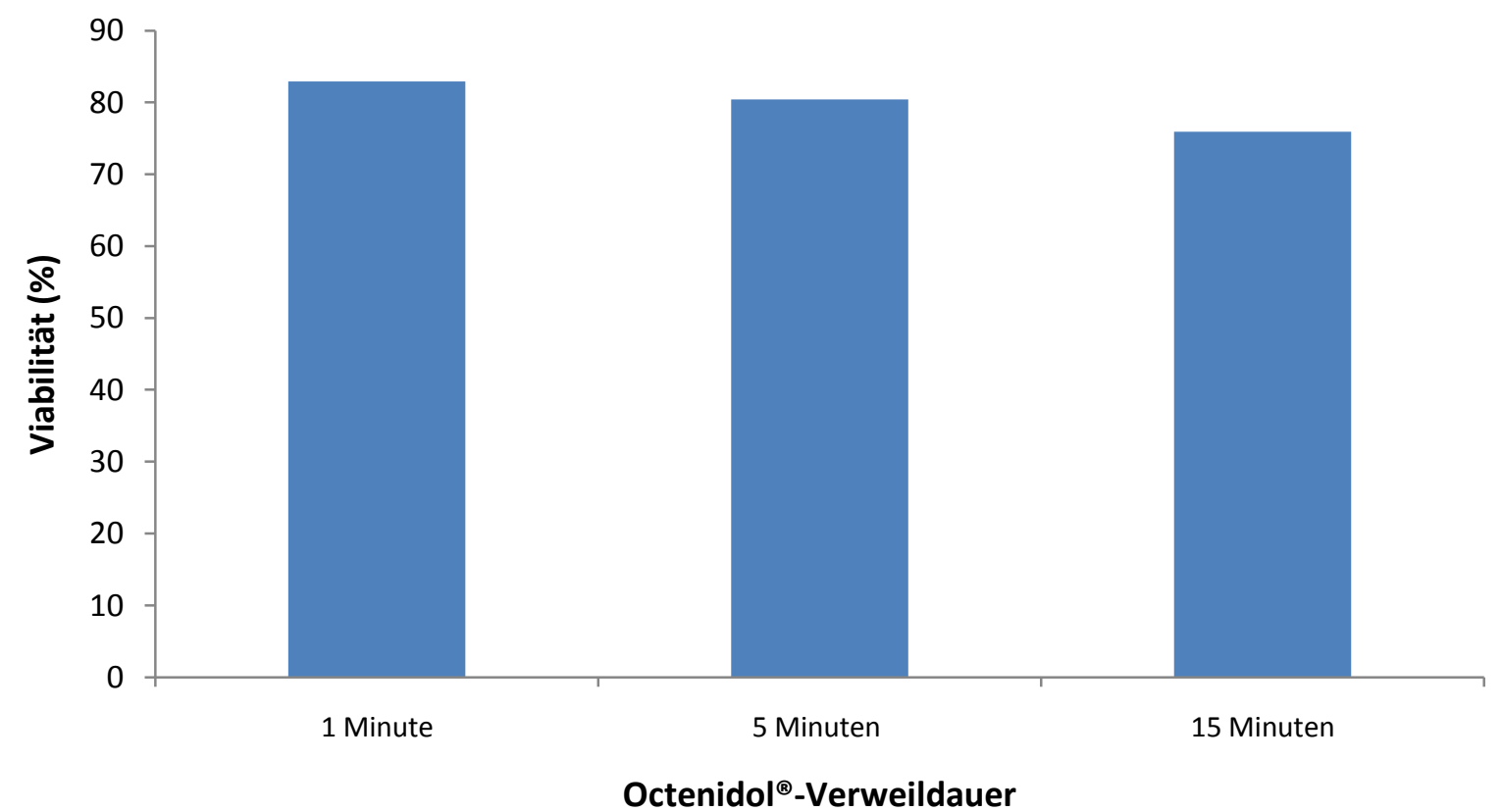

Diagramm 42: Einfluss von Octenidol ${ }^{\circledR}$ auf die Viabilität von HNEPC in Abhängigkeit von der Einwirkzeit 


\subsubsection{Vergleich der Mundspüllösungen untereinander}

Der Vergleich beschreibt die Zellwirkung der einzelnen Mundspüllösungen untereinander bei den unterschiedlichen Einwirkzeiten. Tabelle 21 gibt eine Übersicht über alle Vergleiche. Diagramm 43 stellt die entsprechenden Unterschiede zwischen den einzelnen Mundspüllösungen grafisch dar.

In der Regel liegen die Messwerte bei den fünf Mundspüllösungen immer niedriger als diejenigen der Kontrollmessungen (Diagramm 43). Außerdem sinken in den meisten Fällen die Messwerte mit zunehmender Einwirkzeit. Die Viabilität der HNEPC war bei der Anwendung von CHX $0,2 \%{ }^{\circledR}$ und Listerine ${ }^{\circledR}$ unabhängig von der Einwirkzeit deutlich reduziert. Die negative Wirkung der antiseptischen Therapie mit Betaisodona ${ }^{\circledR}$ und Octenidol $^{\circledR}$ war weniger stark ausgeprägt. Die Meridol ${ }^{\circledR}$-Versuchsreihe wies die meisten vitalen Zellen im Vergleich zu den anderen Mundspüllösungen auf.

Tabelle 21: Paarweiser Vergleich der Mundspüllösungen in Abhängigkeit von der Einwirkzeit (Signifikanzen)

\begin{tabular}{|c|c|c|c|c|}
\hline & \multicolumn{3}{|c|}{ Einwirkzeit } \\
\hline & & 1 Minute & 5 Minuten & 15 Minuten \\
\hline \multirow{10}{*}{ 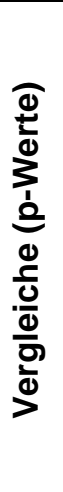 } & $\mathrm{CHX}^{(}{ }^{\circledR}$ vs. Meridol ${ }^{\circledR}$ & 0,0000 & 0,0000 & 0,0004 \\
\hline & $\mathrm{CHX}^{(B)}$ vs. Listerine ${ }^{(B)}$ & 0,1695 & 1,0000 & 0,0963 \\
\hline & $\left.\mathrm{CHX}^{(}\right)$vs. Betaisodona $\left.{ }^{(}\right)$ & 0,0000 & 0,0530 & 0,9090 \\
\hline & $\mathrm{CHX}^{(\mathbb{R})}$ vs. Octenidol $\left.{ }^{(}\right)$ & 0,0001 & 0,0089 & 0,1831 \\
\hline & Meridol $^{\circledR}$ vs. Listerine ${ }^{\circledR}$ & 0,0000 & 0,0000 & 0,0000 \\
\hline & Meridol $^{(}$vs. Betaisodona $\left.{ }^{(}\right)$ & 0,0172 & 0,0000 & 0,0000 \\
\hline & Meridol $^{\circledR}$ vs. Octenidol ${ }^{\circledR}$ & 0,0000 & 0,0001 & 0,0007 \\
\hline & Listerine $^{(\mathbb{R}}$ vs. Betaisodona $^{(\mathbb{B})}$ & 0,0000 & 0,0175 & 0,0273 \\
\hline & Listerine $^{(\circledR)}$ vs. Octenidol $\left.{ }^{(}\right)$ & 0,0003 & 0,0007 & 0,0001 \\
\hline & Betaisodona $\left.^{(}\right)$vs. Octenidol $\left.{ }^{(}\right)$ & 0,0811 & 0,4142 & 0,0575 \\
\hline
\end{tabular}




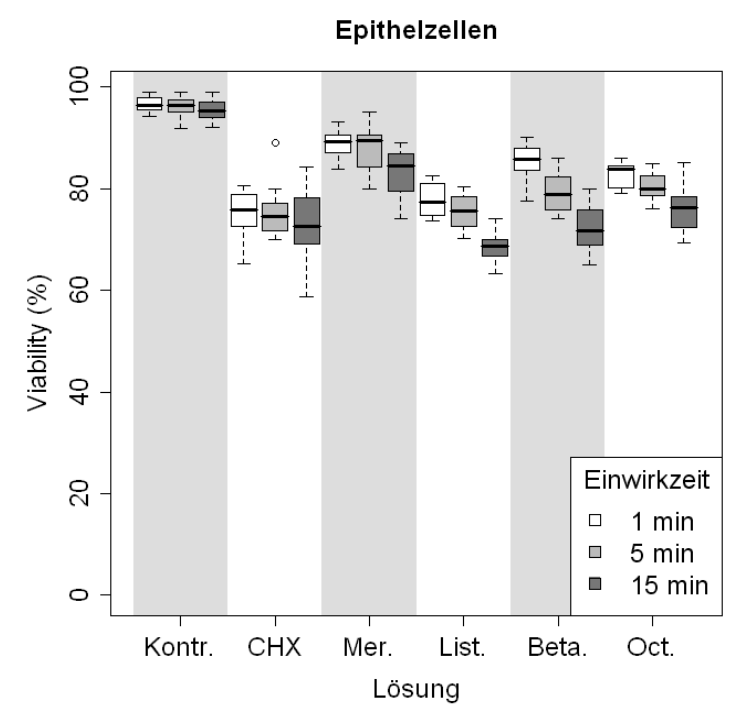

Diagramm 43: Vergleich der Mundspüllösungen in Abhängigkeit von der Einwirkzeit

\subsubsection{Wechselwirkung}

In den Varianzanalysen zeigt sich für alle Messgrößen ein signifikanter Einfluss der Lösungsart sowie der Einwirkzeit (Tab. 22). Eine signifikante Wechselwirkung zwischen Lösungsart und Einwirkzeit war bei der Viabilitätsbestimmung zu erkennen, d. h., die Stärke des Lösungseffekts war je nach Einwirkzeit unterschiedlich ausgeprägt.

Tabelle 22: Einflüsse der Lösung sowie der Einwirkzeit auf die Messwerte bei der Viabilitätsbestimmung mittels Cellometer ${ }^{\mathrm{TM}}$ Auto T4 bei den HNEPC

\begin{tabular}{|l|c|}
\hline \multicolumn{1}{|c|}{ Effekt } & p-Wert \\
\hline Lösung & $<0,0001$ \\
\hline Einwirkzeit & $<0,0001$ \\
\hline Wechselwirkung & $<0,0001$ \\
\hline
\end{tabular}

\subsubsection{Durchmesser der HNEPC nach Antiseptikabehandlung}

Die Bestimmung der mittleren Zelldurchmesser von primären humanen nasalen Epithelzellen wurde parallel zur optischen Zellzählung bzw. Viabilitätsbestimmung mit dem Cellometer ${ }^{\mathrm{TM}}$ Auto T4 durchgeführt. Das Gerät erlaubt die gleichzeitige Bestimmung aller drei Parameter ohne zusätzlichen Aufwand. 


\subsubsection{Ergebnisse der einzelnen Antiseptika nach Einwirkzeiten}

Tabelle 23 gibt die Mittelwerte mit den dazugehörigen Standardfehlern für die Bestimmung des mittleren Zelldurchmessers mittels CellometerTM Auto T4 an. Der Durchmesser der HNEPC war nach der Behandlung der Zellen mit den fünf handelsüblichen Mundspüllösungen $\left(\mathrm{CHX} \mathrm{0,2 \%}{ }^{\circledR}\right.$, Meridol $^{\circledR}$, Listerine ${ }^{\circledR}$, Betaisodona ${ }^{\circledR}$ und Octenidol $\left.{ }^{\circledR}\right)$ bei allen Versuchsreihen (1, 5 und 15 Minuten) im Vergleich zur Kontrolle (21,3 \pm 0,3 micron) signifikant reduziert $(\mathrm{p}<0,0001)$.

Tabelle 23: Mittelwerte und Standardfehler für die Bestimmung des mittleren Zelldurchmessers (in micron) nach der Behandlung mit oralen Antiseptika bei Epithelzellen

\begin{tabular}{|c|c|c|c|}
\hline & \multicolumn{3}{|c|}{ Einwirkzeit } \\
\hline Mundspüllösung & 1 Minute & 5 Minuten & 15 Minuten \\
\hline CHX 0,2 \% ${ }^{\circledR}$ & $20,8 \pm 0,4$ & $20,9 \pm 0,6$ & $19,1 \pm 0,4$ \\
\hline Meridol $^{\circledR}$ & $20,2 \pm 0,2$ & $20,2 \pm 0,1$ & $20,6 \pm 0,2$ \\
\hline Listerine $^{\circledR}$ & $18,3 \pm 0,2$ & $17,8 \pm 0,3$ & $17,3 \pm 0,4$ \\
\hline Betaisodona $^{\circledR}$ & $19,2 \pm 0,1$ & $18,7 \pm 0,1$ & $17,8 \pm 0,1$ \\
\hline Octenidol $^{\circledR}$ & $19,1 \pm 0,1$ & $18,8 \pm 0,1$ & $18,1 \pm 0,1$ \\
\hline
\end{tabular}

\subsubsection{Einfluss der Einwirkzeit}

Der Vergleich beschreibt die Auswirkung der antiseptischen Therapie mit verschiedenen Mundspüllösungen auf den mittleren Durchmesser der HNEPC in Abhängigkeit von der Einwirkzeit. Wegen der besseren Übersichtlichkeit werden die Vergleiche in den Diagrammen 44 von 48 separat ohne Angabe des Standardfehlers dargestellt. Die Standardfehler sind der Tabelle 23 zu entnehmen.

Die $\mathrm{CHX}^{\circledR}$-Versuchsreihe weist eine Reduktion des mittleren Zelldurchmessers in Abhängigkeit von der Einwirkzeit der Mundspüllösung auf. Je länger das Antiseptikum auf den Zellen verbleibt, desto kleiner werden die Epithelzellen im Durchmesser. Zwar wiesen die Ergebnisse nach einer bzw. fünf Minuten nur sehr geringe Unterschiede auf, jedoch war der Durchmesser nach 15 Minuten Behandlung deutlich reduziert. Während nach einer Minute der Durchmesser der HNEPC im Durchschnitt 20,8 \pm 0,4 micron betrug, betrug er nach fünf Minuten 20,9 \pm 0,6 micron und nach 15 Minuten 19,1 $\pm 0,4$ micron. 


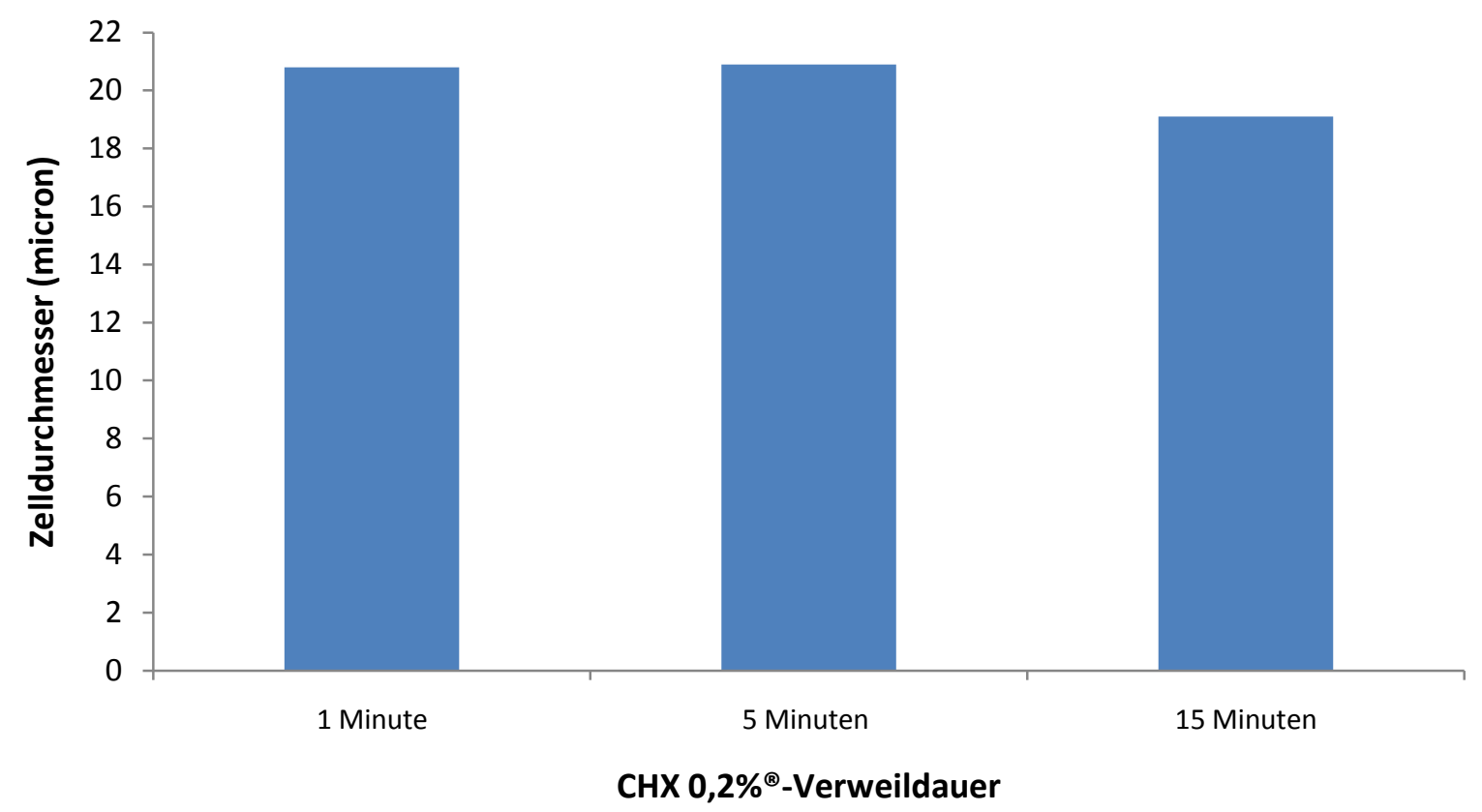

Diagramm 44: Einfluss von CHX 0,2 ${ }^{\circledR}$ auf den mittleren Durchmesser von HNEPC in Abhängigkeit von der Einwirkzeit

Ähnliche Ergebnisse wurden nach der Behandlung der humanen nasalen Epithelzellen mit Meridol $^{\circledR}$ erzielt. Der mittlere Durchmesser war nach 15-minütiger antiseptischer Behandlung im Unterschied zu den $\mathrm{CHX}^{\circledR}$-Versuchen höher als bei den 1- bzw. 5-Minuten-Versuchen. Nach einer Minute Einwirkzeit von Meridol ${ }^{\circledR}$ konnte ein Zelldurchmesser von 20,2 \pm 0,2 micron, nach fünf Minuten 20,2 $\pm 0,1$ micron und nach 15 Minuten 20,6 \pm 0,2 micron gemessen werden. 


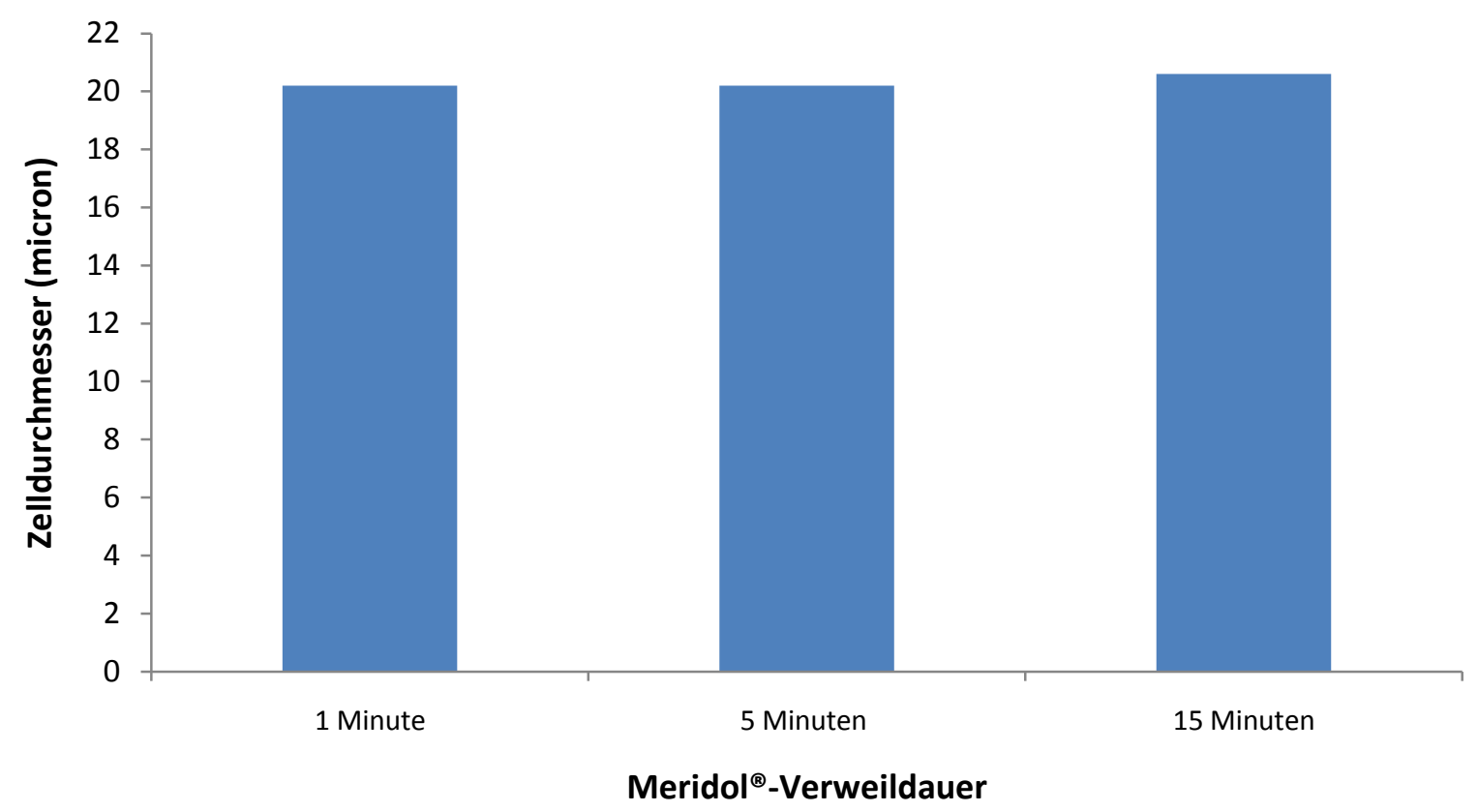

Diagramm 45: Einfluss von Meridol ${ }^{\circledR}$ auf den mittleren Zelldurchmesser der HNEPC in Abhängigkeit von der Einwirkzeit

Die Bestimmungen des mittleren Zelldurchmessers wiesen bei den Versuchen mit Listerine ${ }^{\circledR}$ Lösung wesentliche Unterschiede $\mathrm{zu}$ den oben gezeigten Experimenten auf, wobei eine abfallende Tendenz mit der Dauer der Einwirkung einherging. Die Werte für eine Minute betrugen 18,3 \pm 0,2 micron und für 5 Minuten 17,8 \pm 0,3 micron. Nach 15 Minuten war der mittlere Zelldurchmesser der HNEPC noch niedriger als nach einer bzw. fünf Minuten (17,3 \pm 0,4 micron). 


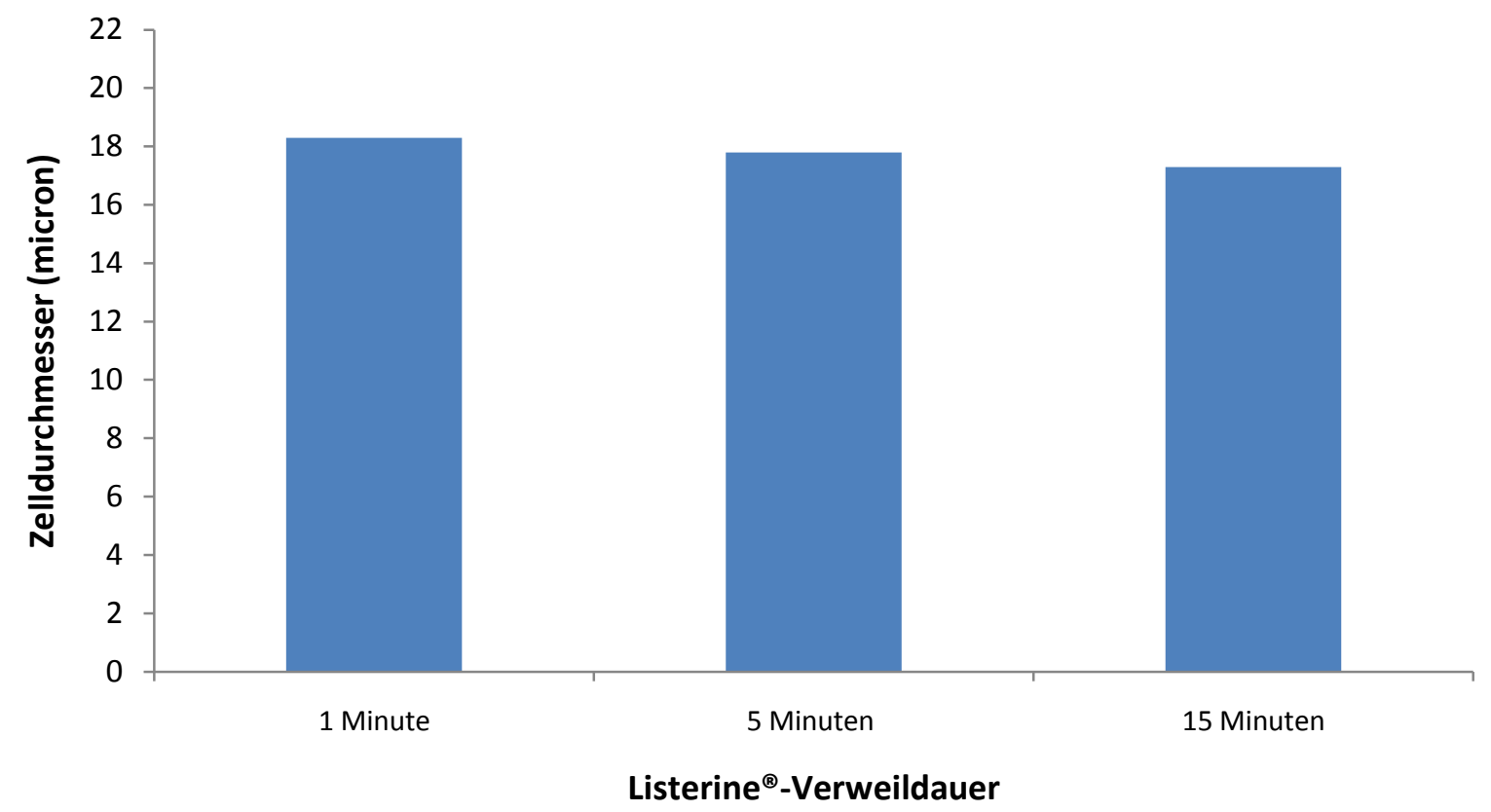

Diagramm 46: Einfluss von Listerine ${ }^{\circledR}$ auf den mittleren Zelldurchmesser der HNEPC in Abhängigkeit von der Einwirkzeit

Während nach einer Minute Einwirkzeit der Betaisodona ${ }^{\circledR}$-Mundspüllösung auf die HNEPC ein mittlerer Zelldurchmesser von 19,2 \pm 0,1 micron bestimmt wurde, wiesen die 5-MinutenProben einen leicht erniedrigten mittleren Epithelzellendiameter (18,7 $\pm 0,1$ micron) auf. Bei den 15-Minuten-Versuchen war eine noch weitere Reduktion des Zelldurchmessers zu verzeichnen $(17,8 \pm 0,1$ micron). 


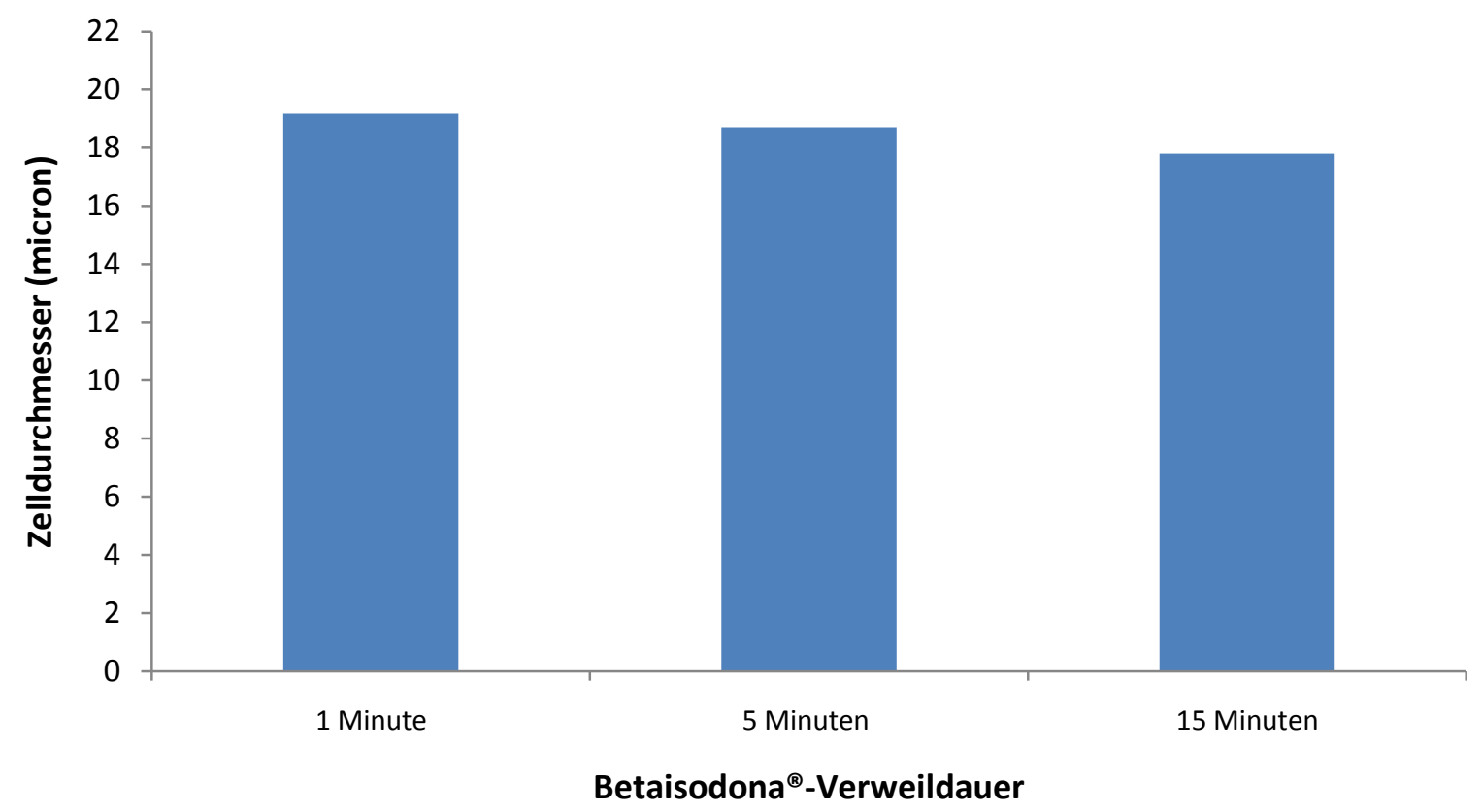

Diagramm 47: Einfluss von Betaisodona ${ }^{\circledR}$ auf den mittleren Zelldurchmesser der HNEPC in Abhängigkeit von der Einwirkzeit

Die Octenidol ${ }^{\circledR}$-Versuchsreihe wies eine ähnlich starke Abhängigkeit des mittleren Zelldurchmessers von der Einwirkzeit der Mundspüllösung auf. Die längere Einwirkzeit von Octenidol $^{\circledR}$ beeinflusste den Zelldurchmesser negativ (1 Minute: 19,1 \pm 0,1 micron; 5 Minuten: 18,8 $\pm 0,1$ micron; 15 Minuten: $18,1 \pm 0,1$ micron).

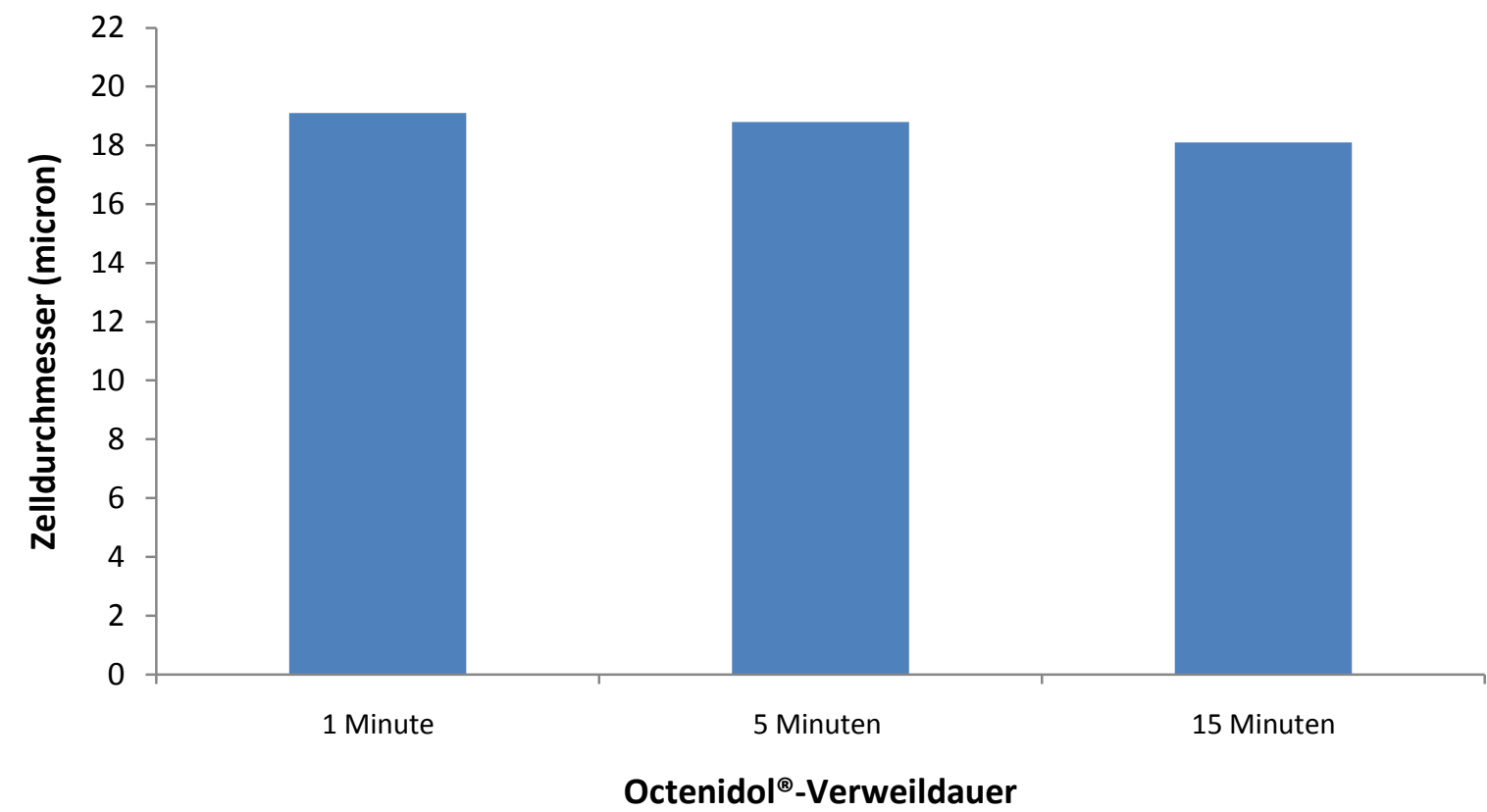

Diagramm 48: Einfluss von Octenidol ${ }^{\circledR}$ auf den mittleren Zelldurchmesser der HNEPC in Abhängigkeit von der Einwirkzeit 


\subsubsection{Vergleich der Mundspüllösungen untereinander}

Der Vergleich beschreibt die Zellwirkung der einzelnen Mundspüllösungen untereinander bei den unterschiedlichen Einwirkzeiten. Tabelle 24 gibt eine Übersicht über alle Vergleiche. Diagramm 49 stellt die entsprechenden Unterschiede zwischen den einzelnen Mundspüllösungen grafisch dar.

In der Regel liegen die Messwerte bei den fünf Mundspüllösungen immer niedriger als diejenigen der Kontrollmessungen (Diagramm 49). Außerdem sinken in den meisten Fällen die Messwerte mit zunehmender Einwirkzeit. Bei der Behandlung der HNEPC mit CHX 0,2 $\%{ }^{\circledR}$ und Meridol ${ }^{\circledR}$ war eine geringe Abweichung der Werte für den mittleren Zelldurchmesser von der Kontrolle zu verzeichnen. Der mittlere Zelldiameter war nach der Anwendung von Betaisodona $^{\circledR}$ und Octenidol ${ }^{\circledR}$ unabhängig von der Einwirkzeit deutlich reduziert. Die negative Wirkung von Listerine ${ }^{\circledR}$ war am stärksten ausgeprägt.

Tabelle 24: Paarweiser Vergleich der Mundspüllösungen in Abhängigkeit von der Einwirkzeit (Signifikanzen)

\begin{tabular}{|c|c|c|c|c|}
\hline & \multicolumn{3}{|c|}{ Einwirkzeit } \\
\hline & & 1 Minute & 5 Minuten & 15 Minuten \\
\hline \multirow{10}{*}{ 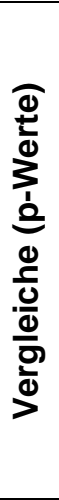 } & $\mathrm{CHX}^{(B}$ vs. Meridol ${ }^{(B)}$ & 0,1645 & 0,2494 & 0,0028 \\
\hline & $\mathrm{CHX}^{\circledR}$ vs. Listerine ${ }^{\circledR}$ & 0,0000 & 0,0001 & 0,0053 \\
\hline & $\mathrm{CHX}^{(\mathbb{R})}$ vs. Betaisodona $\left.{ }^{(}\right)$ & 0,0014 & 0,0021 & 0,0069 \\
\hline & $\mathrm{CHX}^{(}{ }^{(}$vs. Octenidol ${ }^{\circledR}$ & 0,0009 & 0,0028 & 0,0207 \\
\hline & Meridol $^{(B)}$ vs. Listerine ${ }^{(B)}$ & 0,0000 & 0,0000 & 0,0000 \\
\hline & Meridol $^{(}$vs. Betaisodona $\left.{ }^{(}\right)$ & 0,0000 & 0,0000 & 0,0000 \\
\hline & Meridol $^{(\mathbb{R}}$ vs. Octenidol $^{(\circledR)}$ & 0,0000 & 0,0000 & 0,0000 \\
\hline & Listerine $^{(}{ }^{\circ}$ vs. Betaisodona $\left.{ }^{(}\right)$ & 0,0041 & 0,0124 & 0,2692 \\
\hline & Listerine $^{(\mathbb{R}}$ vs. Octenidol $\left.{ }^{(}\right)$ & 0,0083 & 0,0064 & 0,1176 \\
\hline & Betaisodona $\left.^{(}\right)$vs. Octenidol $\left.{ }^{(}\right)$ & 0,4822 & 0,4728 & 0,1587 \\
\hline
\end{tabular}




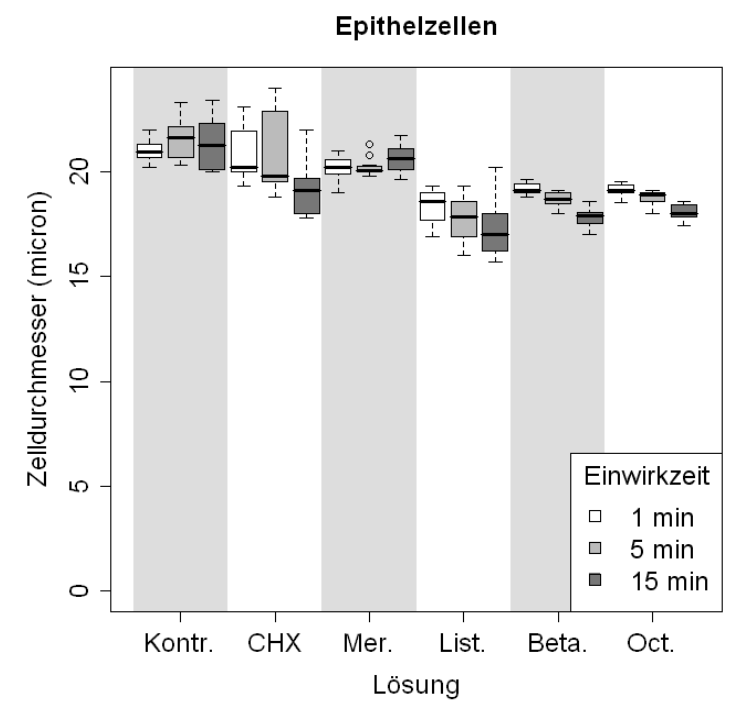

Diagramm 49: Vergleich der Mundspüllösungen in Abhängigkeit von der Einwirkzeit

\subsubsection{Wechselwirkung}

In den Varianzanalysen zeigt sich für alle Messgrößen ein signifikanter Einfluss der Lösungsart sowie der Einwirkzeit (Tab. 25). Eine signifikante Wechselwirkung zwischen Lösungsart und Einwirkzeit war bei der Bestimmung des mittleren Zelldurchmessers der HNEPC nach der antiseptischen Therapie zu erkennen, d. h., die Stärke des Lösungseffekts war je nach Einwirkzeit unterschiedlich ausgeprägt.

Tabelle 25: Einflüsse der Lösung sowie der Einwirkzeit auf die Messwerte bei der Bestimmung des mittleren Zelldurchmessers von HNEPC mittels Cellometer ${ }^{\mathrm{TM}}$ Auto T4

\begin{tabular}{|l|c|}
\hline \multicolumn{1}{|c|}{ Effekt } & p-Wert \\
\hline Lösung & $<0,0001$ \\
\hline Einwirkzeit & $<0,0001$ \\
\hline Wechselwirkung & 0,0003 \\
\hline
\end{tabular}

\subsubsection{Vergleich von MTT-Test und optischer Zellcharakterisierung mittels Cellometer ${ }^{\mathrm{TM}}$ Auto T4}

Der MTT-Test basiert auf einer fotometrischen Bestimmung der metabolischen Aktivität von der zu untersuchenden Zellen. Die Gesamtzellzahl, die Viabilität und der mittlere Zelldurchmesser wurden in der vorliegenden Studie optisch mit dem Cellometer ${ }^{\mathrm{TM}}$ Auto T4 
bestimmt. Dabei wurde der Frage nachgegangen, ob die beiden Methoden miteinander korrelieren.

Da die Kontrollmessungen stets stark von den Messungen bei den anderen Lösungen abwichen, wurden sie nicht in die Korrelationsberechnungen zwischen MTT-Test und Zellzahlbestimmung mit einbezogen (Diagramm 50). Im Gegensatz zu den FibroblastenVersuchen konnte bei den NHEPC kein Zusammenhang zwischen beiden Methoden festgestellt werden $(r h o=0,03, \mathrm{p}<0,71)$.

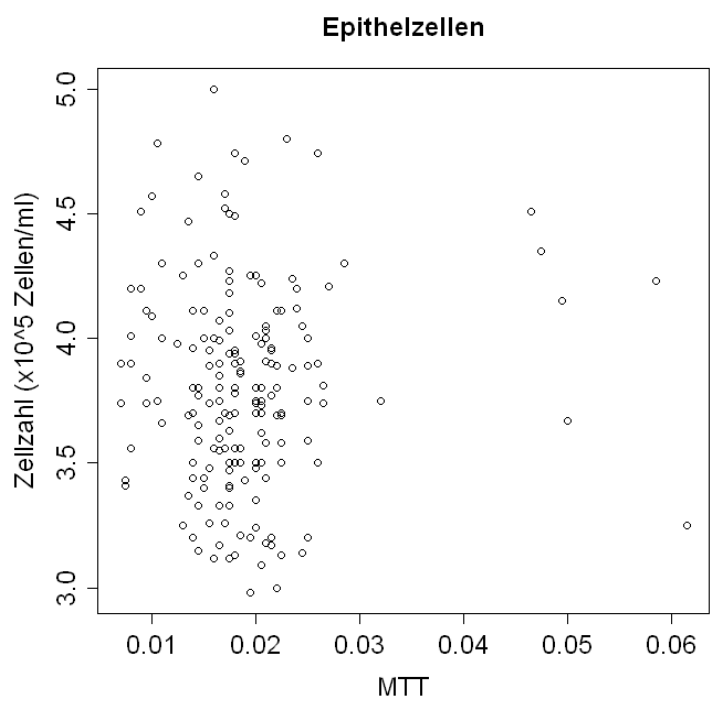

Diagramm 50: Korrelationsbestimmung zwischen MTT-Test und Zellzahlbestimmung mittels Cellometer ${ }^{\mathrm{TM}}$ Auto T4 für HNEPC 


\section{Diskussion}

In dieser Studie sollte untersucht werden, inwiefern die handelsüblichen oralen Antiseptika die Proliferationsfähigkeit bzw. Vitalität der primären humanen Zellen in Abhängigkeit von der Einwirkzeit beeinflussen. Dazu wurden die Gingivafibroblasten und die nasalen Epithelzellen in einer Zellkultur mit den Mundspüllösungen unterschiedlich lang behandelt. Die metabolische Aktivität, die Gesamtzellzahl, die Viabilität und der mittlere Durchmesser der Zellen wurden mittels MTT-Test und Cellometer ${ }^{\mathrm{TM}}$ Auto T4 ermittelt. Das Augenmerk lag auf dem Vergleich der beiden Methoden.

In den Varianzanalysen zeigt sich für alle Messgrößen ein signifikanter Einfluss der Lösungsart sowie der Einwirkzeit. Außer bei der Zellzahl ist auch bei allen anderen Parametern eine signifikante Wechselwirkung zwischen Lösungsart und Einwirkzeit zu erkennen, d.h., die Stärke des Lösungseffekts ist je nach Einwirkzeit unterschiedlich ausgeprägt. Die Dunnet-Vergleiche ergaben, dass sich jede der Mundspüllösungen signifikant von der Kontrolle absetzt. Dabei liegen die Messwerte bei den fünf Spüllösungen in der Regel immer niedriger als diejenigen der Kontrollmessungen. Außerdem sinken in den meisten Fällen die Messwerte mit zunehmender Einwirkzeit.

Da die Kontrollmessungen stets stark von den Messungen bei den anderen Lösungen abweichen, wurden sie nicht in die Korrelationsberechnungen zwischen MTT und Zellzahl mit einbezogen. Zwischen beiden Methoden wurde bei den Fibroblasten ein signifikanter positiver Zusammenhang ermittelt. Bei den Epithelzellen konnte zwischen diesen beiden Parametern kein Zusammenhang erkannt werden.

\subsection{Material und Methode}

\subsubsection{Testverfahren}

In dieser Studie wurde die Einwirkung der handelsüblichen Mundspüllösungen auf die Zellen der Mundschleimhaut und des Parodontalapparates mittels MTT-Test untersucht. Dabei sollten Rückschlüsse auf die Zellvitalität und Proliferation der Zellen gezogen werden. Der Nachweis der Zellvitalität mittels MTT-Test beruht auf der Reduktion des gelben, wasserlöslichen Farbstoffs 3-(4,5-Dimethylthiazol-2-yl)-2,5-diphenyltetrazoliumbromid (MTT) in ein blau-violettes, wasserunlösliches Formazan. Früher wurde angenommen, dass MTT durch mitochondriale Succinat-Dehydrogenasen reduziert wird. Untersuchungen in den 
letzten Jahren legen jedoch nahe, dass die Reduktion hauptsächlich von den pyridinhaltigen Reduktionsäquvivalenten NADH und NADPH und nur teilweise von Succinat abhängig ist. Die Menge des umgesetzten und letztendlich gemessenen Farbstoffs entspricht damit der Glykolyserate der Zellen per se und ist somit weniger ein Maß für die Zellatmung, wie früher angenommen wurde. Die Reduktion von MTT durch NADH und NADPH ist abhängig von Enzymen des Endoplasmatischen Retikulums. Die partielle Reduktion von MTT durch Succinat in den Mitochondrien dagegen ist abhängig von dem Enzym SuccinatDehydrogenase, das zum mitochondrialen Komplex II gehört (MOSMANN 1983, BERRIDGE et al. 1996a, BERRIDGE und TAN 1993). Folglich bestimmt der MTT-Test die Glykolyserate der zu untersuchenden Zellen. Es ist nur bedingt möglich, aus den MTTWerten die Vitalität und Proliferationsfähigkeit der behandelten Zellen abzuleiten. Der MTTTest ist ein seit Langem standardisiertes Verfahren und bietet eine preiswerte Alternative zu den anderen Methoden an. Obwohl einige Studien den MTT-Test als alleinige Nachweismethode für ihre Experimente anwenden (FLEMINGSON et al. 2008), reicht dieses Verfahren allein nicht aus, um die Zellvitalität und die Proliferationsfähigkeit zu untersuchen. Die notwendige Solubilisierung des Reaktionsproduktes und die Abhängigkeit des Ergebnisses vom Glucosegehalt des Mediums sind entscheidende Nachteile, die durch die Entwicklung weiterer Tetrazoliumsalze (XTT, WST-1) ausgeglichen werden können. WST-1 wird in einer gebrauchsfertigen NADH-haltigen Testlösung angeboten und von einer Vielzahl verschiedener Zellarten innerhalb kurzer Zeit zum dunkelroten, wasserlöslichen Formazan reduziert. Dieses Reaktionsprodukt ist ohne weiteren Arbeitsschritt fotometrisch detektierbar. Da WST-1 nicht zytotoxisch wirkt, sind Messungen an einer Zellkultur in bestimmten Zeitabständen (Stunden bis Monate) möglich. Aufgrund dieser einfachen und schnellen Durchführung und Reproduzierbarkeit eignet sich diese Methode für Screening-Tests (TOMINAGA et al. 1999). Der zugrunde liegende Mechanismus ist allerdings noch nicht genau bekannt. Da die Anwesenheit von Mitochondrien oder der Superoxiddismutase die Formazanbildung hemmt, wird angenommen, dass diese Reaktion Superoxid-abhängig ist und extrazellulär und/oder membrangebunden stattfindet (BERRIDGE et al. 1996a, TOMINAGA et.al. 1999). TAN und BERRIDGE (2000) untersuchten den Mechanismus der WST-1Reduzierung unter Einsatz von 15 verschiedenen Zellkulturen. Die Autoren wiesen zunächst darauf hin, dass die Zellmembranen in komplexer und ständiger Kommunikation mit dem Extra- und Intrazellularraum stehen, wozu eine ständige Reduzierung extrazellulär vorliegender Substanzen notwendig ist. Dazu existieren vermutlich verschiedene komplexe (trans)membrane Enzymsysteme (Oxidoreduktasen), die interagieren. Die Autoren wiesen 
nach, dass auf den Zellmembranen gesunder, teilungsfähiger Zellen eine Oxidoreduktase existiert, die in Anwesenheit von NADH oder anderen in Körperflüssigkeiten natürlicherweise vorliegenden Kofaktoren das WST-1 zu Formazan reduziert. Damit wurde nachgewiesen, dass WST-1 die Zellmembran nicht penetriert und folglich nicht zytotoxisch wirkt (TAN und BERRIDGE 2000).

In weiteren Testsystemen kann das Vorhandensein der Kofaktoren NADH und ATP (Primärzellen und Zelllinien) zur Bestimmung der Zahl lebender Zellen ausgenutzt werden. Appliziertes Resazurin wird $\mathrm{NAD}^{+}$-abhängig zum pinkfarbenen, fluoreszierenden Resurfin reduziert. Luciferin wird unter ATP-Aufwand und Verbrauch molekularen Sauerstoffs zu Oxyluciferin oxidiert, wobei $\mathrm{CO}_{2}$ und Licht entstehen. Die jeweiligen Signale werden im Fluoreszenz-, Spektralphotometer bzw. Luminometer oder mit einer CCD-Kamera detektiert (Promega GmbH, 2003, 1 Proliferations assays).

Der MTT-Test ist ein Standardtest für die Bestimmung der metabolischen Aktivität der Zellen in vitro, der bei alleiniger Anwendung nur eingeschränkt Aussagen über die Vitalität, Zellzahl und Proliferationsfähigkeit der Zellen treffen lässt. Aus diesem Grund wurde in der vorliegenden Studie parallel zum MTT-Test bei jedem Versuch eine optische Zellzählung nach dem Prinzip der Trypan-Blau-Färbung durchgeführt. Der Cellometer ${ }^{\text {TM }}$ Auto T4 erlaubt die gleichzeitige automatische Zellzahl-, Viabilität- und Zelldurchmesserbestimmung in einem Vorgang. Die Zellzählung erlaubt einerseits die Quantifizierung der Ergebnisse, andererseits können die Werte, die mit dem MTT-Test ermittelt wurden, mit den gewonnenen Daten verglichen werden. THEISZOVA et al. 2005 verwendeten in ihrer Studie die manuelle Zellzählung mittels einer Zellkammer und der Trypan-Blau-Färbung der Zellen als Kontrolle des MTT-Tests, um die Toxizität von Hydroxylapatit für eine Fibroblastenzelllinie zu untersuchen. Die in dieser Studie angewendete Methode erlaubte dagegen eine vollautomatische Zellzahlbestimmung in einer industriell mit dem Trypan-Blau-Farbstoff beschichteten Zellkammer. Mit dem CellometerTM Auto T4 können Ungenauigkeiten bei der Verdünnung, Färbung und Zellzahlausrechnung vermieden werden, die bei der manuellen Zellzahlbestimmung auftreten können. Gleichzeitig konnte die Viabilität gemessen werden, was ansonsten ein weiteres Verfahren erforderlich macht.

Als Alternativverfahren könnte man ebenfalls eine Zellkoloniezählung unter Einsatz des Umkehrmikroskops durchführen. Die dazu benötigte Überführung der adhärent wachsenden Zellen (z. B. Fibroblasten und Epithelzellen) in eine Suspension wird auch bei der Zellzahlbestimmung mittels Cellometer ${ }^{\mathrm{TM}}$ Auto T4 angewendet und wirkt teilweise zellzerstörend, was ein entscheidender Nachteil beider Methoden darstellt. Folglich hat das 
Ablösen der Zellen einen Einfluss auf das Zählergebnis. Des Weiteren müssen die Zellen mit dem Trypanblau angefärbt werden. Trypan-Blau dient der Unterscheidung zwischen lebenden und toten Zellen. Die Verdünnung der Zellsuspension sollte erst direkt vor Befüllung der Zellkammer erfolgen, um den toxischen Effekt des Trypan-Blaus auf die Zellen zu minimieren. Diese Methoden sind hochsensibel und reproduzierbar (SCHÄRFE 2004). Durch mikroskopische Beobachtung lässt sich außerdem die Konfluenz des Zellrasens sowie die Morphologie der Einzelzellen bewerten (LINDL und BAUER 1994, PINTO et al., 1983).

Zelluläre Lebensprozesse sind mit unterschiedlichen Methoden nachweisbar und werden durch bioaktive Substanzen moduliert. Die verschiedenen Zellviabilität-Nachweismethoden geben u. a. Aufschluss über die Anzahl gesunder Zellen in einer Probe bzw. deren Veränderung im Zeitverlauf (Proliferation), die Integrität der Zellmembran oder den Differenzierungsgrad. Hierbei werden einerseits unspezifische Merkmale untersucht, die größtenteils unabhängig vom Zelltyp sind: Zelldimensionen (Volumen und Größe), metabolische Aktivität oder Permeabilität der Zellmembranen für spezifische Substanzen (z. B. Farbstoffe). Andererseits werden spezifische Merkmale nachgewiesen durch Einsatz unter anderem der ELISA-Technik, der Durchflusszytometrie oder der Fluoreszenzmikroskopie. Zum Nachweis von Zelldifferenzierung wird die Ausprägung der zellartspezifischen Merkmale untersucht (HARTMANN und MEISEL 2007).

Der Cellometer ${ }^{\mathrm{TM}}$ Auto T4 erlaubt schließlich die Bestimmung des mittleren Zelldurchmessers. Die Abweichung dieses Wertes von der Norm kann auf eine eventuelle Zytotoxizität oder eine proliferationshemmende Wirkung der angewendeten Substanzen hindeuten.

Eine weitere Untersuchungsmethode, die es erlaubt, verschiedene Eigenschaften einer Zelle gleichzeitig zu messen, ist die Durchflusszytometrie. Es können die Zellgröße, die Zellgranularität und die Intensität mehrerer Fluorochrome simultan gemessen werden. Die Bindung der Fluorochrome (z. B. FITC) an Antiköper, die gegen das zu untersuchende Antigen gerichtet sind, ermöglicht sowohl die Untersuchung von Strukturen auf der Zelloberfläche als auch im Zytoplasma. Die Fluorochrom-Menge ist proportional zur Anzahl der Bindungsstellen der Antiköper an den Antigenen. Die von den Fluorochromen emittierte Intensität nach der Anregung durch den Laser stellt somit ein Maß für die Anzahl an Bindungsstellen des gewählten Antikörpers dar. Neben den Fluoreszenzsignalen wird in der Durchflusszytometrie auch das Streulicht des Lasers registriert. Sowohl die Größe als auch die Form, Oberfläche und Granularität der Zellen beeinflussen das gestreute Licht, sodass sich ausgehend vom Charakter der Streuung Rückschlüsse auf Zelleigenschaften ziehen lassen. 
Die Zellproliferation kann außerdem anhand der zellulären DNA-Syntheseleistung durch den Einsatz handelsüblicher Reagenzien-Kits quantifiziert werden. Der Nachweis kann dabei im Szintillationszähler oder durch Einsatz peroxidasegekoppelter Antikörper und geeigneter Substrate im ELISA-Photometer erfolgen. Anderen Phasen des Zellzyklus können mithilfe unterschiedlicher monoklonaler Antikörper untersucht werden, die an zellkernassoziierte Proteine binden. Diese Nachweise greifen jedoch nur auf Einzelzellebene (in situ) und beruhen auf immunozytochemischen und -histochemischen Techniken (BHUTIA et al. 2008, TOMINAGA et al. 1999).

Für die weiterführende detailierte Untersuchung der Vorgänge in der Zelle können mehrere Testverfahren angewendet werden. Eines davon ist die Messung des transepithelialen elektrischen Widerstandes (TEER). Adhärente Zellen (z. B. Fibroblasten oder Epithelzellen) bilden in Kultur innerhalb kurzer Zeit einen Monolayer. Die Anzahl und Funktionsfähigkeit der Zell-Zell-Kontakte, sogenannter tight junctions, nimmt unter günstigen Kulturbedingungen zeitabhängig zu und ist durch Inkubation mit bioaktiven Substanzen modulierbar. Der Vorteil dieses Messsystems liegt darin, dass es keinen modulierenden Einfluss auf die Zellvitalität aufweist, sodass Verlaufsuntersuchungen über lange Zeiträume möglich sind. Liegt ein konfluenter Monolayer vor, so steigt der TEER mit der Anzahl und Funktionsfähigkeit der tight junctions an und die parazelluläre Durchlässigkeit für niedermolekulare, wasserlösliche Substanzen nimmt ab. Infolgedessen ist die MonolayerIntegrität zusätzlich durch Transportstudien nachweisbar, wobei niedermolekulare, wasserlösliche Referenzsubstanzen die tight junctions passieren: unter anderem Mannitol, Phenolrot, Lucifer Yellow, Inulin oder Flourescein. Die Substanzsignale werden mithilfe von Fotometrie, Flourometrie, Lumineszens- oder Radioaktivitätsmessungen detektiert (CATALIOTO et al. 2009, CALABRO et al. 2008, IWASAKI et al. 1999).

Das Überleben der Fibroblasten bzw. Epithelzellen nach der Behandlung mit den verschiedenen oralen Antiseptika kann auch mit dem ATP-Biolumineszenztest untersucht werden. Als Marker für die Zellproliferation und das Überleben der Zellen wurde Adenosintriphosphat (ATP), das nur von lebendigen Zellen produziert werden kann, verwendet. Die ATP-Produktion wurde dabei mittels der Luciferin-Luciferase-Reaktion quantifiziert, wie von CROUCH et al. 1993 beschrieben. Die Methode basiert auf der Quantifizierung der Zellzahl durch die Menge des produzierten ATP. Die Messung der Lumineszenz kann anschließend im Lumineszenzdetektor erfolgen. Die HintergrundLumineszenz kann detektiert werden, indem lediglich die Kontrollwells ohne Zellen gemessen werden. 
Mithilfe der ATP-Biolumineszenz kann die Anzahl der lebenden Zellen bestimmt werden. Er erlaubt jedoch keine Unterscheidung zwischen überlebenden Zellen und solchen Zellen, die durch Proliferation neu entstanden sind. Um zwischen Zellen, die lediglich nicht proliferieren, und überlebenden Zellen, die nicht zugrunde gegangen sind, zu unterscheiden, eignet sich die Messung der Laktatdehydrogenase (LDH). LDH wird aus zerstörten Zellen freigesetzt und kann dann im Kulturmedium nachgewiesen werden. In den Kulturen, in denen die Zellen lediglich in ihrer Proliferation stagnieren, findet hingegen keine LDH-Aktivität statt. Dieses intrazelluläre Enzym ist ausschließlich nach Zerstörung von Zellmembranen im Kulturüberstand vorhanden und oxidiert Lactat zu Pyruvat, wobei $\mathrm{NAD}^{+}$reduziert wird. In einer zweiten Reaktion wird ein Tetrazoliumsalz (INT) zum kolorimetrisch messbaren roten Formazan reduziert. Die Absorption des roten Reaktionsproduktes kann in Photometer bestimmt werden.

Die Neutralrot-Färbung ist eine weitere validierte Referenzmethode für Zytotoxizitätsuntersuchungen. Der Farbstoff Neutralrot penetriert Membranen vitaler Zellen und wird in Lysosomen akkumuliert. Nach dem Entfernen nicht transportierter Farbstoffreste werden die Zellen fixiert und lysiert und Neutralrot wird freigesetzt. Dieses wird nachfolgend fotometrisch detektiert. Die Farbintensität korreliert direkt mit der Zellzahl.

Die toxische Wirkung der oralen Antiseptika kann apoptotische Prozesse in den Zellen hervorrufen. Da die Zelle eine gewisse Zeit von der Induktion der Apoptose bis zum vollständigen Zelltod benötigt, ist es von Bedeutung, die apoptotischen Zellen bei der Bestimmung von Zellzahl, Viabilität und Proliferationsfähigkeit zu identifizieren und bei der Auswertung zu berücksichtigen. Die Mundschleimhaut wird durch Apoptose vor der permanenten mutagenen Gefahr aus der Nahrung geschützt (BHUTIA et al. 2008, LÖFFLER und PETRIDES 1997, REHNER und DANIEL 1999). Der komplexe Ablauf des programmierten Zelltods ist zwar noch nicht vollständig aufgeklärt, es werden jedoch charakteristische morphologische und biochemische Merkmale während der Signal(Reaktions-)Kaskade ausgebildet, die mit unterschiedlichen Methoden nachweisbar sind. Der Prozess der Apoptose ist innerhalb von ca. vier Stunden abgeschlossen (FESUS et al. 1991).

Ein Marker der frühen apoptotischen Phase ist die aktivierte Caspase 3 (CPP3), durch welche die Signalkaskade ausgelöst wird und in deren Verlauf die entscheidenden biochemischen Reaktionen ausgelöst werden, die letztlich zum Zelltod führen (TOMINAGA et al. 1999, LANG D et al. 2002, FESUS et al. 1991, KÜHNEL et al. 2000, MARAVEI et al. 1997, CUMMINGS und SCHNELLMANN 2002, BHUTIA et al. 2008). 
Der Caspase-3-Activity-Assay ist ein fluorometric immunosorbent enzyme assay (FIENA). In apoptotischen Zellen wird das intrazellulär vorliegende Proenzym frühzeitig aktiviert, durch Zelllyse freigesetzt und nachfolgend in eine mit Anti-Caspase-3-beschichteten Multititerplatte pipettiert. Die aktivierte Caspase 3 bindet an die Beschichtung und spaltet das angebotene Substrat. Dabei entsteht ein fluorometrisch messbares Produkt, dessen Detektionssignal proportional zur Konzentration der aktivierten Caspase 3 ist (TOMINAGA et al. 1999, LANG D et al. 2002, BHUTIA et al. 2008).

Insbesondere die Caspasen 3 und 7 spielen eine zentrale Rolle bei Reaktionen der Zellen auf induzierte Apoptose. Die Bestimmung der Caspase-3- bzw. -7-Aktivität kann mit dem Caspase-3- bzw. 7-Assay erfolgen. Die Zellen können dabei 24 Stunden lang mit dem Reagens bei Raumtemperatur inkubiert werden und anschließend kann die Fluoreszenz im Photometer gemessen werden. Die Aktivierung der Caspase 9 durch den apoptoseinduzierenden Faktor als Folge des Verlustes der Zellmembranasymmetrie führt auch zum Zelltod und kann mit dem Caspase-9-Assay identifiziert werden (TOMINAGA et al. 1999, LANG D et al. 2002, FESUS et al. 1991, KÜHNEL et al. 2000, MARAVEI et al. 1997, CUMMINGS und SCHNELLMANN 2002, BHUTIA et al. 2008).

Der Apoptose-Nachweis kann mithilfe einer Vielzahl verschiedener zellchemischer Methoden durchgeführt werden und basiert zumeist auf intrazellulären biochemischen Veränderungen, die im Verlauf des programmierten Zelltods auftreten. Zur Aufklärung des komplexen Mechanismus der Apoptose ist es notwendig, verschiedene Nachweisverfahren parallel durchzuführen, da nicht in jedem Zelltyp und auch nicht nach jedem bekannten Stimulus die Gesamtheit der typischen Apoptosemerkmale ausgebildet wird.

Die in vitro funktionierenden Testverfahren eignen sich nur bedingt für die Bestimmung der Zytotoxizität und Apoptoseinduktion in vivo. Eine altbewährte, jedoch aufwendige Methode zum Nachweis einer DNA-Fragmentierung ist die Auftrennung der spezifischen Nucleosomenfragmente durch Elektrophorese. Hierbei werden Apoptose bzw. Nekrose durch ein charakteristisches ungleichmäßiges Muster im Agarose-Gel nachgewiesen. Die DNAFragmentierung ist außerdem mithilfe des TUNEL-Assays (Terminal DesoxynucleotidylTransferase mediated $d U T P-X$ nick end labeling) im Durchflusszytometer oder mit Fluoreszenz- bzw. Lichtmikroskopie nachweisbar. Dabei werden die lysierten apoptotischen Zellen mit DNA-Doppelstrangbrüchen durch enzymatischen Einbau eines biotinylierten oder fluoresceinmarkierten Nucleotids (dUTP) markiert. Der Nachweis nekrotischer Zellen hingegen erfolgt durch enzymatische Markierung von Einzelstrangbrüchen (In-Situ-NickTranslation-Methode). Die TUNEL-Reaktion markiert spezifische DNS-Strangbrüche, die 
während der Apoptose entstehen, sodass eine Unterscheidung zwischen einem Zelltod, der durch Apoptosevorgänge bedingt ist, von einem solchen, der durch Nekrose verursacht wurde, getroffen werden kann (GORZYCA et al. 1993, GOLD et al. 1994).

Der Cell-Death-Detection-ELISAPLUS eignet sich zur Unterscheidung zwischen beiden Formen des Zelltods durch den Nachweis spezifischer DNA-Fragmentierungen (Nukleosomen) im Zellkulturüberstand und Lysat (Nekrose). Sind die Nukleosomen ausschließlich im Zelllysat nachweisbar, so liegt Apoptose vor (TOMINAGA et al. 1999).

MARIOTTI und RUMPF (1999) konnten in ihrer Studie mithilfe des ELISA-Verfahrens die Reduktion der Synthese von Kollagen- und Nicht-Kollagen-Proteinen nach der Behandlung der humanen Gingivafibroblasten mit CHX nachweisen. Dieser Effekt war weniger von der Einwirkzeit, sondern mehr von der Substanzkonzentration abhängig.

Bei allen Studien empfiehlt sich die Anwendung mehrerer Testverfahren, die möglichst auf unterschiedlichen zellulären Mechanismen basieren, voneinander unabhängig sein und gleichzeitig ein und denselben Parameter messen sollten. Die oben beschriebenen Testverfahren sind nicht allein von ihrer Durchführung, den verwendeten Materialien und der Methodik abhängig, sondern sollten auch auf die zu untersuchende Zellart abgestimmt sein.

\subsubsection{Zellauswahl}

Das Parodontium ist eine komplexe Einheit, die aus dem Wurzelzement des Zahnes, dem Alveolarknochen, aus Kollagenfasern, den „Sharpey’schen“ Fasern sowie dem Weichgewebe der Gingiva und der Alveolarmukosa besteht (SCHROEDER 1982).

Der Knochen unterliegt nach dem Wachstumsabschluss einer permanenten Erneuerung, dem „Remodeling“ (HOCK et al. 2001). Durch eine wechselseitig wirkende Aktivierung von Osteoklasten und Osteoblasten wird eine kontinuierliche Erneuerung des mineralisierten Knochenanteils erreicht (FROST 1994). Die Bilanz dieser Osteoklasten- und Osteoblastenaktivität bleibt ausgeglichen, solange der Parodontalapparat nicht geschädigt ist. Ist ein Entzündungsprozess im Gange, folgt eine Bilanzverschiebung zugunsten der Osteoklastentätigkeit - und die knochenresorptiven Prozesse dominieren. Infolgedessen nimmt das Knochenvolumen kontinuierlich ab. Da dieser Prozess sehr oft bei fortgeschrittenen Parodontitiden zu beobachten ist, besteht die Frage, ob die Anwendung der oralen Antiseptika im Rahmen der Full-Mouth-Desinfection in der Parodontitistherapie die Osteoblasten in der Regeneration des Knochens unterstützt oder sie sogar umgekehrt behindert. 
Das Prinzip der gesteuerten Knochenregeneration (Guided Bone Regeneration, GBR) greift auf die Fähigkeit des mesenchymalen Gewebes zurück, eine mineralisationsfähige Matrix zu produzieren (DAHLIN et al. 1988, KOSTOPOULUS und KARRING 1994, NEVINS et al. 1998). Um einen Knochendefekt effektiv nach außen abzugrenzen, kann entweder eine nicht resorbierbare oder eine resorbierbare Membran zwischen dem Weichgewebslappen und dem Defekt eingebracht werden. Eine solche Membran deckt den augmentierten Bereich ab und verhindert einen direkten Kontakt zwischen den Fibroblasten aus dem Weichgewebe und dem Defektinneren (SCHMID et al. 1994, DAHLIN et al. 1989).

In den Vorversuchen zur vorliegenden Studie wurde die Eignung der primären humanen Osteoblasten für die durchzuführenden Versuche überprüft. Dabei wurden die Osteoblasten in einer Zellkultur gezüchtet und anschließend mit den handelsüblichen Mundspüllösungen behandelt. Zwar beschreiben vergleichbare Studien die Kultivierung von Osteoblasten als unproblematisch, jedoch wurde die Verdoppelungszeit in den durchgeführten Vorversuchen mit ca. zwei Wochen gemessen und die Ausbeute der Zellen nach der Behandlung mit den oralen Antiseptika war zu gering. Aus diesem Grund wurden die primären humanen Osteoblasten für die durchgeführte Studie als ungeeignet eingestuft.

Ein wichtiger Bestandteil des Parodonts sind die Fibroblasten genannten Bindegewebsvorläuferzellen. Mehrere Studien beweisen die entscheidende Bedeutung der Fibroblasten bei der Parodontitistherapie (FLEMINGSON et al. 2008, MARIOTTI und RUMPF 1999, MÜLLER und KRAMER 2007, KENT et al. 1996, PULCHER und DANIEL 1992, POGGI et al. 2003). FLEMINGSON et al. (2008) untersuchten in einer ähnlichen Studie die Wirkung von $\mathrm{CHX}^{\circledR}$, Listerine ${ }^{\circledR}$ und Povidon-Jod in verschiedenen Konzentrationen auf die Proliferation der humanen Gingivafibroblasten in vitro. Dabei konnten die Autoren einen deutlich negativen Effekt der antimikrobiellen Therapie auf die Zellen der Mundschleimhaut nachweisen. Die Fibroblasten weisen eine kurze Verdoppelungszeit von nur 62 Stunden auf und sind bei der Kultivierung relativ unempfindlich gegenüber äußeren Einflüssen (Produktzertifikat HGFIB, Provitro GmbH, 2001). Diese Eigenschaften zeichneten diese Zellen als eine optimale Zellart für die vorliegende Studie aus.

Die Gingiva bildet den Weichgewebsabschluss an der Durchtrittsstelle der Zähne in die Mundhöhle. Als ein weiterer Bestandteil des Parodontalapparates hat die epitheliale Abgrenzung zur Mundhöhle vor allem eine Schutzfunktion für das darunter liegende Gewebe. Die Anwendung der Epithelzellen und der epidermalen Keratinozyten der Mundschleimhaut für die Untersuchung der Zelltoxizität und der Proliferationshemmung ist ein etabliertes 
Verfahren (MÜLLER und KRAMER 2007) und war entscheidend für die vorliegende Studie. Es existieren mehrere Arten von Epithelzellen im menschlichen Körper. Für die Untersuchung der oralen Antiseptika sind die Epithelzellen der Mundschleimhaut und die Epithelzellen verwandter oder ähnlicher Gewebe wie z. B. der nasalen oder bronchialen Schleimhaut sehr geeignet. In der vorliegenden Studie wurden die primären humanen nasalen Epithelzellen untersucht. Zwar sind die Effekte der antiseptischen Therapie auf die nasalen Epithelzellen und die oralen Epithelzellen vergleichbar, die Wirkung auf beide Zellarten ist jedoch nicht identisch.

Bei der vorliegenden In-vitro-Studie wurde großer Wert auf eine möglichst praxisnahe Gestaltung der Versuche gelegt, was eine Anknüpfung an den klinischen Alltag schaffen sollte. Aus diesem Grund wurden ausschließlich primäre humane Zellen angewendet. Der Stoffwechsel, die Zellteilung und viele weitere zelluläre Prozesse können so in der Grundlagenforschung untersucht werden. Zelllinien sind Zellen einer Gewebeart, die sich im Lauf der Zellkultur unbegrenzt fortpflanzen können. Es können sowohl immortalisierte Zelllinien als auch primäre Zellen kultiviert werden (Primärkultur). Als Primärkultur bezeichnet man eine nicht immortalisierte Zellkultur, die direkt aus einem Gewebe gewonnen wurde. MÜLLER und KRAMER (2007) beschreiben in ihrer Studie die Kultivierung von humanen Epithelzellen der Linie FL (ATCC CCL62), von primären menschlichen epidermalen Keratinozyten (NHEK) und Mäusefibroblasten der Linie L969 (ATCC CCL1). Zwar verfügen die Zellen einer Zelllinie über gut untersuchte Zelleigenschaften, sind typisiert und ihre Proliferation und das Verhalten in der Zellkultur sind vorhersehbar, sie sind aber in ihren Eigenschaften weiter von der klinischen Situation des Mundhöhlenmilieus entfernt als die primären Zellen. Die meisten Zellen besitzen eine eingeschränkte Lebensdauer, mit Ausnahme von einigen von Tumoren abstammenden Zellen. Nach einer bestimmten Anzahl von Verdopplungen gehen diese Zellen in die Seneszenz und teilen sich nicht mehr. Etablierte oder unsterbliche Zelllinien dagegen haben die Fähigkeit erlangt, sich unendlich oft zu teilen, entweder durch zufällige Mutation, wie bei Tumorzellen, oder durch gezielte Veränderung, wie z. B. durch die künstliche Expression des Telomerase-Gens. Primärzellen haben eine sehr hohe biologische Relevanz und lösen daher Zelllinien in vielen Bereichen zunehmend als Modellsystem ab. Sowohl FLEMINGSON et al. (2008) als auch MARIOTTI und RUMPF (1999) nutzen die primären humanen Fibroblasten für die Untersuchung der Toxizität und der proliferationshemmenden Wirkung der verschiedenen Mundhöhlenantiseptika. Die Gewinnung und die Kultivierung humaner Zellen gestalteten sich komplikationslos. Versuche mit Zellen tierischer Herkunft, wie z. B. Mauszellen (MÜLLER und KRAMER 2007), eignen 
sich zwar für die Untersuchung bestimmten grundlegender Zelleigenschaften in vitro, ein Vergleich mit den menschlichen Zellen oder sogar mit der Situation in vivo gestaltet sich jedoch schwierig.

Um die Toxizität der oralen Antiseptika zu untersuchen, wurden in der vorliegenden Studie primäre humane Fibroblasten und nasale Epithelzellen mit den handelsüblichen Mundspüllösungen, wie CHX 0,2\% ${ }^{\circledR}$, Meridol $^{\circledR}$, Listerine $^{\circledR}$, Betaisodona $^{\circledR}$ und Octenidol ${ }^{\circledR}$, behandelt.

\subsubsection{Mundspüllösungen}

Der Prävention entzündlicher Parodontalerkrankungen kommt eine entscheidende Bedeutung $\mathrm{zu}$, und sie betrifft vor allem die Reduktion schädlicher Zahnbeläge. Derzeit werden antimikrobielle Mundspüllösungen verstärkt als Bestandteil von Präventionsprogrammen für Karies und Parodontitis zusätzlich zur mechanischen Zahnreinigung angesehen. Unter den chemischen Präventionsmaßnahmen mit antibakteriell wirksamen Substanzen erwiesen sich Chlorhexidin $0,2 \%{ }^{\circledR}$, Meridol $^{\circledR}$, Listerine ${ }^{\circledR}$, Betaisodona ${ }^{\circledR}$ und Octenidol ${ }^{\circledR}$ als die klinisch relevanten Mundspüllösungen, wobei die antiseptische Wirkung dieser Substanzen sowohl in zahlreichen Studien als auch evidenzbasiert nachgewiesen werden konnte.

Die handelsüblichen oralen Antiseptika wurden für die vorliegende Studie so ausgewählt, dass sie einerseits bei der Aufteilung nach den Generationen bzw. ihrer Substantivität zu unterschiedlichen Gruppen gehören und andererseits eine Relevanz im klinischen Alltag besitzen.

Als Vertreter der ersten Generation der antiseptischen Wirkstoffe wurden Listerine ${ }^{\circledR}$ und PVP-Jod (Betaisodona ${ }^{\circledR}$ ) ausgewählt (NETUSCHIL et al. 2002). Die größte antibakterielle Wirksamkeit von Mundspüllösungen aus dieser Gruppe wird den ätherischen Ölen zugeschrieben, wobei Listerine $^{\circledR}$ als bekanntester Vertreter dieser Gruppe gilt (MORAN et al. 1997, RIEP et al. 1999). Allerdings muss hier auf eventuell bestehende Allergien geachtet werden. Die Öle sind für die Störung bzw. die Veränderung der Zellmembran (TEUSCHER et al. 1990) pathogener Keime wie Aggregatibacter actinomycetemcomitans oder Candida albicans schon nach einer Einwirkzeit von 30 Sekunden (KUBERT et al. 1993) sowie für die Hemmung der Prostaglandinbiosynthese (WAGNER und WIESNER 1988) verantwortlich. Zusätzlich kann die Glykolyse bzw. die Glykosyltransferase in der Plaque gehemmt werden. 
BERNIMOULIN und DESCHER (1995) berichteten außerdem von einer antiinflammatorischen und cyclooxygenasehemmenden Aktivität der ätherischen Öle.

Die Verweildauer der Wirksubstanzen in der Mundhöhle, ihre Substantivität, scheint aber gering zu sein. Weiterhin ist nicht hinreichend geklärt, inwiefern der als Lösungsmittel dienende Alkohol, der denaturiert auf die Bakterienzelle einwirkt, zum antibakteriellen Effekt beiträgt. Aber aufgrund der o. g. Effekte konnten BALBUENA et al. (1998) eine Stunde nach einmaliger Spülung eine signifikante Reduktion der Bakterienzahl registrieren. Der plaquehemmenden Wirkung von Listerine ${ }^{\circledR}$ liegt laut SCHEIE (2003) ein deutlicher bakterizider Effekt zugrunde. Die Wirkung des Alkohols als eines Bestandteils der antiseptischen Mundspüllösungen ist auch für die Zellen der Mundschleimhaut und des Parodontalapparates von Bedeutung. In zahlreichen Lang- und Kurzzeitstudien konnte durch mikrobiologische und klinische Untersuchungen der plaque- und gingivitisinhibierende Effekt der Listerine ${ }^{\circledR}$-Lösung mit unterschiedlichen Befunden dokumentiert werden (LÖE et al. 1976, YANKELL et al. 1988, ROSS et al. 1989, FINE et al. 1992, BRECX et al. 1992, MORAN et al. 1997, RIEP et al. 1999, CIANCIO 2003, BERNIMOULIN 2003, OUHAYOUN 2003 und 2004, SANTOS 2003). Die Plaquereduktion durch Listerine ${ }^{\circledR}$ betrug dabei zwischen $19 \%$ und $56 \%$. Die Resultate der Gingivitisreduktionen schwankten zwischen $29 \%$ und $36 \%$. Bei keiner der Studien wurden Nebenwirkungen registriert. SCHIFFNER (1999) stellte jedoch fest, dass Zahnverfärbungen und Geschmacksirritationen auftreten können.

Die Wirkung von Listerine ${ }^{\circledR}$ auf die humanen Gingivafibroblasten stellt die Studie von FLEMINGSON et al. (2008) dar. In dieser Arbeit wurde die Toxizität der drei Mundspüllösungen Chlorhexidin, PVP-Jod und Listerine ${ }^{\circledR}$ in Abhängigkeit von der Konzentration und der Einwirkzeit der Substanzen auf die Bindegewebsvorläuferzellen der Mundschleimhaut untersucht. Bei der Behandlung der Zellen mit Listerine ${ }^{\circledR}$ war in allen Versuchen eine proliferationshemmende Wirkung der Mundspüllösung festzustellen. Die stark verdünnte Listerine ${ }^{\circledR}$-Lösung $(1 \%$ und $2 \%$ ) war toxischer als die CHX- und PVP-JodLösungen bei gleicher Verdünnung. Die Ergebnisse waren konzentrationsabhängig signifikant unterschiedlich, die Abhängigkeit der zellschädigenden Wirkung von der Einwirkzeit wies keine Signifikanz auf.

Ein weiterer Vertreter der oralen Antiseptika der ersten Generation ist Povidon-Jod (PVPJod). PVP-Jod (Handelsname Betaisodona ${ }^{\circledR}$ ) ist ein wasserlöslicher Komplex aus Jod und Polyvinylpyrrolidon (PVP, Povidon), der als Desinfektionsmittel bzw. Antiseptikum verwendet wird. 
PVP-Jod zeichnet sich durch ein breites Wirkspektrum aus, das nicht nur grampositive und gramnegative Bakterien, sondern auch Viren, Protozoen, Sporen und Pilze umfasst (REIMER et al. 2002, WUTZLER et al. 2003). Diese Wirkung beruht zum einen auf dem starken oxidativen Potenzial des Jods (SCHREIER et al. 1997) und zum anderen darauf, dass die Freisetzung zahlreicher Pathogenitätsfaktoren wie z. B. der Exotoxine gehemmt wird (KÖNIG et al. 1997, WUTZLER et al. 2003). Auch einer zu starken Freisetzung entzündungsfördernder Mediatoren wie z. B. der Zytokine oder gewebszerstörender Enzyme kann hierdurch entgegengewirkt werden (KÖNIG et al. 1997, KRAMER et al. 2002). Im Allgemeinen zeichnen sich lokal anwendbare PVP-Jod-Präparate durch eine gute Verträglichkeit und ein geringes Risiko der Allergisierung bzw. Toxizität aus (REIMER et al. 2002).

PVP-Jod findet in zahlreichen medizinischen Fachgebieten Verwendung. Dazu ist vor allem seine Verwendung in der Vorbereitung des Operationsfeldes, in der Haut- und Schleimhautantiseptik (RUDOLPH et al. 2000), der Spülung von Körperhöhlen und Fistelgängen und in der Wundbehandlung zu zählen. Weiterhin gab es zahlreiche Untersuchungen zur Effektivität von PVP-Jod zur Mundhöhlenantiseptik vor zahnärztlichen Eingriffen, um die Bakteriämierate zu senken (SCOPP und ORVIETO 1971, JOKINEN 1978, MACFARLANE et al. 1984, RECHMANN et al. 1989, YAMALIK et al. 1992, RAHN et al. 1994).

Umstritten ist aber seit einiger Zeit, ob sich PVP-Jod negativ auf die Wundheilung auswirkt. Dank der stark oxidierenden Wirkung des Jods werden nämlich nicht nur Krankheitserreger, sondern auch körpereigene Zellen (NIEDNER 1997) und hier vor allem das regenerierende Epithel (GÖRTZ und HÄRING 1986) angegriffen. In den 1980er Jahren konnte anhand von In-vitro- und In-vivo-Untersuchungen eine zytotoxische Wirkung von PVP-Jod (RODEHEAVER et al. 1982, LINEWEAVER et al. 1985, FLEMINGSON et al. 2008) gezeigt werden, die unter anderem dosisabhängig auftrat. Andere Autoren hingegen postulieren trotz allem eine insgesamt die Wundheilung fördernde Wirkung (HAUPTMANN et al. 1992). So zeigt die liposomale Zubereitung von Povidon-Jod bei gleicher Wirksamkeit eine deutlich bessere Gewebeverträglichkeit mit zumindest in vitro tendenziell nachweisbarer Proliferationsförderung.

Die Wirkstoffe der zweiten Generation wurden in der vorliegenden Studie durch Chlorhexidin und die Wirkstoffkombination Aminflourid/Zinnflourid (Meridol ${ }^{\circledR}$ ) vertreten (NETUSCHIL et al. 2002). Als Standard in der Prävention und Therapie oraler Entzündungen hat sich der Wirkstoff Chlorhexidin ( $\mathrm{CHX})$ etabliert. Tatsächlich ist es das effektivste und am meisten 
verbreitete antimikrobielle Mittel für den intraoralen Gebrauch (STELZEL 2002). Nach seiner Entwicklung im Jahr 1954 von DAVIES et al. untersuchten LÖE und SCHIÖTT (1970) die Wirksamkeit von Chlorhexidindigluconat zur Beeinflussung der Plaquebildung. Dieses Chlorhexidinsalz zeigte im Vergleich $\mathrm{zu}$ anderen Salzen (Acetat, Chlorid) die konzentrationsabhängig ausgeprägtesten bakterioziden und bakteriostatischen Eigenschaften. Im Ergebnis zahlreicher Studien zählt Chlorhexidin zu den effektivsten Wirkstoffen für die antiseptische Mundspülung. Die Keimzahlverminderungen in Mundspülflüssigkeiten bis $>2 \mathrm{lg}$ und die Effektivitätszunahme nach 5 bis 120 Minuten unterstreichen die Wirksamkeit von CHX gegenüber anderen oralen Antiseptika (ROBERTS und ADDY 1981, KRAMER et al. 1990). CHX wirkt in Abhängigkeit von der Konzentration bakteriostatisch oder bakteriozid (KRAMER und WALLHÄUSSER 1993, GJERMO 1978, LANGE 1995).

Bei der Mundspülung mit Chlorhexidin werden die Moleküle an saure Makromoleküle der oralen Oberflächen (Schleimhaut) gebunden (GJERMO 1978). Das so gebundene Chlorhexidin wird nach und nach innerhalb von acht bis zwölf Stunden wieder freigesetzt (CIANCIO 1995, NETUSCHIL et al. 1989, STELZEL 2002, ADDY und WRIGHT 1978). Die antimikrobielle Langzeitwirkung ist ein großer Vorteil gegenüber anderen Mundspüllösungen. Zahlreiche Studien belegen die antiseptische Wirksamkeit zur Verbesserung der Mundhygiene durch Plaque- und Gingivitisreduktion (LÖE und SCHIÖTT 1970, ALBERS und MAAS 1985, BRINER et al. 1986, HEFTI und HUBER 1987, MARUNIAK et al. 1992). Weiterhin vergleichen die Arbeiten von BERGENHOLZ und HÄNSTRÖM (1974), ADDY und WRIGHT (1978), ROBERTS und ADDY (1981), KRAMER et al. (1990), SCHREIL (1991) sowie BRECX et al. (1993) die antimikrobielle Wirksamkeit verschiedener Präparate mit Chlorhexidin. In allen Studien wird deutlich, dass Chlorhexidin eine effektivere Wirkung im Hinblick auf die Plaqueinhibition sowie die Beeinflussung der Gingivitis besitzt als die anderen untersuchten Präparate.

Zwar besitzt Chlorhexidin bei Langzeitanwendung das Risiko von Nebenwirkungen wie einer Schwarz-Braun-Verfärbung von Zähnen, Kunststofffüllungen und Zungenrücken (LÖE et al. 1976, GREENSTEIN et al. 1986), Geschmacksstörungen, Desqamationen und Mundschleimhautläsionen (FLÖTRA et al. 1971, RUSTHON 1977, SKOGLUND und HOLST 1982) oder Wundheilungsstörungen nach sofortiger Applikation post operationem (BASSETTI und KALLENBERGER 1980). Jedoch lassen sich diese Begleiterscheinungen bei geringerer Konzentration reduzieren, ohne dass ein signifikanter Unterschied in der klinischen Wirksamkeit hinsichtlich Infektionsprophylaxe, Plaque- und Gingivitishemmung $\mathrm{zu}$ verzeichnen wäre. Aus diesem Grund wird aktuell eine Konzentration von 0,1\% 
empfohlen (FLÖTRA et al. 1972, CUMMING und LÖE 1973, RIETHE und STOLL 1977, KREMERS und LAMPERT 1979, SKOGLUND und HOLST 1982, JENKINS et al. 1994, LANGE 1995). Die CHX-Spüllösung kann in einer Konzentration von 0,1\% bis 0,2\% tatsächlich als „chemische Zahnbürste“ eingesetzt werden, wenn eine mechanische Zahnreinigung vorübergehend nicht möglich ist, wie z. B. nach chirurgischen Eingriffen oder bei einer hochakuten Gingivitis (BAY 1978, LANGE 1995, ADDY et al. 1986). Die Anwendungsdauer von Chlorhexidin sollte aufgrund der bekannten Nebenwirkungen 14 Tage nicht überschreiten (SCHMIDT 1988, SPLIETH und KRAMER 2000).

Die antibakterielle Wirkung von CHX ist unumstritten und mit den oben genannten Studien eindeutig belegt, die Toxizität dieses Präparates für die Zellen der Mundschleimhaut und des Parodontalapparates ist bis jetzt sehr wenig untersucht. Die proliferationshemmende Wirkung von CHX auf die humanen Gingivafibroblasten wurde sowohl in der Studie von FLEMINGSON et al. (2008) als auch in der Untersuchung von MARIOTTI und RUMPF (1999) beschrieben. Beide Arbeiten zeigten eine signifikante konzentrationsabhängige Toxizität von CHX auf die Zellen in vitro sowie eine Hemmung der Kollagen- und NonKollagen-Protein-Synthese, was einen negativen Effekt auf die Wundheilung haben kann. In letzter Zeit sind fluoridhaltige Präparate, insbesondere eine Kombination von Aminfluorid (Olaflur, AmF) und Zinnfluorid $\left(\mathrm{SnF}_{2}\right)$, wie sie in der Mundspüllösung Meridol ${ }^{\circledR}$ enthalten ist, als entzündungs- und plaquehemmende Substanz erkannt worden. Entsprechend den Empfehlungen der DGZMK gehört die Anwendung von Fluoriden zu den drei Eckpfeilern der zahnmedizinischen Prävention. Zur Beeinflussung von Plaque und Gingivitis durch Fluoride wurden zahlreiche Studien durchgeführt (ALBERS und MAAS 1985, TRACHSLER 1988, FLORES-DE-JACOBY 1991). Durch die Eigenschaft der Plaque, Fluoridionen zu kumulieren, kann eine ausreichende Fluoridkonzentration in der Plaque angereichert werden (GUGGENHEIM 1983, JENKINS und EDGAR 1977). In Kombinationspräparaten dient das Aminfluorid als Komplexbildner für das Zinnfluorid. Nach dem Einbringen des $\mathrm{AmF} / \mathrm{SnF}_{2^{-}}$ Komplexes in die Mundhöhle kommt es durch die tensidähnliche Oberflächenaktivität des Präparates zu einer raschen Verteilung in der Mundhöhle und der Anlagerung an orale Strukturen (WALKER 1988). In dieser Kombination ergeben sich dann die ausgeprägten Affinitäten zur Oberfläche der Plaquebakterien, zur Mundschleimhaut und zum Zahnschmelz (SCHMID H 1983). Durch die beschriebenen Eigenschaften ist $\mathrm{AmF} / \mathrm{SnF}_{2}$ in der Lage, die Adhäsion von Mikroorganismen auf der Zahnoberfläche zu behindern (GÄNGLER 2005, STÖSSER 2006). Die außergewöhnlichen antibakteriellen Eigenschaften der $\mathrm{AmF} / \mathrm{SnF}_{2^{-}}$ Kombination werden durch reduzierte Plaque- und Gingivitisindizes deutlich belegt 
(SCHULZ L und SCHULZ E 1989, STÖSSER et al. 1992, NETUSCHIL et al. 2003, BRECX et al. 2003, GUARNELLI 2004, TROMBELLI et al. 2003). Die quantitativen und qualitativen Nebenwirkungen sind bei Aminfluorid/Zinnfluorid-Lösungen weniger von Bedeutung (SCHREIL 1991), sodass sie als Adjuvans zur mechanischen Zahnreinigung eingesetzt werden können (BANOCZY und NEMES 1989, BRECX et al. 1992 und 1993).

Die Wirkung von Aminfluorid/Zinnfluorid-Mundspüllösungen hinsichtlich ihrer Toxizität auf die Zellen der Mundschleimhaut und des Parodontalapparates ist in der Literatur nicht exakt beschrieben, sodass die Meridol ${ }^{\circledR}$-Mundspüllösung als eine zu testende Substanz in die vorliegende Arbeit mit aufgenommen wurde.

Octenidol $^{\circledR}$ als Chemotherapeutikum der dritten Generation besitzt die Eigenschaft der Adhäsionsminderung der oralen Mikroflora auf der Schmelzoberfläche (LANG NP et al. 1998). Die oberflächenaktiven Substanzen werden bevorzugt als Netzmittel in Zahnpasten eingesetzt und führen durch eine Reduktion der Oberflächenspannung zu einer Verringerung der mikrobiellen Kohäsion und somit zu einer Auflösung der Bakterienverbände (CIANCIO 1992). Das Wirkungsspektrum umfasst grampositive und gramnegative Bakterien, Pilze sowie eine Reihe von Virusarten. Bei der Anwendung auf Wunden war keine Resorption nachweisbar, sodass nach derzeitigem Stand des Wissens resorptiv-toxische Risiken auszuschließen sind. Noch nicht vollständig geklärt ist die Frage einer im Vergleich zu den Iodophoren oder zu Polihexanid erhöhten Zytotoxizität. Gute klinische Erfahrungen liegen vor bei der Erstversorgung von Schürf-, Biss- und Schnittwunden sowie mit 1:1 verdünnter Lösung bei Verbrennungswunden. Kontraindikationen sind Spülungen der Bauchhöhle und der Harnblase sowie die Anwendung am Trommelfell.

Dieses Präparat besitzt ein breites antimikrobielles Wirkspektrum und eine geringe systemische Toxizität, eine gute lokale Verträglichkeit an Haut und Schleimhäuten. Das Antiseptikum Octenidin ist seit 1995 als Octenisept $^{\circledR}$ in Deutschland für die Schleimhautdesinfektion zugelassen. Es zeichnete sich bisher besonders in der Gynäkologie und Urologie durch sehr gute Verträglichkeit und Wirksamkeit aus (ENZELSBERGER et al. 1995). In-vitro-Versuche zeigten die abtötende Wirkung von Octenisept ${ }^{\circledR}$ auf grampositive und gramnegative Bakterien innerhalb von 30 Sekunden (GORONCY-BERMES 1990). Dabei hat der Wirkstoff Octenidinhydrochlorid keinen negativen Einfluss auf die Wundheilung (HARKE 1997). KALTEIS et al. (2003) beschreiben dagegen in ihrer In-vivoStudie eine geringe Toxizität von Octenidin. 
Seit 2008 ist im Handel eine neue Mundspüllösung auf der Basis von Octenidin (Octenidol ${ }^{\circledR}$ ) erhältlich. Diese Lösung wird zur Regeneration von entzündlichen Erkrankungen im Mundraum, bei eingeschränkter Mundhygienefähigkeit, zur unterstützenden Behandlung von MRSA-Patienten, bei Parodontitis und Gingivitis, in der (Kinder-)Onkologie, in der Intensivpflege von beatmeten Patienten und begleitend zur Strahlentherapie angewendet. Octenidol $^{\circledR}$ ist hochwirksam gegenüber den Leitkeimen der infektiösen Erkrankungen aus dem Formkreis der Parodontitis und Gingivitis (odontogene Infektionen). Das Präparat erreicht bereits bei einer Einwirkzeit von 30 Sekunden Keimreduktion um 4,7 bis 8 lg-Stufen. Da die tatsächliche Keimzahl der geprüften gramnegativen und grampositiven anaeroben und microaerophilen Erregerarten bei einer aggressiven oder chronischen Form der Parodontitis in einem Bereich zwischen $10^{2}$ und $10^{5}$ liegt, im Fall von P. micros bei $10^{4}$, ist eine sichere Keimreduktion erreichbar (MUTTERS et al. 2007).

Die Wirkung von Octenidol $^{\circledR}$ auf die Zellen der Mundschleimhaut und des Parodontalapparates ist bis jetzt nicht untersucht worden, sodass die Frage nach der Vorbeugung der Parodontitiden durch die Octenidin-Mundspüllösung bzw. eine eventuelle Komplikation der Wundheilungsstörung im Sinne einer Nebenwirkung bei der Anwendung dieses Präparates noch völlig offen ist. Angesichts des großen Potenzials dieser Mundspüllösung wurde in der vorliegenden Studie der Frage nach einer eventuell zelltoxischen Wirkung von Octenidol ${ }^{\circledR}$ für die Zellen der Mundschleimhaut und des Parodontalapparates nachgegangen.

\subsubsection{Einwirkzeit}

Im Idealfall ist anzunehmen, dass bei der für die Anwendung fertigen unverdünnten Lösung $(100 \%)$ und einer realistischen Einwirkzeit (z. B. 1, 5 und 15 Minuten) keine Zellschädigung auftritt. Bei deutlich längeren Einwirkzeiten ist für die unverdünnte Lösung eine Zellschädigung nicht erwünscht. Das Auftreten einer Zellschädigung unter diesen Bedingungen ist jedoch mit hoher Wahrscheinlichkeit nicht von klinischer Bedeutung. Längere Einwirkzeiten (z. B. 1 Stunde) der unverdünnten Mundspüllösung sind in vivo unwahrscheinlich. Eine Zellschädigung bei dieser Kombination ist daher mit hoher Wahrscheinlichkeit klinisch nicht relevant.

Die Einwirkzeiten der oralen Antiseptika in der vorliegenden Studie wurden in Anlehnung an die Studie von FLEMINGSON et al. (2008) mit einer, fünf und 15 Minuten gewählt. Laut 
dieser Studie wurden die o. g. Einwirkzeiten an die klinische Anwendung der Mundspüllösungen in vivo angepasst, sodass eine direkte Verbindung zwischen den Ergebnissen der In-vitro-Studie und der Situation des Patienten geschaffen werden konnte. In dieser Studie wude festgestellt, dass die toxische Zellwirkung der antiseptischen Wirkstoffe umso deutlicher ausgeprägt war, je länger die Einwirkzeit gewählt wurde.

Die Studie von MARIOTTI und RUMPF (1999) untersuchte die Auswirkung von Chlorhexidin auf die Kollagen- und Nicht-Kollagen-Proteinproduktion der humanen GingivaFibroblasten in vitro. Die Einwirkzeiten wurden mit der Studie von FLEMINGSON et al. (2008) identisch gewählt. Die beiden Arbeiten beschreiben die o. g. Kontaktzeit als optimal für die Untersuchung der Zelltoxizität und der proliferationshemmenden Wirkung der antiseptischen Mundspüllösungen auf die Zellen der Mundschleimhaut und des Parodontalapparates. Aus diesem Grund wurden die Einwirkzeiten der oralen Antiseptika in der vorliegenden Studie mit einer, fünf und 15 Minuten gewählt.

\subsection{Ergebnisse}

\subsubsection{Bestimmung der Toxizität von oralen Antiseptika mittels MTT-Test}

In dieser Studie wurden die primären humanen Zellen in insgesamt 24 Versuchen mit den fünf handelsüblichen Mundspüllösungen $\left(\mathrm{CHX} \mathrm{0,2 \%}{ }^{\circledR}\right.$, Meridol $^{\circledR}$, Listerine ${ }^{\circledR}$, Betaisodona ${ }^{\circledR}$ und Octenidol $^{\circledR}$ ) in einer Zellkultur behandelt. Die metabolische Aktivität von primären humanen Gingivafibroblasten (HGFIB) und nasalen Epithelzellen (HNEPC) wurde mit dem MTT-Test bestimmt. Aus den Ergebnissen dieses Tests wurde deren Viabilität abgeleitet. Die Viabilität von HGFIB als auch HNEPC war nach der Behandlung der Zellen mit den handelsüblichen Mundspüllösungen im Vergleich $\mathrm{zu}$ Kontrolle signifikant reduziert. Außerdem sanken in den meisten Fällen die Messwerte mit zunehmender Einwirkzeit. Ein signifikanter Unterschied zwischen den einzelnen Lösungen in ihrer negativen Wirkung auf die HGFIB bzw. HNEPC konnte beim MTT-Test nicht festgestellt werden.

\subsubsection{Chlorhexidin}

Die Studie von FLEMINGSON et al. (2008) kam zu ganz ähnlichen Ergebnissen bei der Behandlung humaner Gingivafibroblasten mit Chlorhexidin. Bei den Versuchen mit der unverdünnten CHX-Lösung konnte eine signifikante Reduktion der Proliferationsfähigkeit der Zellen von $98,5 \%$ bis $99,8 \%$ im Vergleich zur Kontrolle nachgewiesen werden. Dabei wiesen die Ergebnisse eine deutliche Abhängigkeit von der Einwirkzeit der oralen Antiseptika 
auf die HGFIB auf. So wurden die Werte nach einer Minute CHX-Kontaktzeit mit 0,006 OD, nach fünf Minuten mit 0,005 OD und nach 15 Minuten mit 0,0006 OD gemessen (Kontrolle: 0,415 OD). Im Unterschied zur vorliegenden Arbeit (1 Minute: 0,0190 \pm 0,0021 OD, 5 Minuten: 0,0184 \pm 0,0020 OD, 15 Minuten: 0,0154 \pm 0,0016 OD, Kontrolle: 0,365 OD) beschreibt FLEMINGSON et al. (2008) eine deutlich höhere Zelltoxizität der unverdünnten CHX-Lösung. Da die o.g Arbeit den MTT-Test als einzige Nachweismethode für die Zelltoxizität von Mundspüllösungen verwendet, ist es schwierig, die Objektivität dieser Ergebnisse bzw. der Ausmaß der Schädigung der Gingivafibroblasten nachvollziehen. In der vorliegenden Studie wurden die gewonnen Werte mithilfe eines zweiten Testverfahrens, der optischen Zellzahl-, Viabilität- und Zelldurchmesserbestimmung, in ihrer Aussage verglichen und bekräftigt.

MARIOTTI und RUMPF (1999) untersuchten die Wirkung von CHX auf die HGFIB, indem sie die Produktion von Kollagen- und Nicht-Kollagen-Proteinen der Fibroblasten gemessen haben. Die Ergebnisse zeigten, dass einerseits eine signifikante Reduktion der Proteinsynthese nach der Behandlung der Zellen mit 0,12\% Chlorhexidin festgestellt werden konnte, andererseits aber die Proliferationskapazität der Fibroblasten nicht beeinträchtigt wurde.

Die klinische Relevanz dieser Ergebnisse ist unumstritten hoch. Die antiseptische Therapie als eine Präventionsmaßnahme in der Zahnmedizin kann einerseits Plaqueneubildung, Gingivitis und bakterielle Besiedelung erfolgreich verhindern bzw. reduzieren (MÜLLER und KRAMER 2007) und andererseits die Wundheilung beeinträchtigen. Diese Erfahrung haben BASSETTI und KALLENBERGER (1980) gemacht, indem sie die Mundschleimhautwunden und die Wunden des angrenzenden Knochens nach der Behandlung mit 0,5\%, 0,2\% und 0,1 \% CHX untersuchte. Die Wundheilung war entweder ausgeblieben oder deutlich gestört. Der Anteil des Granulationsgewebes in der Wunde war im Vergleich zur Kontrolle signifikant erhöht, wobei die Kollagensynthese deutlich beeinträchtigt war. Des Weiteren haben SHAHAN et al. (1993) gezeigt, dass die initiale Wundheilung nach der Behandlung der Läsion mit 0,12\% CHX 48 Stunden später im Vergleich zu Kontrolle einsetzte. Zu ähnlichen Ergebnissen kamen auch WELK et al. (2007), indem sie unter anderem Chlorhexidin auf seine Toxizität für die Epithelzellen des Peritoneums überprüften. Alle untersuchten Lösungen wirkten sich negativ auf die Epithelzellen aus. Vor allem war dieser Effekt für die unverdünnten Lösungen, die im Handel frei verkäuflich sind und gebrauchsfertig angeboten werden, zu beobachten.

Eine aktuelle Studie von RAJABALIAN et al. (2009) beschreibt eine ähnliche zytotoxische Wirkung von CHX auf Gingivafibroblasten, Epithelzellen, Makrophagen und Osteoblasten. 
Die besondere Toxizität von CHX auf die Epithelzellen spielt eine wichtige Rolle in der Heilung der Mundschleimhautwunden nach parodontologischen Eingriffen dar. Im Gegensatz dazu konnten KOZLOVSKY et al. (2007) eine bessere Epithelisation der Mundschleimhautwunden nach der Behandlung mit CHX in ihrer Studie an Ratten zeigen. Die durchschnittliche Wundfläche und der Abstand zwischen den Epithelrändern waren nach der antibiotischen Therapie in Abhängigkeit von der Zeit im Vergleich zur Kontrolle signifikant kleiner, sodass die eingesetzte Mundspüllösung keinen negativen Effekt auf die Wundheilung hatte.

GIANNELLI et al. (2008) legen nahe, dass CHX in vitro hochzytotoxisch ist, und raten zu einer vorsichtigen Anwendung dieses Antiseptikums bei chirurgischen Angriffen in der Mundhöhle. Die Anwendung von im Handel erhältlichen Konzentrationen von CHX (0,12\% und $0,2 \%$ ) für die Wunddesinfektion kann $\mathrm{zu}$ schweren toxischen Effekten auf die Gingivafibroblasten führen und sich negativ auf die Wundheilung auswirken.

Die Studie von SANCHEZ et al. (1998) über die Wundheilung der Hautwunden bei Hunden beschreibt einen positiven Effekt von CHX in den Konzentrationen, die für die Fibroblasten in vitro tödlich sind. In anderen Untersuchungen zur Wundheilung der Mundschleimhaut wurde die Schlussfolgerung gezogen, dass CHX die Wundheilung nicht störe (HIRST et al. 1973, HAMP et al. 1975). In vivo wurde ein Effekt beschrieben, wonach die ortständigen Zellen vor der toxischen Wirkung von CHX geschützt wurden (HIDALGO und DOMINGUEZ 2001, BABICH et al. 1995). Die Bindung von CHX an die Bakterien kann die zur Verfügung stehende Konzentration von CHX in der Mundhöhle verringern, sodass der zelltoxische Effekt in vivo auf die Zellen der Mundschleimhaut nicht so stark ausgeprägt sein kann, wie es die In-vitro-Studien nahelegen. So scheint CHX eine niedrigere Toxizität in vivo zu haben, als sie in vitro nachgewiesen wurde.

\subsubsection{Meridol $^{\circledR}$}

Die Wirkung von Meridol ${ }^{\circledR}$ auf die Zellen der Mundschleimhaut und des Parodontalapparates ist mit der von CHX vergleichbar. Die Ergebnisse der vorliegenden Studie zeigen zwar eine geringere Zytotoxizität von Meridol ${ }^{\circledR}$ im Vergleich zu CHX, die Werte weisen aber keine Signifikanz auf. Zu einer ähnlichen Schlussfolgerung kamen auch WELK et al. (2007), indem sie die Wirkung von CHX, Meridol ${ }^{\circledR}$, Colgate $^{\circledR}$ und Listerine ${ }^{\circledR}$ auf die Peritoneumzellen neonataler Ratten untersuchten. In dieser Studie war die Zytotoxizität von Meridol ${ }^{\circledR}$ auf die Epithelzellen am wenigsten stark ausgeprägt. Zwar liegen keine vergleichbaren MTT- 
Ergebnisse vor, die optische Auswertung der Proben im Rahmen der vorliegenden Arbeit weist jedoch auf eine ähnliche Wirkung von Meridol ${ }^{\circledR}$.

Eine weitere Studie beschreibt eine positive Auswirkung der oralen Antiseptika auf die Wundheilung von Ratten (KOZLOVSKY et al. 2007). Zwar wurde die Wirkung von Meridol $^{\circledR}$ auf die Mundschleimhaut- und Bindegeweberegeneration als nicht schädlich beschrieben, allerdings wiesen die Versuche mit CHX und Listerine ${ }^{\circledR}$ vergleichsweise bessere Ergebnisse auf.

\subsubsection{Listerine ${ }^{\circledR}$}

Listerine $^{\circledR}$ ist neben CHX die meistuntersuchte Mundspüllösung in der Zahnmedizin. In der vorliegenden Studie wies Listerine ${ }^{\circledR}$ im Vergleich mit den fünf handelsüblichen Mundspüllösungen die stärkste Zytotoxizität sowohl auf humane Gingivafibroblasten als auch auf die Epithelzellen der Nasenschleimhaut auf. Die Studie von FLEMINGSON et al. (2008) unterstützt diese Aussage, weist aber eine stärkere Zytotoxizität auf die Gingivafibroblasten als die vorliegende Arbeit nach. So wurden nach einer Minute Listerine ${ }^{\circledR}$-Behandlung Werte von 0,011 OD gemessen, was einer Reduktion im Vergleich zur Kontrolle von $97 \%$ entspricht. Die 5-Minuten-Werte unterschieden sich nicht wesentlich von denen nach einer Minute (0,010 OD bzw. 97,6\%). Nach 15 Minuten Einwirkzeit war der zytotoxische Effekt von Listerine ${ }^{\circledR}$ noch stärker ausgeprägt (0,002 OD und 99,5\%).

WELK et al. (2007) beschreiben dagegen eine niedrigere Toxizität im Vergleich zu CHX und Colgate ${ }^{\circledR}$. Bei der Konzentration von $1 \%$ wiesen die Ergebnisse sogar eine Signifikanz auf. In der Arbeit von KOZLOVSKY et al. (2007) wird die Wirkung von Listerine ${ }^{\circledR}$ als nicht schädlich für die Regeneration von Mundschleimhautepithel und Bindegewebe beschrieben. Die unterstützende antiseptische Therapie bei der Wundheilung mittels Listerine ${ }^{\circledR}$ ist mit der CHX-Therapie vergleichbar und ist sogar effektiver als Meridol ${ }^{\circledR}$. Die starke Zytotoxizität von Listerine $^{\circledR}$ im Vergleich zu den anderen oralen Antiseptika der vorliegenden Studie könnte auf eine toxische bzw. konservierende Wirkung des Alkohols als Bestandteils der Listerine $^{\circledR}$-Mundspüllösung zurückgeführt werden. Das Vorhandensein von Alkohol in den anderen Mundspüllösungen ( $\mathrm{CHX} \quad 0,2 \%{ }^{\circledR}$ und Betaisodona $\left.{ }^{\circledR}\right)$ dieser Studie kann die Hypothese der stärkeren Zytotoxizität von alkoholhaltigen Antiseptika nicht bekräftigen. 


\subsubsection{Betaisodona ${ }^{\circledR}$}

PVP-Jod ist ein seit Langem eingesetztes Antiseptikum sowie eine Mundhöhlen- und Operationsgebietsdesinfektion. In der vorliegenden Studie wurde festgestellt, dass Betaisodona $^{\circledR}$ in der handelsüblichen Konzentration zytotoxisch auf die humanen Gingivafibroblasten wirkt. Diese Ergebnisse stimmen mit der Studie von SANCHEZ et al. (1998) überein, die beschreibt, dass Betaisodona ${ }^{\circledR}$ in Konzentrationen von $5 \%$ bis 0,5\% tödlich für die embryonalen Fibroblasten von Kaninchen in vitro ist. Die Arbeiten von LINEAWEAVER et al. (1985) und BARNHARDT et al. (2005) bekräftigen den zytotoxischen Effekt von Betaisodona ${ }^{\circledR}$ auf die humanen Gingivafibroblasten. FLEMINGSON et al. (2008) beschreibt eine 97,3-prozentige Reduktion der vitalen Fibroblasten nach einminütigem Kontakt mit PVP-Jod im Vergleich zur Kontrolle. Die zytotoxische Wirkung war dabei von der Einwirkzeit der Mundspüllösung abhängig und wies bereits nach 15 Minuten eine 99-prozentige Schädigung der HGFIB im Vergleich zur Kontrolle auf. Die MTT-Werte beschreiben dabei eine deutlich stärkere Zytotoxizität von Betaisodona ${ }^{\circledR}$ im Vergleich zu den Ergebnissen der vorliegenden Studie.

Die Zelltoxizität von Betaisodona ${ }^{\circledR}$ für humane Hautzellen wurde in der Studie von HIRSCH et al. (2009) dargestellt. Die Vitalität und das Proliferationspotenzial von HaCaT-Zellen, primären humanen Keratinozyten und Fibroblasten wurden als Folge der antiseptischen Therapie deutlich reduziert. Angesichts des zytotoxischen Effekts der antiseptischen Lösungen auf die oben genannten Zellen ist es notwendig, die antibakterielle Therapie im Rahmen der zahnärztlichen Angriffe auf das Nötigste einzuschränken.

\subsubsection{Octenidol ${ }^{\circledR}$}

Der Wirkstoff Octenidindihydrochlorid bindet wie auch $\mathrm{CHX}$ bevorzugt an saure Phospholipide der Plasmamembran von Mikroorganismen und der Zellmembran von humanen und Säugerzellen (GILBERT und MOORE 2005). Die Bindung ist mit einer toxischen Reaktion verbunden. Eine offene Frage ist jedoch, inwieweit der zellgebundene Wirkstoff gegenüber Mikroorganismen biologisch aktiv bleibt und schädigend auf die Zellen der Mundschleimhaut und der Bindegewebe wirkt.

Die Studie von MÜLLER und KRAMER (2007) weist nach, dass Octenidin von den Zellen gebunden wird und somit eine Art Wirkstoffdepot über mehrere Stunden liefert. Dabei ist die mikrobiozide Wirksamkeit von zellgebundenem Octenidin dem der von CHX weit überlegen 
(EMILSON et al. 1981, ROBRISH et al. 1981, SLEE und O'CONNOR 1983, KRAMER et al. 1998).

HIRSCH et al. (2009) verwendeten Betaisodona ${ }^{\circledR}$ und Octenidin für die antiseptische Therapie von chronischen und schlecht heilenden Wunden. Beide Antiseptika induzierten eine starke Reduktion der Zellvitalität (bis zu $0 \%$ ) von HaCaT-Zellen, primären humanen Keratinozyten und Fibroblasten bei einer 7,5-prozentigen Konzentration von Betaisodona ${ }^{\circledR}$ und einer 12,5-prozentigen Konzentration von Octenidin. Des Weiteren war die Proliferationsfähigkeit der Hautzellen bei der Anwendung von 7,5-prozentigen antiseptischen Lösungen um $0 \%$ reduziert.

In der vorliegenden Studie zeigen die Ergebnisse des MTT-Tests eine deutlich niedrigere Zytotoxizität von Octenidin auf die Zellen der Mundschleimhaut und des Parodontalapparates im Vergleich zu den übrigen Mundspüllösungen. Die MTT-Messungen sind mit der Studie von HIRSCH et al. (2009) vergleichbar und sind ähnlich hoch. Neben seiner zytotoxischen Wirkung verengt Octenidin die Arteriolen und beeinflusst somit negativ die Durchblutung der Wundregion bzw. wirkt sich nachhaltig auf die Wundheilung aus. Dieser Effekt ist zwar nicht so stark ausgeprägt wie bei den alkoholhaltigen Antiseptika, er beeinflusst jedoch die Mikrozirkulation der Gewebe negativ (LANGER et al. 2004).

\subsubsection{Bestimmung der Toxizität von oralen Antiseptika mittels Cellometer ${ }^{\mathrm{TM}}$ Auto T4}

Als eine zweite Nachweismethode wurde bei jedem Versuch parallel zum MTT-Test eine optische Zellzahl- und Viabilitätsbestimmung durchgeführt sowie der mittlerer Zelldurchmesser gemessen. Die Zellzahl, Viabilität und der Zelldurchmesser von HGFIB als auch HNEPC waren nach der Behandlung der Zellen mit den getesteten handelsüblichen Mundspüllösungen im Vergleich zur Kontrolle signifikant reduziert. Außerdem sanken in den meisten Fällen die Messwerte mit zunehmender Einwirkzeit. Ein signifikanter Unterschied zwischen CHX 0,2 \% ${ }^{\circledR}$, Meridol ${ }^{\circledR}$ und Listerine ${ }^{\circledR}$ bzw. zwischen Betaisodona ${ }^{\circledR}$ und Octenidol ${ }^{\circledR}$ in ihrer negativen Wirkung auf HGFIB bzw. HNEPC konnte bei der Auswertung mittels Cellometer ${ }^{\mathrm{TM}}$ Auto T4 nicht festgestellt werden. Die Ergebnisse der CHX 0,2 \% ${ }^{\circledR}-$, Meridol $^{\circledR}{ }_{-}$ und Listerine ${ }^{\circledR}$-Versuche wiesen in den meisten Fällen im Vergleich zu den Werten der Betaisodona ${ }^{\circledR}-$ und Octenidol $^{\circledR}-$ Versuche eine Signifikanz auf. Betaisodona ${ }^{\circledR}$ und Octenidol $^{\circledR}$ zeigten folglich geringere Zytotoxizität zu den HGFIB und HNEPC im Vergleich zu CHX 0,2 $\%{ }^{\circledR}$, Meridol $^{\circledR}$ und Listerine ${ }^{\circledR}$ auf. 


\subsubsection{Chlorhexidin}

Die Bestimmung der Zellviabilität mittels MTT-Test ist ein standardisiertes Verfahren, das in vielen Studien zum Einsatz kommt (FABREGUETTE et al. 1994, TATNALL et al. 1990, DAMOUR et al. 1992). Dieses Testverfahren allein genügt aber nicht, um eine exakte Aussage über die Zellviabilität zu treffen. Aus diesem Grund bekräftigten einige Studien die Ergebnisse des MTT-Tests mithilfe eines weiteren Verfahrens (HUTH et al. 2006). In der vorliegenden Arbeit wurde die Bestimmung der Zellviabilität einerseits indirekt über die metabolische Aktivität der Zellen mittels MTT-Test andererseits mithilfe der optischen Zellcharakterisierung (Cellometer ${ }^{\mathrm{TM}}$ Auto T4) durchgeführt. Dieses Verfahren erlaubte gleichzeitig die Ermittlung der Zellzahl und des mittleren Zelldurchmessers. Die deutlich schwächer ausgeprägte Reduktion der Zellzahl und der Viabilität der CHX-Versuche beider Zellarten im Vergleich zur Kontrolle bestätigt die Ergebnisse des MTT-Tests nur teilweise. Zwar wies die zytotoxische Wirkung von CHX 0,2\% ${ }^{\circledR}$ auf die HGFIB und HNEPC eine Abhängigkeit von der Einwirkzeit auf, d. h., je länger die Zellen dem Antiseptikum ausgesetzt waren, desto stärker war seine Toxizität; jedoch wiesen die Werte eine deutlich geringere Toxizität im Vergleich zu den Ergebnissen des MTT-Tests dieser Studie und der Untersuchung von FLEMINGSON et al. (2008) auf. Und das trotz des Verlustes bzw. der Schädigung der Zellen bei der Überführung in eine Suspension und bei der Anfärbung mit der Trypan-Blau-Lösung. Die Reduktion lag höchstens im Bereich von $30 \%$ bis $50 \%$ und nicht wie bei MTT-Test bei $90 \%$ bis $99 \%$.

Die geringe Verminderung des mittleren Zelldurchmessers in Abhängigkeit von der Einwirkzeit ist eine unspezifische Größe für die Bestimmung der Zelltoxizität. Demzufolge spielte sie eine geringe Rolle bei der Auswertung der Ergebnisse. Trotz alledem war auch bei diesen Werten eine Zytotoxizität von CHX 0,2\% ${ }^{\circledR}$ festzustellen. Die Studie von HUTH et al. (2006) beschreibt dagegen einerseits die hohe Zytotoxizität von CHX auf die Epithelzellen der Mundschleimhaut in vitro, was die Ergebnisse der vorliegenden Studie unterstützt, andererseits weist sie auf eine nicht toxische Wirkung auf die humanen Gingivafibroblasten hin, was unseren Ergebnissen widerspricht. Die Tatsache, dass beim MTT-Test eine wesentlich höhere Toxizität festgestellt wurde als bei den anderen Verfahren, könnte damit erklärt werden, dass der MTT-Test im Gegensatz zu den optischen Veränderungen in der Zelle letztlich nur die Glykolyserate bestimmt, die bei stagnierenden und proliferationsgehemmten Zellen reduziert ist, aber noch nicht zu strukturellen Veränderungen der Zellmorphologie führt. An dieser Stelle sind weitere Untersuchungen für die Bestimmung 
z. B. der Apoptoserate anhand der Caspase-3- bzw. -7-Aktivität oder der Proteinproduktionshemmung mithilfe der ELISA-Technik erforderlich.

\subsubsection{Meridol $^{\circledR}$}

Die Auswirkung von Meridol $^{\circledR}$ auf die Zellen der Mundschleimhaut und des Parodontalapparates ist mit den Ergebnissen der CHX-Versuche vergleichbar. Zwar war die Reduktion der Zellzahl, der Viabilität und des Zelldurchmessers über die Zeit weniger ausgeprägt als bei den CHX-Versuchen, jedoch wurde eine ähnliche Ausprägung der Meridol ${ }^{\circledR}$-Zytotoxizität auf die HGFIB und HNEPC ermittelt. Die Korrelation der Ergebnisse des MTT-Tests und der optischen Zellcharakterisierung mittels Cellometer ${ }^{\mathrm{TM}}$ Auto T4 war mit der CHX-Versuchsreihe gleich stark ausgeprägt. Eine leicht höhere Zytotoxizität von CHX 0,2 \% ${ }^{\circledR}$ konnte mit dem Vorhandensein des Alkohols in der Mundspüllösung erklärt werden, da Alkohol allein schon eine toxische Wirkung auf die Zellen besitzt (POGGI et al. 2003).

\subsubsection{Listerine ${ }^{\circledR}$}

Die Studie von WELK et al. (2007) untersuchte die Zytotoxizität von Listerine ${ }^{\circledR}$ auf die Peritonealschleimhaut in vitro. Der toxische Effekt dieser alkoholhaltigen Mundspüllösung war sowohl konzentrations- als auch zeitabhängig. Die in der vorliegenden Studie gewonnenen Daten unterstützen die Ergebnisse von WELK et al. (2007). Im Vergleich zu den anderen Mundspüllösungen (CHX, Meridol ${ }^{\circledR}$ und Triclosan) wies die unverdünnte Listerine ${ }^{\circledR}$ Lösung die gleiche Zytotoxizität auf wie CHX und Triclosan. In den geringeren Konzentrationen war Listerine ${ }^{\circledR}$ sogar für die Zellen am wenigsten toxisch. Diese Ergebnisse widersprechen jedoch den gewonnen Werten in unserer Arbeit. Die vorliegende Studie weist auf eine starke Zytotoxizität von Listerine ${ }^{\circledR}$ im Vergleich $\mathrm{zu}$ den anderen getesteten Mundspüllösungen hin.

Das Vorhandensein von Alkohol in der Listerine ${ }^{\circledR}$-Lösung könnte eine Erklärung für deren toxischen Effekt sein. Seit Jahrhunderten wurden Mundspüllösungen für die Mundgesundheit bzw. kosmetische Zwecke genutzt. Heute gibt es in den meisten Ländern eine Vielzahl von Mundspüllösungen für die breite Öffentlichkeit in Form von nicht verschreibungspflichtigen Produkten. Alkohol wird in Mundspüllösungen als Lösungs- oder als Konservierungsmittel verwendet. Seit Jahren wurden die Mundspüllösungen mit unterschiedlichsten Bestandteilengenutzt, jedoch wurde die Frage nach ihrem Alkoholgehalt, der eine Bedrohung 
für die Gesundheit darstellen könnte, erst in jüngster Zeit gestellt. Die hohe Alkoholmenge in einigen Mundspüllösungen kann im Kontakt mit der Mundschleimhaut eine schädliche Wirkung sowohl über einen lokalen Mechanismus als auch über eine systemische Alkoholbelastung aufweisen. Die Erhöhung der Zeitdauer des Kontaktes der Schleimhaut mit Alkohol kann sowohl bei Menschen als auch bei Versuchstieren zu hyperkeratotischen Läsionen führen. Im Moment ist es nicht möglich, einen kausalen Zusammenhang zwischen der Verwendung von alkoholhaltigen Mundspülungen und der Entwicklung oraler Krebserkrankungen zu beweisen. Eine gewisse zytotoxische Wirkung auf die Zellen der Mundschleimhaut und des Parodontalapparates wurde in einigen Studien schon belegt (CARRETERO PALAEZ et al. 2004, SHARMA et al. 2004). Listerine ${ }^{\circledR}$ besaß in der vorliegenden Arbeit im Vergleich mit den anderen Mundspüllösungen einen ausgeprägten zytotoxischen Effekt sowohl auf die HGFIB als auch auf die HNEPC. Da in dieser Studie aber mehrere alkoholhaltige Lösungen getestet wurden, konnte keine stärkere Zytotoxizität der alkoholhaltigen Lösungen im Vergleich mit den alkoholfreien Mundspülungen nachgewiesen werden. Die Studie von MOHARAMZADEH et al. 2009 zeigte anhand des darin entwickelten 3D-tissue-engineered human oral mucosal model keine signifikante Zellschädigung der Gingivafibroblasten und Keratinozyten nach der Behandlung mit alkoholhaltigen Mundspüllösungen. Die unterschiedlichen Testverfahren (Proliferationsassay, tissue-viability assay, Transmissionelektronmokroskopie, IL1ß-immunosorbent assay), die in dieser Arbeit zum Einsatz kamen, belegen die Ergebnisse auf verschiedenen Ebenen.

\subsubsection{Betaisodona ${ }^{\circledR}$}

Eine Infektion ist, trotz der Verwendung von Antibiotika und moderner steriler Technik, eine der häufigsten Komplikationen der Wundheilung. Sie ist verantwortlich für eine erhebliche Morbidität des Patienten, belastende Krankheitszustände und längere Krankenhausaufenthalte. Das alles muss vermieden werden, um eine ordnungsgemäße Heilung sicherzustellen. Zu diesem Zweck werden seit mehreren Jahren topische Antiseptika angewendet. Unter den ältesten und effektivsten ist Povidon-Jod (Betaisodona ${ }^{\circledR}$ ) zu nennen, das aus einem wasserlöslichen Komplex von elementarem Jod und einem synthetischen Polymer besteht und über ein breites antimikrobielles Spektrum verfügt. Unter einer Therapie mit Betaisodona ${ }^{\circledR}$ entwickeln sich keine Resistenzen. Da es in einigen Berichten aufgeführt wurde, dass die PVP-Jod-Therapie die Wundheilung beeinträchtigen könnte, sollte die Anwendung von PVP-Jod in mehreren Studien kritisch überprüft werden, wobei der 
Schwerpunkt auf In-vivo-Modelle gelegt wurde. PVP-Jod-Lösungen hatten praktisch keine nachteiligen Auswirkungen auf die Wundheilung. Die Anwendung der 10-prozentigen PVPJod-Lösung bei Ratten, Meerschweinchen, Kaninchen oder Schweinen führte werder zu einer Verringerung der Zugfestigkeit der Wunde noch zu einer verzögerten Reepithelisierung. In drei Studien am Menschen bestand, was die Heilung anging, kein signifikanter Unterschied zwischen der 1-, 5- und 10-prozentigen PVP-Jod-Lösung, mit Ausnahme einer leichten Verzögerung während der ersten 24 Stunden nach der Anwendung der 5-prozentigen PVPJod-Lösung in einer Studie. Die PVP-Jod-Salbe (10\%) verzögerte die Wundheilung bei Ratten während des vierten bis zehnten Tages nach der Behandlung. Aber in den nächsten zwei Wochen war die Heilung beschleunigt; von Tag 24 an verlief die Heilung gegenüber den Kontrollen gleich schnell. Keine Verzögerungen wurden bei Schweinen und Kaninchen gemessen. In menschlichen Wunden kam es bei der Heilung zu keiner Verzögerung. Auf der Grundlage dieser Untersuchungen kann der Schluss gezogen werden, dass Povidon-JodPräparate keine nachteiligen Auswirkungen auf die Wundheilung haben (GOLDENHEIM 1993).

Einige In-vitro-Studien aus den vergangenen Jahren haben die Wirkung von Betaisodona ${ }^{\circledR}$ auf die Zellen überprüft. VAN DEN BROEK et al. (1982) beschreiben Povidon-Jod in einer Konzentration von mehr als $0,05 \%$ als zytotoxisch für Granulozyten und Monozyten. TATNALL et al. (1987) weisen einen toxischen Effekt von Betaisodona ${ }^{\circledR}$ auf Keratinozyten in Konzentration größer als 0,004 \% nach. LINEAWEAVER et al. (1985) beschreiben eine Konzentration von $0,05 \%$ als nicht schädlich für Fibroblasten. Höhere Konzentrationen, einschließlich der 10-prozentigen Konzentration, die üblicherweise in der Klinik Anwendung findet, sind definitiv zytotoxisch für Bindegewebszellen. Diese Studien belegen, dass die Konzentrationen von Povidon-Jod in vitro, die für die Bestimmung der Zytotoxizität angenommen wurden, viel niedriger sind als bei der tatsächlichen Anwendung im klinischen Alltag in vivo. Folglich wirkt Betaisodona ${ }^{\circledR}$ auf die meisten Zellen, die an der Wundheilung beteiligt sind, zytotoxisch.

Die vorliegende Arbeit unterstützt diese Aussage. Der zytotoxische Effekt von Betaisodona ${ }^{\circledR}$ auf HGFIB und HNEPC wies eine signifikante Reduktion der Zellzahl, der Viabilität und des mittleren Zelldurchmessers im Vergleich zur Kontrolle auf. Eine Abhängigkeit der Zytotoxizität von der Einwirkzeit war deutlich vorhanden und stieg mit der Kontaktdauer. 
In der In-vivo-Studie von LINEAWEAVER et al. (1985) wurden die chirurgisch induzierten Wunden bei Ratten mit verschiedenen Lösungen jeweils dreimal täglich behandelt. Vier Tage postoperativ wurden die Wunden auf ihre Zugfestigkeit geprüft. Die Wunden, die mit Betaisodona ${ }^{\circledR}$ behandelt wurden, wiesen letztlich nur eine 21-prozentige Zugfestigkeit im Vergleich zu den Wunden auf, die nur mit einer Kochsalzlösung behandelt wurden. Es gab keine Unterschiede am Tag 8, 12 und 16. Die Epithelisierung setzte nach Povidon-JodTherapie verzögert ein.

Trotz der Zytotoxizität von Povidon-Jod in In-vitro-Studien deuten die Ergebnisse der Invivo-Studien darauf hin, dass Povidon-Jod in einer Konzentration von $1 \%$ oder weniger keine Wundheilungsverzögerung bzw. -störung verursacht. In höheren Konzentrationen kann vorübergehend der Blutfluss im Wundbett verringert werden (BRENNAN und LEAPER 1985), aber Konzentrationen von $1 \%$ oder weniger scheinen diesen Effekt nicht zu haben (BRANEMARK et al. 1966, BRANEMARK und EKHOLM 1967, BRENNAN und LEAPER 1985). Alle oben aufgeführten Studien wurden an gesunden menschlichen oder tierischen Probanden mit akuten chirurgisch induzierten Wunden durchgeführt, sodass die zytotoxischen Effekte beim entzündlichen, infizierten bzw. parodontal vorgeschädigten Gewebe anders ausgeprägt waren und nur bedingt mit der Wirkung von Betaisodona ${ }^{\circledR}$ im gesundem Gewebe vergleichbar sind. In mehreren Studien wurde diskutiert, ob die Behandlung der Wunden mit Povidon-Jod im Vergleich zur Behandlung mit Kochsalzlösung zu einer Beeinträchtigung der Heilung führen könnte. Wenn Povidon-Jod die Wundheilung durch eine Verringerung der Infektionsraten begünstigen sollte, könnte man erwarten, dass die mit Betaisodona ${ }^{\circledR}$ behandelten Wunden eine viel höhere Heilungsrate aufweisen als nach Kochsalzspülungen. In einigen Studien wurden keine wesentlichen Unterschiede zwischen den beiden Therapieansätzen gesehen (LINEAWEAVER et al. 1985, HUGHES-PAPSIDERO und LAVINE 1984, GRUBER et al. 1975). Dieser Befund zeigt, dass die antibakterielle Wirkung von Povidon-Jod entweder die Wundheilung nicht unterstützt oder dass dieser Effekt durch eine andere Wirkung, wie etwa die Zytotoxizität, ausgeglichen wird. Die zytotoxische Wirkung von Povidon-Jod wurde in der vorliegenden Arbeit deutlich belegt. Der detaillierte Mechanismus der Zellschädigung benötigt weitere Untersuchungen auf verschiedenen Ebenen. 


\subsubsection{Octenidol ${ }^{\circledR}$}

Die Anwendung von Octenisept ${ }^{\circledR}$ in Gynäkologie und Urologie zur Haut- und Schleimhautdesinfektion ist seit Langem gang und gäbe. In den letzten Jahren wurde Octenisept $^{\circledR}$ (Wirkstoff: Octenidin) auch für die intraorale Wunddesinfektion bzw. als prophylaktische Mundspüllösung $\left(\right.$ Octenidol $^{\circledR}$ ) eingesetzt. Der Einfluss der Octenidol ${ }^{\circledR}$ Therapie auf die Zellen der Mundschleimhaut und des Parodontalapparates wurde bis jetzt allerdings noch nicht untersucht. Die Zytotoxizität von Octenisept ${ }^{\circledR}$ bei der Anwendung als Hautantiseptikum scheint aber eine negative Rolle bei der Wundheilung zu spielen. HIRSCH et al. (2009) behandelten die primären Keratinozyten, Fibroblasten und HaCaT-Zellen mit fünf verschiedenen Hautantiseptika (Prontosan ${ }^{\circledR}$, Lavasept ${ }^{\circledR}$, Braunol ${ }^{\circledR}$, Octenisept ${ }^{\circledR}$ und Betaisodona $\left.{ }^{\circledR}\right)$. Bei allen Lösungen wurde ein deutlicher zytotoxischer Effekt im Vergleich zur Kontrolle festgestellt. In Konzentrationen von $4 \%, 7,5 \%$ und 12, 5\% sank die Viabilität der primären Keratinozyten nach der Octenisept ${ }^{\circledR}$-Behandlung auf $0 \%$. Der gleiche Effekt wurde in der Wirkung auf die Fibroblasten in Konzentrationen von 7,5\% und 12,5\% beobachtet. Die Anwendung zweier Testverfahren in dieser Studie (MTT-Test und BrdUELISA) bekräftigt die Aussagekraft der vorliegenden Ergebnisse. Eine weitere Studie beschreibt eine deutliche Reduktion der Hautdurchblutung nach einer Octenisept ${ }^{\circledR}$-Therapie im Maus-Modell (LANGER et al. 2004). Die geringe Durchblutung der Wundgebiete als Folge der antiseptischen Behandlung hat einen negativen Effekt auf die Wundheilung bzw. führt zu einer Verzögerung der Geweberegeneration in vivo. Die vorliegende Studie beschreibt die Wirkung der Octenidol $^{\circledR}{ }^{-}$Mundspüllösung auf die humanen Gingivafibroblasten und die nasalen Epithelzellen als toxisch. Die Zytotoxizität war mit steigender Kontaktdauer stärker ausgeprägt. Diese Ergebnisse stimmen mit den Ergebnissen der o .g. Arbeiten überein.

Der nützliche antibakterielle Effekt von Octenidol ${ }^{\circledR}$ bzw. Octenisept ${ }^{\circledR}$ in der Wundversorgung muss in Relation zur Zytotoxizität dieser Lösungen auf die Zellen der Haut und Mundschleimhaut betrachtet werden. Aus diesem Grund soll vor jeder antiseptischen Behandlung das Risiko-Nutzen-Profil der jeweiligen Therapie abgewogen werden.

\subsubsection{Vergleich der einzelnen Mundspüllösungen untereinander}

Neben den allgemeinen zytotoxischen Effekten oraler Antiseptika auf die Zellen der Mundschleimhaut und des Parodontalapparates konnten in der vorliegenden Arbeit Unterschiede der Zytotoxizität zwischen den einzelnen Mundspüllösungen festgestellt 
werden. Die Abweichungen der einzelnen Antiseptika in den Ergebnissen des MTT-Tests waren so gering ausgeprägt, sodass die Zytotoxizität von $\mathrm{CHX} 0,2 \%{ }^{\circledR}, \mathrm{Meridol}^{\circledR}$, Listerine ${ }^{\circledR}$, Betaisodona ${ }^{\circledR}$ und Octenidol ${ }^{\circledR}$ als ähnlich stark eingestuft werden darf. Die leicht geringere Toxizität von Betaisodona ${ }^{\circledR}$ und Octenidol ${ }^{\circledR}$ im Vergleich zu den anderen Mundspüllösungen wies keine Signifikanz auf. Bei der optischen Zellcharakterisierung mittels Cellometer ${ }^{\mathrm{TM}}$ Auto T4 war diese Tendenz noch stärker ausgeprägt, sodass die beiden Antiseptika eine deutlich geringere Zytotoxizität sowohl bei den HGFIB- als auch bei den HNEPC-Versuchen im Vergleich zu CHX 0,2 \% ${ }^{\circledR}$, Meridol ${ }^{\circledR}$ und Listerine ${ }^{\circledR}$ aufwiesen. Octenidol ${ }^{\circledR}$ hatte im Vergleich zu Betaisodona ${ }^{\circledR}$ eine leicht geringere zytotoxische Wirkung auf HGFIB und HNEPC.

Die Studie von FLEMINGSON et al. (2008) kommt beim Vergleich der Zytotoxizität der CHX-, der Listerine ${ }^{\circledR}$ - und der Betaisodona ${ }^{\circledR}$-Mundspüllösung zu dem gleichen Ergebnis, dass Betaisodona ${ }^{\circledR}$ sich nämlich weniger toxisch auf die humanen Gingivafibroblasten auswirkt. Die Arbeit von HIRSCH et al. (2009) beschreibt einen gleich starken zytotoxischen Effekt von Betaisodona ${ }^{\circledR}$ und Octenisept ${ }^{\circledR}$ auf die primären humanen Keratinozyten, Fibroblasten und HaCaT-Zellen. WELK et al. (2007) kamen zum Ergebnis, dass Meridol ${ }^{\circledR}$ im Vergleich mit CHX und Listerine ${ }^{\circledR}$ die geringste Zytotoxizität für Epithelzellen aufwies. Dabei war kein Unterschied zwischen der CHX- und Listerine ${ }^{\circledR}$-Behandlung festzustellen. KOZLOVSKY et al. (2007) schreiben dagegen Meridol ${ }^{\circledR}$ im Vergleich zu CHX und Listerine ${ }^{\circledR}$ die stärkste zytotoxische Wirkung zu. Die Vermutung, dass der Alkohol als Bestandteil der Mundspüllösungen für deren zelltoxische Wirkung verantwortlich sei, hat sich nicht bestätigt (MOHARAMZADEH et al. 2009). Auch die vorliegende Arbeit kam zu dem Ergebnis, dass Alkohol keine wesentliche Rolle für die Stärke des zytotoxischen Effektes antiseptischer Therapien auf Fibroblasten und Epithelzellen spielt, da die getestete Mundspüllösung Betaisodona $^{\circledR}$ trotz der geringsten Zytotoxizität alkoholhaltig ist. CHX wird als ein Universalantiseptikum in der Zahnmedizin eingesetzt. Octenidol ${ }^{\circledR}$ weist aber im Vergleich zu CHX eine bessere antibakterielle Langzeitwirkung und dabei die geringste Zytotoxizität auf (MÜLLER und KRAMER 2007).

Trotz der widersprüchlichen Ergebnisse der verschiedenen Arbeiten wiesen die meisten Studien eine zelltoxische Wirkung der Mundspüllösungen auf die Zellen der Mundschleimhaut und des Parodontalapparates nach. Die Nutzung oraler Antiseptika im Anschluss an die Parodontaltherapie, bei der Kontrolle von Plaquebildung und der Reduktion von Gingivitis ist unentbehrlich (ADDY 1986, JONES 1997, BRECX et al. 1989 und 1997, LANGEBAEK und BAY 1976, ASBOE-JÖRGENSEN et al. 1974, BOLLEN et al. 1998). 
Die hervorragenden antimikrobiellen Eigenschaften der Mundspüllösungen können angesichts ihrer Zytotoxizität nur eingeschränkt, am besten allerdings in Form verdünnter Lösungen, angewendet werden (JONES 1997). Folglich dürfen die antiseptischen Mundspüllösungen angesichts ihrer zelltoxischen Wirkung auf die Zellen der Gingiva und des Parodontalapparates in der Parodontaltherapie zur Plaquereduzierung nicht universal eingesetzt werden.

Auf der Grundlage dieser Ergebnisse schlagen wir vor, dass eine klinische Anwendung der untersuchten Mundspüllösungen bei Patienten mit frischen, offenen Schleimhaut- bzw. Parodontalläsionen vermieden werden sollte. Wir schlagen vor, dass die Mundspüllösungen am ersten Tag nach dem operativen Eingriff angewendet werden, da Blutgerinnsel zu diesem Zeitpunkt die direkte Exposition des verletzten Gewebes gegenüber der zelltoxischen Wirkung der oralen Antiseptika verhindern.

\subsubsection{Vergleich der beiden Testverfahren}

Die Ergebnisse des MTT-Tests machen deutlich, dass die Anwendung von Mundspüllösungen einen gravierenden zytotoxischen Effekt auf die Zellen der Mundschleimhaut und des Parodontalapparates hat. In der Studie von FLEMINGSON et al. (2008) wurde die Zytotoxizität von CHX, Listerine ${ }^{\circledR}$ und Betaisodona ${ }^{\circledR}$ auf humane Gingivafibroblasten schon nach einer Minute antiseptischer Behandlung mit $97 \%$ bis 98,5\% und nach 15 Minuten mit $99 \%$ bis 99,8 \% bestimmt. Die vorliegende Studie beschreibt einen leicht geringeren, aber trotzdem sehr stark ausgeprägten zellschädigenden Effekt der antiseptischen Therapie. Das Ableiten der Viabilität aus diesen Ergebnissen gestaltet sich allerdings schwierig, da der Test nicht die Anzahl der vitalen, apoptotischen oder toten Zellen bestimmt, sondern die Glykolyserate und somit die metabolische Aktivität der behandelten Zellen. Folglich werden die Zellen, die nach einem Kontakt mit oralen Antiseptika in ihrer Glykosespaltung gehemmt wurden, für tot erklärt, obwohl diese Hemmung möglicherweise nur vorübergehender Natur ist und die Vitalität der Zellen dadurch nur gering beeinflusst wäre. Folglich gehört der MTTTest zur grundlegenden Bestimmung der Zytotoxizität von Substanzen auf die Zellen in vitro und kann nur die Richtung angeben, ob eine getestete Substanz möglicherweise proliferationshemmend wirkt. Aus diesem Grund ist es sinnvoll, den MTT-Test nicht als alleiniges Nachweisverfahren zu nutzen, sondern parallel dazu weitere Testverfahren, die eventuell auf anderen Prinzipien basieren, anzuwenden. 
Die optische Zellcharakterisierung mittels Cellometer ${ }^{\mathrm{TM}}$ Auto T4 weist eine deutlich geringere Zytotoxizität der getesteten Substanzen im Vergleich zum MTT-Test auf. Die Methode basiert auf einer Färbung der Zellen mit der Trypan-Blau-Lösung. Die Bestimmung der Zellzahl und des mittleren Zelldurchmessers geschieht computergestützt vollautomatisch. Die Werte stimmen mit den Werten der manuellen Zellzählung in einer Zellkammer überein. Die Viabilitätsmessung hängt von dem Anfärben der Zellen mit der Trypan-Blau-Lösung ab. Da die Überführung der adhärent wachsenden Zellen in eine Suspension und die Färbung selbst zytotoxisch auf die Zellen wirken, ist die Bestimmung der Viabilität ziemlich unpräzise.

In der vorliegenden Studie wurde bei den HGFIB-Versuchen zwischen den beiden Methoden ein signifikanter positiver Zusammenhang ermittelt. Bei den Epithelzellen konnte kein Zusammenhang erkannt werden. Insgesamt stimmen die Ergebnisse beider Nachweisverfahren überein und weisen eine Abhängigkeit von der Einwirkzeit auf. Die Unterschiede in der Ausprägung des zytotoxischen Effekts sind aus den oben genannten Gründen zu erklären. Viele Vorteile des MTT-Tests (kostengünstig, leicht durchzuführen, nicht störungsanfällig) machen diesen Test als Grundbestimmungsmethode bei den Forschern sehr beliebt und die Bestimmung der Zytotoxizität sehr einfach. Die Ermittlung der Viabilität dagegen ist hierbei dagegen nicht sinnvoll. Die optische Zellcharakterisierung ist zwar teuer, geschieht aber vollautomatisch und ziemlich sicher. Die Anwendung beider Testverfahren nebeneinander erlaubt es, eine bessere Aussage über die Zytotoxizität der antiseptischen Therapie in vitro $\mathrm{zu}$ treffen. Für eine weitergehende Untersuchung der intra- und extrazellulären Prozesse als Folge des Einsatzes oraler Antiseptika sollten weitere Testverfahren, wie z. B. die Bestimmung der Apoptoserate mittels Aktivitätsbestimmung von Caspase 3 bzw. 7 oder die Hemmung der Proteinsynthese mithilfe der ELISA-Methode, angewendet werden.

\subsection{Schlussfolgerung}

Die Ergebnisse der vorliegenden Studie haben gezeigt, dass die getesteten Mundspüllösungen auf humane Gingivafibroblasten und nasale Epithelzellen zytotoxisch wirken. Außerdem war eine Abhängigkeit von der Einwirkzeit festzustellen. Folglich sollte die Anwendung der oralen Antiseptika in der Klinik auf das Nötigste beschränkt werden. Die geringere Zytotoxizität und die gleichzeitig gute antibakterielle Wirkung von Betaisodona ${ }^{\circledR}$ und 
Octenidol $^{\circledR}$ öffnen neue Therapiemöglichkeiten in der Parodontologie. Schließlich sollen die Testverfahren vor der Durchführung der Studie validiert sein, um die gewonnenen Ergebnisse exakt zu interpretieren. 


\section{Zusammenfassung}

Ziel der Untersuchung war es, den Effekt von Octenidol ${ }^{\circledR}$ auf humane Fibroblasten und Epithelzellen im Vergleich zur Wirkung anderer oraler Antiseptika und in Abhängigkeit von der Einwirkzeit zu ermitteln.

Fünf Mundspüllösungen wurden dabei verwendet: Chlorhexamed $0,2 \%{ }^{\circledR}$, Listerine ${ }^{\circledR}$, Meridol $^{\circledR}$, Betaisodona ${ }^{\circledR}$ und Octenidol $^{\circledR}$. Bei den Kontrollproben wurde keine Mundspüllösung angewendet. Die Zellen waren primäre humane Gingivafibroblasten (HGFIB, Provitro) sowie primäre humane nasale Epithelzellen (HNEPC, Provitro). Die Zellen wurden in zellspezifischen Medien kultiviert bei einer Ausgangszellzahl von $2 \times 10^{5}$ Zellen/ml. Danach wurden sie jeweils eine, fünf und 15 Minuten mit den entsprechenden Lösungen kontaminiert. Anschließend erfolgte ein Auswaschen mit PBS-Lösung. Die Versuche wurden für jede Gruppe und jede Einwirkzeit zwölfmal wiederholt. Metabolische Aktivität (MTT-Test) sowie Zellzahl, Zellviabilität und der mittlere Zelldurchmesser (Cellometer ${ }^{\mathrm{TM}}$ Auto T4) wurden bestimmt.

Statistische Auswertung: Der Einfluss der Spüllösung, der Einwirkzeit sowie des Wechselwirkungseffekts dieser beiden Faktoren auf die verschiedenen Messgrößen wurde, getrennt für beide Zelltypen, mit zweifaktoriellen Varianzanalysen untersucht. Im Falle eines signifikanten Einflusses der Lösung wurde anschließend jede der Spüllösungen mit der Kontrolle verglichen (Dunnett-Vergleiche). Zusätzlich wurden alle Spüllösungen untereinander paarweise mit t-Tests (Bonferroni-adjustiert) verglichen. Der Zusammenhang zwischen MTT-Messung und Zellzahl wurde mit Pearson's Korrelationskoeffizient rho untersucht. Als Signifikanzniveau wurde für alle Tests $\alpha=5 \%$ festgelegt. Bei den paarweisen Vergleichen der Spüllösungen wurde ein signifikanter Unterschied nur bei einem p-Wert unterhalb des Bonferroni-adjustierten Signifikanzniveaus von 0.05/10 =0.005 angenommen.

Für beide Messparameter war ein signifikanter Einfluss der Spüllösung sowie der Einwirkzeit in beiden Zelllinien festzustellen $(\mathrm{p}<0,001)$. Dabei unterschied sich jede Spüllösung signifikant von der Kontrolle ( $\mathrm{p}<0,0001$ ). Bei der Bestimmung der metabolischen Aktivität war kein signifikanter Unterschied zwischen Octenidol ${ }^{\circledR}$ und den anderen Spüllosungen in beiden Zelllinien und für alle Einwirkzeiten festzustellen ( $p>0.005)$. Bei der FibroblastenZellzahl zeigte sich ein signifikant geringerer Einfluss von Octenidol $^{\circledR}$ gegenüber Chlorhexamed $0,2 \%{ }^{\circledR}$, Meridol ${ }^{\circledR}$ und Listerine ${ }^{\circledR}$ bei einer und bei fünf Minuten Einwirkzeit (p $<0.005)$. Bei 15 Minuten und bei Betaisodona ${ }^{\circledR}$ lag kein signifikanter Unterschied vor $(\mathrm{p}>$ 
0.005). Bei den Epithelzell-Zahlen waren für die Einwirkzeiten von einer bzw. fünf Minuten keine Unterschiede zwischen Octenidol ${ }^{\circledR}$ und den anderen festzustellen $(\mathrm{p}>0.005)$, nach 15 Minuten lediglich im Vergleich zu Chlorhexamed $0,2 \%{ }^{\circledR}(\mathrm{p}<0.005)$.

Octenidol $^{\circledR}$ zeigte, wie auch die anderen oralen Antiseptika, einen negativen Effekt auf humane Gingivafibroblasten und Epithelzellen. Bei der Zellproliferation waren zwischen den Spüllösungen in Abhängigkeit von Einwirkzeit und Zelltyp keine Unterschiede festzustellen. Bei Zellzahl, Zellviabilität und Zelldurchmesser hingegen zeigte Octenidol $^{\circledR}$ wie auch Betaisodona $^{\circledR}$ einen geringeren negativen Effekt. 


\section{Anhang}

\subsection{Materialliste}

Tabelle 26: Materialliste

\begin{tabular}{|c|c|c|c|c|}
\hline $\mathbf{N r}$ & Material & \begin{tabular}{|l|} 
Besonderheiten \\
\end{tabular} & Bestell-Nr. & Hersteller \\
\hline 1. & $\begin{array}{l}\text { Primäre humane } \\
\text { Gingivafibroblasten }\end{array}$ & HGFIB & 1210412 & $\begin{array}{l}\text { Provitro GmbH, Berlin, } \\
\text { Deutschland }\end{array}$ \\
\hline 2. & $\begin{array}{l}\text { primären humanen } \\
\text { nasalen Epithelzellen }\end{array}$ & HNEPC & 1210711 & $\begin{array}{l}\text { Provitro GmbH, Berlin, } \\
\text { Deutschland }\end{array}$ \\
\hline 3. & Einfriermedium & Cryo-SFM-Medium & 2040102 & $\begin{array}{l}\text { Provitro GmbH, Berlin, } \\
\text { Deutschland }\end{array}$ \\
\hline 4. & $\begin{array}{l}\text { Fibroblasten- } \\
\text { Anzuchtmedium }\end{array}$ & $\begin{array}{l}\text { Fibroblast growth } \\
\text { medium }\end{array}$ & 2010401 & $\begin{array}{l}\text { Provitro GmbH, Berlin, } \\
\text { Deutschland }\end{array}$ \\
\hline 5. & $\begin{array}{l}\text { Epithelzellen- } \\
\text { Anzuchtmedium }\end{array}$ & $\begin{array}{l}\text { Airway epithelial } \\
\text { cell growth medium }\end{array}$ & 2030701 & $\begin{array}{l}\text { Provitro GmbH, Berlin, } \\
\text { Deutschland }\end{array}$ \\
\hline 6. & Dispase II Lösung & \begin{tabular}{|l} 
Passage-Kit 3, \\
Dispase II solution
\end{tabular} & 2040003 & $\begin{array}{l}\text { Provitro GmbH, Berlin, } \\
\text { Deutschland }\end{array}$ \\
\hline 7. & $\begin{array}{l}\text { Phosphat-gepufferter } \\
\text { Kochsalzlösung }\end{array}$ & $\begin{array}{l}\text { Passage-Kit } 2 / 3, \\
\text { Phosphate-buffered } \\
\text { saline, } \mathrm{PBS}, \mathrm{pH} 7,4\end{array}$ & 2040002 & $\begin{array}{l}\text { Provitro GmbH, Berlin, } \\
\text { Deutschland }\end{array}$ \\
\hline 8. & $\begin{array}{l}\text { Trypsin-EDTA- } \\
\text { Lösung }\end{array}$ & Passage-Kit 2 & 2040002 & $\begin{array}{l}\text { Provitro GmbH, Berlin, } \\
\text { Deutschland }\end{array}$ \\
\hline 9. & $\begin{array}{l}\text { Neutralisierende } \\
\text { Lösung }\end{array}$ & $\begin{array}{l}\text { Passage-Kit 2, } \\
\text { neutralisation } \\
\text { solution }\end{array}$ & 2040002 & $\begin{array}{l}\text { Provitro GmbH, Berlin, } \\
\text { Deutschland }\end{array}$ \\
\hline 10. & Zellkammer & Einmalartikel & 91-CMCC-01 & $\begin{array}{l}\text { Peqlab Biotechnologie } \\
\text { GmbH, Erlangen, } \\
\text { Deutschland }\end{array}$ \\
\hline 11. & $\begin{array}{l}\text { CELLSTAR } \AA \\
\text { 12-well-Kulturplatten }\end{array}$ & unbeschichtet, steril & 665180 & $\begin{array}{l}\text { Fa. Greiner bio-one, } \\
\text { Frickenhausen, } \\
\text { Deutschland }\end{array}$ \\
\hline 12. & $\begin{array}{l}\text { BD FalconTM } \\
\text { Zellkulturflaschen }\end{array}$ & $\begin{array}{l}75 \mathrm{~cm}^{2} \text {-Bodenfläche, } \\
250 \mathrm{ml}\end{array}$ & 353024 & $\begin{array}{l}\text { Fa. Becton \& Dickinson, } \\
\text { Heidelberg, Deutschland }\end{array}$ \\
\hline 13. & MTT-Lösung & $\begin{array}{l}\text { 3-(4,5-Dimethyl- } \\
\text { thiazol-2-yl)-2,5- } \\
\text { diphenyl-2H- } \\
\text { tetrazoliumbromid }\end{array}$ & 2128 & $\begin{array}{l}\text { Fa. Sigma-Aldrich, } \\
\text { Taufkirchen, Deutschland }\end{array}$ \\
\hline 14. & DMSO-Lösungsmittel & Dimethylsulfoxid & 8.02912 .1000 & $\begin{array}{l}\text { Fa. Merck, Darmstadt, } \\
\text { Deutschland }\end{array}$ \\
\hline
\end{tabular}




\subsection{Abkürzungsverzeichnis}

AIF

AP

ATP

BrdU

CHX

CPC

CPP3

CTL zytotoxische T-Lymphozyten

DGZMK Deutsche Gesellschaft für Zahn- und Mundkrankheiten

DMSO Dimethylsulfoxid

DNA Desoxyribonukleinsäure

E. coli

EDTA Ethylendiamintetraessigsäure

EGF epidermal growth factor

ELISA enzyme-linked immunosorbent assay

F.n. $\quad$ Fusobacterium nucleatum

FACS fluorescence activated cell sorting

FCS fetales Kälberserum

FIENA fluorometric immunosorbent enzyme assay

FITC Fluoresceinisothiocyanat

GBR Guided Bone Regeneration

HGFIB humane Gingivafibroblasten 
HIV Humanes Immundefizienz-Virus

HNEPC humane nasale Epithelzellen

ICE Interleukin-1 $\alpha$-converting Enzyme

IL Interleukin

LDH Laktatdehydrogenase

$\lg \quad$ Logarithmus

MIC maximale Hemmkonzentration (MHK)

MMPs Matrixmetalloproteinasen

MRSA Methicillin Resistente Staphylococcus Aureus

MTT 3-(4,5-Dimethyl-thiazol-2-yl-)2,5-diphenyl-2H-tetrazoliumbromid

NHEK primäre menschliche epidermale Keratinozyten

NK-Zellen natürliche Killerzellen

NUG Nekrotisierende ulzerierende Gingivitis

NUP Nekrotisierende ulzerierende Parodontitis

OD Lm1(Exzitation) - Lm2(Emission)

OSFMD one-stage full-mouth-disinfection

P. micros Peptostreptococcus micros

PARP Poly-(ADP-Ribose-)Polymerase

PBS Phosphate-buffered saline

PE Phycoerythrin

ppm parts per million

PVP Polyvinylpyrrolidon, Povidon

RANKL Rezeptoraktivator des nuklearen Faktor-kB Liganden 
S. mutans Streptococcus mutans

SF $\quad$ Sulkusfluid

sp. $\quad$ Spezies

sub-MIC submaximale Hemmkonzentration

TdR radioaktiv markiertes Thymidin

TEER transepithelialer elektrischer Widerstand

TNF- $\alpha \quad$ Tumor Necrosis Factor- $\alpha$

TUNEL Terminal Desoxynucleotidyl-Transferase mediated dUTP-X nick end labeling

UTP Uridintriphosphat

UV Ultraviolett

WST 2-(4-Iodophenyl)-3-(4-nitrophenyl)-5-(2,4-disulfophenyl)-2H-tetrazolium water-soluble tetrazolium salt

XTT 2,3-Bis((2-methoxy-4-nitro-5-sulfophenyl)-5-(phenylamino)carbonyl)-2Htetrazoliumhydroxid 


\subsection{Abbildungsverzeichnis}

Abbildung 1: Gingivitis-Parodontitis-Modell (modifiziert nach SALVI et al. 1997, S. 178).

Abbildung 2: Pathogenetisches Modell (modifiziert nach PAGE und KORNMAN 1997, S. 10) ...... 19

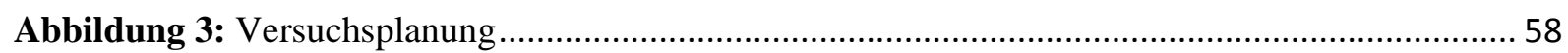

Abbildung 4: Orale Antiseptika: $\mathrm{CHX} \mathrm{0,2 \%}{ }^{\circledR}$, Meridol $^{\circledR}$, Listerine ${ }^{\circledR}$, Betaisodona ${ }^{\circledR}$ und Octenidol $^{\circledR} 60$

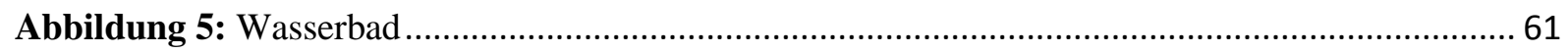

Abbildung 6: Reinraumwerkbank ............................................................................. 61

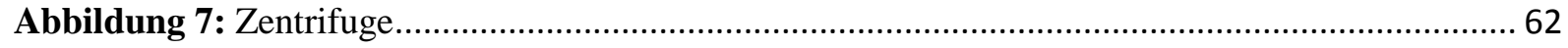

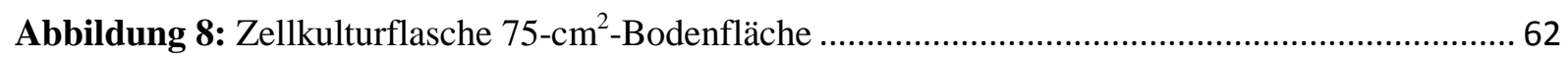

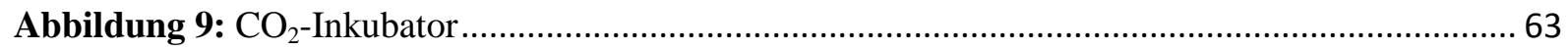

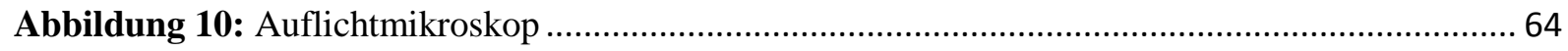

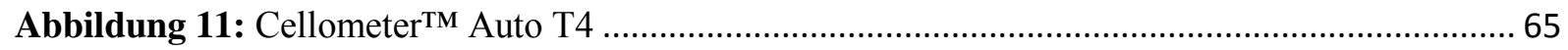

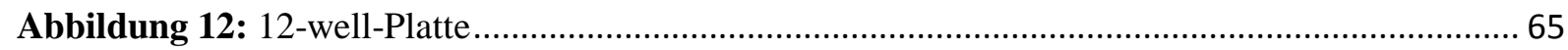

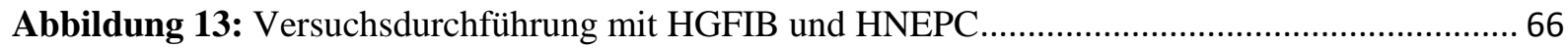

Abbildung 14: Primäre HGFIB und HNEPC in vitro 24 Stunden bzw. 96 Stunden nach der Aussaat 67

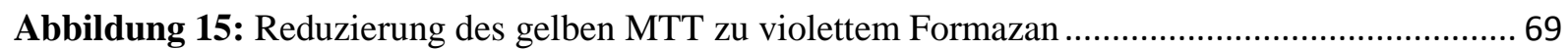

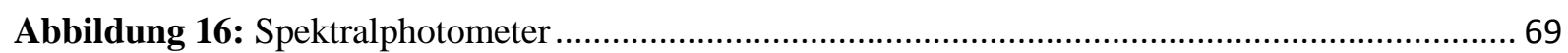

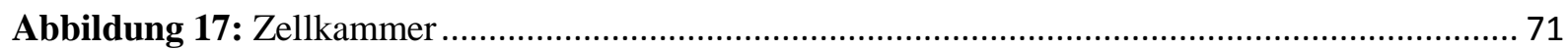




\subsection{Tabellenverzeichnis}

Tabelle 1: Mundspüllösungen

Tabelle 2: Mittelwerte und Standardfehler der MTT-Messungen (OD) nach der Behandlung mit oralen Antiseptika bei Fibroblasten.

Tabelle 3: Paarweiser Vergleich der Mundspüllösungen in Abhängigkeit von der Einwirkzeit (Signifikanzen)

Tabelle 4: Einfluss der Lösung sowie der Einwirkzeit auf die Messwerte des MTT-Tests bei den HGFIB

Tabelle 5: Mittelwerte und Standardfehler für die Zellzahlbestimmung (x10 Zellen/ml) nach der Behandlung mit oralen Antiseptika bei Fibroblasten

Tabelle 6: Paarweiser Vergleich der Mundspüllösungen in Abhängigkeit von der Einwirkzeit (Signifikanzen)

Tabelle 7: Einfluss der Lösung sowie der Einwirkzeit auf die Messwerte bei der optischen Zellzahlbestimmung mittels Cellometer ${ }^{\mathrm{TM}}$ Auto T4 bei den HGFIB

Tabelle 8: Mittelwerte und Standardfehler für die Viabilitätsbestimmung (in \%) nach der Behandlung mit den oralen Antiseptika beim Zelltyp Fibroblasten ......

Tabelle 9: Paarweiser Vergleich der Mundspüllösungen in Abhängigkeit von der Einwirkzeit (Signifikanzen)

Tabelle 10: Einfluss der Lösung sowie der Einwirkzeit auf die Messwerte bei der Viabilitätsbestimmung mittels Cellometer ${ }^{\mathrm{TM}}$ Auto T4 bei den HGFIB

Tabelle 11: Mittelwerte und Standardfehler für die Bestimmung des mittleren Zelldurchmessers (in micron) nach der Behandlung mit den oralen Antiseptika beim Zelltyp Fibroblasten....

Tabelle 12: Paarweiser Vergleich der Mundspüllösungen in Abhängigkeit von der Einwirkzeit (Signifikanzen)

Tabelle 13: Einfluss der Lösung sowie der Einwirkzeit auf die Messwerte bei der Bestimmung des mittleren Zelldurchmessers der HGFIB mittels CellometerTM Auto T4

Tabelle 14: Mittelwerte und Standardfehler für die MTT-Messungen (OD) nach der Behandlung mit oralen Antiseptika bei Epithelzellen 
Tabelle 15: Paarweiser Vergleich der Mundspüllösungen in Abhängigkeit von der Einwirkzeit (Signifikanzen)

Tabelle 16: Einflüsse der Lösung sowie der Einwirkzeit auf die Messwerte des MTT-Tests bei den HNEPC.

Tabelle 17: Mittelwerte und Standardfehler für die Zellzahlbestimmung (x10 Zellen/ml) nach der Behandlung mit den oralen Antiseptika bei Epithelzellen

Tabelle 18: Paarweiser Vergleich der Mundspüllösungen in Abhängigkeit von der Einwirkzeit (Signifikanzen)

Tabelle 19: Einflüsse der Lösung sowie der Einwirkzeit auf die Messwerte bei der optischen Zellzahlbestimmung mittels Cellometer ${ }^{\mathrm{TM}}$ Auto T4 bei den HNEPC

Tabelle 20: Mittelwerte und Standardfehler für die Viabilitätsbestimmung (in \%) nach der Behandlung mit oralen Antiseptika bei Epithelzellen

Tabelle 21: Paarweiser Vergleich der Mundspüllösungen in Abhängigkeit von der Einwirkzeit (Signifikanzen)

Tabelle 22: Einflüsse der Lösung sowie der Einwirkzeit auf die Messwerte bei der Viabilitätsbestimmung mittels Cellometer ${ }^{\mathrm{TM}}$ Auto T4 bei den HNEPC

Tabelle 23: Mittelwerte und Standardfehler für die Bestimmung des mittleren Zelldurchmessers (in micron) nach der Behandlung mit oralen Antiseptika bei Epithelzellen

Tabelle 24: Paarweiser Vergleich der Mundspüllösungen in Abhängigkeit von der Einwirkzeit (Signifikanzen)

Tabelle 25: Einflüsse der Lösung sowie der Einwirkzeit auf die Messwerte bei der Bestimmung des mittleren Zelldurchmessers von HNEPC mittels Cellometer ${ }^{\mathrm{TM}}$ Auto T4

Tabelle 26: Materialliste 160 


\subsection{Diagrammverzeichnis}

Diagramm 1: Einfluss der CHX-Mundspüllösung auf die HGFIB in Abhängigkeit von der Einwirkzeit

Diagramm 2: Einfluss von Meridol ${ }^{\circledR}$ auf die HGFIB in Abhängigkeit von der Einwirkzeit 75

Diagramm 3: Einfluss von Listerine ${ }^{\circledR}$ auf die HGFIB in Abhängigkeit von der Einwirkzeit 76

Diagramm 4: Einfluss von Betaisodona ${ }^{\circledR}$-Mundspüllösung auf die HGFIB in Abhängigkeit von der Einwirkzeit

Diagramm 5: Einfluss von Octenidol ${ }^{\circledR}$ auf die HGFIB in Abhängigkeit von der Einwirkzeit

Diagramm 6: Vergleich der Mundspüllösungen in Abhängigkeit von der Einwirkzeit

Diagramm 7: Einfluss von CHX 0,2\% ${ }^{\circledR}$-Mundspüllösung auf die Gesamtzellzahl von HGFIB in Abhängigkeit von der Einwirkzeit.

Diagramm 8: Einfluss von Meridol ${ }^{\circledR}$ auf die Gesamtzellzahl von HGFIB in Abhängigkeit von der Einwirkzeit

Diagramm 9: Einfluss von Listerine ${ }^{\circledR}$ auf die Gesamtzellzahl von HGFIB in Abhängigkeit von der Einwirkzeit

Diagramm 10: Einfluss von Betaisodona ${ }^{\circledR}$ auf die Gesamtzellzahl von HGFIB in Abhängigkeit von der Einwirkzeit

Diagramm 11: Einfluss von Octenidol ${ }^{\circledR}$ auf die Gesamtzellzahl von HGFIB in Abhängigkeit von der Einwirkzeit

Diagramm 12: Vergleich der Mundspüllösungen in Abhängigkeit von der Einwirkzeit

Diagramm 13: Einfluss von $\mathrm{CHX}^{\circledR}$ auf die Viabilität von HGFIB in Abhängigkeit von der Einwirkzeit

Diagramm 14: Einfluss von Meridol $^{\circledR}$ auf die Viabilität von primären HGFIB in Abhängigkeit von der Einwirkzeit

Diagramm 15: Einfluss von Listerine ${ }^{\circledR}$ auf die Viabilität von primären HGFIB in Abhängigkeit von der Einwirkzeit

Diagramm 16: Einfluss von Betaisodona ${ }^{\circledR}$ auf die Viabilität von HGFIB in Abhängigkeit von der Einwirkzeit 
Diagramm 17: Einfluss von Octenidol ${ }^{\circledR}$ auf die Viabilität von HGFIB in Abhängigkeit von der Einwirkzeit

Diagramm 18: Vergleich der Mundspüllösungen in Abhängigkeit von der Einwirkzeit

Diagramm 19: Einfluss von CHX 0,2 \% ${ }^{\circledR}$ auf den mittleren Durchmesser der HGFIB in Abhängigkeit von der Einwirkzeit

Diagramm 20: Einfluss von Meridol $^{\circledR}$ auf den mittleren Zelldurchmesser der HGFIB in Abhängigkeit von der Einwirkzeit 93

Diagramm 21: Einfluss von Listerine ${ }^{\circledR}$ auf den mittleren Zelldurchmesser der HGFIB in Abhängigkeit von der Einwirkzeit.

Diagramm 22: Einfluss von Betaisodona ${ }^{\circledR}$ auf den mittleren Zelldurchmesser der HGFIB in Abhängigkeit von der Einwirkzeit. 95

Diagramm 23: Einfluss von Octenidol ${ }^{\circledR}$ auf den mittleren Zelldurchmesser der HGFIB in Abhängigkeit von der Einwirkzeit.

Diagramm 24: Vergleich der Mundspüllösungen in Abhängigkeit von der Einwirkzeit

Diagramm 25: Korrelationsbestimmung zwischen MTT-Test und Zellzahlbestimmung mittels Cellometer ${ }^{\mathrm{TM}}$ Auto T4 für HGFIB

Diagramm 26: Einfluss von CHX 0,2 \% ${ }^{\circledR}$ auf die HNEPC in Abhängigkeit von der Einwirkzeit .... 100

Diagramm 27: Einfluss von Meridol $^{\circledR}$ auf die HNEPC in Abhängigkeit von der Einwirkzeit..... 100

Diagramm 28: Einfluss von Listerine ${ }^{\circledR}$ auf die HNEPC in Abhängigkeit von der Einwirkzeit. 101

Diagramm 29: Einfluss von Betaisodona ${ }^{\circledR}$ auf die HNEPC in Abhängigkeit von der Einwirkzeit ... 102

Diagramm 30: Einfluss von Octenidol ${ }^{\circledR}$ auf die HNEPC in Abhängigkeit von der Einwirkzeit...... 102

Diagramm 31: Vergleich der Mundspüllösungen in Abhängigkeit von der Einwirkzeit 103

Diagramm 32: Einfluss von CHX 0,2 ${ }^{\circledR}$ auf die Zellzahl von HNEPC in Abhängigkeit von der Einwirkzeit 106

Diagramm 33: Einfluss von Meridol ${ }^{\circledR}$ auf die Zellzahl von primären HNEPC in Abhängigkeit von der Einwirkzeit 106

Diagramm 34: Einfluss von Listerine ${ }^{\circledR}$ auf die Zellzahl von primären HNEPC in Abhängigkeit von der Einwirkzeit 
Diagramm 35: Einfluss von Betaisodona ${ }^{\circledR}$ auf die Zellzahl von primären HNEPC in Abhängigkeit von der Einwirkzeit

Diagramm 36: Einfluss von Octenidol ${ }^{\circledR}$ auf die Zellzahl von primären HNEPC in Abhängigkeit von der Einwirkzeit

Diagramm 37: Vergleich der Mundspüllösungen in Abhängigkeit von der Einwirkzeit

Diagramm 38: Einfluss der $\mathrm{CHX}^{\circledR}$-Mundspüllösung auf die Viabilität von HNEPC in Abhängigkeit von der Einwirkzeit

Diagramm 39: Einfluss von Meridol ${ }^{\circledR}$ auf die Viabilität von primären HNEPC in Abhängigkeit von der Einwirkzeit

Diagramm 40: Einfluss von Listerine ${ }^{\circledR}$ auf die Viabilität von HNEPC in Abhängigkeit von der Einwirkzeit

Diagramm 41: Einfluss der Betaisodona ${ }^{\circledR}$-Mundspüllösung auf die Viabilität von HNEPC in Abhängigkeit von der Einwirkzeit.

Diagramm 42: Einfluss von Octenidol ${ }^{\circledR}$ auf die Viabilität von HNEPC in Abhängigkeit von der Einwirkzeit

Diagramm 43: Vergleich der Mundspüllösungen in Abhängigkeit von der Einwirkzeit 116

Diagramm 44: Einfluss von CHX 0,2 \% ${ }^{\circledR}$ auf den mittleren Durchmesser von HNEPC in Abhängigkeit von der Einwirkzeit. 118

Diagramm 45: Einfluss von Meridol $^{\circledR}$ auf den mittleren Zelldurchmesser der HNEPC in Abhängigkeit von der Einwirkzeit

Diagramm 46: Einfluss von Listerine ${ }^{\circledR}$ auf den mittleren Zelldurchmesser der HNEPC in Abhängigkeit von der Einwirkzeit.

Diagramm 47: Einfluss von Betaisodona ${ }^{\circledR}$ auf den mittleren Zelldurchmesser der HNEPC in Abhängigkeit von der Einwirkzeit.

Diagramm 48: Einfluss von Octenido ${ }^{\circledR}$ auf den mittleren Zelldurchmesser der HNEPC in Abhängigkeit von der Einwirkzeit.

Diagramm 49: Vergleich der Mundspüllösungen in Abhängigkeit von der Einwirkzeit 123

Diagramm 50: Korrelationsbestimmung zwischen MTT-Test und Zellzahlbestimmung mittels Cellometer ${ }^{\mathrm{TM}}$ Auto T4 für HNEPC 


\section{Literaturverzeichnis}

ABBOTT DM, GUNSOLLEY JC, KOERTGE TE, PAYNE EL (1994):

The relative efficacy of $0.1 \%$ and $0.2 \%$ delmopinol mouthrinses in inhibiting the development of supragingival dental plaque and gingivitis in man

J Periodontol $\underline{65}, 437-441$

ADDY M (1986):

Chlorhexidine compared with other locally delivered antimicrobials. A short review

J Clin Periodontol 13, 957-964

ADDY M, WRIGHT R (1978):

Comparison of the in vivo and in vitro antibacterial properties of povidone iodine and chlorhexidine gluconate mouthrinses

J Clin Periodontol 205, 195-205

ADDY M, MORAN J, NEWCOMBE RG (2007):

Meta-analyses of studies of $0.2 \%$ delmopinol mouth rinse as an adjunct to gingival health and plaque control measures

J Clin Periodontol $\underline{34}, 58-65$

ALBERS HK, MAAS J (1985):

Vergleichende klinische Untersuchungen zur Plaqueentwicklung und zum

Entzündungsverlauf der marginalen Gingiva bei Anwendung einer Chlorhexidin-, Amin/Zinnfluorid- und acetylsalicylsäurehaltigen Mundspülung

Quintessenz $\underline{36}$ (12), 2325-2337

AL-DOORI Z, GORONCY-BERMES P, GEMMELL CG, MORRISON D (2007):

Low-level exposure of MRSA to octenidine dihydrochloride does not select for resistance

J Antimicrob Chemother $\underline{59}$ (6), 1280-1281

APATZIDOU D A, KINANE DF (2004):

Quadrant root planing versus sameday full-mouth root planing. I. Clinical findings

J Clin Periodontol $\underline{31}$, 132-140

ASBOE-JÖRGENSEN AV, ATTSTRÖM R, LANG NP (1974):

Effect of a chlorhexidine dressing on the healing after periodontal surgery

J Periodontol $\underline{45}$ (1), 13-17

ASHLEY KC (1984):

The antimicrobial properties of two commonly used antseptic mouthwashes - Corsodyl and Oraldene

Appl Bacteriol 무, 221-225

ASIKAINEN S, ALALUUSUA S, SAXEN L (1991):

Recovery of A.actinomycetemcomitans from teeth, tongue, and saliva

J Periodontol 62, 203-206 
AXELSSON P, LINDHE J (1978):

Effect of controlled oral hygiene procedures on caries and periodontal disease in adults J Clin Periodontol $\underline{5}, 133-151$

AXELSSON P, LINDHE J (1981):

Effect of controlled oral hygiene procedures on caries and periodontal disease in adults Results after 6 years

J Clin Periodontol $\underline{8}, 239-248$

AXELSSON P, LINDHE J (1987):

Efficacy of mouthrinses in inhibiting dental plaque and gingivitis in man J Clin Periodontol 14, 205-212

BABICH H, BORENFREUND E (1991):

Cytotoxicity of T-2 toxin and its metabolites determined with the neutral red cell viability assay

Appl Environ Microbiol 57 (7), 2101-2103

BABICH H, WURZBURGER BJ, RUBIN YL, SINENSKY MC, BLAU L (1995):

An in vitro study on the cytotoxicity of chlorhexidine digluconate to human gingival cells Cell Biol Toxicol $\underline{11}, 79-88$

BADERSTEN A, NILVEUS R, EGELBERG J (1981):

Effect of nonsurgical periodontal therapy. I. Moderately advanced periodontitis

J Clin Periodontol $\underline{8}, 57-72$

BADERSTEN A, NILVEUS R, EGELBERG J (1984):

Effect of nonsurgical periodontal therapy (II). Severely advanced periodontitis

J Clin Periodontol 11, 63-76

BADERSTEN A, NILVEUS R, EGELBERG J (1987):

Effect of nonsurgical periodontal therapy (VIII). Probing attachment changes related to clinical characteristics

J Clin Periodontol 14, 425-432

BALBUENA L, STAMMBAUGH K, RAMIREZ SG, YEAGER C (1998):

Effects of tropical oral antiseptic rinses on bacterial counts of saliva in healthy human subjects. Otolaryn Head

Neck Surg 118, 625-629

BANG JS, CIMASONI G (1971):

Total protein in human crevicular fluid

J Dent Res 1971, 1683

BANTEL H, RUCK P, SCHULZE-OSTHOFF K (2000):

In situ monitoring of caspase activation in hepatobiliary diseases

Cell Death Differ 7 (5), 504-505 
BANOCZY J, NEMES J (1989):

Effect of amine fluoride (AmF)/stannous fluoride $(\mathrm{SnF} 2)$ toothpaste and mouthwashes on dental plaque accumulation, gingivitis and root-surface caries

Proc Finn Dent Soc 1991 (구), 555-559

BARKVOLL P, EMBERY G, ROLLA G (1988):

Studies on the interaction between sodium lauryl sulfate and hydroxyapatite using Fourier transformed infrared spectroscopy

J Biol Buccale $\underline{16}, 75-79$

BARNHARDT BD, CHUANG A, LUCCA JJ, ROBERTS S, LIEWEHR F, JOYCE AP (2005):

An in vitro evaluation of the cytotoxicity of various endodontic irrigants on human gingival fibroblasts

J Endod $\underline{8}, 613-615$

BASSETTI C, KALLENBERGER A (1980):

Influence of chlorhexidine rinsing on the healing of oral mucosa and osseous lesions

J Clin Periodontol ㅁ, 443-456

BAY LM (1978):

Effect of toothbrushing with different concentrations of chlorhexidine on the development of dental plaque and gingivitis

J Dent Res $\underline{57}$, 181-185

BERGENHOLZ A, HÄNSTRÖM L (1974):

The plaque-inhibiting effect of hexetidine (Oraldene $®)$ - mouthwash compared to that of chlorhexidine

Community Dent Oral Epidemiol 2, 70-74

BERNIMOULIN JP (2003):

Recent concepts in plaque formation

J Clin Periodontol $\underline{30}$ (5), 7-9

BERNIMOULIN JP, DESCHER J (1995):

Antimikrobielle Lösungen in der Parodontologie - Eine allgemeine Übersicht

Parodontologie $\underline{6}, 173-180$

BERRIDGE MV, TAN AS (1993):

Characterization of the Cellular Reduction of 3-(4,5-dimethylthiazol-2-yl)-2,5-

diphenyltetrazolium bromide (MTT): Subcellular Localization, Substrate Dependence, and Involvement of Mitochondrial Electron Transport in MTT Reduction

Arch Biochem Biophys $\underline{303}$, 474-482

BERRIDGE MV, TAN AS (2000):

Cell-surface NAD(P)H-oxidase: relationship to trans-plasma membrane NADHoxidoreductase and a potential source of circulating NADH-oxidase

Antioxid Redox Signal 2 (2), 277-288 
BERRIDGE MV, TAN AS, MCCOY KD, WANG R (1996a):

The Biochemical and Cellular Basis of Cell Proliferation Assays That Use Tetrazolium Salts Biochemica 2, 1-30

BERRIDGE MV, TAN AS, MCCOY KD, KANSARA M, RUDERT F (1996b):

CD95 (Fas/Apo-1)-induced apoptosis results in loss of glucose transporter function J Immunol 156 (11), 4092-4099

BHUTIA SK, MALLICK SK, STEVENS SM, PROKAI L, VISHWANATHA JK, MAITI TK (2008):

Induction of mitochondria-dependent apoptosis by Abrus agglutinin derived peptides in human cervical cancer cell

Toxicol in Vitro 22 (2), 344-351

BIJL P, DREYER WP, GROBLER SR (1986):

The periotron gingival crevicular fluid meter. An assessment of three different instruments J Periodont Res 21, 39-44

BÖCKERS M, BORK K (1986):

Kontaktdermatitis durch PVP-Jod

Dtsch Med Wochenschr 111, 1110-1112

BOLLEN CM, VANDERKERCKHOVE BN, PAPAIOANNOU W, QUIRYNEN M (1996): Full- versus partial-mouth disinfection in the treatment of periodontal infections. A pilot study: long-term microbiological observations

J Clin Periodontol 23, 960-970

BOLLEN CM, MONGARDINI C, PAPAIOANNOU W, QUIRYNEN M (1998):

The effect of a one-stage full-mouth disinfection on different intraoralniches. Clinical and microbiological observations

J Clin Periodontol 25, 56-66

BOWEN WN (1990):

Mechanisms of action of known plaque inhibitors

Z Stomatol $\underline{87}$ (5), 19-23

BOWLES D, MÜHLEMANN HR (1971):

Effects on gingival fluid of periodontal ligament trauma

Helv Odontol Acta $\underline{15}$, 58-60

BRANEMARK PI, EKHOLM R (1967):

Tissue injury caused by wound disinfectants

J Bone Joint Surg Am $\underline{49}$ (1), 48-62

BRANEMARK PI, ALREKTSSON B, LINDSTRÖM J, LUNDBORG G (1966):

Local tissue effects of wound disinfectants

Acta Chir Scand Suppl 357, 166-176 
BRECX M (1997):

Strategies and agents in supragingival chemical plaque control

Periodontol $2000 \underline{15}, 100-108$

BRECX M, THEILADE J, ATTSTRÖM R, GLANTZ PO (1987):

The effect of chlorhexidine and Octapinol ${ }^{\circledR}$ on early human plaque formation. A light and electron microscopic study

J Periodont Res $\underline{22}$, 290-295

BRECX M, LIECHTI T, WIDMER J, GEHR P, LANG NP (1989):

Histological and clinical parameters of human gingiva following 3 weeks of chemical (chlorhexidine) or mechanical plaque control

J Clin Periodontol 16 (3), 150-155

BRECX M, BROWNSTONE E, MACDONALD L, GEISKEY S, CHEANG M (1992):

Efficacy of Listerine ${ }^{\circledR}$, Meridol ${ }^{\circledR}$ and chlorhexidine mouthrinses as supplements to regular toothcleaning measures

J Clin Periodontol $\underline{19}$, 202-207

BRECX M, MACDONALD LL, LEGARY K, CHEANG M, FORGAY MGE (1993):

Longterm effects of Meridol ${ }^{\circledR}$ and chlorhexidine mouthrinses on plaque, gingivitis, staining and bacterial vitality

J Dent Res 르, 1194-1197

BRECX M, NETUSCHIL L, HOFFMANN T (2003):

How to select the right mouthrinses in periodontal prevention and therapy(II): Clinical use and recommentations

Int J Dent Hyg 1, 188-194

BRENNAN SS, LEAPER DJ (1985):

The effect of antiseptics on the healing wound: a study using the rabbit ear chamber

Br J Surg $\underline{72}$ (10), 780-782

BRILL N (1959):

Removal of particles and bacteria from gingival pockets by tissue fluids

Acta Odontol Scand 17, 431-440

BRILL N, KRASSE H (1958):

The passage of tissue fluid into the clinically healthy gingival pocket

Acta Odontol Scand 16, 233-245

BRILL N, BJÖRN H (1959):

Passage of tissue fluid into human gingival pockets

Acta Odontol Scand 17, 11-21

BRILL N, KRASSE H (1959):

Effect of mechanical stimulation on flow of tissue fluid through gingival pocket epithelium Acta Odontol Scand 17, 115-130 
BRINER WW, GROSSMAN E, BUCKNER RY, REBITSKI GF, SOX TE, SETSER RE, EBERT ML (1986):

Effect of chlorhexidine gluconate mouthrinse on plaque bacteria

J Periodont Res 21 (16), 44-52

BROWN LJ, LÖE H (2000):

Prevalence, extent, severity and progression of periodontal disease

Periodontol 2000 2, 57-71

CABRAL CT, FERNANDES MH (2007):

In vitro comparison of chlorhexidine and povidone-iodine on the long-term proliferation and functional activity of human alveolar bone cells

Clin Oral Investig 11 (2), 155-164

CALABRO AR, KONSOULA R, BARILE FA (2008):

Evaluation of in vitro cytotoxicity and paracellular permeability of intact monolayers with mouse embryonic stem cells

Toxicol In Vitro $\underline{22}$ (5), 1273-1284

CALDWELL RC, SANDHAM HJ, MANN WV, FINN SB, FORMICOLA AJ (1971):

The effect of a dextranase mouthwash on dental plaque in young adults and children J Am Dent Assoc 르, 124-131

CARRETERO PELÁEZ MA, ESPARZA GÓMEZ GC, FIGUERO RUIZ E, CERERO LAPIEDRA R (2004):

Alcohol-containing mouthwashes and oral cancer. Critical analysis of literature

Med Oral $\underline{9}$ (2), 116-123

CATALIOTO RM, FESTA C, TRIOLO A, ALTAMURA M, MAGGI CA, GIULIANI S (2009):

Differential effect of ethanol and hydrogen peroxide on barrier function and prostaglandin E2 release in differentiated Caco-2 cells: selective prevention by growth factors

J Pharm Sci $\underline{98}$ (2), 713-727

CATE JM, MARSH PD (1994):

Procedures for establishing efficacy of antimicrobial agents for chemotherapeutic caries prevention

J Dent Res $\underline{73}$ (3), 695-703

CHAPPLE IL, CROSS IA, GLENWRIGHT HD, MATTHEWS JB (1995):

Calibration and reliability of the Periotron 6000 for individual gingival crevicular fluid samples

J Periodontal Res 30, 73-79

CHARLES CH, SHARMA NC, GALUSTIANS HJ, QAQISH J, MCGUIRE JA,VINCENT JW (2001):

Comparative efficacy of an antiseptic mouthrinse and anantiplaque/antigingivitis dentifrice A six-month clinical trial

J Am Dent Assoc 132, 667-677 
CIANCIO SG (1992):

Agents for the management of plaque and gingivitis

J Dent Res 1ㅜ, 1450-1454

CIANCIO SG (1995):

Nonsurgical chemical periodontal therapy

Periodontol 2000 9, 27-37

CIANCIO SG (2003):

Improving oral health: current considerations

J Clin Periodontol $\underline{30}$ (5), 4-6

CIMASONI G (1983):

Crevicular fluid updated

Monogr Oral Sci 12 (III-VII), 1-152

CLAFFEY N, EGELBERG J (1994):

Clinical characteristics of periodontal sites with probing attachment loss following initial periodontal treatment

J Clin Periodontol 21, 670-679

COBB CM (1996):

Non-surgical pocket therapy: mechanical

Ann Periodontol 1, 443-490

COLLAERT B, EDWARDSSON S, ATTSTROM R, HASE JC, ASTROM M, MOVERT R (1992):

Rinsing with delmopinol $0.2 \%$ and chlorhexidine $0.2 \%$ : short-term effect on salivary microbiology, plaque, and gingivitis

J Periodontol $\underline{63}$, 618-625

COLLAERT B, EDWARDSSON S, ATTSTROM R, HASE JC, ASTROM M (1993):

Microbiology of early supragingival plaque development after delmopinol treatment Oral Microbiol Immunol $\underline{8}, 36-41$

COSTERTON JW, LEWANDOWSKI Z, DEBEER D, CALDWELL D, KORBER D, JAMES G (1994):

Biofilms, the customized microniche

J Bacteriol 176, 2137-2142

CROUCH SP, KOZLOWSKI R, SLATER KJ, FLETCHER J (1993):

The use of ATP bioluminescence as a measure of cell proliferation and cytotoxicity J Immunol Methods $\underline{160}$ (1), 81-88

CUMMING BR, LÖE H (1973):

Optimal dosage and method of delivering chlorhexidine solutions for the inhibition of plaque J Periodont Res $\underline{8}$, 57-62 
CUMMINGS BS, SCHNELLMANN RG (2002):

Cisplatin-Induced Renal Cell Apoptosis: Caspase 3-Dependent and -Independent Pathways JPET $\underline{302}$ (1), 8-17

CURTIS MA, GRIFFITHS GS, PRICE SJ, COULTHURST SK, JOHNSON NW (1988):

The total protein concentration of gingival crevicular fluid. Variation with sampling time and gingival inflammation

J Clin Periodontol 15 , 628-632

CURTIS MA, STERNE JA, PRICE SJ, GRIFFITHS GS, COULTHURST SK, WILTON JM (1990):

The protein composition of gingival crevicular fluid sampled from male adolescents with no destructive periodontitis: baseline data of a longitudinal study

J Periodontal Res $\underline{25}$, 6-16

DAHLIN C, LINDE A, GOTTLOW J, NYMAN S (1988):

Healing of bone defects by guided tissue regeneration

Plast Reconstr Surg $\underline{81}, 672-676$

DAHLIN C, SENNERBY L, LEKHOLM U, LINDE A, NYMAN S (1989):

Generation of new bone around titanium implants using a membrane technique: an

experimental study in rabbits

Int J Oral Maxillofac Implants $\underline{4}, 19-25$

DAMOUR O, HUA SZ, LASNE F, VILLAIN M, ROUSSELLE P, COLLOMBEL C (1992):

Cytotoxicity evaluation of antiseptics and antibiotics on cultured human fibroblasts and keratinocytes

J Periodontol $\underline{18}$ (6), 479-85

DAMOUR O, AUGUSTIN C, BLACK AF (1998):

Applications of reconstructed skin models in pharmaco-toxicological trials

Med Biol Eng Comput $\underline{36}$ (6), 825-832

DANSER MM, VAN WINKELHOFF AJ, Loos GJ (1994):

Short-term effect of full-mouth extraction on periodontal pathogens

colonizing the oral mucous membranes

J Clin Periodontol 21, 484-489

DANSER MM, TIMMERMAN MF, VAN WINKELHOFF AJ (1996):

The effect of periodontal treatment on periodontal bacteria on the oral mucous membranes

J Periodontol $\underline{67}, 478-485$

DARVEAU RP, TANNER A, PAGE RC (1997):

The microbial challenge in periodontitis

Periodontol $2000 \underline{14}, 12-32$ 
DAVIES GE, FRANCIS J, MARTIN AR, ROSE FL, SWAIN G (1954):

1:6- Di-4 -chlorophenyldiguaniddohexane (Hibitane). Laboratory investigation of a new antbacterial agent of high potency

Br J Pharmacol 9, 192-196

DEBATIN K (2000):

Activation of apoptosis pathways by anticancer treatment

Toxicol Lett $\underline{15}, 41-48$

DEPAOLA LG, OVERHOLSTER CD, MEILLER TF, MINAH GE, NIEHAUS C (1989):

Chemotherapeutic inhibition of supragingival dental plaque and gingivitis

J Clin Periodontol $\underline{16}, 311-315$

DERISO AJ, LADOWSKI JS, DILLON TA, JUSTICE JWÖ, PETERSON AC (1996):

Chlorhexidine Gluconate $0.12 \%$ oral rinse reduces the incidence of total nosocomial respiratory infection and nonprophylactic systemic antibiotic use in patients undergoing heart surgery

Chest $\underline{109}, 1556-1561$

DRISKO CH (2001):

Nonsurgical periodontal therapy

Periodontol $2000 \underline{25}, 77-88$

DZINK JL, SOCRANSKY SS (1985):

Comparative in vitro activity of sanguinarine against oral microbial isolates

Antimicrob Agents Chemother 27, 663-665

EGELBERG J (1963):

Diffusion of histamine into the gingival crevice and through the crevicular epithelium Acta Odontol Scand 21, 271-282

EGELBERG J (1964):

Gingival exudate measurements for evaluation of inflammatory changes of the gingivae Odont Revy 15, 381-398

EGELBERG J (1966a):

The blood vessels of the dento-gingival junction

J Periodontal Res $\underline{1}, 163-179$

EGELBERG J (1966b):

Permeability of the dento-gingival blood vessels. Application of the vascular labelling method and gingival fluid measurements

J Periodontal Res $\underline{1}, 180-191$

EGELBERG J (1966c):

Permeability of the dento-gingival blood vessels (II). Clinically healthy gingivae J Periodontal Res $\underline{1}$, 276-286 
EGELBERG J (1966d):

Permeability of the dento-gingival blood vessels (IV). Effect of histamine on vessels in clinically healthy and chronically inflamed gingivae

J Periodontal Res $\underline{1}$, 297-302

EGELBERG J (1966e):

Permeability of the dento-gingival blood vessels. Chronically inflamed gingivae

J Periodontal Res 1, 287-296

EGELBERG J (1967):

The topography and permeability of vessels at the dento-gingival junction in dogs

J Periodontal Res 1, 1-39

ELWORTHY A, GREENMAN J, DOHERTY FM, NEWCOMBE RG, ADDY M (1996):

The substantivity of a number of oral hygiene products deter mined by the duration of effects on salivary bacteria

J Periodontol $\underline{6}, 572-576$

EMILSON CG, BOWEN WH, ROBRISH SA, KEMP CW (1981):

Effect of the antibacterial agents octenidine and chlorhexidine on the plaque flora in primates Scand J Dent Res $\underline{89}$ (5), 384-92

ENZELSBERGER H, EPPEL W, DORNINGER G, WEWALKA G (1995):

Efficacy of various methods for preoperative vaginal antisepsis

Geburtsh Frauenheilkd 55, 707-710

FABREGUETTE A, ZHI HUA S, LASNE F, DAMOUR O (1994):

Evaluation of the cytotoxicity of antiseptics used in current practice on cultures of fibroblasts and keratinocytes

Pathol Biol (Paris) $\underline{42}$ (9), 888-892

FERRETTI GA, ASH RC, BROWN AT (1987):

Chlorhexidine for prophylaxis against oral infections and associated complications in patients receiving bone marrow transplants

JADA $\underline{114}, 461-465$

FERRETTI GA, ASH R C, BROWN AT, PARR MD, ROMOND EH, LILLICH XT (1988):

Control of oral mucositis and candidiasis in marrow transplantation: a prospective double blind trial of chlorhexidine digluconate oral rinse

Bone Marrow Transplant $\underline{3}$, 483-493

FERRETTI GA, RAYBOULD TP, BROWN AT, MACDONALD JS, GREENWOOD M, MARUYAMMA Y, GEIL J, LILLICH TT, ASH RC (1990):

Chlorhexidine prophylaxis for chemotherapy- and radiotherapy induced stomatitis: A randomized double-bind trial

Oral Surg Oral Med Oral Pathol $\underline{69}, 331-338$

FESUS L, DAVIES PJ, PIACENTINI M (1991):

Apoptosis: molecular mechanisms in programmed cell death

Eur J Cell Biol $\underline{56}$ (2), 170-177 
FINE DH, LETIIZIA J, MANDEL ID (1985):

The effect of rinsing with Listerine ${ }^{\circledR}$ antiseptic on the properties of developing dental plaque $\mathrm{J}$ Clin Periodontol $\underline{12}, 660-665$

FINE DH, MENDIETA C, BARNETT ML, FURGANG D, MEYERS R, OLSHAN A, VINCENT J (1992):

Efficacy of preprocedural rinsing an antiseptic in reducing viable bacteria in dental aerosols J Periodontol $\underline{63}$, 821-826

FINE DH, FURGANG D, SINATRA K, CHARLES C, MCGUIRE A, KUMAR LD (2005): In vivo antimicrobial effectiveness of an essential oil-containing mouth rinse $12 \mathrm{~h}$ after a single use and 14 days' use

J Clin Periodontol 32, 335-340

FLEMINGSON M, EMMADI P, AMBALAVANAN N, RAMAKRISHNAN T, VIJAYALAKSHMI R (2008):

Effect of three commercial mouth rinses on cultured human gingival fibroblast: An in vitro study

Indian J Dent Res 19 (1), 29-35

FLEMMIG TF:

Parodontologie: Ein Kompendium

Thieme, Stuttgart / New York 1993

FLORES-DE-JACOBY L:

Möglichkeiten der Plaque- und Gingivitisprävention. Neue Erkenntnisse zum

Wirkstoffsystem Aminfluorid/Zinnfluorid

Quintessenz, Berlin 1991

FLORES-DE-JACOBY L, THOR G, LANGE D E (1975):

Vergleichende klinische und zytologische Untersuchung nach der Anwendung von zwei

Zahnpasten

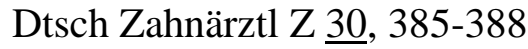

FLÖTRA L, GJERMO P, RÖLLA G, WAERHAUG J (1971):

Side effects of chlorhexidine mouth washes

Scand J Dent Res $\underline{79}, 119-125$

FLÖTRA L, GJERMO P, ROLLA P, WAERHAUG J (1972):

A 4-month study on the effect of chlorhexidine mouth washes on 50 soldiers

Scan J Dent Res $\underline{80}, 10-17$

FRANCOEUR R (1997):

Improving access, efficacy, and cost effectiveness of alcohol rehabilitation for poor patients J Health Hum Serv Adm $\underline{19}$ (4), 425-441

FRITZSCHE T, SAXER UP (1989):

Fluoride retention and clearance after rinsing with fluoridated mouthwashes

Schweiz Monatsschr Zahnmed 99, 299-306 
FROST HM (1994):

Wolff's law and bone's structural adaptations to mechanical usage: an overview for clinicians Angle Orthod 64, 175-188

FRUNDER H:

Physiologische Chemie

Volk und Wissen, Berlin 1984

GAFFAR A, AFFITTO J, NABI N, HERLES S, KRUGER I, OLSEN S (1994):

Recent advances in plaque, gingi-vitis, tartar and prevention technology

Int Dent J 44, 63-70

GÄNGLER P:

Konservierende Zahnheilkunde und Parodontologie

Thieme, Stuttgart 2005

GIANNELLI M, CHELLINI F, MARGHERI M, TONELLI P, TANI A (2008):

Effect of chlorhexidine digluconate on different cell types: A molecular and ultrastructural investigation

Toxicol InVitro 22, 308-317

GIERTSEN E, SCHEIE AA, ROLLA G (1989):

In vivo effects of zinc and chlorhexidine on dental plaque ureolysis and glycolysis

J Dent Res $\underline{68}, 1132-1134$

GILBERT P, MOORE LE (2005):

Cationic antiseptics: diversity of action under a common epithet

J Appl Microbiol 99 (4), 703-715

GJERMO P (1978):

Pharmakodynamische Aspekte über die plaquehemmende Wirkung von Chlorhe-xidin

ZWR $\underline{87}$ (7), 337-338

GJERMO P (1989):

Chlorhexidin and related compounds

J Dent Res $\underline{68}$, 1602-1608

GOLD R, SCHMIED M, GIEGERICH G, BREITSCHOPF H, HARTUNG HP, TOYKA KV, LASSMANN H (1994):

Differentiation between cellular apoptosis and necrosis by the combined use of in situ tailing and nick translation techniques

Lab Invest $\underline{71}$ (2), 219-225

GOLDENHEIM PD (1993):

An appraisal of povidone-iodine and wound healing

Postgrad Med J $\underline{69}$ (3), 97-105

GOODSON JM (2000):

Gingival crevice fluid flow

Periodontol 2000 31, 43-54 
GORDEN P, CARPENTIER JL, ORCI L (1985):

Insulin action at the cellular level: anatomical considerations

Diabetes Metab Rev 1 (1-2), 99-117

GORDON JM, LAMSTER IB, SEIGER C (1985):

Efficacy of Listerine ${ }^{\circledR}$ antiseptic in inhibiting the development of plaque and gingivitis J Clin Periodontol 12, 697-704

GORONCY-BERMES H:

Untersuchug über die Wirkung von Octenisept gegen Mikroorganismen der Vaginalflora S\&M Forschung, S\&M Forsch Norderst 1990, 33-42

GÖRTZ G, HÄRING R (1986):

PVP-Jod als Alternative zu anderen Antiseptika und Lokalantibiotika in der Chirurgie, Handchirurgie, Mikrochirurgie

Plast Chir $\underline{18}, 3-14$

GORZYCA W, KRAM A, TUZIAK T, DARZYNKIEWICZ Z, MELAMED MR (1993):

Proliferating cell nuclear antigen in archival surgical specimens of malignant lymphoma and metastatic carcinoma: immunohistochemical and flow cytometric analysis

Patol Pol $\underline{44}$ (3), 121-128

GREENSTEIN G, BERMAN C, JAFFIN R (1986):

Chlorhexidine. An adjunct to periodontoal therapy

J Clin Periodontol 57, 370-377

GREENWELL H, BISSADA NF, MAYBURY JE, DE MARCO TJ (1983):

Clinical and microbiologic effectiveness of Keyes' method of oral hygiene on human periodontitis treated with and without surgery

J Am Dent Assoc 106, 457-461

GRIFFITHS GS (2003):

Formation, collection and significance of gingival crevice fluid

Periodontol $2000 \underline{31}, 32-42$

GRIFFITHS GS, STERNE JA, WILTON JM, EATON KA, JOHNSON NW (1992):

Associations between volume and flow rate of gingival crevicular fluid and clinical assessments of gingival inflammation in a population of British male adolescents J Clin Periodontol $\underline{19}$, 464-470

GROSSMANN E, MECKEL AH, ISAACS RL, FERRETTI GA, STURZENBERGER OP, BOLLMER BW, MOORE DJ, LIJANA RC, MANHART MD (1989):

A clinical comparison of antibacterial mouthrinses: effects of chlorhexidine, phenolics, and sanguinarine on dental plaque and gingivitis

J Periodontol $\underline{60}, 435-440$

GRUBER RP, VISTNES L, PARDOE R (1975):

The effect of commonly used antiseptics on wound healing Plast Reconrts SUT 55, 472-476 
GUARNELLI MA (2004):

Evaluation of additional amine fluoride/stannous fluoride-containing mouthrinse during supportive therapy in patients with generalized aggressive periodontitis

J Clin Periodontol 31, 742-748

GUGGENHEIM B:

Cariology today

Karger, Basel / New York 1983

HAMILTON IR, BOWDEN GHW:

Fluoride effects on oral bacteria

In: Fejerskov O, Ekstrand J, Burt BA: Fluoride in dentistry

Munksgaard, Kopenhagen 1996

HAMMERLE CH, JOSS A, LANG NP (1991):

Short-term effects of initial periodontal therapy (hygienic phase)

J Clin Periodontol 18, 233-239

HAMP SE, ROSLING B, LINDHE J (1975):

Effect of chlorhexidine on gingival wound healing in the dog. A histometric study

J Clin Periodontal $2,43-52$

HANCOCK EB, CRAY R J, O'LEARY TJ (1979):

The relationship between gingival crevicular fluid and gingival inflammation. A clinical and histologic study

J Periodontol 50, 13-19

HARKE A:

Einfluß von Octenisept auf immunmodulatorische Reaktionen

S\&M Forschung, S \& M Forsch Nordest 1997

HARTMANN A, MOHR JP, THOMPSON JL, RAMOS O, MAST H (1999):

Interrater reliability of plaque morphology classification in patients with severe carotid artery stenosis

Acta Neurol Scand 99 (1), 61-64

HARTMANN R, MEISEL H (2007):

Food-derived peptides with biological activity: from research to food applications

Curr Opin Biotechnol 18 (2), 163-169

HASE J C, AINAMO J, ETEMADZADEH H, ASTROM M (1995):

Plaque formation and gingivitis after mouthrinsing with $0.2 \%$ delmopinol hydrochloride, $0.2 \%$ chlorhexidine digluconate and placebo for 4 weeks, following an initial professional tooth cleaning

J Clin Periodontol 22, 533-539

HAUNFELDER JK:

Praxis der Zahnheilkunde. Bd. 4: Parodontologie

Urban u. Schwarzenberg, München / Wien / Baltimore 1990 
HAUPTMANN S, SCHÄFER H, FRITZ A, HAUPTMANN P (1992):

Untersuchung der wachstumsbeeinflussenden Wirkung von Wundsalben an der Zellkultur Hautarzt $\underline{43}, 432-435$

HEEG P, CHRISTIANSEN B:

Hautantiseptik

In: Kramer A, Gröschel D, Heeg P, Hingst V, Lippert H, Rotter M, Weuffen W:

Klinische Antiseptik

Springer Verlag, Berlin / Heidelberg / New York 1993

HEFTI A F, HUBER B (1987):

The effect on early plaque formation, gingivitis and salivary bacterial counts of mouthwashes containing hexetidine/zinc, aminefluoride/tin or chlorhexidine

J Clin Periodontol 14, 515-518

HIDALGO E, DOMINGUEZ C (2001):

Mechanisms underlying chlorhexidine-induced cytotoxicity

Toxicol In Vitro 15 (4-5), 271-276

HIRSCH T, JACOBSEN F, RITTIG A, GOERTZ O, NIEDERBICHLER A, STEINAU HU, SEIPP HM, STEINSTRAESSER L (2009):

A comparative in vitro study of cell toxicity of clinically used antiseptics

Hautarzt $\underline{60}$ (12), 984-91

HIRST RC, EGELBERG R, HORNBUCKLE GC, OLIVER RC, ROTHBUN

WE (1973):

Microscopic evaluation of topically applied chlorhexidine gluconate on gingival wound healing in dogs

J Southern Calif Dent Assoc 41, 311-317

HOCK JM, KRISHNAN V, ONYIA JE, BIDWELL JP, MILAS J, STANISLAUS D (2001): Osteoblast apoptosis and bone turnover

J Bone Miner Res 16, 975-984

HOFBAUER LC, LACEY DL, DUNSTAN CR, SPELSBERG TC, RIGGS BL, KHOSLA S (1999):

Interleukin- $1 \beta$ and tumor necrosis factor- $\alpha$, but not interleukin- 6 , stimulate osteoprotegerin ligand gene expression in human osteoblastic cells

Bone 25, 255-259

HOPPENBROUWERS PM, DRIESSENS FC, BORG GREVEN JM (1986):

The vulnerability of unexposed human dental roots to demineralization

J Dent Res 모, 955-958

HUDELMAIER RM:

In vitro Untersuchungen der antibakteriellen Wirkung einer Amin-/Zinnfluoridverbindung Med Diss Tübingen 1987, 7-21 
HUGHES-PAPSIDERO J, LEVINE H (1984):

Effects of benzoyl peroxide on the stimulation of granulation tissue over major neck vessels. Otolalyngol

Head Neck Susg $\underline{92}, 362-365$

HUTH KC, JAKOB FM, SAUGEL B, CAPPELLO C, PASCHOS E, HOLLWECK R, HICKEL R, BRAND K (2006):

Effect of ozone on oral cells compared with established antimicrobials

Eur J Oral Sci 114 (5), 435-440

INTERNATIONAL WORKSHOP for a Classification of Periodontal Diseases and Conditions, 1999 Papers, Oak Brook, Illinois (1999)

Ann Periodontol 4, 1-112

IWASAKI T, KANDA T, MIZUSAWA H (1999):

Effects of pericytes and various cytokines on integrity of endothelial monolayer originated from blood-nerve barrier: an in vitro study

J Med Dent Sci 46 (1), 31-40

JENKINS S, EDGAR WM (1977):

Distribution and forms of $F$ in saliva and plaque

Caries Res 11, 226-231

JENKINS S, ADDY M, NEWCOMBE RG (1994):

Dosisabhängige Wirkung von Chlorhexidin auf die Plaque im Vergleich mit Triclosan

J Clin Periodontol 21, 250-255

JERVØE-STORM PM, SEMAAN E, ALAHDAB H, ENGEL S, FIMMERS R, JEPSEN S (2006):

Clinical outcomes of quadrant root planing versus fullmouth root planing

J Clin Periodontol 33, 209-215

JOKINEN MA (1978):

Prevention of post-extraction bacteremia by local prophylaxis

Int J Oral Surg $\underline{7}, 450-452$

JONES CG (1997):

Chlorhexidine: is it still the gold standard?

Periodontol $2000 \underline{15}, 55-62$

KALTEIS T, LURING C, SCHAUMBURGER J, PERLICK L, BATHIS H, GRIFKA J (2003):

Tissue toxicity of antiseptics

Z Orthop Ihre Grenzgeb 141, 233-238 
KAMMA JJ, BRADSHAW DJ, FULFORD MR, MARSH PD, FRANDSEN E, OSTERGAARD E, SCHEL AJ, TEN CATE JM, MOORER WR, MAVRIDOU A, MANDILARA G, STOESSER L, KNEIST S, ARAUJO R, CONTRERAS N, GORONCYBERMES P, BURKE F, O'MULLANE D, O'SULLIVAN M, WALKER JT (2006):

Attitudes of general dental practitioners in Europe to the microbial risk associated with dental unit water systems

Int Dent J $\underline{56}$ (4), 187-195

KAWAI T, MATSUYAMA T, HOSOKAWA Y, MAKIHIRA S, SEKI M, KARIMBUX NY (2006):

$\mathrm{B}$ and T lymphocytes are the primary sources of RANKL in the bone resorptive lesion of periodontal disease

Am J Pathol 169, 987-998

KELSTRUP J, HOLM-PEDERSEN P, POULSEN S (1978):

Reduction of the formation of dental plaque and gingivitis in humans by crude mutanase Scand J Dent Res $\underline{86}, 93-102$

KENT W, DYKEN A, RAHMETULLA, ALISON C, SUZANNE M (1996):

Effect of in vitro passage of healthy human gingival fibroblast on cellular morphology and cytokine expression

Arch Oral Biol 41, 263-270

KIRCHMAYR W (1957):

Zum Problem der sogenannten Jodüberempfindlichkeit

Wien Klin Wochenschr 69, 578-579

KNOWLES JW, BURGETT FG, NISSLE RR, SHICK RA, MORRISON EC, RAMFJORD SP (1979):

Results of periodontal treatment related to pocket depth and attachment level. Eight years J Periodontol 50, 225-233

KÖNIG B, REIMER K, FLEISCHER W, KÖNIG W (1997):

Effects of Betaisodona on parameters of host defense

Dermatology $\underline{195}(2), 42-48$

KOSHY G, KAWASHIMA Y, KIJI M, NITTA H, UMEDA M, NAGASAWA T, ISHIKAWA I (2005):

Effects of single-visit full-mouth ultrasonic debridement versus quadrant-wise ultrasonic debridement

J Clin Periodontol $\underline{32}$, 734-743

KOSTOPOULUS L, KARRING T (1994):

Augmentation of the rat mandible using guided tissue regeneration

Clin Oral Implants Res $\underline{5}, 75-82$

KOWOLLIK J (1994):

Mundspüllösungen als Additivum der häuslichen Zahnpflege

Zahnärztl Mitt $\underline{84}, 1346$ 
KOZLOVSKY A, ARTZI Z, HIRSHBERG A, ISRAELI-TOBIAS C, REICH L (2007): Effect of local antimicrobial agents on excisional palatal wound healing: a clinical and histomorphometric study in rats

J Clin Periodontol $\underline{34}$ (2), 164-171

KRAMER A, WALLHÄUSSER KH:

Wirkungsspektrum und Anwendungseigenschaften häufig aus prophylaktischer Indikation angewendeter Antiseptika

In: Kramer A, Weuffen W: Klinische Anwendung von Antiseptika

Springer Verlag, Berlin 1993

KRAMER A, PITTEN FA (1998):

Sofortmaßnahmen bei akzidentieller Kontamination mit infektiösen Material

Hyg Med 23, 312-314

KRAMER A, PITTEN FA (2000):

Wirksamkeit oraler Antiseptika für prophylaktische Indikationen

Zahnarzt Wirtschaft Praxis 4, 96-99

KRAMER A, BÖTTCHER L, BÖTTCHER U, NIESLER M, NEUMANN K, WEUFFEN W: Antiseptische Effektivität ausgewählter Antiseptika zur prophylaktishen Mundhöhlenspülung In: Knoll KH: Angewandte Hygiene in ZMK-Klinik und Praxis

Medizinisches Zentrum für Hygiene und Medizinische Mikrobiologie der Philipps-Universität Marburg 1990, 211-217

KRAMER A, EXNER M, HEEG P, HINGST V, ROSIN M, WAHL G:

Antiseptik in der Mundhöhle

In: Kramer A: Klinische Antiseptik

Springer Verlag, Berlin 1993

KRAMER A, HÖPPE H, KRULL B, PITTEN F-A, ROSSENAU S (1997/98):

Antiseptische Wirksamkeit und Akzeptanz von Octinisept ${ }^{\circledR}$ im Vergleich zu ausgewählten herkömmlichen Mundhöhlenantiseptika

Zent B1 Hyg Umweltmed 200 (Gustav-Fischer), 443-456

KRAMER A, HÖPPE H, KRULL B, PITTEN FA, ROSENAU S (1998):

Antiseptic efficacy and acceptance of Octenisept computed with common antiseptic mouthwashes

Zentralbl Hyg Umweltmed 200 (5-6), 443-56

KRAMER A, BELOW H, BEHRENS-BAUMANN W, MÜLLER G, RUDOLPH P, REIMER K (2002):

New aspects of the tolerance of the antiseptic povidone-iodine in different ex vivo models

Dermatology 204 (1), 86-91

KREMERS L, LAMPERT F (1979):

Klinische Untersuchungen über die plaquereduzierende Wirkung von Chlorhexidindigluconat mit unterschiedlichen Konzentrationen

Dtsch Zahnärztl Z 쓰, 365-366 
KUBERT D, RUBIN M, BARNETT ML, VINCENT JW (1993):

Antiseptic mouthrinse-induced microbial cell surface alterations

Am J Dent $\underline{6}, 277-279$

KÜHNEL F, ZENDER L, PAUL Y, TIETZE MK, TRAUTWEIN C, MANNS M, KUBICKA S (2000):

NFkB Mediates Apoptosis through Transcriptional Activation of Fas (CD95) in Adenoviral Hepatitis

J Biol Chem 275: 6421-6427

LAMSTER IB, ALFANO MC, SEIGER MC, GORDEN JM (1983):

The effect of Listerine ${ }^{\circledR}$ antiseptic on reduction of existing plaque and gingivitis

Clin Prev Dent $\underline{5}, 12-16$

LANG D, DOHLE F, TERSTESSE M, BANGEN P, AUGUST C, PAUELS HG, HEIDENRECH S (2002):

Down-Regulation of Monocyte Apoptosis by Phagocytosis of Platelets: Involvement of a Caspase-9, Caspase-3, and Heat Shock Protein 70-Dependent Pathway

J Immunol 168: 6152-6158

LANG NP, BRECX MC (1986):

Chlorhexidine digluconate - an agent for chemical plaque control and prevention of gingival inflammation

J Periodont Res $\underline{21}$ (16), 74-89

LANG NP, GUSBERTI FA, SIGRIST BE (1985):

Ätiologie der Parodontalerkrankungen

Acta Parod 14, 1

LANG NP, HASE JC, GRASSI M, HAMMERLE CH, WEIGEL C, KELTY E, FRUTIG F (1998):

Plaque formation and gingivitis after supervised mouthrinsing with $0.2 \%$ delmopinol hydrochloride, $0.2 \%$ chlorhexidine digluconate and placebo for 6 months

Oral Dis $\underline{4}, 105-113$

LANGE DE (1995):

Über den Einsatz von Chlorhexidindigluconat (CHX) als antimikrobiell wirkendes

Medikament in der Stomatologie

Dent For $\underline{5}$ (2), 9-15

LANGEBAEK J, BAY L (1976):

The effect of chlorhexidine mouthrinse on healing after gingivectomy

Scand J Dent Res $\underline{84}$ (4), 224-228

LANGER S, SEDIGH SALAKDEH M, GOERTZ O, STEINAU HU, STEINSTRAESSER L, HOMANN HH (2004):

The impact of topical antiseptics on skin microcirculation

Eur J Med Res $\underline{9}$ (9), 449-454 
LANKER KLOSSNER B, WIDMER H-R, FREY F (1997):

Nondevelopment of resistance by bacteria during hospital use of povidone-iodine,

Dermatology $\underline{2}, 10-13$

LEER MP, KOLGEN W, BJOKLUND V, BERGMAN T, TRIBBICK G, PERSSON B, BJORKLUND P, RAMAEKERS FC, BJORKLUND B, NAP M, JORNVALL H, SCHUTTE B (1999):

Immuncytochemical detection and mapping of a cytokeratin 18 neoepitope exposed during early apoptosis

J Pathol 187, 567-572

LINDAU GD (1997):

Antimikrobielle Wirkstoffe in der Zahnheilkunde

Bayer Zahnärztebl 12, 36-38

LINDHE J, KARRING ES:

Anatomy of the Periodontium

In: Lindhe J, Karring ES, Lang NP: Clinical Periodontology and Implant Dentistry

Munksgaard, Kopenhagen 1998

LINDL T, BAUER J:

Inhibition des Zellwachstums (quantitative Neutralmethode). (Inhibition of cell growth (quantitative neutral method).

In: LINDL T, BAUER J: Zell- und Gewebekultur

Gustav Fischer Verlag, Stuttgart / Jena / New York 1994

LINEAWEAVER W, HOWARD R, SOUCY D, MC MORRIS S, FREEMAN J, CRAIN C, ROBERTSON J, RUMLEY T (1985):

Topical antimicrobial toxicity

Arch Surg 120, 267-270

LISTGARTEN MA (1987):

Nature of periodontal diseases: Pathogenic mechanisms

J Periodont Res 22, 172-178

LISTGARTEN MA (1994):

The structure of dental plaque

Periodontology 2000 5, 52-65

LÖE H, SILNESS J (1963):

Periodontal disease in pregnancy. Prevalence and severity

Acta Odontol Scand 21, 533-551

LÖE H, SCHIÖTT CR (1970):

The effect of mouthrinses and topical application of chlorhexidine on the development of dental plaque and gingivitis in man

J Periodont Res $\underline{5}, 79-83$ 
LÖE H, THEILADE E, JENSEN S (1965):

Experimental gingivitis in man

J Periodontol $\underline{36}, 177-187$

LÖE H, SCHIÖTT CR, GLAVIND L, KARRING T (1976):

Two years oral use of chlorhexidine in man. General design and clinical effects

J Periodontol Res 20, 135-144

LÖFFLER G, PETRIDES P:

Nebenschilddrüse

In: LÖFFLER G, PETRIDES P: Biochemie und Pathochemie

Springer Verlag, Berlin / Heidelberg / New York / Tokyo 1997

LOOS B, CLAFFEY N, EGELBERG J (1988):

Clinical and microbiological effects of root debridement in periodontal furcation pockets

J Clin Periodontol 15, 453-463

MACFARLANE TW, FERGUSON MM, MULGREW CJ (1984):

Post-extraction Bacteriaemia: Role of antiseptics and antibiotics

Br Dent J 156, 197-181

MADLENA M, GINTNER Z, BANOCZY J, DOMBI C (2005):

Evaluation of clinical effects of amine fluorid/stannous fluorid containing toothpaste and mouthrinse

Fogorv Sz $\underline{98}, 229-232$

MARAVEI DV, TRBOVICH AM, PEREZ GI, TILLY KI, BANACH D, TALANIAN RV, WONG WW, TILLY JL (1997):

Cleavage of cytoskeletal proteins by caspases during ovarian cell death: evidence that cellfree systems do not always mimic apoptotic events in intact cells

Cell Death Differ $\underline{4}$ (8), 707-712

MARIOTTI AJ, RUMPF DAH (1999):

Chlorhexidine-Induced Changes to Human Gingival Fibroblast Collagen and Non-Collagen Protein Production

J Periodontol $\underline{70}$, 1443-1448

MARSH P (2004):

Dental plaque as a microbial biofilm

Caries Res $\underline{38}$, 204-211

MARSH P, BRADSHAW DJ (1995):

Dental plaque as a biofilm

$\mathrm{J}$ Ind Microbiol 15, 169-175

MARTIN A, CLYNES M (1991):

Acid phosphatase: endpoint for in vitro toxicity tests

In Vitro Cell Dev Biol 27, 183-184 
MARUNIAK J, CLARK WB, WALKER CB, MAGNUSSON I, MARKS RG, TAYLOR M, CLOUSER B (1992):

The effects of 3 mouthrinses on plaque and gingivitis development

J Clin Periodont $\underline{19}, 19-23$

MCGAW WT, BELCH A (1985):

Oral complications of acute leucemia: prophylactic impact of a chlorhexidine mouthrinse regimen

Oral Surg Oral Med Oral Pathol $\underline{60}, 275-280$

MEISEL H, GÜNTHER S, MARTIN D, SCHLIMME E (1998):

Apoptosis induced by modified ribonucleosides in human cell culture systems

FEBS Lett $\underline{433}$ (3), 265-268

MERTE K:

Parodontologie für die Praxis

Barth, Leipzig / Berlin / Heidelberg 1992

MICHEELIS W, REICH E:

Dritte Deutsche Mundgesundheitsstudie (DMS III). Ergebnisse, Trends und Problemanalysen auf der Grundlage bevölkerungsrepräsentativer Stichproben in Deutschland 1997

Deutsche Zahnärzteverlag, Köln 1999

MICHEELIS W, SCHIFFNER U:

Vierte Deutsche Mundgesundheitsstudie (DMS IV). Neue Ergebnisse zu oralen

Erkrankungsprävalenzen, Risikogruppen und zum zahnärztlichen Versorgungsgrad in

Deutschland 2005

Deutsche Zahnärzteverlag, Köln 2006

MICHELS P, TARNOW J (2001):

Natriuretic peptides: physiological, pathophysiological and clinical aspects

Anasthesiol Intensivmed Notfallmed Schmerzther $\underline{36}$, 406-416

MOHARAMZADEH K, FRANKLIN KL, BROOK IM, VAN NOORT R (2009):

Biologic assessment of antiseptic mouthwashes using a three-dimensional human oral mucosal model

J Periodontol 80 (5), 769-775

MONGARDINI C VAN, DEKEYSER C, QUIRYNEN M (1999):

One stage fullversuspartial-mouth disinfection in the treatment of chronic adult or generalized early-onset periodontitis. Long-term clinical observations

J Periodontol 70, 632-645

MORAN J, ADDY M, NEWCOMBE R (1989):

Comparison of the effect of toothpastes containing enzymes or antimicrobial compounds with a conventional fluoride toothpaste on the development of plaque and gingivitis

J Clin Periodontol 16, 295-299 
MORAN J, ADDY M, ROBERTS S (1992):

A 4-day plaque regro wth study comparing an essential oil mouthrinse with a triclosan mouthrinse

J Clin Periodontol 19 , 578-582

MORAN J, ADDY M, NEWCOMBE R (1997):

A 4-day plaque regrowth study comparing an essential oil mouthrinse with a Triclosan mouthrinse

J Clin Periodontol 24, 637-639

MORRISON EC, RAMFJORD SP, HILL RW (1980):

Short-term effects of initial, nonsurgical periodontal treatment (hygienic phase)

J Clin Periodontol 7, 199-211

MOSMANN T (1983):

A rapid calorimetric assay for cellular growth and survival. Application to proliferation and cytotoxity assay

J Immunol Met $\underline{65}$, 55-63

MÜLLER G, KRAMER A (2007):

Wechselwirkung von Octenidin und Chlorhexidin mit Säugerzellen und due resultierende Mikrobiozidie (Remanenzverhalten) der Reaktionsprodukte

GMS Krankenhyg Interdiszip Bd 2 (2), 1863-1870

MUTTERS R, BYKOW H, MAJID K (2007):

Mikrobiozide Wirksamkeit antiseptischer Mundspüllösungen auf Basis von Octenidin, Chlorhexidin bzw. Amin-/Zinnfluorid gegenüber Parodontitis-Erregern GMS Krankenhaushyg Interdiszip 2 (2): 48

NAUMANN G:

Mikrobiologie der Mundhöhle

In: Naumann G, Schmidt J, Friemel H: Medizinische Mikrobiologie und Immunologie für Stomatologen

Barth, Leipzig 1983

NETUSCHIL L (1991):

Zukünftige Plaque- und Chemotherapiekonzepte

Oralprophylaxe $\underline{13}, 47-54$

NETUSCHIL L, REICH E, BRECX M (1989):

Direct measurement of the bactericidal effect of chlorhexidine on human dental plaque J Clin Periodontol 16, 484-488

NETUSCHIL L, RAUH T, RIETHE P (1997):

Substantivität und antibakterielle Wirkung von Aminfluorid/Zinnfluorid in situ Parodontologie $1,7-16$

NETUSCHIL L, BRUHN G, HOFFMANN T (2002):

Auswahl und Anwendung von oralen Chemoprophylactica

DFZ $\underline{3}, 50-54$ 
NETUSCHIL L, HOFFMANN T, BRECX M (2003):

How to select the right mouthrinses in periodontal prevention and therapy. Test systems and clinical investigations

Int J Dent Hyg 1 , 143-150

NEVINS M, MELLONIG JT, CLEM DS, REISER GM, BUSER DA (1998):

Implants in regenerated bone: long-term survival

Int J Periodontics Restorative Dent $\underline{18}, 34-45$

NIEDNER R (1997):

Cytotoxicity and sensitization of povidone-iodine and other frequently used antiinfective agents

Dermatology $\underline{195}(2), 89-92$

NORDLAND P, GARRETT S, KIGER R, VANOOTEGHEM R, HUTCHENS LH, EGELBERG J (1987):

The effect of plaque control and root debridement in molar teeth

J Clin Periodontol 14, 231-236

OUHAYOUN JP (2003):

Penetrating the plaque biofilm: Impact of essential oil mouthwash

J Clin Periodontol $\underline{30}$ (5), 10-12

OUHAYOUN JP (2004):

Den Plaque-Biofilm effizient bekämpfen. Zur Wirksamkeit von Mundspülungen mit ätherischen Ölen

Oralprophyl Kinderzahnheilkd 26, 58-60

OVERHOLSTER CD, MEILLER TF, DEPAOLA LG, MINAH GE, NIEHAUS C (1990):

Comparative effects of 2 chemotherapeutics mouthrinse on the development of supragingival dental plaque and gingivitis

J Clin Periodontol 17, 575-579

PAGE RC (1999):

Milestones in periodontal research and the remaining critical issues

J Periodontal Res $\underline{34}, 331-339$

PAGE RC, KORNMAN KS (1997):

The pathogenesis of human periodontitis: an introduction

Periodontol $2000 \underline{14}, 9-11$

PAN PH, FINNEGAN MB, STURDIVANT L, BARNETT ML (1999):

Comparative antimicrobial activity of an essential oil and an amine fluorid/stannous fluoride mouthrinse in vitro

J Clin Periodontol 26, 474-479

PASTER BJ, BOCHES SK, GALVIN JL, ERICSON RE, LAU CN, LEVANOS VA (2001): Bacterial diversity in human subgingival plaque

J Bacteriol 183, 3770-3783 
PATEL M, BELSON M, OSTERLOH J, SCHWARTZ M (2006):

Medical toxicology and public health: update on research and activities at the Centers for Disease Control and Prevention

J Med Toxicol $\underline{2}$ (1), 27-28

PFISTER W:

Die Mikroflora der Zahnplaque - Ihre Rolle in Ätiologie, Pathogenese und Therapie von Gingivitis und Periodontitis marginalis

Med Diss Erfurt 1985, 13-17

PHILSTROM BL, WOLFF LF, BAKDASH MB, SCHAFFER EM, JENSEN JR, AEPPLI DM, BANDT CL (1987):

Salt and peroxide compared with conventional oral hygiene. Clinical results

J Periodontol 58, 291-300

PINTO M, ROBINE-LEON S, APPAY MD, KEDINGER M, TRIADOU N, DUSSAULX E, LACROIX B, SIMON-ASSMANN P, HAFFEN K, FOGH J, ZWEIBAUM A (1983):

Enterocyte-like differentiation and polarization of the human colon carcinoma cell line Caco2 in culture

Biol Cell 느, 323-330

PITTEN FA, KRAMER A (2001):

Efficiacy of cetylpyridinium chloride used as oropharyngeal antiseptic

Arzneim Forsch-Drug-Res $\underline{7}, 588-595$

PLISCHKE I:

Klinisch kontrollierte Studie der Wirkung verschiedener Mundspüllösungen auf die bakterielle Vitalität und Neubildung der Plaque

Med Diss Dresden 2001

POGGI P, RODRIGUEZ Y BAENA R, RIZZO S, ROTA MT (2003):

Mouthrinses with alcohol: Cytotoxic effects on human gingival fibroblasts in vitro J Periodontol $\underline{5}, 623-629$

PRICKLER H:

Die Mundhöhle

In: Weuffen W, Kramer A, Krasilinkow AP: Grundlagen der Antiseptik (Bd I/3)

Fischer Verlag, Stuttgart 1980

PROYE M, CATON J, POLSON A (1982):

Initial healing of periodontal pockets after a single episode of root planing monitored by controlled probing forces

J Periodontol 53, 296-301

PULCHER JJ, DANIEL JC (1992):

The effect of chlorhexidine digluconate on human fibroblasts in vitro J Periodontol 63, 526-532 
QUIRYNEN M, MARECHAL M (1990):

Comparative antiplaque activity of sanguinarine and chlorhexidine in man

J Clin Periodontol 17, 223-227

QUIRYNEN M, BOLLEN CM, VANDEKERCKHOVE BN, DEKEYSER C, PAPAIOANNOU W, EYSSEN H (1995):

Full- vs. partial-mouth disinfection in the treatment of periodontal infections: short-term clinical and microbiological observations

J Dent Res 누, 1459-1467

QUIRYNEN M, MONGARDINI C, PAUWELS M, BOLLEN CM (1999):

One stage full- versus partial-mouth disinfection in the treatment of chronic adult or generalized early-onset periodontitis. Long-term impact on microbial load J Periodontol $\underline{70}$, 646-656

RAHN R, DIEHL O, SCHÄFER V, SHAH PM, FLEISCHER W, REIMER K (1994): The effect of topical Povidone-Iodine and Chlorhexidine on the incidence of bacteremia following dental treatment procedures

Hyg Med 19, 128-131

RAHN R, ADAMIETZ IA, BÖTTCHER HD, REIMER K, FLEISCHER W (1996):

PVP-Iod-Lösung zur Mucositis-Prophylaxe bei therapeutischer Bestrahlung

Dtsch Z Mund Kiefer Gesichts Chir 20, 137-140

RAJABALIAN S, MOHAMMADI M, MOZAFFARI B (2009):

Cytotoxicity evaluation of Persica mouthwash on cultured human and mouse cell lines in the presence and absence of fetal calf serum

Indian J Dent Res Volume 20 Issue 2, 169-173

RAMBERG P, FURUICHI Y, LINDHE J, GAFFA A (1992):

A model for studying the effects of mouthrinses on de novo plaque formation

J Clin Periodontol $\underline{19}$, 509-520

RECHMANN P, SEEWALD M, STRASSBURG M, NAUMANN P (1989):

Incidence of bacteremia following extractions - a double blind study on local disinfection using chlorhexidine

Dtsch Zahnarztl Z $\underline{44}$, 622-624

REES TD, ORTH CF (1986):

Oral ulcerations with use of hydrogen peroxide

J Periodontol 57, 689-692

REHNER G, DANIEL H:

Biochemie der Ernährung

Spektrum Akademischer Verlag GmbH, Heidelberg / Berlin 1999 
REIMER K, VOGT PM, BRÖGMANN B, HAUSER J, ROSSBACH O, KRAMER A, RUDOLPH P,BOSSE B, SCHREIER H, FLEISCHER W (2000):

An innovative topical drug formulation for wound healing and infection treatment: in vitro and in vivo investigations of a povidone-iodine liposome hydrogel

Dermatology 201, 235-241

REIMER K, WICHELHAUS TA, SCHÄFER V, RUDOLPH P, KRAMER A, WUTZLER P, GANZER D, FLEISCHER W (2002):

Antimicrobial effectiveness of povidone-iodine and consequences for new application areas Dermatology 204 (1), 114-120

RENTON-HARPER P, ADDY M, MORAN J, DOHERTY FM, NEWCOMBE RG (1996): A comparison of chlorhexidine, cetylpyridinium chloride, triclo san and C31G mouthrinse products for plaque inhibition

J Periodontol $\underline{5}, 486-489$

RIEP BG, BERNIMOULIN JP, BARNETT ML (1999):

Comparative antiplaque effectiveness of an essential oil and amine fluorid/stannous fluoride mouthrinse J Clin Periodontol 26, 595-600

RIETHE P, STOLL B (1977):

Über den Einfluss von Chlorhexidindigluconat auf Plaque und Gingivitis Dtsch Zahnärztl Z $\underline{32}$, 753-754

ROBERTS WR, ADDY M (1981):

Comparison of the in vivo and in vitro antibacterial properties of antiseptic mouthrinses containing chlorhexidine, alexidine, cetyl pyridinium chloride and hexetidine. Relevance to mode of action

J Clin Periodontol $\underline{8}, 295-310$

ROBRISH SA, EMILSON CG, KEMP CW, EBERLEIN D, BOWEN WH (1981):

A comparison of viable counts and adenine nucleotide analysis to determine the effect of antimicrobial agents on dental plaque

Curr Microbiol 5, 343-347

RODEHEAVER G, BELLAMY W, KODY M, SPATAFORA G, FITTON L, LEYDEN K, EDLICH R (1982):

Bacterial activity and toxicity of iodine-containing solutions in wounds

Arch Surg 117, 181-185

ROSS NM, CHARLES CH, DILLS SS (1989):

Long-term effects of Listerine antiseptic on dental plaque and gingivitis

J Clin Dent $\underline{1}, 92-95$

RUDOLPH P, REIMER K, MLYNSKI S, REESE M, KRAMER A (2000):

Modell zur Ermittlung der Nasenverträglichkeit lokaler Antiinfektiva mittels In-vitro-

Bestimmung der Ziliaraktivität

Hyg Med 25, 500-503 
RUNDEGREN J, HVID EB, JOHANSSON M, ASTROM M (1992):

Effect of 4 days of mouth rinsing with delmopinol or chlorhexidine on the vitality of plaque bacteria

J Clin Periodontol 19, 322-325

RUSTHON A (1977):

Safety of hibitane: Human experience

J Clin Periodontol 4, 73-79

RUTKAUSKAS JS, DAVIS JW (1999):

Effects of chlorhexidine during immunsuppressive chemotherapy

Oral Surg Oral Med Oral Pathol 투, 441-448

SALVI GE, LAWRENCE HP, OFFENBACHER S, BECK JD (1997):

Influence of risk factors on the pathogenesis of periodontitis

Periodontol $2000 \underline{14}, 173-201$

SANCHEZ IR, SWAIM SF, NUSBAUM KE, HALE AS, HENDERSON RA, MCGUIRE JA (1998):

Effects of chlorhexidine diacetate and povidone-iodine on wound healing in dogs

Vet Surg 17, 291-295

SANTOS A (2003):

Evidence-based control of plaque and gingivitis

J Clin Periodontol $\underline{30}$ (5), 13-16

SANZ M, NEWMAN MG, ANDERSON L, MATOSKA W, OTOMO-CORGEL J, SALTINI C (1989):

Clinical enhancement of post-periodontal surgical therapy by a $0.12 \%$ chlorhexidine gluconate mouthrinse

J Periodontol $\underline{60}$ (10), 570-576

SCHACHTELE CF (1975):

Glucose transport in Streptococcus mutans: preparation of cytoplasmic membranes and characteristics of phosphotransferase activitiy

J Dent Res 54, 330-338

SCHÄRFE J (2004):

Elektronische Zellvitalitätsbestimmung, ein Vergleich mit dem klassischen Trypanblau Assay

BIOspektrum $\underline{3}$ (10), $334-336$

SCHEIE AA:

The role of antimicrobials

In: Fejerskov O, Kidd AM: Dental Caries. The disease and clinical management

Munksgaard, Kopenhagen 2003

SCHIFFNER U (1995):

Mechanische und chemische Plaquereduktion

Dtsch Zahnärtzl Z 0, 863-869 
SCHIFFNER U (1998):

Zur Rolle der chemischen Plaquekontrolle. Teil 1: Möglichkeiten der mechanischen Mundhygiene und Allgemeines zur Anwendung plaquehemmender Substanzen Oralprophylaxe 20, 198-203

SCHIFFNER U (1999):

Zur Rolle der chemischen Plaquekontrolle. Teil 2: Substanzen zur chemischen Plaquekontrolle - Wirkung und Nebenwirkung

Oralprophylaxe 21, 13-19

SCHIFFNER U (2000):

Chemische Plaquekontrolle. Welche antibakteriellen Zusätze zu Zahnpasten und Spüllösungen sind empfehlenswert?

Dtsch Zahnärztl Z 55, 160-167

SCHMID H (1983):

Chemie und Oberflächenwirkung der Aminfluoride

Dtsch Zahnärztl Z $\underline{38}, 9-13$

SCHMIDT J (1988):

Chlorhexidin. Wirkung, Nebenwirkung, Anwendung

Restaurative Zahnmed 5, 348-349

SCHMIDT J, HAMMERLE CH, OLAH AJ, LANG NP (1994):

Membrane permeability is unnecessary for guided generation of new bone. An experimental study in the rabbit

Clin Oral Implants Res $\underline{5}, 125-130$

SCHÖNBERGER W, GRIMM W (1982):

Transiente Hypothyreosen durch jodhaltige Desinfizientien bei Neugeborenen

Dtsch Med Wschr 107, 1222-1227

SCHREIER H, ERDOS G, REIMER K, KÖNIG B, FLEISCHER W (1997):

Molecular effects of povidone-iodine on relevant microorganisms: an electronmicroscopic and biochemical study

Dermatology $\underline{195},(2), 111-116$

SCHREIL G:

Antibakterielles und klinisches Wirkungsspektrum von Meridol ${ }^{\circledR}$

Med Diss Tübingen 1991

SCHROEDER HE:

Orale Strukturbiologie

Thieme Verlag, Stuttgart / New York 1982

SCHUBERT R (1985)

Disinfectant properties of new povidone-iodine preparations

J Hosp Infect $\underline{6}$ (A), 33-36 
SCHULZ L, SCHULZ E:

Tierexperimentelle und klinische Studien zur plaque-, karies und gingivitishemmenden Wirkung einer Aminflourid-Zinnflourid-Mundspüllösung

Med Diss Erfurt 1989

SCOPP IW, ORVIETO LO (1971):

Gingival degerming by povidone-iodine irrigation, bacteremia reduction in extraction prodedures

JADA $\underline{83}, 1294-96$

SHAHAN MH, CHUANG AH, BRENNAN WA, DIRKSEN TR, VAN DYKE TE, MCPHERSON JC (1993):

The effect of chlorhexidine irrigation on tensile wound strength

J Periodontol 64 (8), 719-722

SHARMA NC, GALUSTIANS HJ, QAQISH J, CHARLES CH, VINCENT JW, MCGUIRE JA (2003):

Antiplaque and antigingivitis effectiveness of a hexetidine mouthwash

J Clin Periodontol 30, 590-594

SHARMA NC, CHARLES CH, LYNCH NC, QAQISH J, MCGUIRE JA, GALUSTIANS JG, KUMAR LD (2004):

Adjunctive benefit of an essential oil-containing mouthrinse in reducing plaque and gingivitis in patients who brush and floss regularly

J Am Dent Assoc 135, 496-504

SHAVER KJ, SCHIFF T (1970):

Oral clinical functionality of enzyme AP used as a mouthwash

J Periodontol 41, 333-336

SHEEN S, EISENBURGER M, ADDY M (2003):

Effect of toothpaste on the plaque inhibitory properties of a cetylpyridinium chloride mouth rinse

J Clin Periodontol $\underline{30}, 255-267$

SILNESS J, LÖE H (1964):

Periodontal Disease in Pregnancy II. Correlation Between Oral Hygiene and Periodontal Condition

Acta Odontol Scand $\underline{22}$ (1), $121-135$

SIMONSSON T, HVID EB, RUNDEGREN J, EDWARDSSON S (1991):

Effect of delmopinol on in vitro dental plaque formation, bacterial acid production and the number of microorganisms in human saliva

Oral Microbiol Immunol $\underline{6}, 305-309$

SKOGLUND LA, HOLST E (1982):

Desquamative mucosal reactions due to chlorhexidine gluconate

Int J Oral Surg 11, 380-382 
SLEE AM, O’CONNOR JR (1983):

In vitro antiplaque activity of octenidine dihydrochloride (WIN 41464-2) against preformed plaques of selected oral plaque-forming microorganisms

Antimicrob Agents Chemother 23 (3), 379-384

SLOTS J (1979):

Subgingival microflora and periodontal disease

J Clin Periodontol $\underline{6}, 351-382$

SLOTS J, TING M (2002):

Systemic antibiotics in the treatment of periodontal disease

Periodontol $2000 \underline{28}, 106-176$

SPJKERVET FKL, VAN SAENE HKF, PANDERS AK, VERMEY A,VAN SAENE JJM, MEHTA DM, FIDLER V (1989):

Effect of chlorhexidine rinsing on the oropharyngeal ecology in patients with head and neck cancer who have irradiation mucositis

Oral Surg Oral Med Oral Pathol 67, 154-161

SPLIETH C, KRAMER A:

Chlorhexidineinsatz

In: Splieth C: Professionelle Prävention

Quintessenz, Berlin 2000

STELZEL M (2002):

Antiinfektiöse Therapie

Parodontologie $\underline{13}$, 363-372

STÖSSER L (2006):

Die antibakterielle Wirkung der Fluoride auf die dentale Plaque.

Oralprophyl Kinderzahnheilkd 28, 170-176

STÖSSER L, SCHULZ L, SCHULZ E, KÜNZEL W (1990):

Die plaqueinhibibierende Aktivität einer Aminfluo-rid/Zinnfluorid- Kombination im

Tierversuch an der Ratte

ZMK 78, 691-694

STÖSSER L, KÜNZEL W, SCHOLZ E (1992):

Die plaqueinhibierende Aktivität einer Aminfluorid/Zinnfluorid-Kombination

Dtsch Zahnärztl Z $\underline{47}, 455-456$

STRÜBING W, GÜLZOW HJ:

Bakterienstoffwechsel unter dem Einfluss von Aminfluorid/Zinnfluorid

In: Flores-de-Jacoby L: Möglichkeiten der Plaque- und Gingivitisprävention

Quintessenz, Berlin 1991 
SUOMI JD, GREENE JC, VERMILLION JR, DOYLE J, CHANG JJ, LEATHERWOOD EC (1971):

The effect of controlled oral hygiene procedures on the progression of periddontal disease in adults: results after third and final year

J Periodontol $\underline{42}, 152-160$

TAN AS, BERRIDGE MV (2000):

Superoxide produced by activated neutrophils efficiently reduces the tetrazolium salt, WST-1 to produce a soluble formazan: a simple colorimetric assay for measuring respiratory burst activation and for screening anti-inflammatory agents

J Immunol Meth $\underline{238}$ (1-2), 59-68

TANNER A, KENT R, MAIDEN MF, TAUBMAN MA (1996):

Clinical, microbiological and immunological profile of healthy, gingivitis and putative active periodontal subjects

J Periodontal Res $\underline{31}$, 195-204

TATNALL FM, LEIGH IM, GIBSON JR (1987):

Comparative toxicity of antimicrobial agents on transformed keratinocytes

J Invest Dermatol 89, 316-317

TATNALL FM, LEIGH IM, GIBSON JR (1990):

Comparative study of antiseptic toxicity on basal keratinocytes, transformed human

keratinocytes and fibroblasts

Skin Pharmacol $\underline{3}$ (3), 157-163

TAUBMAN MA, VALVERDE P, HAN X, KAWAI T (2005):

Immune response: the key to bone resorption in periodontal disease

J Periodontol $\underline{76}$ (11), 2033-2041

TENENBAUM H, DAHAN M, SOELL M (1999):

Effectiveness of a sanguinarine regimen after scaling and root planing

J Periodontol 70, 307-311

TENOVUO J, HANNUKSELA S, LENANDER-LUMIKARI M (1995):

Effects of delmopinol on antimicrobial peroxidase systems and lysozyme in vitro and in human whole saliva

Eur J Oral Sci 103, 247-252

TEUSCHER E, MELZIG M, VILLMAN E, MÖRITZ KU (1990):

Untersuchungen zum Wirkmechanismus ätherischer Öle

Z Phytother 11, 87-92

THEILADE E (1986):

The non-specific theory in microbial etiology of inflammatory periodontal diseases

J Clin Periodontol 13, 905-911

THEILADE E, WRIGHT WH, JENSEN SB, LÖE H (1966):

Experimental gingivitis in man. A longitudinal clinical and bacteriological investigation J Periodontal Res $\underline{1}, 1-13$ 
THEISZOVÁ M, JANTOVÁ S, DRAGÚNOVÁ J, GRZNÁROVÁ P, PALOU M (2005):

Comparison the cytotoxicity of hydroxyapatite measured by direct cell counting and MTT test in murine fibroblast NIH-3T3 cells

Biomed Pap Med Fac Univ Palacky Olomouc Czech Repub 149 (2), 393-396

TOMINAGA H, ISHIYAMA M, OHSETO F, SASAMOTO K, HAMAMOTO T, SUZUKIC K, WATANABE M (1999):

A water-soluble tetrazolium salt useful for colorimetric cell

viability assay

Anal Commun 36, 47-50

TRACHSLER R:

Plaque- und Entzündungshemmung mit Amin-/Zinnfluorid Mundwasser bei Erwachsenen Med Diss Zürich 1988

TRAGANOS F, KAPUSCINSKI J, GONG J, ARDELT B, DARZYNKIEWICZ RJ, DARZYNKIEWICZ Z (1993):

Caffeine prevents apoptosis and cell cycle effects induced by camptothecin or topotecan in HL-60 cells

Cancer Res $\underline{53}$ (19), 4613-4618

TROMBELLI L, BOTTEGA S, ORLANDRINI E, SCAPOLI C, TORI M, TATAKI SD (2003):

Response to a plaque control regime on different levels of gingival inflammation Minerva Stomatol 52, 75-79

VALENCIA IC, KIRSNER RS, KERDEL FA (2004):

Microbiologic evaluation of skin wounds: alarming trend toward antibiotic resistance in an inpatient dermatology service during a 10-year period

J Am Acad Dermatol $\underline{50}, 845-849$

VAN DEN BROEK PJ, BUYS LF, VAN FURTH R (1982):

Interaction of povidone-iodine compounds, phagocytic cells, and microorganisms

Antimicrob Agents Chemother 22 (4), 593-597

VAN DER VELDEN U, VAN WINKELHOFF AJ, ABBAS F (1986):

The habitat of periodontopathic micro-organisms

J Clin Periodontol 13, 243-248

VAN DYKE TE (1992):

New agents in the chemical control of plaque and gingivitis-reaction paper

J Dent Res $\underline{71}, 1457-1458$

VANDEKERCKHOVE BN, BOLLEN CM, DEKEYSER C, DARIUS P, QUIRYNEN M (1996):

Full- versus partial-mouth disinfection in the treatment of periodontal infections. Long-term clinical observations of a pilot study

J Periodontol $\underline{67}, 1251-1259$ 
WAGNER H, WIESNER N (1988):

In vitro Hemmung der Prostaglandinsynthese durch ätherische Öle, phenolische

Verbindungen und Knoblauchinhaltsstoffe

Z Phytother $\underline{9}, 11-14$

WALKER CB (1988):

Microbiological effects of mouthrinses containing antimicrobials

Clin Periodontol $\underline{15}, 499-505$

WECKE J, KERSTEN T, MADELA K, MOTER A, GЦBEL U, FRIEDMANN A (2000): A novel technique for monitoring the development of bacterial biofilms in human periodontal pockets

FEMS Microbiol Let $\underline{191}, 95-101$

WEISDORF DJ, BOSTROM B, RAETHER D, MATTINGLY M, WALKER P, PIHLSTROM B, FERRIERI P, HAAKE R, GOLDMAN A, WOODS W, RAMSAY NKC, KERSEY JH (1989):

Oropharyngeal mucositis complicating bone marrow transplantation; prognostic factors and the effect of chlorhexidine mouth rinse

Bone Marrow Transplant $\underline{4}, 89-95$

WEISS EI, SHANIZTKI B, DOTAN M, GANESHKUMAR N, KOLENBRANDER PE, METZGER Z (2000):

Attachment of Fusobacterium nucleatum PK1594 to mammalian cells and its coaggregation with periodontopathogenic bacteria are mediated by the same galactose-binding adhesin Oral Microbiol Immunol 15, 371-377

WELK A, ROSIN M, LÜDTKE C, SCHWAHN C, KRAMER A, DAESCHLEIN G (2007): The Peritoneal Explant Test for Evaluating Tissue Tolerance to Mouthrinses

Skin Pharmacol Physiol 20, 162-166

WENNSTRÖM JL, TOMASI C, BERTELLE A, DELLASEGA E (2005):

Full-mouth ultrasonic debridement versus quadrant scaling and root planing as an initial approach in the treatment of chronic periodontitis

J Clin Periodontol 32, 851-859

WILLERSHAUSEN B, GRUBER I, HAMM G, OBTMEIER R (1990):

Action of different mouthwash solutions on infection rate of gingiva - study with army recruits

Quintessenz 41, 1309-1316

WUTZLER P, SAUERBREI A, KLÖCKING R, BURKHARDT J, SCHACKE M, THUST R, FLEISCHER W, REIMER K (2000):

Virucidal and chlamydicidal activities of eye drops with povidone-iodine liposome complexm Ophtalmic Res $\underline{32}, 118-125$

WUTZLER P, SAUERBREI A, HÄRTL A, REIMER K (2003):

Comparative testing of liposomal and aqueous formulations of povidone-iodine for their angioirritative potential at the chorioallantoic membrane of ex ovo cultivated chick embryos Dermatology 207, 43-47 
YAMALIK MK, YUCETAS S, ABBASOGLU U (1992):

Effects of various antiseptics on bacteremia following tooth extraction

J Nihon Univ Sch Dent $\underline{34}, 28-33$

YANKELL SL, DOLAN NM, EMLING RC (1988):

Laboratory evaluations of herbal sodium bicarbonate dentifrice

J Clin Dent (A), 6-8

ZEE VAN DER E, EVERTS V, BEERTSEN W (1997):

Cytocines modulate routes of collagen breakdown. Review with special emphasis on mechanisms of collagen degradation in the periodontium and the burst hypothesis of periodontal disease progression

J Clin Periodontol 24, 297-305 


\section{Danksagung}

An dieser Stelle möchte ich mich bei Allen, die zum Gelingen meiner Dissertation beigetragen haben, bedanken.

Ich danke herzlich Herrn Prof. Dr. R. Mausberg, Prof. Dr. M. Hülsmann und Frau Dr. E. Hornecker für die Möglichkeit, meine Doktorarbeit in der Abteilung Präventive Zahnmedizin, Parodontologie und Kariologie $\mathrm{zu}$ schreiben, für die freundliche Überlassung des interessanten Themas, für die organisatorische Unterstützung und ihre konstruktive Anregungen.

Mein besonderer Dank gilt Herrn Dr. Dirk Ziebolz für die Betreuung der Arbeit. Ich danke ihm für die Aufmerksamkeit, die er der Arbeit entgegengebracht hat, für die jederzeit gewährte Unterstützung bei der Planung und Durchführung der vorliegenden Dissertation, sowie für zahlreiche unersetzliche Ratschläge, Geduld und die überaus angenehme Zusammenarbeit.

Ich möchte unseren MTA Frau Gudrun Grzyb, Monika Hoch, Astrid Stehen und Jutta Schulz für die Einführung in die Methodik und ihre große Hilfe danken. Sie waren jederzeit mit Rat und Tat zur Stelle und sorgten mit Ihrer ausgeglichenen, freundschaftlichen Art dafür, dass das Arbeiten Spaß gemacht hat.

Allen Mitarbeitern des Labors und insbesondere Herrn Dr. H. J. Rolf, Prof. Dr. N. Miosge und MTA Frau B. Sadowski danke ich für die Unterstützung, gute Ratschläge, kollegiale Zusammenarbeit, Hilfsbereitschaft und für das immer freundliche und herzliche Arbeitsklima. 


\section{Lebenslauf}

Ich wurde am 5. Februar 1978 als ältester Sohn der Bauzeichnerin Elvira Zyba, geb. Reinke, und des Dipl.-Ingenieurs Vasilij Zyba in Charkow (Ukraine) geboren. Mein Bruder Alexander Zyba ist 27 Jahre alt. Seit 2003 bin ich mit Valentina Zyba, geb. Ponomarjow, verheiratet. Im April 2008 wurde unserer Sohn Kyrill und im März 2010 unsere Tochter Emma geboren.

Von 1985 bis 1995 besuchte ich die Mittelschule und von 1990 bis 1995 die Musikschule in Satschepilowka (Ukraine). Im Wintersemester 1995/1996 begann ich mit dem Studium an der Fakultät für Fremdsprachen der Staatlichen Pädagogischen Universität in Charkow und absolvierte bis zur Ausreise nach Deutschland 1996 zwei Semester. Nach einem intensiven Sprachkurs in Hannover 1997 war ich Stipendiat des Göttinger Institutes und des Studienkollegs Hamburg, wo ich mein deutsches Abitur nachholte. Im Sommersemester 2000 fing ich mein Humanmedizinstudium an der Georg-August-Universität Göttingen an. Ab April 2002 arbeitete ich im Stammzelllabor der Abteilung Kardiologie und Pneumologie. Im November 2006 absolvierte ich die Ärztliche Prüfung in Humanmedizin und erhielt die Approbation als Arzt. Im April 2006 begann ich das Studium der Zahnmedizin an der GeorgAugust-Universität zu Göttingen. Gleichzeitig war ich als wissenschaftliche Hilfskraft in der Abteilung Kardiologie und Pneumologie tätig. Seit August 2008 bin ich ein Doktorand in der Abteilung Parodontologie an der Georg-August-Universität Göttingen, wo die vorliegende Arbeit entstand. Mit bestandenem Staatsexamen der Zahnmedizin erhielte ich im Oktober 2009 die Approbation als Zahnarzt. Seit Januar 2010 bin ich als Assistenzarzt in der Abteilung Mund-, Kiefer- und Gesichtschirurgie, Plastische Operationen und Spezielle Schmerztherapie im Klinikum Bremen-Mitte tätig. 